\title{
Fighting Hypoxia to Improve PDT
}

\author{
Ludivine Larue ${ }^{1}$, Bauyrzhan Myrzakhmetov ${ }^{2}$, Amina Ben-Mihoub ${ }^{3}$, Albert Moussaron ${ }^{1}$, \\ Noémie Thomas ${ }^{4}$, Philippe Arnoux ${ }^{1}$, Francis Baros ${ }^{1}$, Régis Vanderesse ${ }^{3}$ (D) Samir Acherar $^{3}(\mathbb{D})$ \\ and Céline Frochot $1, *$ (1) \\ 1 Laboratoire Réactions et Génie des Procédés (LRGP), UMR 7274, CNRS, Université de Lorraine, \\ 54000 Nancy, France; ludivine.larue@univ-lorraine.fr (L.L.); albert.moussaron@univ-lorraine.fr (A.M.); \\ philippe.arnoux@univ-lorraine.fr (P.A.); francis.baros@univ-lorraine.fr (F.B.) \\ 2 M.Kh. Dulaty Taraz State University, Taraz 080012,Kazakhstan; baur_86_86@mail.ru \\ 3 Laboratoire de Chimie Physique Macromoléculaire (LCPM), UMR 7375, CNRS, Université de Lorraine, \\ 54000 Nancy, France; amina.ben-mihoub@univ-lorraine.fr (A.B.-M.); \\ regis.vanderesse@univ-lorraine.fr (R.V.); samir.acherar@univ-lorraine.fr (S.A.) \\ 4 Biologie, Signaux et Systèmes en Cancérologie et Neurosciences, CRAN, UMR 7039, Université de Lorraine, \\ CNRS, 54000 Nancy, France; noemie.thomas@univ-lorraine.fr \\ * Correspondence: celine.frochot@univ-lorraine.fr; Tel.: +33-3-72-74-37-80
}

Received: 30 September 2019; Accepted: 26 October 2019; Published: 30 October 2019

\begin{abstract}
Photodynamic therapy (PDT) has drawn great interest in recent years mainly due to its low side effects and few drug resistances. Nevertheless, one of the issues of PDT is the need for oxygen to induce a photodynamic effect. Tumours often have low oxygen concentrations, related to the abnormal structure of the microvessels leading to an ineffective blood distribution. Moreover, PDT consumes $\mathrm{O}_{2}$. In order to improve the oxygenation of tumour or decrease hypoxia, different strategies are developed and are described in this review: (1) The use of $\mathrm{O}_{2}$ vehicle; (2) the modification of the tumour microenvironment (TME); (3) combining other therapies with PDT; (4) hypoxia-independent PDT; (5) hypoxia-dependent PDT and (6) fractional PDT.
\end{abstract}

Keywords: PDT; oxygen; hypoxia

\section{Introduction}

In the case of cancer, tissue hypoxia is a key feature of virtually all solid tumours [1]. The hypoxic adaptation, which is recognized as a source of therapeutic failure in clinical oncology [2] is critical for tumour expansion, invasion and metastasis, and some studies aim to target hypoxia for enhanced cancer therapy [3,4]. In vivo, reduced oxygenation induces a lack of nutrients and growth factors, increased acidosis and production of products coming from the close necrotic area. This leads to alteration of cells and cell-matrix interaction and even sometimes to cell death. Nevertheless, some tumor cells survive and these "hypoxic" cells become very aggressive and induce a local tumor relapse [5]. It is necessary for a treatment to be efficient to detect and control oxygenation in the tissue. Photodynamic therapy (PDT) has been applied to cure many diseases such as AMD, psoriasis, Barrett's esophagus, and various malignant cancers for over a decade [6]. PDT is a simple and efficient approach relying on irradiation to move a photosensitizer (PS) from the ground state to a singlet excited state and then to a triplet excited state. This excited PS can react with the surrounding medium to produce Reactive Oxygen Species (ROS) such as superoxide anion $\left(\mathrm{O}^{2-\bullet}\right)$ and hydroxyl radical $\left(\mathrm{HO}^{\bullet}\right)$ or transfer its energy to triplet oxygen to generate singlet oxygen $\left({ }^{1} \mathrm{O}_{2}\right)$. Success of PDT requires that the PS incorporate preferentially into the tumor cell, that the number of photons be correctly evaluated in order to excite a majority of the PS molecules, and that there be enough $\mathrm{O}_{2}$ to induce the photo-oxidation process [7]. Indeed, PDT, like radiotherapy, suffers from a severe drawback: the 
need for $\mathrm{O}_{2}$ to be efficient. Therefore, PDT displays a low efficiency in hypoxia or when hypoxia occurs due to the consumption of molecular $\mathrm{O}_{2}$ by the PS, leading to PDT resistance. When the oxygen concentration in the medium is not high enough, the photodamage is reduced or even no photodynamic reaction occurs at all [8]. These spare hypoxic cells can induce the regrowth of the tumor. Hypoxia occurring during PDT has been studied by several teams last years [9-11]. Bush et al. for example used in 2000 oxygen-sensitive electrodes during PDT treatment in vivo [10]. The same team also showed that the spatial distribution of hypoxia during PDT treatment can influence the balance between destruction of the tumor and damage of the neovessels [12]. Several approaches have been described during the last decades to overcome hypoxia in PDT. In this review, we chose to divide them onto six strategies developed in the literature to fight hypoxia for an enhancement of PDT: (1) The use of $\mathrm{O}_{2}$ vehicles; (2) the modification of the tumour microenvironment (TME); (3) combining other therapies with PDT; (4) hypoxia-independent PDT; (5) hypoxia-dependent PDT and (6) fractional PDT.

\section{2. $\mathrm{O}_{2}$ vehicles}

Various clinical applications (i.e. radio-, chemo- and phototherapies) involve the presence of $\mathrm{O}_{2}$ in the neighbourhood of the tumours to be treated, but hypoxia can lead to a poor treatment efficiency with enhanced malignant cell survival, increased angiogenesis and metastasis. The supply of $\mathrm{O}_{2}$ is therefore a major asset and a new modality for many disease interventions $[13,14]$. In fact, the increase of the arterial and capillary $\mathrm{O}_{2}$ pressure $\left(\mathrm{pO}_{2}\right)$ improves the transport of dissolved $\mathrm{O}_{2}$ into the tissue.

\subsection{Hyperoxygenation/Hyperbaric Oxygenation (HBO)}

Hyperoxic vasodilatation in healthy tissue makes way to vasoconstriction in hypoxic tissues, so one idea is to perform hyper-oxygenation during PDT of pre-existing hypoxic cells and to compensate the $\mathrm{O}_{2}$ depletion. This so-called hyperbaric oxygenation (HBO) can be realized in several ways, which will be developed in this section. One way is to provide additional $\mathrm{O}_{2}$ in the areas to be treated by the addition of ${ }^{1} \mathrm{O}_{2}$ itself, $\mathrm{H}_{2} \mathrm{O}_{2}$, or other molecules. Another way is to favour the formation of ROS at the expense of ${ }^{1} \mathrm{O}_{2}$ by switching the photochemistry of PSs from a type II to a type I mechanism $[15,16]$. Some other interesting reviews on this topic can help in understanding the history, the notion of hypoxia and the broad scope of HBO [17-19].

Hjelde et al. in 2005 [20] compared the in vitro PDT efficiency under normoxic or hyperoxic exposure on AY27 tumour cells, human colon adenocarcinoma WiDr and SW840 cells. The cultured cancer cells were incubated with 5-ALA and irradiated ( $435 \mathrm{~nm}, 0.5$ and $30 \mathrm{~min}, 12.9 \mathrm{~mW} \cdot \mathrm{cm}^{-2}$ ), which matched a total light dose of 0.387 and $23.22 \mathrm{~J} \cdot \mathrm{cm}^{-2}$ respectively. After PDT treatment under normoxia $\left(21 \mathrm{kPa} \mathrm{O}_{2}\right)$ and hyperoxia $(100,200,300$, or $400 \mathrm{kPa})$, the cells' survival was evaluated and surprisingly, showed no significant difference between normoxia and HBO. However, the three cell lines exhibited very different sensitivities to PDT in normoxic conditions: At $21 \mathrm{kPa}$, and within 5 min illumination, about $90 \%$ of WiDr and SW840 cells were killed, while only $20-25 \%$ of AY27 cells were destroyed and an illumination for up to 30 min was necessary to attain a similar result.

Mei et al. in 2019 [21] used 5-ALA with or without HBO for PDT treatment of human squamous carcinoma (A431 cell line) in vitro. For $\mathrm{HBO}$ assays, the cells were flushed by a mixture $98 \% \mathrm{O}_{2}$ plus $2 \% \mathrm{CO}_{2}(0.25 \mathrm{MPa})$ for $1 \mathrm{~h}$ daily before addition of 5-ALA. Both treatments, after irradiation $(530 \mathrm{~nm}$, $5 \mathrm{~J} \cdot \mathrm{cm}^{-2}, 8$ days) indicated: (a) a decrease of cell proliferation as a function of a concentration gradient $(0,0.1,0.3,1$, and $3 \mathrm{mM}$ ALA), (b) a synergistic effect of the combination ALA-HBO, especially at 1 and $3 \mathrm{mM}$ ALA with $30-35 \%$ cell viability. Western blot analysis allowed the detection of apoptosis-related protein Bax, Bcl-2 and caspase 3 . The data suggested synergistically increased levels of the proteins Bax and caspase, but a decrease for Bcl-2 in A431 cells, evidencing a mitochondria-intrinsic pathway cell apoptosis. Furthermore, it has been shown that the dual ALA-HBO treatment reduced ROS production in A431 cells and favoured autophagy. It can be considered that ALA-HBO could be used in vivo for the treatment of human squamous carcinomas. 
Chen et al. [22,23] used hyper-oxygenation in vivo in mammary carcinoma tumours implanted into $\mathrm{C} 3 \mathrm{H}$ mice $(6-8 \mathrm{~mm})$. Tumours were treated by Photofrin and illuminated at $630 \mathrm{~nm}\left(200 \mathrm{~J} \cdot \mathrm{cm}^{-2}\right.$, $\left.150 \mathrm{~mW} \cdot \mathrm{cm}^{-2}\right)$. Hyperbaric conditions were attained when the mice were under a 3-atmosphere pressure. Under normal conditions ( $1 \mathrm{~atm}$ and normoxia) about $20 \%$ of the tumour disappeared after 60 days. In normobaric conditions $\left(\mathrm{NBO}, 100 \% \mathrm{O}_{2}\right.$ ), this percentage increase to $80 \%$. In hyperbaric conditions $\left(\mathrm{HBO}, 100 \% \mathrm{O}_{2}\right.$ ), it was only $60 \%$. Reduction of light fluence to $75 \mathrm{~mW} \cdot \mathrm{cm}^{-2}$ combined with NBO treatment led to a $70 \%$ tumour cure. The relative negative effect of $\mathrm{HBO}$ was perhaps due to a reduced cardiac outcome. The same team used also an atmospheric composition of $95 \% \mathrm{O}_{2}$ and $5 \%$ carbon dioxide (carbogen) [24]. They did not observe any effects after decreasing the fluence. In all cases (HBO, NBO or carbogen) the rate of cellular death was doubled, compared to normal atmospheric conditions. In 2003, they [25] used the same protocol as previously, but measured the $\mathrm{O}_{2}$ concentration in tumour in vivo with the Oxylite system. First, only room air (RA) and NBO conditions were used. Table 1 shows the important effect of NBO on the survival rate of tumours after different times (as a tumour fraction).

Table 1. \% Mammary carcinoma tumour implanted into C3H mice after PDT treatment $(630 \mathrm{~nm}$, total light irradiation of $150 \mathrm{~mW} \cdot \mathrm{cm}^{-2}$ ).

\begin{tabular}{ccccc}
\hline & $\mathbf{0 ~ h}$ & $\mathbf{4} \mathbf{h}$ & $\mathbf{1 8} \mathbf{h}$ & $\mathbf{2 4} \mathbf{h}$ \\
\hline RA & 0.495 & 0.381 & 0.043 & 0.0045 \\
NBO & 0.185 & 0.120 & 0.006 & 0.00035 \\
\hline
\end{tabular}

Similar results as previously were obtained using carbogen and $\mathrm{HBO}$ conditions. Li et al. [26] used also hyperbaric conditions with upconversion nanoparticles (UCNPs). They synthesized a core@shell $\mathrm{NPs} \mathrm{NaGdF}_{4}: \mathrm{Yb}, \mathrm{Er}, \mathrm{Ca} @ \mathrm{NaYbF}_{4}: \mathrm{Ca}$, with an upconversion core which can transfer its energy to Rose Bengal, and produce ROS under $808 \mathrm{~nm}$ laser excitation (Figure 1). It was demonstrated that PDT assisted by $\mathrm{HBO}$ led to strong depletion of collagen fibre in the extracellular matrix, with a reduction of hypoxia and a simultaneous enhancement of NP levels in the tumour blood vessels.

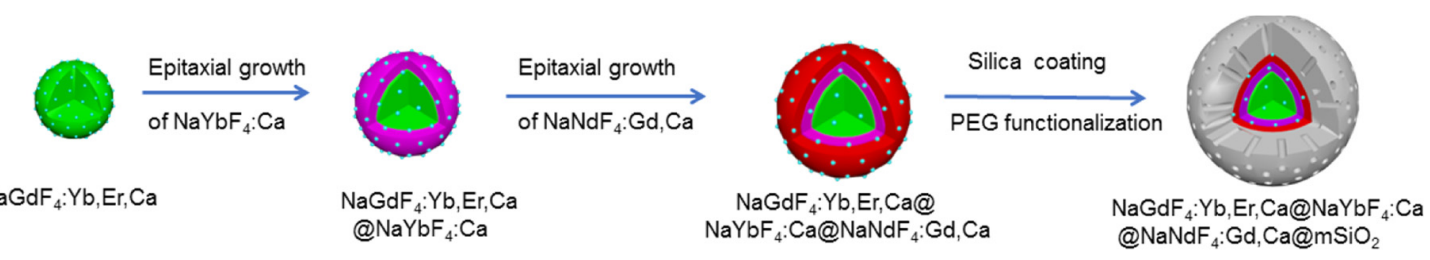

Figure 1. Schematic illustration for the synthesis of NaGdF4:Yb,Er,Ca@NaYbF4:Ca@NaNdF4:Gd,Ca $@$ mSiO2 NPs. Reprinted from [26] with permission from the American Chemical Society, Copyright 2018.

In vivo experiments were performed on xenograft $4 \mathrm{~T} 1$ cells (murine breast tumour cell line) tumour-transplanted mice mouse model. Fluorescence in tumour was observed $6 \mathrm{~h}$ after NP administration, up to $48 \mathrm{~h}$ and disappeared progressively from the tumour. Consequently, a second treatment (16 min of irradiation with an $808 \mathrm{~nm}$ laser, $0.75 \mathrm{~W} \cdot \mathrm{cm}^{-2}$ ) was administered $48 \mathrm{~h}$ after the first one. In vitro, $4 \mathrm{~T} 1$ cell viability was measured to about $75 \%$ under hypoxia, about $35 \%$ in normoxia and $20 \%$ in $\mathrm{HBO}$ conditions. In vivo, the tumour weight, initially $0.5 \mathrm{~g}$, decreased to about $0.1 \mathrm{~g}$ with $\mathrm{UCNP}$ in $\mathrm{HBO}$ conditions.

Maier et al. [27] conducted a clinical pilot study to treat patients with advanced oesophageal carcinoma in 2000. They used $\mathrm{HpD}$ and illumination $\left(630 \mathrm{~nm}, 300 \mathrm{~J} \cdot \mathrm{cm}^{-2}\right), 14$ patients were treated by PDT and 17 with PDT under HBO ( 2 absolute atm pressures). A difference was observed between the two groups, with a median overall survival for the PDT group of 7.0 months (12-months survival rate was $28.6 \%$ ) and 12 months for the PDT/HBO group (the 12 -months survival rate was $41.2 \%$ for the PDT/HBO group). The same team published in 2000 another study for the treatment of advanced carcinoma of the cardia and oesophagus [28]. In the same conditions (vide supra), 23 patients were 
treated by PDT and 29 with PDT/HBO. The mean survival time for the PDT group was 8.7 months and for the PDT/HBO group 13.8 months. This experience was re-conducted the same year on 31 patients for PDT alone and 44 patients for PDT/HBO for the treatment of tumour at the oesophago-gastric junction [29]. A median overall survival of 7 and 12 months was observed, respectively. In order to avoid the prolonged photosensitivity of the skin of $\mathrm{HpD}$, the authors evaluated the efficacy of Photosan ${ }^{\circledR}$ and ALA on patients with oesophageal cancer [30,31]. As expected, polyhematoporphyrin seemed to be more effective than ALA in terms of reduction of dysphagia, tumour stenosis and Karnovsky performance status. A questionnaire of the patients indicated a best comfort for oral administration of ALA than intravenous injection of Photosan ${ }^{\circledR}$ and no complication or sunburn occurred for either treatment. Such a comparison has been made on lung cancer and more particularly in the treatment of advanced malignant bronchogenic stenosis $[32,33]$ and no definitive conclusions have been drawn. At the best of our knowledge, no further investigations in the field of $\mathrm{HBO}$ have been undertaken by this team.

In 2001, Schouwink et al. [34] conducted preclinical studies for optimization of PDT by $m$-THPC in female BALB/c mice bearing human mesothelioma (H-MESO1) tumour. To overcome the PDT-induced $\mathrm{O}_{2}$ deficit, they proposed a preliminary treatment by nicotinamide $\left(300 \mathrm{mg} \cdot \mathrm{kg}^{-1}\right)$ and/or carbogen (i.e. a mixture $5 \% \mathrm{CO}_{2}$ and $95 \% \mathrm{O}_{2}$ ) $30 \mathrm{~min}$ and/or $5 \mathrm{~min}$ before illumination, respectively. In a first series, they studied the influence of nicotinamide injection and/or carbogen breathing on the mean time of regrowth of tumour from 2 to $5 \mathrm{~mm}$ diameter. The mean time was found to be about 42 days in hypoxic conditions and 17 days in hyperbaric conditions. They analysed also the mean median $\mathrm{pO}_{2}$ and they observed no significant increase of oxygenation with nicotinamide alone (17.6 $\mathrm{mm} \mathrm{Hg}$ to be compared to a control value of $12.6 \mathrm{~mm} \mathrm{Hg}$ ), but a $\mathrm{pO}_{2}$ of $24.8 \mathrm{~mm} \mathrm{Hg}$ for nicotinamide plus carbogen. The efficiency of PDT by $m$-THPC $\left(0.15 \mathrm{mg} \cdot \mathrm{kg}^{-1}, 100 \mathrm{~mW} \cdot \mathrm{cm}^{-2}\right)$ was then discussed and mice survival (after $24 \mathrm{~h}$ post PS-injection and illumination) reached $11 \%$ for PDT alone and $58 \%$ for PDT and carbogen, the nicotinamide bringing almost no improvement. Table 2 lists recent articles involving $\mathrm{HBO}$ as $\mathrm{O}_{2}$ vehicle.

Table 2. Summary of publications about $\mathrm{HBO}$ as $\mathrm{O}_{2}$ vehicle.

\begin{tabular}{|c|c|c|c|c|c|c|c|}
\hline Ref & Application & $\mathrm{O}_{2}$ Source & PS & Energy of Excitation & $\begin{array}{l}\text { Type of } \\
\text { ROS }\end{array}$ & In Vitro & In Vivo \\
\hline [20] & PDT & $\begin{array}{c}\text { Hyperbaric } \\
\text { chamber with } 100 \% \\
\mathrm{O}_{2} \\
(21,100,200,300 \text {, or } \\
400 \mathrm{kPa})\end{array}$ & 5-ALA & $\begin{array}{c}435 \mathrm{~nm}, 12.9 \mathrm{~mW} \cdot \mathrm{cm}^{-2} \\
0.5 \mathrm{~min} \text { and } 30 \mathrm{~min}\end{array}$ & ${ }^{1} \mathrm{O}_{2}$ & $\begin{array}{l}\text { AY27, } \\
\text { WiDr } \\
\text { and } \\
\text { SW840 } \\
\text { cell line }\end{array}$ & No \\
\hline [21] & PDT & $\begin{array}{c}\mathrm{HBO}(0.25 \mathrm{MPa} \\
\left.98 \% \mathrm{O}_{2}+2 \% \mathrm{CO}_{2}\right)\end{array}$ & 5-ALA & $\begin{array}{c}630 \mathrm{~nm}, 5 \mathrm{~J} \cdot \mathrm{cm}^{-2} \\
8 \mathrm{~h} \text { per days }\end{array}$ & ROS & $\begin{array}{c}\text { A431 } \\
\text { cancer } \\
\text { cell line }\end{array}$ & No \\
\hline [22-25] & PDT & $\begin{array}{c}\mathrm{HBO} \text { or NBO } 100 \% \\
\mathrm{O}_{2} \text { (hyperbaric } \\
\text { chamber: } 3 \text { atp) }\end{array}$ & Photofrin & $\begin{array}{l}630 \mathrm{~nm}, \text { "Fractional light" } \\
\text { group: } 150 \mathrm{~mW} \cdot \mathrm{cm}^{-2}, \\
200 \mathrm{~J} \cdot \mathrm{cm}^{-2}, 30 \mathrm{~s} \text { light and } \\
\text { dark intervals } \\
\text { "Reduced light dose rate" } \\
\text { group: } 75 \mathrm{~mW} \cdot \mathrm{cm}^{-2}, \\
200 \mathrm{~J} \cdot \mathrm{cm}^{-2}\end{array}$ & ${ }^{1} \mathrm{O}_{2}$ & No & $\begin{array}{c}\mathrm{MCa} \\
\text { tumour-bearing } \\
\text { mice }\end{array}$ \\
\hline [26] & PDT & $\begin{array}{l}\text { HBO (hyperbaric } \\
\text { chamber: } 2.5 \text { atm) }\end{array}$ & $\mathrm{RB}$ & $\begin{array}{c}808 \mathrm{~nm} \\
16 \mathrm{~min}, 0.75 \mathrm{~W} \cdot \mathrm{cm}^{-2}\end{array}$ & ROS & $\begin{array}{l}4 \mathrm{~T} 1 \text { cell } \\
\text { line }\end{array}$ & $\begin{array}{l}\text { 4T1 tumour } \\
\text { bearing mice }\end{array}$ \\
\hline [27-33] & PDT & $\begin{array}{l}\text { HBO (hyperbaric } \\
\text { chamber: } 2 \text { atm } \mathrm{O}_{2} \text { ) }\end{array}$ & $\begin{array}{c}\text { HpD } \\
\text { (Photosan) } \\
\text { or } \\
\text { 5-ALA }\end{array}$ & $630 \mathrm{~nm}, 300 \mathrm{~J} \cdot \mathrm{cm}^{-2}$ & nd & No & $\begin{array}{l}\text { Clinical study } \\
\text { on patients with } \\
\text { oesophageal } \\
\text { carcinoma }\end{array}$ \\
\hline [34] & PDT & $\begin{array}{l}\text { Nicotinamide and } \\
\text { carbogen }(95 \% \\
\text { oxygen with } 5 \% \\
\text { carbodioxide) }\end{array}$ & $m$-THPC & $\begin{array}{l}652 \mathrm{~nm}, 20,100 \text { and } \\
200 \mathrm{~mW} \cdot \mathrm{cm}^{-2}, 5 \mathrm{~min}\end{array}$ & nd & No & $\begin{array}{c}\text { H-MESO1 } \\
\text { tumour-bearing } \\
\text { mice }\end{array}$ \\
\hline
\end{tabular}

nd: not determined; HBO: hyperbaric oxygen; 5-ALA: 5-aminolevulinic acid; RB: Rose Bengal; HpD: haematoporphyrin derivatives; $m$-THPC: $m e t a$-tetra(hydroxyphenyl)chlorin. 


\subsection{Red Blood Cells $(\mathrm{RBC})$ or Hemoglobin $(\mathrm{Hb})$}

A new optical method based on in vivo laser-induced photodissociation of blood oxyhemoglobin have been proposed by Asimov et al. [35] to solve the hypoxia problem in malignant tissue and to stimulate the aerobic metabolism of cells. The kinetics of laser-induced oxygenation of cutaneous tissue dependence on the laser-irradiation time was investigated. It was found that upon He-Ne laser irradiation $\left(632 \mathrm{~nm}, 225 \mathrm{~W} \cdot \mathrm{m}^{-2}\right)$ of the cutaneous blood vessels, a local increase in the $\mathrm{O}_{2}$ concentration in the irradiated region was observed. Based on the obtained results, the proposed optical method for local hypoxia elimination in malignant tissues may be a good key to increase the efficiency of the different therapeutic procedure in oncology.

Luo et al. [36] developed stable nanosize artificial red cells denoted as I-ARCs by loading complexes of indocyanine green (ICG) and $\mathrm{O}_{2}$ carrier (hemoglobin, $\mathrm{Hb}$ ) to incorporate an $\mathrm{O}_{2}$ supply and monitor the PDT process. The in vitro studies of I-ARCs compared to deoxy-I-ARCs and ICG NPs (INPs) were performed on MCF-7 human breast cancer cell line under NIR laser irradiation $\left(100 \mathrm{~mW} \cdot \mathrm{cm}^{-2}, 808 \mathrm{~nm}\right.$, $5 \mathrm{~min}$ ). I-ARCs showed massive generation of ROS (9.5 times stronger than INPs) and 10.7-times higher formation of ferryl- $\mathrm{Hb}$ than deoxy-I-ARCs. I-ARCs presented the best phototoxic effects against MCF-7, with a cell viability of $8.9 \%$. The authors explained the remarkable phototoxicity in I-ARCs by the enhanced both ROS production and ferryl-Hb generation. Similarly, the result of PDT-treated mice bearing MCF-7 tumours obtained with I-ARCs was the best compared to the other systems (Figure 2).

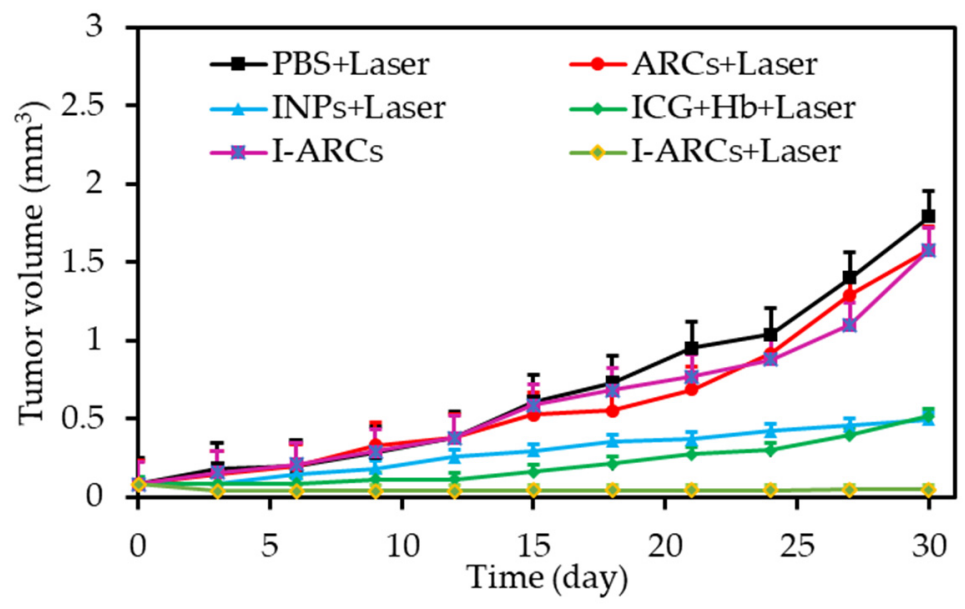

Figure 2. MCF-7 tumour growth curves of different groups after treatments. ${ }^{*} p<0.05,{ }^{* *} p<0.01$. All injectants were oxygenated before experiments. Adapted from Luo et al. [36].

Two years later, the same team [37] designed a protein hybridization approach by developing a bioinspired hybrid protein $\mathrm{O}_{2}$ nanocarrier with encapsulated chlorin e6 (Ce6) (C@HPOC) via intermolecular disulfide conjugations for $\mathrm{O}_{2}$-augmented immunogenic PDT against tumour growth and metastasis. In vitro ${ }^{1} \mathrm{O}_{2}$ production ability of $\mathrm{C} @ \mathrm{HPOC}$ was investigated in $4 \mathrm{~T} 1$ tumour cells and compared to that of Ce6 and C@HSA. It was found that under laser irradiation $\left(600 \mathrm{~nm}, 0.1 \mathrm{~W} \cdot \mathrm{cm}^{-2}\right.$, $2 \mathrm{~min}$ ) C@HPOC significantly enhanced the ${ }^{1} \mathrm{O}_{2}$ levels compared to the other systems. The PDT treatment revealed that at $1 \mu \mathrm{g} \cdot \mathrm{mL}^{-1}$ of Ce6, C@HPOC showed the highest PDT effect (80\% apoptosis ratio of $4 \mathrm{~T} 1$ cells) compared to Ce6 and C@HSA under the same conditions, indicating that C@HPOC boosted the PDT effect to kill tumour cells. In addition, according to the in vivo results, $\mathrm{O}_{2}$-boosted PDT of C@HPOC provoked immunogenic cell death with enhanced release of danger-associated molecular patterns from 4T1 tumour cells and then promoted the maturation of dendritic cells. Finally, the well-defined C@HPOC evoked $\mathrm{O}_{2}$-enhanced immunogenic PDT, which not only destroyed the primary tumours but also effectively suppressed distant tumours and lung metastasis in metastatic triple-negative breast cancer model by evoking systemic anti-tumour immunity. 
Tang et al. [38] developed a novel red blood cells (RBC)-facilitated PDT methodology. They first loaded the phthalocyanine $\mathrm{ZnF}_{16}$-Pc into ferritin NPs and then coupled the $\mathrm{ZnF}_{16}$-Pc-loaded ferritins (P-FRT) onto RBC membranes to afford P-FRT-RBC-NPs. According to the in vitro and hypoxic tumour models, using RBCs as $\mathrm{ZnF}_{16}$-Pc carriers could enhance the PDT efficiency. It was shown that RBCs could provide $\mathrm{O}_{2}$ to enable sustained ${ }^{1} \mathrm{O}_{2}$ production even when P-FRT-RBC NPs were under hypoxic conditions (Figure 3).

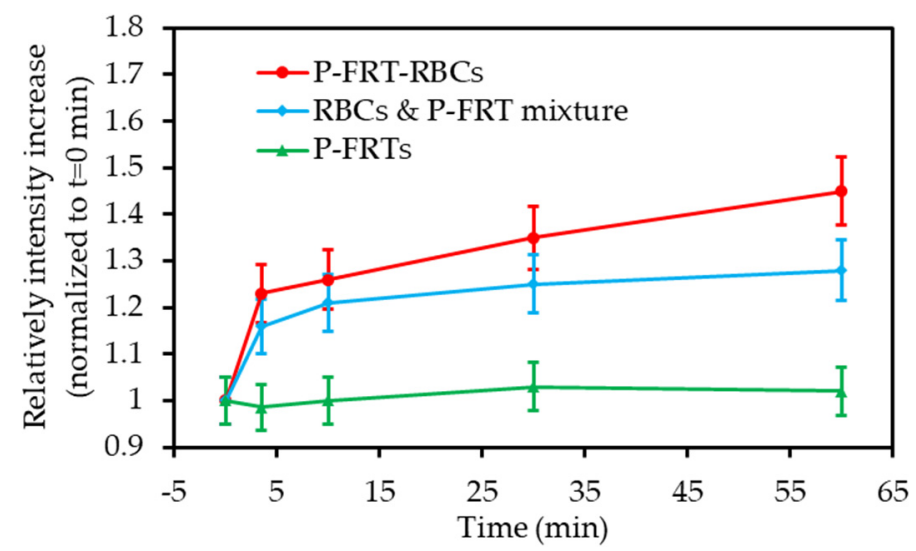

Figure 3. P-FRT-RBCs showed enhanced PDT effect under hypoxic environments. Comparison of ${ }^{1} \mathrm{O}_{2}$ generation among P-FRT-RBCs, a mixture of RBCs and free P-FRTs, and free P-FRTs, conducted in an Ar-filled cuvette. The cuvette was irradiated by a $671 \mathrm{~nm}$ laser $\left(0.1 \mathrm{~W} \cdot \mathrm{cm}^{-2}\right)$ for up to $60 \mathrm{~min}$. SOSG was used as an indicator of ${ }^{1} \mathrm{O}_{2}$ production. Adapted from Tang et al. [38].

P-FRT-RBCs were injected onto U87MG human glioma tumour bearing mice $(671 \mathrm{~nm}$, $\left.100 \mathrm{~mW} \cdot \mathrm{cm}^{-2}, 30 \mathrm{~min}\right)$. Significant improvement in the PDT efficiency was observed with P-FRT-RBC or $\mathrm{O}_{2}$-treated P-FRT-RBC groups compared to that of the P-RBC and CO-treated P-FRT-RBC groups (76.7\% of tumour suppression). Such results validated the contribution of $\mathrm{O}_{2}$ released from $\mathrm{RBCs}$ in the enhanced treatment.

Wang et al. [39] reported a novel strategy for overcoming biological barriers and site specific hypoxia cancer therapy under NIR control. The latter consisted of preparing orthogonal excitation-emission UCNPs functionalized with a novel ultrasensitive specific hypoxia probe (HP) and RB, conjugated to the surface of RBC to finally obtain RBC microcarriers. According to the in vitro PDT results under hypoxic conditions, the inactive HP present in RBC microcarriers could be transformed into an active state specifically to trigger the $\mathrm{O}_{2}$ release from oxygenated $\mathrm{Hb}$ under $980 \mathrm{~nm}$ excitation. PDT efficiency enhanced greatly under $808 \mathrm{~nm}$ excitation because of the increasing of $\mathrm{O}_{2}$ amount from RBC microcarriers. Consequently, the highest cell mortality $(60 \%)$ was achieved with RBC microcarriers after alternately irradiating by $980 \mathrm{~nm}$ and $808 \mathrm{~nm}$ laser, indicating a highest PDT efficacy which was due to the large amount of released $\mathrm{O}_{2}$. PDT for hypoxia tumours studies was investigated onto U87MG solid tumour-bearing mice. Much higher anti-tumour efficacy by remarkably regressing the solid tumour volumes was observed with RBC microcarriers in the presence of the alternate $980 \mathrm{~nm}$ and $808 \mathrm{~nm}$ laser irradiation, compared to that with Si microcarriers and RBC alone (Figure 4a,b).

Cao et al. [40] designed a multi-functional nanocomplexe (BP@RB-Hb) by simple molecular assembly of bis(pyrene) (BP), RB, $\mathrm{Hb}$ and nanoliposomes (Figure 5) to improve both the depth and the effectiveness of antitumour PDT treatment. In brief, upon two-photon laser irradiation, RB was excited indirectly through intra-particle FRET mechanism for improving treatment depth. At meantime, $\mathrm{Hb}$ could supply extra $\mathrm{O}_{2}$ into tumour through targeting effect for enhanced PDT efficiency. 
a)

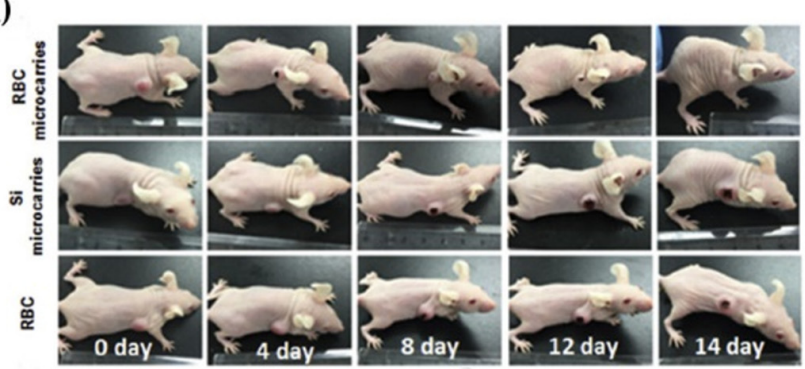

b)

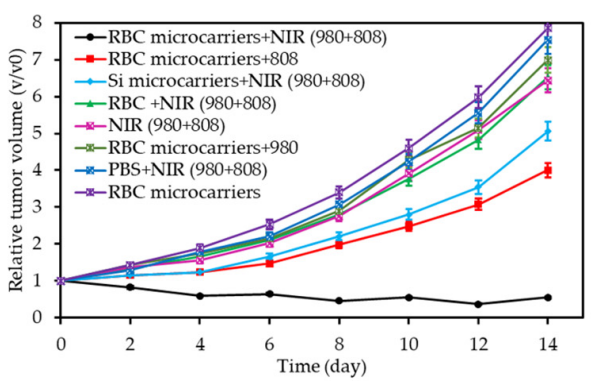

Figure 4. PDT for hypoxia tumours. (a) Digital photos of U87MG tumour-bearing mice after 14days of $\mathrm{O}_{2}$ release and PDT treatments under NIR irradiation. From up to down mice were treated with RBC microcarriers + 980-nm +808-nm laser; Si microcarriers + 980-nm +808-nm laser; RBC + 980-nm +808 -nm laser. (b) Tumour growth profiles of the mice bearing U87MG tumour with different treatments. Reprinted from [39] with permission from Elsevier, Ltd, Copyright 2017.

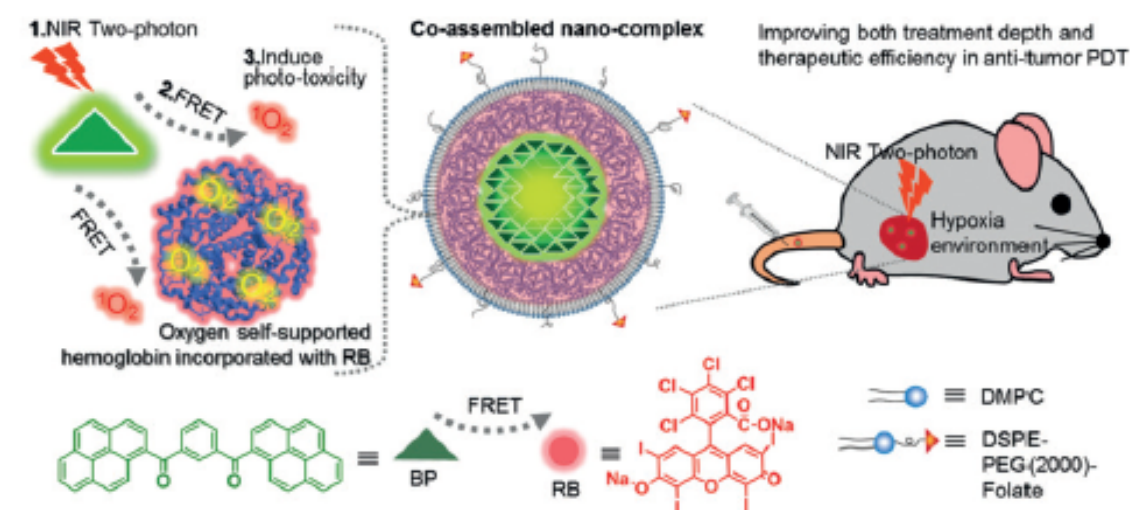

Figure 5. The BP@RB-Hb structure and the process of one-/two photon. Reprinted from [40] with permission from John Wiley and Sons, Copyright 2018.

In vitro studies were performed on MCF-7 cells lines at different concentrations of deoxy-BP@RB-Hb or BP@RB-Hb (0-1.25 mg· $\left.\mathrm{mL}^{-1}\right)$. Upon mono-photon laser irradiation $(150 \mathrm{~W}$, $480 \mathrm{~nm}$ cutoff filter), BP@RB-Hb showed the best photocytotoxicity, which was explained by more ROS production by BP@RB-Hb via intra-particle FRET between RB and BP species.

Finally, in vivo photodynamic studies were also done in a mouse cancer model (BALB/c nude mice). BP@RB-Hb or BP@RB was injected to the mouse followed by two-photon laser (800 nm, $\left.390 \mathrm{~mW} \cdot \mathrm{cm}^{-2}, 8 \mathrm{~min}\right)$. A significant anti-tumour effect was observed in the case of group injected with BP@RB-Hb. Furthermore, in vivo BP@RB-Hb showed a higher anti-tumour efficiency to the hyperoxic tumour than the hypoxic tumour after two-photon laser irradiation (Figure 6).

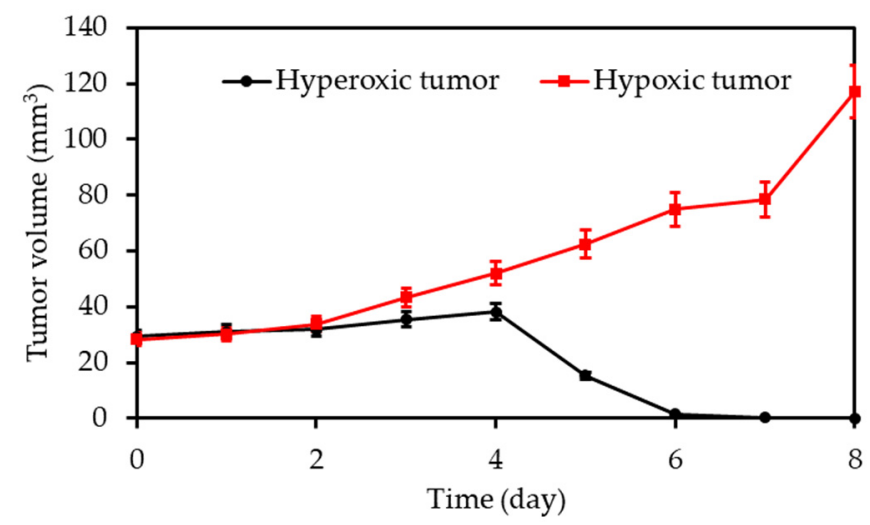

Figure 6. Tumour volume under hyperoxia and hypoxia. Adapted from Cao et al. [40] 
Guo et al. [41] designed an $\mathrm{O}_{2}$-delivering photosensitive liposome ( $\mathrm{LIH}$ ) by loading complexes of $\mathrm{Hb}$ and ICG. LIH showed out-standing ability as an $\mathrm{O}_{2}$ carrier and could generate massive ${ }^{1} \mathrm{O}_{2}$ under NIR laser irradiation $\left(808 \mathrm{~nm}, 1 \mathrm{~W} \cdot \mathrm{cm}^{-2}, 1 \mathrm{~min}\right)$, even in hypoxia conditions. In vitro $\mathrm{O}_{2}$ carrying was investigated on CT-26 cancer colon cells. It was found LIH could not only get inside CT-26 cells and deliver $\mathrm{O}_{2}$ into cells in hypoxia condition, but also down-regulated hypoxia-associated protein to cells. Thus, the sufficient ${ }^{1} \mathrm{O}_{2}$ produced by LIH under NIR laser treatment $\left(808 \mathrm{~nm}, 1 \mathrm{~W} \cdot \mathrm{cm}^{-2}\right.$, $1 \mathrm{~min}$ ) enhanced dramatically the PDT phototoxicity in hypoxic CT-26 cells. According to the in vivo studies on mice bearing tumours, $\mathrm{LIH}$ accumulated preferentially into subcutaneous and orthotopic CT-26 tumours. In addition, the vascular endothelial growth factor (VEGF) and Hypoxia-inducible factor- $1 \alpha$ (HIF-1 $\alpha)$ expression level in LIH treated tumours was also down-regulated and this state was maintained for several days. Consequently, under NIR laser irradiation $\left(808 \mathrm{~nm}, 1.5 \mathrm{~W} \cdot \mathrm{cm}^{-2}, 3 \mathrm{~min}\right)$ dramatically enhanced PDT efficacy against hypoxic tumour in vivo was observed.

Liu and his team [42] synthesized $\mathrm{Hb}$-conjugated biodegradable polypeptides as $\mathrm{O}_{2}$ carrier via click reaction between polypeptides and $\mathrm{Hb}-\mathrm{BODIPY}-\mathrm{Br}_{2} \mathrm{NPs}$ denoted (p-Hb-B-NPs). The $\mathrm{O}_{2}$-carrying ability of the prepared NPs was confirmed by comparing the dissolved $\mathrm{O}_{2}$ concentration of $\mathrm{p}-\mathrm{Hb}-\mathrm{B}-\mathrm{NPs}$ to that of $\mathrm{O}_{2}$ saturated ultrapure water. PDT efficiency of the NPs was investigated on hepatocellular carcinoma HepG2 cancer cells $\left(620 \mathrm{~nm}, 25 \mathrm{~mW} \cdot \mathrm{cm}^{-2}, 10 \mathrm{~min}\right)$ under normal or $\mathrm{N}_{2}$ atmosphere and compared to that of p-B-NPs. Even under low light irradiation both NPs showed phototoxic effect under normal atmosphere, where the best effect was obtained at a $4 \mu \mathrm{M} \mathrm{p}-\mathrm{Hb}-\mathrm{B}-\mathrm{NPs}$ concentration, however a non-phototoxic effect was observed under $\mathrm{N}_{2}$ atmosphere. Furthermore, $\mathrm{p}-\mathrm{Hb}-\mathrm{B}-\mathrm{NPs}$ found to be able to release $\mathrm{O}_{2}$ even in hypoxic conditions.

$\mathrm{Xu}$ et al. [43] prepared a new biocompatible and stable nanocarrier ( $\mathrm{HbTcMs}$ ) with $\mathrm{O}_{2}$ supply for enhanced PDT. A well-defined triblock copolymer mPEG-b-PAA-b-PS copolymer could self- assemble in aqueous solution to form micelles. The micelles and the PS (carboxyphenyl-porphyrin, TCPP) both covalently conjugated to $\mathrm{Hb}$ via amidation reactions formed a nanocarrier ( $\mathrm{HbTcMs}$ ). According to the $\mathrm{O}_{2}$ binding ability results, $\mathrm{HbTcMs}$ was found to be able not only to retain the $\mathrm{O}_{2}$ binding capacity as $\mathrm{Hb}$ did, but also showed better stability against both oxidation and trypsin digestion. $\mathrm{HbTcMs}$ conjugate showed little dark toxicity and rapid efficiency of cellular uptake by $4 \mathrm{~T} 1$ cells. More importantly, under light irradiation $\left(600 \mathrm{~nm}, 70 \mathrm{~mW} \cdot \mathrm{cm}^{-2}, 2 \mathrm{~min}\right), \mathrm{HbTcMs}$ could generate more ${ }^{1} \mathrm{O}_{2}$ to exert better phototoxicity in vitro compared to the carriers without $\mathrm{O}_{2}$ supply.

Liu et al. [44] designed man-made red blood cells (RBCs). A complex between $\mathrm{Hb}$ and polydopamine (PDA, an enzyme-mimicking) was constructed and methylene blue (MB) was encapsulated inside the biovesicle (Hb-PDA-MB, $500 \mathrm{~nm}$ in transverse length and $2000 \mathrm{~nm}$ in longitudinal length). To evaluate the influence of $\mathrm{Hb}$ other complexes were synthesized in which $\mathrm{Hb}$ was substituted with albumin bovine serum (BSA) (called BSA-PDA@RBCM and BSA-PDA-MB@RBCM, respectively). $\mathrm{Hb}$ was unchanged in the vesicle and the capability of $\mathrm{Hb}$ to carry $\mathrm{O}_{2}$ was the same for free $\mathrm{Hb}$ and $\mathrm{Hb}$ into the vesicle. ${ }^{1} \mathrm{O}_{2}$ formation was higher for $\mathrm{MB}$ inside the vesicle than in solution due to the extra $\mathrm{O}_{2}$ supply. In $4 \mathrm{~T} 1$ cell line upon light illumination $\left(660 \mathrm{~nm}, 30 \mathrm{~mW} \cdot \mathrm{cm}^{-2}, 1 \mathrm{~min}\right)$ DCFH-DA revealed the formation of ${ }^{1} \mathrm{O}_{2}$. In hypoxic media, the vesicles were still able to produce ${ }^{1} \mathrm{O}_{2}$, whereas almost no more ${ }^{1} \mathrm{O}_{2}$ was produced by $\mathrm{MB}$ alone. The phototoxicity of $\mathrm{Hb}$-PDA-MB decreased by $10 \%$ in hypoxic media compared to normoxic one whereas a decrease of $50 \%$ was obtained with free $\mathrm{MB}\left(660 \mathrm{~nm}, 220 \mathrm{~mW} \cdot \mathrm{cm}^{-2}, 5 \mathrm{~min}\right)$. In vivo in $4 \mathrm{~T} 1$ tumour bearing mice, they used the same vesicle labelling with both Ce6 and DiR (1,1-dioctadecyl-3,3,3,3-tetramethylindotricarbocyanine) and could observe that the tumour stopped growing. Some tumours even completely disappeared (Table 3 ). 
Table 3. Summary of publications about $\mathrm{RBC}$ as $\mathrm{O}_{2}$ vehicle.

\begin{tabular}{|c|c|c|c|c|c|c|c|}
\hline Ref & Application & Vehicle & PS & Energy of Excitation & Type of ROS & In Vitro & In Vivo \\
\hline [36] & PDT & $\begin{array}{c}\text { Artificial red cells } \\
\text { (ARCs) containing } \\
\mathrm{Hb}\end{array}$ & IGC & $\begin{array}{c}\text { In vitro: } 808 \mathrm{~nm}, 100 \mathrm{~mW} \cdot \mathrm{cm}^{-2}, \\
5 \mathrm{~min} \\
\text { In vivo: } 808 \mathrm{~nm}, 100 \mathrm{~mW} \cdot \mathrm{cm}^{-2} \\
30 \mathrm{~min}\end{array}$ & ROS & MCF-7 cell line & $\begin{array}{l}\text { MCF-7 tumour-bearing } \\
\text { mice }\end{array}$ \\
\hline [37] & PDT & $\mathrm{Hb}$ & Ce6 & $\begin{array}{c}\text { In vitro: } 660 \mathrm{~nm}, 0.1 \mathrm{~W} \cdot \mathrm{cm}^{-2}, 2 \\
\min \\
\text { In vivo: } 660 \mathrm{~nm}, 0.1 \mathrm{~W} \cdot \mathrm{cm}^{-2}, 30 \\
\min \end{array}$ & ${ }^{1} \mathrm{O}_{2}$ & $4 \mathrm{~T} 1$ cell line & $\begin{array}{l}\text { 4T1 tumour-bearing } \\
\text { mice }\end{array}$ \\
\hline [38] & PDT & RBCs & $\mathrm{ZnF}_{16} \mathrm{Pc}$ & $\begin{array}{c}\text { In vitro: } 671 \mathrm{~nm}, 100 \mathrm{~mW} \cdot \mathrm{cm}^{-2} \\
0-60 \mathrm{~min} \\
\text { In vivo: } 671 \mathrm{~nm}, 100 \mathrm{~mW} \cdot \mathrm{cm}^{-2} \\
30 \mathrm{~min}\end{array}$ & ${ }^{1} \mathrm{O}_{2}$ & U87MG cell line & $\begin{array}{l}\text { U87MG tumour bearing } \\
\text { mice }\end{array}$ \\
\hline [39] & PDT & RBCs & $\mathrm{RB}$ & $\begin{array}{c}980 \mathrm{~nm}+808 \mathrm{~nm}, 1.5 \mathrm{~W} \cdot \mathrm{cm}^{-2} \\
15 \mathrm{~min}\end{array}$ & ${ }^{1} \mathrm{O}_{2}$ & U87MG cell line & $\begin{array}{l}\text { U87MG tumour-bearing } \\
\text { mice }\end{array}$ \\
\hline [40] & PDT & $\mathrm{Hb}$ & $\mathrm{RB}$ & $\begin{array}{l}\text { In vitro: two-photon } 808 \mathrm{~nm} \text {, } \\
390 \mathrm{~mW} \cdot \mathrm{cm}^{-2}, 20 \mathrm{~min} \\
\text { In vivo: two-photon } 808 \mathrm{~nm}, \\
390 \text { or } 250 \mathrm{~mW} \cdot \mathrm{cm}^{-2}, 8 \text { or } 15 \\
\text { min }\end{array}$ & ${ }^{1} \mathrm{O}_{2}$ & MCF-7 cell line & $\begin{array}{l}\text { MCF-7 tumour-bearing } \\
\text { mice }\end{array}$ \\
\hline [41] & PDT & $\mathrm{Hb}$ & ICG & $808 \mathrm{~nm}, 1 \mathrm{~W} \cdot \mathrm{cm}^{-2}, 1 \mathrm{~min}$ & ${ }^{1} \mathrm{O}_{2}$ & CT-26 cell line & $\begin{array}{l}\text { S180 and CT26 } \\
\text { tumour-bearing mice }\end{array}$ \\
\hline [42] & PDT & $\mathrm{Hb}$ & BODIPY-Br 2 & $635 \mathrm{~nm}, 25 \mathrm{~mW} \cdot \mathrm{cm}^{-2}, 10 \mathrm{~min}$ & ${ }^{1} \mathrm{O}_{2}$ & HepG2 cell line & No \\
\hline [43] & PDT & $\mathrm{Hb}$ & ТСРP & $600 \mathrm{~nm}, 70 \mathrm{~mW} \cdot \mathrm{cm}^{-2}, 2 \mathrm{~min}$ & ${ }^{1} \mathrm{O}_{2}$ & 4T1 cell line & No \\
\hline [44] & PDT & $\begin{array}{l}\text { RBC membranes } \\
\text { encapsulating } \mathrm{Hb}\end{array}$ & MB & $\begin{array}{c}\text { In vitro: } 660 \mathrm{~nm}, 30 \mathrm{~mW} \cdot \mathrm{cm}^{-2} \\
5 \mathrm{~min} \\
\text { In vivo: } 660 \mathrm{~nm}, 220 \mathrm{~mW} \cdot \mathrm{cm}^{-2} \\
5 \mathrm{~min}\end{array}$ & ${ }^{1} \mathrm{O}_{2}$ & $4 \mathrm{~T} 1$ cell line & $\begin{array}{l}\text { 4T1 tumour-bearing } \\
\text { mice }\end{array}$ \\
\hline [45] & PDT & $\mathrm{Hb}-\mathrm{RBC}$ & ICG & $\begin{array}{l}808 \mathrm{~nm} \\
60 \mathrm{~mW} \cdot \mathrm{cm}^{-2} \\
5 \mathrm{~min}\end{array}$ & ${ }^{1} \mathrm{O}_{2}$ & $\begin{array}{c}\text { Macrophages } \\
\text { (RAW264.7 cell line) }+ \\
\text { multicellular tumour } \\
\text { spheroids }\end{array}$ & $\begin{array}{c}\text { MCF-7 tumour bearing } \\
\text { mice }\end{array}$ \\
\hline
\end{tabular}

Hb: Hemoglobin; ICG: Indocyanine green; Ce6: Chlorin e6; RBC: Red Blood cells; ZnF 16 Pc: zinc 1,2,3,4,8,9,10,11,15,16,17,18,22,23,24,25-hexadecafluoro-29H,31H-phthalocyanine; RB: Rose Bengal; BODIPY-Br 2 : 4,4-difluoro-4-bora-3a,a-diaza-s-indacene brominated; TCPP: carboxyphenyl-porphyrin; MB: methylene blue. 
Zirconium (IV)-based MOF (UiO-66) NPs (diameter $55 \mathrm{~nm}$ ) coated with ICG were loaded with $\mathrm{O}_{2}$ and coextruded with $\mathrm{Hb}-\mathrm{RBC}$ membranes by Gao et al. [45]. They presented high $\mathrm{O}_{2}$ storage capacities. The production of ${ }^{1} \mathrm{O}_{2}$ was observed by DPBF after irradiation at $808 \mathrm{~nm}$ during $2 \mathrm{~min}$ (Figure 7). A photothermal effect was measured with a temperature of $43{ }^{\circ} \mathrm{C}$ after 5 min irradiation. The NPs were encapsulated in RBC membrane from male ICR mice and the circulation half-lives increased. The uptake of the NP in macrophages (RAW264.7 cell line) was confirmed. The ${ }^{1} \mathrm{O}_{2}$ production in multicellular tumour spheroids (MCTSs) was observed by DCFH-DA. The PDT efficiency was assessed showing a high cell mortality after NIR irradiation $\left(808 \mathrm{~nm}, 0.06 \mathrm{~W} \cdot \mathrm{cm}^{-2}, 5 \mathrm{~min}\right)$. Intravenous injection of the NP in MCF-7 and light irradiation $\left(808 \mathrm{~nm}, 0.06 \mathrm{~W} \cdot \mathrm{cm}^{-2}, 1 \mathrm{~min}\right)$ tumour-bearing mice showed a notably tumour growth inhibition.

a)

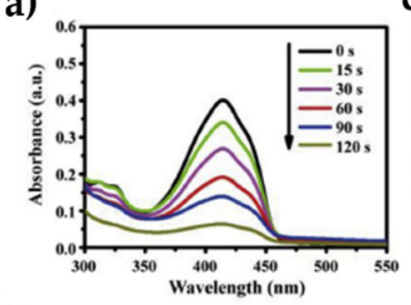

c)

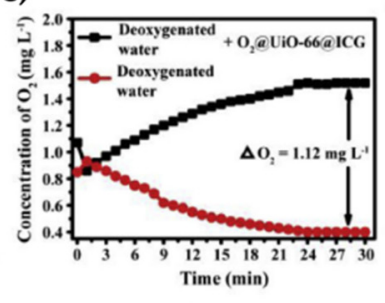

d)

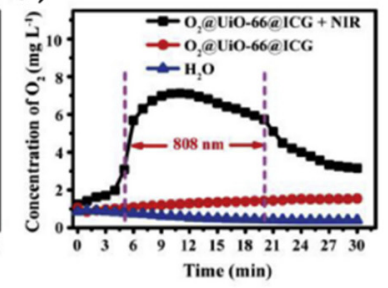

5 min

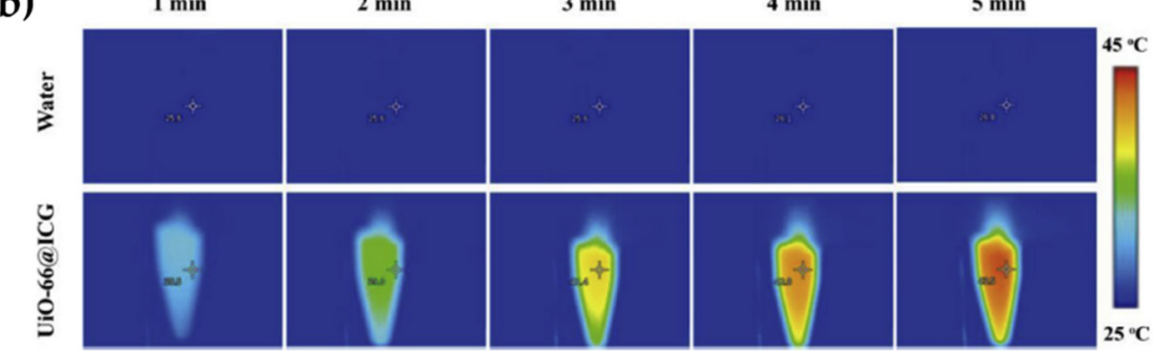

Figure 7. (a) The absorbance changes of DPBF treated with UiO-66@ICG in DMF after $808 \mathrm{~nm}$ laser irradiation for different times. (b) Infrared thermal images of pure $\mathrm{H}_{2} \mathrm{O}$ and UiO-66@ICG aqueous dispersion $\left(1 \mathrm{mg} \cdot \mathrm{mL}^{-1}\right)$ after irradiation for $5 \mathrm{~min}$ by $808 \mathrm{~nm}$ laser $\left(0.06 \mathrm{~W} \cdot \mathrm{cm}^{-2}\right)$. (c) $\mathrm{O}_{2}$ concentration in $20 \mathrm{~mL}$ deoxygenated water before and after adding $5 \mathrm{mg}$ of $\mathrm{O}_{2} @$ UiO-66@ICG. (d) $\mathrm{O}_{2}$ concentration changes in solutions of $\mathrm{O}_{2} @ \mathrm{UiO}-66 @ \mathrm{ICG}$ under irradiation by $808 \mathrm{~nm}$ laser. $\mathrm{DO}_{2}$ : Enhanced $\mathrm{O}_{2}$ concentration. The $\mathrm{O}_{2}$ loading capacity per $1 \mathrm{~g}$ of ICG@UiO-66 was calculated as follows: the loading capacity of ICG@UiO-66 $\frac{1}{4}\left(\mathrm{DO}_{2}\right.$ : Enhanced $\mathrm{O}_{2}$ concentration)/ (ICG@UiO-66 concentration). The $\mathrm{O}_{2}$ loading capacity of ICG@UiO-66 was determined to be $\sim 140 \mathrm{mmol} \cdot \mathrm{g}^{-1} \mathrm{or} 4.48 \mathrm{mg} \cdot \mathrm{g}^{-1}$. Reprinted from [45] with permission from Elsevier Ltd, Copyright 2018.

\subsection{Perfluorocarbon}

Perfluorocarbons (PFCs) are organofluorine compounds with the formula CxFy. PFCs are capable of dissolving relatively high volumes of gases due to the weak intermolecular interactions in these PFCs. They can maintain a higher $\mathrm{O}_{2}$ content than the tumour matrix at a given $\mathrm{O}_{2}$ partial pressure thanks to their high $\mathrm{O}_{2}$ capacity. In this context, since 201619 publications have described the use of PFC to relieve tumour hypoxia and improve PDT efficiency. It can be used as the contrast enhancement agent of ultrasonography in the clinic [46], different formulations of liquid PFC have been explored to serve as an artificial blood substitute. PFCs could be excreted by exhalation from lungs or skin pores. Oxypherol (Fluosol-43) has obtained FDA approval in improving myocardial oxygenation and preventing abnormalities in ventricular function [47]. Oxygent ${ }^{\mathrm{TM}}$ is a concentrated PFC emulsion being developed for use as a temporary $\mathrm{O}_{2}$ carrier. It has been approved in Russia to increase $\mathrm{O}_{2}$ delivery during acute blood loss.

Cheng et al. [48] developed nanodroplets of perfluorohexane (PFH) coated with a lipid shell incorporating IR780 as a PS (diameter $200 \mathrm{~nm}$ ). The irradiation of NPs in water with an $808 \mathrm{~nm}$ laser 
for $5 \mathrm{~s}$ intervals during $60 \mathrm{~s}\left(2 \mathrm{~W} \cdot \mathrm{cm}^{-2}\right)$ showed an higher ${ }^{1} \mathrm{O}_{2}$ production than irradiation of $\mathrm{PFH}$ or IR780 alone. MCF-7 cells or CT26 murine colon adenocarcinoma cells irradiated with $808 \mathrm{~nm}$ laser $\left(20 \mathrm{~s}, 2 \mathrm{~W} \cdot \mathrm{cm}^{-2}\right)$ led to an increase of ${ }^{1} \mathrm{O}_{2}$ production with the NPs compared to PFH or IR780 alone. Phototoxicity of the nanodroplets on the two cell lines was observed. Photothermal effect did not play any role. The effects of the NPs in hypoxia were studied in CT26 cells in hypoxic conditions. After irradiation, NPs still maintained superior cytotoxicity to traditional PDT. In vivo evaluation of ${ }^{1} \mathrm{O}_{2}$ production on CT26 tumour-bearing mice with SOSG indicated higher ${ }^{1} \mathrm{O}_{2}$ generation with the conjugate than with PFH or IR780 alone. The tumour growth of the mice was inhibited after intratumoural injection. The tumour volume of mice receiving NPs and irradiation $(808 \mathrm{~nm}, 10+10 \mathrm{~s}$, $2 \mathrm{~W} \cdot \mathrm{cm}^{-2}$ ) was four folds lower than the volume of mice receiving IR780 alone.

PCF nanoemulsions (diameter $175 \mathrm{~nm}$ ) containing a fluorous porphyrin were synthetized by Day et al. [49]. They could encapsulate $\mathrm{O}_{2}$ with high concentration and produced ${ }^{1} \mathrm{O}_{2}$ after light illumination ( $\left.420 \mathrm{~nm}, 8.5 \mathrm{~mW} \cdot \mathrm{cm}^{-2}, 30 \mathrm{~min}\right)$. A minimal leaching of fluorous porphyrin to the hydrophilic medium was detected. The uptake of the emulsions in human malignant melanoma cells (A375) was successfully observed with confocal microscopy. Cell death was observed after irradiation (420 $\mathrm{nm}, 8.5 \mathrm{~mW} \cdot \mathrm{cm}^{-2}, 30 \mathrm{~min}$ ), whereas minimal death occurred with an emulsion containing a fluorous rhodamine. In summary, fluorous porphyrins sequestered in PFC nanoemulsions were able to deliver ${ }^{1} \mathrm{O}$ and to perform efficient PDT.

$\mathrm{Liu}$, et al. [50] synthesized a core shell NP ( $\mathrm{Au}$ core, $\mathrm{SiO}_{2}$ and $\mathrm{CuO}_{2}$ shell) incorporated into PHF droplets to form a liposome (diameter $190 \mathrm{~nm}$ ). The plasmon-induced resonance energy transfer (PIRET) from $\mathrm{Au}$ to $\mathrm{Cu}_{2} \mathrm{O}, \mathrm{Au} @ \mathrm{SiO}_{2} @ \mathrm{Cu}_{2} \mathrm{O}\left(670 \mathrm{~nm}, 0.48 \mathrm{~mW} \cdot \mathrm{cm}^{-2}, 10 \mathrm{~min}\right)$ produced ${ }^{1} \mathrm{O}_{2}$ with a quantum yield evaluated at 0.71 . NPs successfully incorporated into MCF-7 cells. ${ }^{1} \mathrm{O}_{2}$ production in these cells was greatly enhanced by the $\mathrm{O}_{2}$ supply of $\mathrm{PFH}$. A strong phototoxicity appeared after light illumination $\left(670 \mathrm{~nm}, 0.48 \mathrm{~mW} \cdot \mathrm{cm}^{-2}, 10 \mathrm{~min}\right.$ ) (Figure $\left.8 \mathrm{a}\right)$. The caspase 3 protein activity, an apoptosis indicator, showed a 3.6 higher amount than without irradiation (Figure $8 b$ ). The NPs induced significant phototoxicity to MCF-7 cells under both normoxic and hypoxic conditions. The $\mathrm{O}_{2}$ self-enriched effect of the NPs could guarantee PDT efficacy in MCF-7 cells. Irradiation of multicellular tumour spheroids (MCTS) of MCF-7 cells showed a high mortality. Tumour growth measurements on MCF-7 cancer-bearing female Balb/c mice conducted to a complete inhibition during 14 days after injection of the NP and irradiation $\left(670 \mathrm{~nm}, 0.48 \mathrm{~mW} \cdot \mathrm{cm}^{-2}, 10 \mathrm{~min}\right)$.

a)

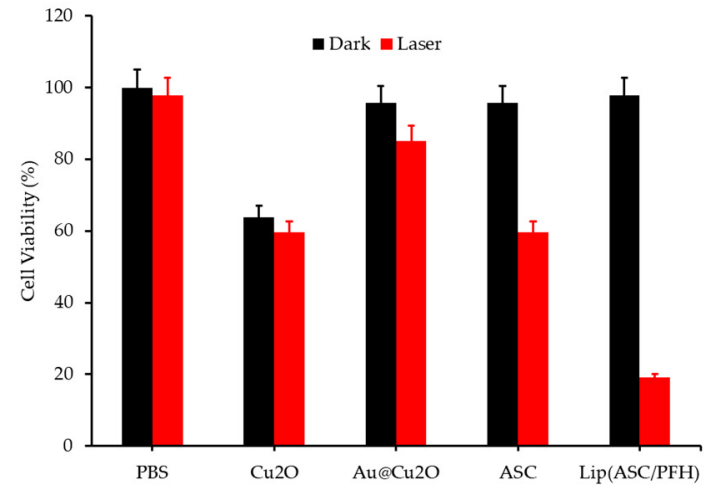

b)

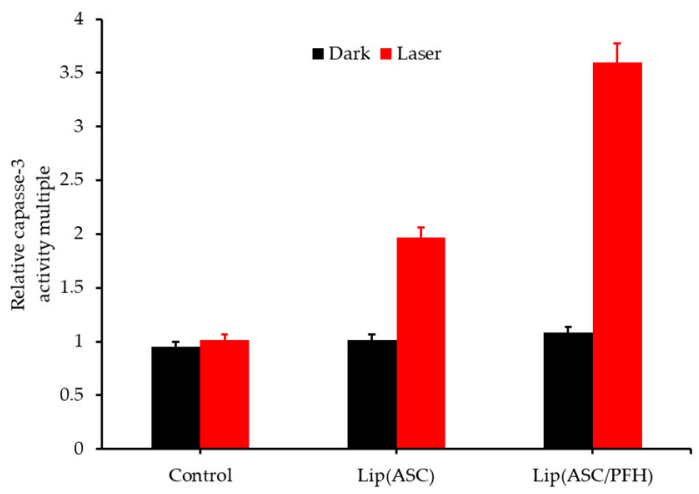

Figure 8. PDT in vitro on MCF-7 cells. (a) Cytotoxicity of different samples in the presence or absence of irradiation $\left(670 \mathrm{~nm}, 0.48 \mathrm{~W} \cdot \mathrm{cm}^{-2}\right)$. (b) Relative activity multiple of caspase-3 protein in MCF-7 cells activated by $\operatorname{Lip}\left(\right.$ ASC) and $\operatorname{Lip}(\mathrm{ASC} / \mathrm{PFH})\left(20 \mu \mathrm{g} \cdot \mathrm{mL}^{-1}\right)$ with or without $670 \mathrm{~nm}$ irradiation for $10 \mathrm{~min}$. Adapted from Liu et al. [50].

Que et al. [51] elaborated fluorine-containing NPs (a core of pentafluorophenyl and 5,10,15,20-tetrakis(4-aminophenyl) porphyrin) coated with PEG as spherical micelles (diameter $30 \mathrm{~nm}$ ). ${ }^{1} \mathrm{O}_{2}$ production, measured with ABDA was highly dependent of the concentration of PFC in the core, as $\mathrm{O}_{2}$ supplier $\left(655 \mathrm{~nm}, 1.52 \mathrm{~mW} \cdot \mathrm{cm}^{-2}, 15 \mathrm{~min}\right)$. The porphyrin in copolymers was then loaded with 
Pd. The heavy atom effect played a role in the enhanced PDT efficacy. No dark cytotoxicity was observed on SMMC-7721 cells (human hepatoma cell line). The phototoxicity of the micelles after irradiation $\left(655 \mathrm{~nm}, 1.52 \mathrm{~mW} \cdot \mathrm{cm}^{-2}, 60 \mathrm{~min}\right)$ showed a cell viability less than $30 \%$ and correlated with the PFC amount.

A nanoliposome was prepared by Sheng et al. [52] by incorporating perfluorooctyl bromide (PFOB) and ICG into a core coated by a bilipidic shell (diameter $200 \mathrm{~nm}$ ). The release of $\mathrm{O}_{2}$ from the NPs was assured by diffusion during at least $24 \mathrm{~h}$. The photothermal effect of the NP was evaluated after laser irradiation $\left(808 \mathrm{~nm}, 1 \mathrm{~W} \cdot \mathrm{cm}^{-2}, 5 \mathrm{~min}\right)$ with a temperature increase from 43 to $50{ }^{\circ} \mathrm{C} .{ }^{1} \mathrm{O}_{2}$ measured by SOSG under hypoxia was highly increased with the conjugate compared to ICG or liposome-ICG alone. The ROS production measured in vitro on human triple-negative breast cancer MDA-MB-231 cells led to the same results. Under irradiation $\left(808 \mathrm{~nm}, 1 \mathrm{~W} \cdot \mathrm{cm}^{-2}, 3 \mathrm{~min}\right)$ the cell viability decreased to $10 \%$ both in normoxia and hypoxia by a combination of PDT and PTT effects. Mice bearing MDA-MB-231 tumours treated with the conjugate and irradiated $\left(808 \mathrm{~nm}, 1 \mathrm{~W} \cdot \mathrm{cm}^{-2}\right.$, $10 \mathrm{~min}$ ) achieved almost complete tumour destruction without tumour recurrence.

Song et al. [53] synthesized nanodroplets of PFC (diameter $160 \mathrm{~nm}$ ) loaded with $\mathrm{O}_{2}$ and stabilized by albumin. Ce6 was modified (three hexylamine were added to increase the hydrophobicity) and loaded into the lipid bilayers of PEG-modified liposomes. The release of $\mathrm{O}_{2}$ was triggered by an external ultrasound activation (Figure 9). This activation enhanced PDT and radiotherapy efficiency. 4T1 tumour-bearing mice placed under hyperoxic inhalation were treated with ultrasound (US). Oxygenation levels showed an increase of $50 \%$ for the mice treated with the conjugate. $4 \mathrm{~T} 1$ tumour-bearing mice were treated with US and irradiated $\left(671 \mathrm{~nm}, 1.2 \mathrm{~W} \cdot \mathrm{cm}^{-2}, 5 \mathrm{~min}\right)$. Mice tumour growth was significantly inhibited compared to the control group. Similar results were obtained on mice bearing CT-26 colon cancer tumours.

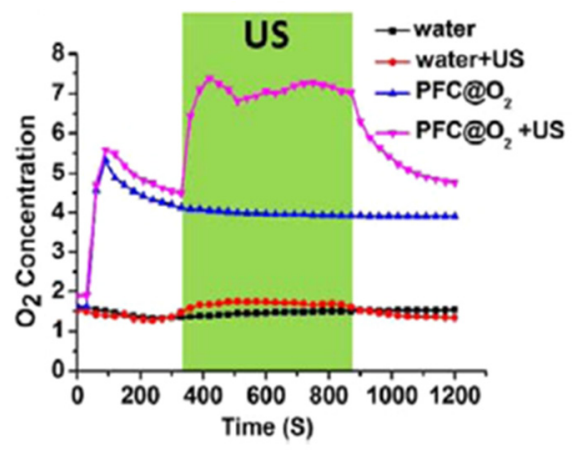

Figure 9. Time-dependent changes of dissolved $\mathrm{O}_{2}$ concentrations in deoxygenated pure water without or with addition of $\mathrm{O}_{2}$-loaded PFC nanoemulsion $(\mathrm{PFC@O})$. An US treatment was applied on these solutions within the indicated period. Reprinted from [53] with permission from the American Chemical Society, Copyright 2016.

Tang et al. [54] designed PFC nanodroplets coated with IR Dye 800CW (for in vivo imaging) and incorporating $\mathrm{ZnF}_{16} \mathrm{Pc}$ as a PS and perylene diimide (PDI) as photoacoustic agent (PA) imaging agent (diameter $110 \mathrm{~nm}$ ). The high $\mathrm{O}_{2}$ solubility in PFC enhanced PDT. The PDI agent converted light energy into heat for contrast-enhanced ultrasound imaging and for a photothermal effect. The PA intensity was registered proportionally to the PDI concentration. Under irradiation at $671 \mathrm{~nm}$ at different irradiance (until $1.2 \mathrm{~W} \cdot \mathrm{cm}^{-2}, 5 \mathrm{~min}$ ) the temperature of the solutions increased until $89^{\circ} \mathrm{C}$ showing the photothermal effect for an irradiance of $1.2 \mathrm{~W} \cdot \mathrm{cm}^{-2}$. Phototoxicity was observed after light irradiation $\left(671 \mathrm{~nm}, 100 \mathrm{~mW} \cdot \mathrm{cm}^{-2}, 200 \mathrm{~s}\right)$ on U87MG cells with a viability less than $34 \%$ without photothermal effect. ${ }^{1} \mathrm{O}_{2}$ was produced in normoxic and hypoxic media due to $\mathrm{O}_{2}$ supply by PFC. Same conclusions were observed on U87MG cells. Mice irradiated at $500 \mathrm{~mW} \cdot \mathrm{cm}^{-2}$ during $10 \mathrm{~min}(671 \mathrm{~nm})$ presented a complete tumour eradication (Figure 10). 


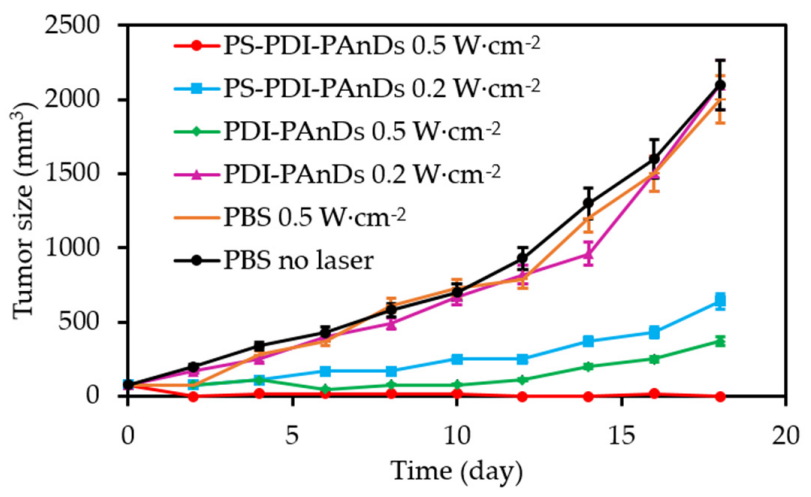

Figure 10. Tumour growth curves. Complete tumour eradication was found in the combinational PTT/Oxy-PDT treatment group with i.v. injection of PS-PDI-PAnDs plus a $0.5 \mathrm{~W} \cdot \mathrm{cm}^{-2}$ laser irradiation. Significant tumour growth inhibition was also observed with animals treated with PTT only (i.v. injection of PS-PDI-PAnPs plus a $0.5 \mathrm{~W} \cdot \mathrm{cm}^{-2}$ laser irradiation) and Oxy-PDT only (i.v. injection of PS-PDI-PAnDs plus a $0.2 \mathrm{~W} \cdot \mathrm{cm}^{-2}$ laser irradiation), indicating tumour growth inhibition rates of $82.3 \%$ and $67.5 \%$, respectively, on day 18 . Adapted from Tang et al. [54].

Tang et al. [55] designed a nanodroplet of perfluorohexane (PFH) as core and a lipid shell containing IR780 as the PS. The high concentration of $\mathrm{O}_{2}$ on PFH is playing as a sponge for $\mathrm{O}_{2}$ and was able to overcome hypoxia in tumours. After irradiation $\left(808 \mathrm{~nm}, 2 \mathrm{~W} \cdot \mathrm{cm}^{-2}, 20 \mathrm{~s}\right){ }^{1} \mathrm{O}_{2}$ production measured by the SOSG probe was higher with the conjugate than the lipidic NPs without PFH even when the conjugate was in hypoxic conditions. CT26 murine colon adenocarcinoma cells incubated and irradiated $\left(808 \mathrm{~nm}, 2 \mathrm{~W} \cdot \mathrm{cm}^{-2}, 20 \mathrm{~s}\right)$ showed a higher level of ${ }^{1} \mathrm{O}_{2}$ with the conjugates than with the lipidic NPs alone. The phototoxicity of the conjugate in hypoxia presented a high mortality in the CT26 cells, while almost no cells were killed with the lipidic NPs. The NPs were injected intravenously in mice bearing CT26 subcutaneous tumours kept in hypoxia $\left(7 \% \mathrm{O}_{2}\right)$ during $30 \mathrm{~min}$. After light illumination $\left(808 \mathrm{~nm}, 2 \mathrm{~W} \cdot \mathrm{cm}^{-2}, 10+10 \mathrm{~s}\right)$ the tumour growth was inhibited whereas no efficacy was observed for the lipidic NP.

Tao et al. [56] prepared fluorinated covalent organic polymers (COPs) by linking covalently a porphyrin (THPP) with perfluorosebacic acid (PFSEA) and PEG (diameter $\sim 60 \mathrm{~nm}$ ). PFCE, a type of PFC, was loaded into the porous structure of the NP. The dissolved $\mathrm{O}_{2}$ concentration was enhanced compared to the control. ${ }^{1} \mathrm{O}_{2}$ level measured by SOSG showed a significant increased production after irradiation $\left(660 \mathrm{~nm}, 10 \mathrm{~mW} \cdot \mathrm{cm}^{-2}, 30 \mathrm{~min}\right)$.

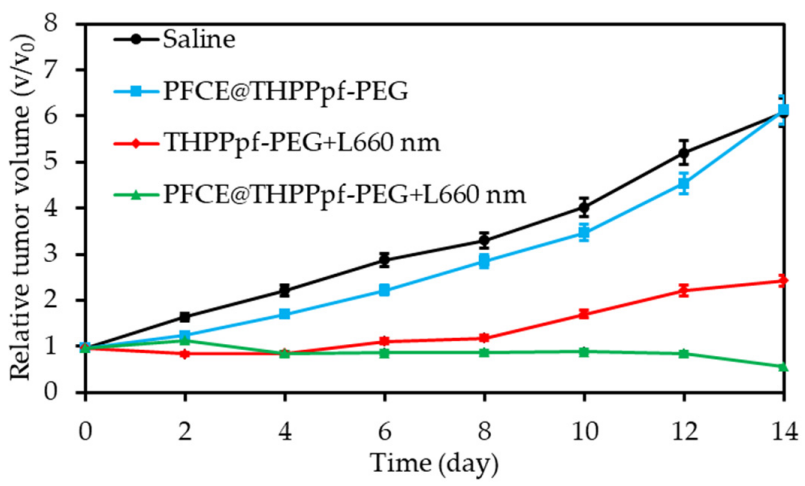

Figure 11. Tumour growth curves of four groups of mice after treatments as indicated. $V_{0}$ and $V$ stand for the tumour volumes before and after the treatments, respectively. Adapted from Tao et al. [56].

Cellular uptake of the conjugates was successfully achieved on $4 \mathrm{~T} 1$ cells. Phototoxicity of $80 \%$ was evaluated after irradiation $\left(660 \mathrm{~nm}, 10 \mathrm{~mW} \cdot \mathrm{cm}^{-2}, 60 \mathrm{~min}\right)$. The tumour growth of $4 \mathrm{~T} 1$ tumour-bearing 
mice after intravenous injection and irradiation $\left(660 \mathrm{~nm}, 50 \mathrm{~mW} \cdot \mathrm{cm}^{-2}, 30 \mathrm{~min}\right)$ was fully inhibited after 14 days (Figure 11).

Wang et al. [57] synthesized hollow MoSx NPs (HMoSx) by incorporating PFH in the core and loaded with albumin (HSA) and aluminum phthalocyanine (AlPc) (diameter $140 \mathrm{~nm}$ ). The NP were then loaded with $\mathrm{O}_{2}$. A photothermal effect was observed after irradiation $\left(670 \mathrm{~nm}, 1 \mathrm{~W} \cdot \mathrm{cm}^{-2}, 5 \mathrm{~min}\right)$, the temperature reached $68{ }^{\circ} \mathrm{C} .{ }^{1} \mathrm{O}_{2}$ production measured by DPBF showed a significant enhancement for the conjugate after irradiation. Phototoxicity assays realized on 4T1 cell lines led to an efficient activity of the conjugate on normoxia and hypoxia, when it was loaded with $\mathrm{O}_{2}$. Intracellular $\mathrm{ROS}$ generation on $4 \mathrm{~T} 1$ cells was also confirmed by measurement with the ROS-ID probe. Tumour growth measurements on $4 \mathrm{~T} 1$ tumour mice conducted to a complete inhibition during 16 days after injection of the conjugate and irradiation $\left(670 \mathrm{~nm}, 1 \mathrm{~W} \cdot \mathrm{cm}^{-2}, 5 \mathrm{~min}\right)$ confirming the dual PTT/PDT effect.

Wang et al. [58] prepared a polymeric micelle constituted of perfluorooctanoic acid and branched polyethyleneimine and incorporating $\mathrm{Ce} 6$ (diameter $120 \mathrm{~nm}$ ). A non-fluorinated micelle was prepared as control. The two NPs were loaded with $\mathrm{O}_{2}$ and the $\mathrm{O}_{2}$ released concentration was significantly higher for the fluorinated NP (Figure 12). ROS production measured by DCFH-DA on C6 cells showed high concentration for the conjugate after irradiation $\left(630 \mathrm{~nm}, 30 \mathrm{~mW} \cdot \mathrm{cm}^{-2}, 3 \mathrm{~min}\right)$. Hypoxia was greatly overcome by the conjugate in $\mathrm{C} 6$ cells compared to the control. Tumour growth measurements on BALB/c nude mice bearing $\mathrm{C} 6$ tumours conducted to a significant inhibition during 12 days after intravenous injection of the NP and irradiation $\left(660 \mathrm{~nm}, 500 \mathrm{~mW} \cdot \mathrm{cm}^{-2}, 20 \mathrm{~min}\right)$.

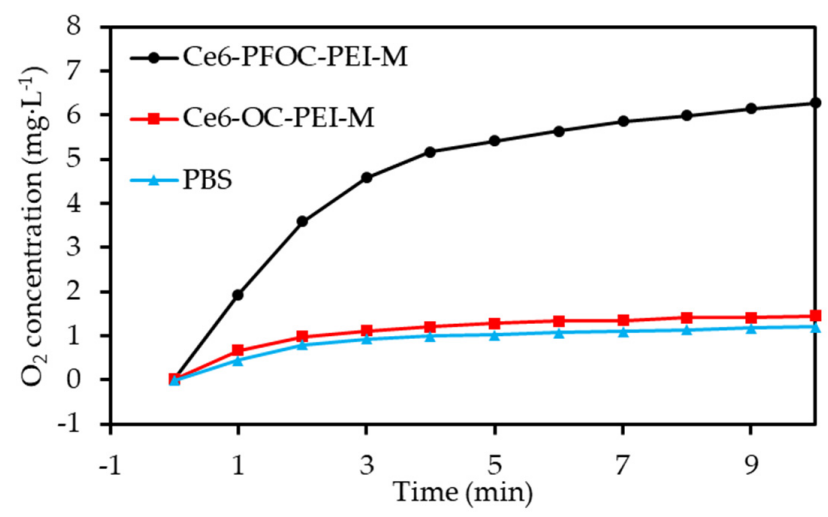

Figure 12. $\mathrm{O}_{2}$ concentration changed after the addition of $\mathrm{O}_{2}$ saturated Ce6-PFOC-PEI-M, Ce6-OC-PEI-M and PBS into deoxygenated water. Adapted from Wang et al. [58].

Yu et al. [59] designed PFH nanoliposomes incorporating $\mathrm{O}_{2}$ and $\mathrm{Ce} 6$ (diameter $100 \mathrm{~nm}$ ). PFH was able to encapsulate and then release $\mathrm{O}_{2}$. The dissolved $\mathrm{O}_{2}$ concentration was greatly enhanced during ultrasonic activation. The ROS generation using DPBF showed a time-dependent production for the conjugate in contrary to the control without PFH. Phototoxicity of the conjugate was clearly established in contrary to the control without PFH. In vivo tumour growth volume measurements on mice bearing subcutaneous $4 \mathrm{~T} 1$ tumour showed that the conjugate induced the best tumour inhibition $\left(670 \mathrm{~nm}, 1 \mathrm{~W} \cdot \mathrm{cm}^{-2}, 1 \mathrm{~min}\right)$.

Yuan et al. [60] synthesized fluorinated polypeptide micelles incorporating a NIR PS BODIPY (diameter $150 \mathrm{~nm}$ ). The NPs was water dispersible and the PFC concentration allowed a high $\mathrm{O}_{2}$ loading. Higher levels of dissolved $\mathrm{O}_{2}$ were measured with the conjugate compared to the non fluorined one. The same tendency was observed for the photosensitized ${ }^{1} \mathrm{O}_{2}$ generation after irradiation at $635 \mathrm{~nm}\left(0.5 \mathrm{~mW} \cdot \mathrm{cm}^{-2}, 360 \mathrm{~s}\right)$. Phototoxicity $\left(635 \mathrm{~nm}, 34 \mathrm{~mW} \cdot \mathrm{cm}^{-2}, 10 \mathrm{~min}\right)$ measured on HepG2 cells at the same irradiance showed a better efficacy of the conjugate compared to the non fluorined one, confirming the role of $\mathrm{PFH}$ in $\mathrm{O}_{2}$ supply. Tumour growth measurements on $4 \mathrm{T1}$ tumour-bearing mice conducted to a complete inhibition during 19 days after injection of the NP and irradiation $(635 \mathrm{~nm}$, $\left.100 \mathrm{~mW} \cdot \mathrm{cm}^{-2}, 10 \mathrm{~min}\right)$. 
Zhang et al. [61] synthesized perfluorooctyl bromide nanoliposomes incorporation IR780 NIR PS (diameter $270 \mathrm{~nm}$ ). The photothermal effect of the NP was evaluated after laser irradiation ( $808 \mathrm{~nm}$, $1 \mathrm{~W} \cdot \mathrm{cm}^{-2}, 5 \mathrm{~min}$ ) with a temperature increase from $25^{\circ} \mathrm{C}$ to $70{ }^{\circ} \mathrm{C} .{ }^{1} \mathrm{O}_{2}$ generation was measured by SOSG under the same fluence with a high amount for the conjugate in contrary to the non-fluorinated NP. Intracellular ${ }^{1} \mathrm{O}_{2}$ generation was observed after light irradiation $\left(808 \mathrm{~nm}, 1 \mathrm{~W} \cdot \mathrm{cm}^{-2}, 5 \mathrm{~min}\right)$. PTT and PDT treatments on 4T1 cancer cells showed less viability for the fluorinated conjugate and better efficacy with combined PTT/PDT. Tumour growth measurements on 4T1 cancer-bearing mice conducted to a complete inhibition during 18 days after injection of the NP and PTT/PDT treatment (808 $\mathrm{nm}$ laser (on $30 \mathrm{~s}$, off to room temperature, 20 cycles), $1.0 \mathrm{~W} \cdot \mathrm{cm}^{-2}$ ) (Figure 13a,b).
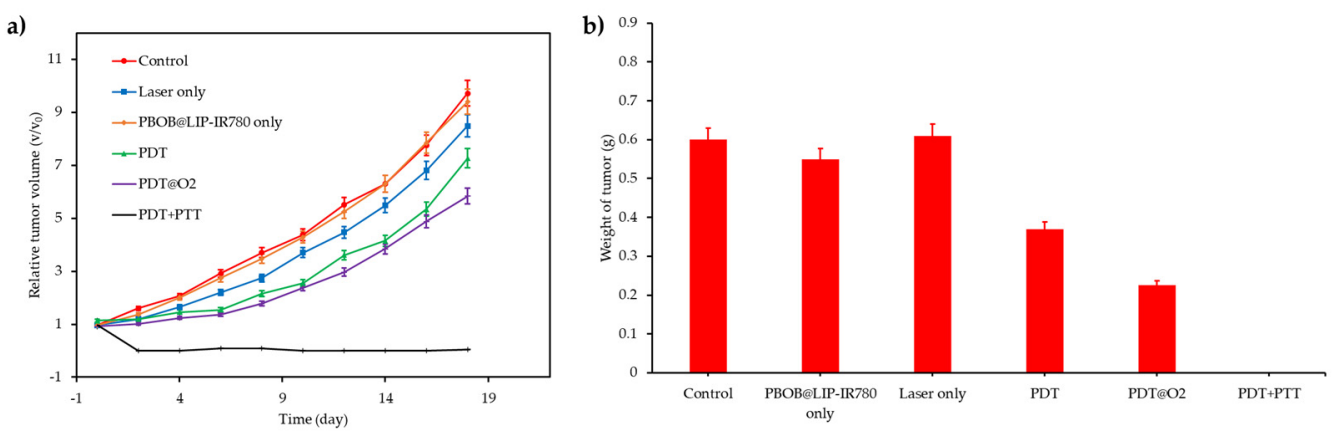

Figure 13. (a) Tumour growth curves of six groups after various treatments. (b) Weight of tumours $18 \mathrm{~d}$ post various treatments. (Values are means \pm s.d., $\mathrm{n}=5,{ }^{*} p<0.05$.). Adapted from Zhang et al. [61].

Zhao et al. [62] elaborated a NP made of a core of perfluorooctyl bromide and a shell with the PS IR780 and a tumour penetrating peptide CRGDK (diameter $210 \mathrm{~nm}$ ). Hypoxia measurements made on MDA-MB-231 tumour-bearing mice showed a significant attenuation in the tumour where the conjugate was injected, confirming the role of $\mathrm{PFH} \mathrm{n}$ in the $\mathrm{O}_{2}$ delivery. Tumour growth measurements on MDA-MB-231 tumour-bearing mice conducted to a complete inhibition during 13 days after injection of the NP and irradiation $\left(808 \mathrm{~nm}, 2 \mathrm{~W} \cdot \mathrm{cm}^{-2}, 20 \mathrm{~s}\right)$.

NPs with a PFH core and a hyaluronic acid (HA) and Ce6 shell were synthetized (diameter $220 \mathrm{~nm}$ ) by Hu D. et al. [63]. These "on-off" NPs were redox-activatable and could release Ce6 and $\mathrm{O}_{2}$ in hypoxic tumours. The ${ }^{1} \mathrm{O}_{2}$ of the conjugate increased significantly in reducing conditions after light irradiation $\left(660 \mathrm{~nm}, 100 \mathrm{~mW} \cdot \mathrm{cm}^{-2}, 5 \mathrm{~min}\right)$. The cellular uptake of the NP was studied on MDA-MB-231 cells. The ROS production in vitro was significantly higher with that conjugate than with NP with incomplete composition. NPs were intravenously injected in MDA-MB-231 breast tumour xenograft mouse model. NPs retention in the organs was stronger after $24 \mathrm{~h}$ than for free Ce6, especially in the tumour (5.8 fold) (Figure 14).

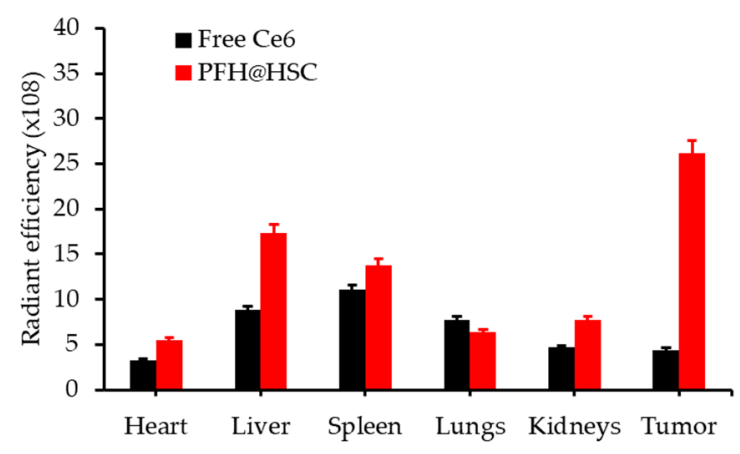

Figure 14. In vivo biodistribution of NPs. Semiquantitative fluorescence analysis of the radiant efficiency of organs and tumours isolated at $24 \mathrm{~h}$ post-injection. Adapted from Hu et al. [63]

Table 4 lists the recents publications with PFH. 
Table 4. Summary of publications about PFC as $\mathrm{O}_{2}$ vehicle.

\begin{tabular}{|c|c|c|c|c|c|c|c|}
\hline Ref & Application & $\mathrm{O}_{2}$ Source & PS & Energy of Excitation & Type of ROS & In Vitro & In Vivo \\
\hline [48] & PDT & PFH & IR780 & $808 \mathrm{~nm}, 2 \mathrm{~W} \cdot \mathrm{cm}^{-2}, 20 \mathrm{~s}$ & ${ }^{1} \mathrm{O}_{2}$ & $\begin{array}{c}\text { MCF-7 and CT26 } \\
\text { adenocarcinoma cell } \\
\text { lines }\end{array}$ & $\begin{array}{l}\text { CT26 tumour-bearing } \\
\text { mice }\end{array}$ \\
\hline [49] & PDT & PFC & Fluorous porphyrin & $420 \mathrm{~nm}, 8.5 \mathrm{~mW} \cdot \mathrm{cm}^{-2}, 30 \mathrm{~min}$ & ${ }^{1} \mathrm{O}_{2}$ & A375 cell line & No \\
\hline [50] & PDT & PFH & Plasmon resonance & $670 \mathrm{~nm}, 0.48 \mathrm{~mW} \cdot \mathrm{cm}^{-2}, 10 \mathrm{~min}$ & ${ }^{1} \mathrm{O}_{2}$ & MCF-7 cell line & $\begin{array}{l}\text { MCF-7 tumour-bearing } \\
\text { mice }\end{array}$ \\
\hline [51] & PDT & Pentafluorophenyl & $\begin{array}{c}\text { 5,10,15,20-tetrakis } \\
\text { (4-aminophenyl) } \\
\text { porphyrin }\end{array}$ & $\begin{array}{c}\text { In vitro: } 655 \mathrm{~nm}, 1.52 \mathrm{~mW} \cdot \mathrm{cm}^{-2} \text {, } \\
15 \mathrm{~min} \\
\text { In vivo: } 655 \mathrm{~nm}, 1.52 \mathrm{~mW} \cdot \mathrm{cm}^{-2}, \\
60 \mathrm{~min}\end{array}$ & ${ }^{1} \mathrm{O}_{2}$ & SMMC-7721 cell line & No \\
\hline [52] & PDT & PFOB & ICG & $\begin{array}{l}\text { In vitro: } 808 \mathrm{~nm}, 1 \mathrm{~W} \cdot \mathrm{cm}^{-2}, 3 \mathrm{~min} \\
\text { In vivo: } 808 \mathrm{~nm}, 1 \mathrm{~W} \cdot \mathrm{cm}^{-2}, 10 \mathrm{~min}\end{array}$ & ${ }^{1} \mathrm{O}_{2}+\mathrm{ROS}$ & $\begin{array}{l}\text { MDA-MB-231 } \\
\text { cell line }\end{array}$ & $\begin{array}{c}\text { MDA-MB-231 } \\
\text { tumour-bearing mice }\end{array}$ \\
\hline [53] & $\begin{array}{l}\text { Ultrasound } \\
\text { triggered PDT } \\
\text { and RT }\end{array}$ & $\mathrm{PFC}$ & Ce6 & $671 \mathrm{~nm}, 1.2 \mathrm{~W} \cdot \mathrm{cm}^{-2}, 5 \mathrm{~min}$ & ${ }^{1} \mathrm{O}_{2}$ & $4 \mathrm{~T} 1$ and CT26 cell line & $\begin{array}{l}4 \mathrm{~T} 1 \text { and } \mathrm{CT} 26 \\
\text { tumour-bearing mice }\end{array}$ \\
\hline [54] & PDT & $\mathrm{PFC}$ & $\mathrm{ZnF}_{16} \mathrm{Pc}$ & $\begin{array}{c}\text { In vitro: } 671 \mathrm{~nm}, 100 \mathrm{~mW} \cdot \mathrm{cm}^{-2}, \\
200 \mathrm{~s} \\
\text { In vivo: } 671 \mathrm{~nm}, 500 \mathrm{~mW} \cdot \mathrm{cm}^{-2} \\
10 \mathrm{~min}\end{array}$ & ${ }^{1} \mathrm{O}_{2}$ & U87MG cell line & $\begin{array}{l}\text { U87MG } \\
\text { tumour-bearing mice }\end{array}$ \\
\hline [55] & PDT & PFH & IR780 & $808 \mathrm{~nm}, 2 \mathrm{~W} \cdot \mathrm{cm}^{-2}, 20 \mathrm{~s}$ & ${ }^{1} \mathrm{O}_{2}$ & CT26 cell line & $\begin{array}{l}\text { CT26 tumour-bearing } \\
\text { mice }\end{array}$ \\
\hline [56] & PDT & PFSEA & THPP & $\begin{array}{c}\text { In vitro: } 660 \mathrm{~nm}, 10 \mathrm{~mW} \cdot \mathrm{cm}^{-2} \\
30 \mathrm{~min} \\
\text { In vivo: } 660 \mathrm{~nm}, 50 \mathrm{~mW} \cdot \mathrm{cm}^{-2} \\
60 \mathrm{~min}\end{array}$ & ${ }^{1} \mathrm{O}_{2}$ & $4 \mathrm{~T} 1$ cell line & $\begin{array}{l}\text { 4T1-tumour-bearing } \\
\text { mice }\end{array}$ \\
\hline [57] & $\mathrm{PDT}+\mathrm{PTT}$ & PFH & AlPc & $670 \mathrm{~nm}, 1 \mathrm{~W} \cdot \mathrm{cm}^{-2}, 5 \mathrm{~min}$ & ${ }^{1} \mathrm{O}_{2}$ & $4 \mathrm{~T} 1$ cell line & $\begin{array}{l}\text { 4T1-tumour-bearing } \\
\text { mice }\end{array}$ \\
\hline [58] & PDT & $\begin{array}{l}\text { Perfluorooctanoic } \\
\text { acid }\end{array}$ & Ce6 & $\begin{array}{c}\text { In vitro: } 630 \mathrm{~nm}, 30 \mathrm{~mW} \cdot \mathrm{cm}^{-2} \\
3 \mathrm{~min} \\
\text { In vivo: } 630 \mathrm{~nm}, 500 \mathrm{~mW} \cdot \mathrm{cm}^{-2} \\
20 \mathrm{~min}\end{array}$ & ${ }^{1} \mathrm{O}_{2}$ & $\begin{array}{l}\text { C6, HepG2 and } \\
\text { HeLa cell lines }\end{array}$ & $\begin{array}{l}\text { C6 glioma } \\
\text { tumour-bearing mice }\end{array}$ \\
\hline [59] & PDT & PFH & Ce6 & $670 \mathrm{~nm}, 1 \mathrm{~W} \cdot \mathrm{cm}^{-2}, 1 \mathrm{~min}$ & ${ }^{1} \mathrm{O}_{2}$ & $4 \mathrm{~T} 1$ cell line & $\begin{array}{l}4 \mathrm{~T} 1 \text { tumour-bearing } \\
\text { mice }\end{array}$ \\
\hline
\end{tabular}


Table 4. Cont.

\begin{tabular}{|c|c|c|c|c|c|c|c|}
\hline Ref & Application & $\mathrm{O}_{2}$ Source & PS & Energy of Excitation & Type of ROS & In Vitro & In Vivo \\
\hline$[60]$ & PDT & $\begin{array}{c}\text { Fluorinated } \\
\text { polypeptide NPs }\end{array}$ & BODIPY-Br ${ }_{2}$ & $\begin{array}{c}\text { In vitro: } 635 \mathrm{~nm}, 34 \mathrm{~mW} \cdot \mathrm{cm}^{-2}, \\
10 \mathrm{~min} \\
\text { In vivo: } 635 \mathrm{~nm}, 100 \mathrm{~mW} \cdot \mathrm{cm}^{-2} \\
10 \mathrm{~min}\end{array}$ & ${ }^{1} \mathrm{O}_{2}$ & HepG2 cell line & $\begin{array}{l}\text { 4T1 tumour-bearing } \\
\text { mice }\end{array}$ \\
\hline$[61]$ & PDT + PTT & $\begin{array}{l}\text { Perfluorooctyl } \\
\text { bromide }\end{array}$ & IR780 & $\begin{array}{l}\text { In vitro: } 808 \mathrm{~nm}, 1 \mathrm{~W} \cdot \mathrm{cm}^{-2}, 5 \mathrm{~min} \\
\text { In vivo: } 808 \mathrm{~nm}, 1 \mathrm{~W} \cdot \mathrm{cm}^{-2} \text {, on } 30 \mathrm{~s} \text {, } \\
\text { off to room temperature, } 20 \text { cycles }\end{array}$ & ${ }^{1} \mathrm{O}_{2}$ & 4T1 cell line & $\begin{array}{l}4 \mathrm{~T} 1 \text { tumour-bearing } \\
\text { mice }\end{array}$ \\
\hline$[62]$ & PDT & $\begin{array}{l}\text { Perfluorooctyl } \\
\text { bromide }\end{array}$ & IR780 & $808 \mathrm{~nm}, 2 \mathrm{~W} \cdot \mathrm{cm}^{-2}, 20 \mathrm{~s}$ & ${ }^{1} \mathrm{O}_{2}$ & $\begin{array}{l}\text { MDA-MB-231 and } \\
\text { MCF-7 cell lines }\end{array}$ & $\begin{array}{l}\text { MDA-MB-231 } \\
\text { tumour-bearing } \\
\text { mice }\end{array}$ \\
\hline$[63]$ & PDT & PFH & Ce6 & $\begin{array}{c}\text { In vitro: } 660 \mathrm{~nm}, 100 \mathrm{~mW} \cdot \mathrm{cm}^{-2} \text {, } \\
5 \mathrm{~min} \\
\text { In vivo: } 660 \mathrm{~nm}, 100 \mathrm{~mW} \cdot \mathrm{cm}^{-2}, \\
10 \mathrm{~min}\end{array}$ & ${ }^{1} \mathrm{O}_{2}+\mathrm{ROS}$ & MDA-MB-231 cell line & $\begin{array}{l}\text { MDA-MB-231 } \\
\text { tumour-bearing mice }\end{array}$ \\
\hline$[64]$ & PDT & PFC & Hypocrellin B & $\begin{array}{c}630 \mathrm{~nm}, 20 \mathrm{~mW} \cdot \mathrm{cm}^{-2}, 300 \mathrm{~s}, \\
6 \mathrm{~J} \text { per well }\end{array}$ & ${ }^{1} \mathrm{O}_{2}$ & H1299 cell line & No \\
\hline$[65]$ & PDT & $\begin{array}{l}\text { NPs with } \\
\text { fluorocarbon } \\
\text { chains }\end{array}$ & IR780 & $\begin{array}{l}\text { In vitro: } 808 \mathrm{~nm}, 2 \mathrm{~W} \cdot \mathrm{cm}^{-2}, 20 \mathrm{~s} \\
\text { In vivo: } 808 \mathrm{~nm}, 2 \mathrm{~W} \cdot \mathrm{cm}^{-2}, 5 \mathrm{~min}\end{array}$ & ${ }^{1} \mathrm{O}_{2}$ & 4T1 tumour spheroids & $\begin{array}{l}4 \mathrm{~T} 1 \text { tumour-bearing } \\
\text { mice }\end{array}$ \\
\hline
\end{tabular}


The in vivo hypoxia intensity declined with the NP compared to the NP without PFH. The NP showed effective tumour growth inhibition compared to NP with incomplete composition even if the tumour did not disappear completely $\left(660 \mathrm{~nm}, 100 \mathrm{~mW} \cdot \mathrm{cm}^{-2}, 10 \mathrm{~min}\right)$.

$\mathrm{Hu}$ et al. [64] synthesized different amphiphilic fluorous random copolymers with different amount of perfluorocarbon, that embed Hypocrellin B (HB) as PS, assembled themself into micelles in water (diameter $200 \mathrm{~nm}$ ). The $\mathrm{O}_{2}$ carrying ability of the conjugate was related to the PFC content. ${ }^{1} \mathrm{O}_{2}$ production of $\mathrm{HB}$ after light irradiation $(630 \mathrm{~nm}, 6 \mathrm{~J} /$ well) of the conjugate measured with SOSG was equivalent as for $\mathrm{HB}$ in water. The phototoxicity $\left(630 \mathrm{~nm}, 20 \mathrm{~mW} \cdot \mathrm{cm}^{-2}, 300 \mathrm{~s}\right)$ of the conjugate in human lung carcinoma H1299 cells depended on the amount of PFC. The highest amount led to the best efficiency.

Ma et al. [65] prepared NPs with fluorocarbon chains and IR780 PS in the core and iRGD peptides on the shell (diameter $80 \mathrm{~nm}$ ). ${ }^{1} \mathrm{O}_{2}$ concentration was measured in vitro and in vivo with SOSG showing increased values for the conjugate $\left(808 \mathrm{~nm}, 2 \mathrm{~W} \cdot \mathrm{cm}^{-2}, 20 \mathrm{~s}\right)$. ROS generation measured on $4 \mathrm{~T} 1$ tumour spheroids showed an enhanced concentration even inside the spheroid showing efficacy of the tumour-penetrating iRGD peptide. High phototoxicity was observed at $7.5 \mu \mathrm{g} \cdot \mathrm{mL}^{-1}$ with a cell viability less than $20 \%\left(808 \mathrm{~nm}, 2 \mathrm{~W} \cdot \mathrm{cm}^{-2}, 20 \mathrm{~s}\right)$. $\mathrm{O}_{2}$ concentration in $4 \mathrm{~T} 1$ solid tumours measured by photoacoustic system showed an enhanced amount after injection of the NPs and irradiation. Tumour growth measurements on $4 \mathrm{~T} 1$ cancer-bearing mice conducted to a complete inhibition during 12 days after injection of the NPs and irradiation $\left(808 \mathrm{~nm}, 2 \mathrm{~W} \cdot \mathrm{cm}^{-2}, 5 \mathrm{~min}\right)$ (Table 4$)$.

\section{4. $\mathrm{O}_{2}$ Microbubbles}

Free $\mathrm{O}_{2}$ gas bubbles are not recommended to be directly injected into blood flow for hemolysis reason. A new approach of $\mathrm{O}_{2}$ delivery, well documented in a review of Khan et al. [66] consists in the use of $\mathrm{O}_{2}$ loaded micro-/nanobubbles to bring $\mathrm{O}_{2}$ to the hypoxic tumour without side effects. In such particles, the shell is generally a monolayer biomaterial (lipids, proteins, polymers ... ) that encapsulates the core gas.

Huang et al. [67] have developed a new strategy for externally triggered PDT of tumour hypoxia using bone marrow-derived monocytes/macrophages as cellular vehicles for co-transport of $\mathrm{O}_{2}$ and Ce6. Superparamagnetic iron oxide NPs (SPIONs) were co-entrapped within the polymer to afford functional bubbles denoted (SCOPBs). According to the in vitro studies, these functional bubbles were found harmless to cellular hosts without external trigger. However, significant apoptosis of cancer cells co-incubated with therapeutic monocytes was observed when treated with high frequency magnetic field (HFMF) and red light laser irradiation due to the combined effect of PDT and magnetic hyperthermia was observed. Furthermore, upon tumour treatment with HFHM ( 9 min) and red laser irradiation $\left(660 \mathrm{~nm}, 100 \mathrm{~mW} \cdot \mathrm{cm}^{-2}, 10 \mathrm{~min}\right.$ ), the therapeutic monocytes exhibited a superior performance in inhibiting tumour growth on tramp-C1 tumour-bearing mice. Moreover, immunohistochemistry (IHC) staining of tumour sections confirmed the successful cellular transport of the therapeutic payloads to tumour hypoxia and the pronounced antitumour effect elicited by combined hyperthermia/PDT along with the additional $\mathrm{O}_{2}$ supply.

In 2018, Song et al. [68] developed nanocapsules composed of a decane core and a polymer shell linked to Ce6, surrounded by lipid molecules conjugated to a hydrophilic polymer PEG $(263.2 \pm 10.3 \mathrm{~nm}$ with a thickness of about $20 \mathrm{~nm}$ for the shell). The $\mathrm{O}_{2}$ nanobubbles $\left(\mathrm{NBs}-\mathrm{O}_{2}\right)$ were finally obtained by $\mathrm{O}_{2}$ infusion in the nanocapsules. Fluorinated caps on the PCL polymer avoided the liberation of $\mathrm{O}_{2}$ at an undesired place. The authors had then compared their ability to release $\mathrm{O}_{2}$ in comparison with well-known $\mathrm{O}_{2}$ carrier, lipid-coated $\mathrm{O}_{2}$ microbubbles (LOMs). They followed the level of $\mathrm{O}_{2}$ dissolved in a hypoxic solution over time. LOMs showed a higher and faster increase of $\mathrm{O}_{2}$ concentration, at

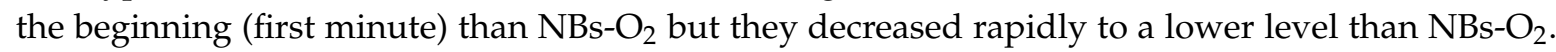
This indicated a better robustness of these nanobubbles due to their thicker shell. They also compared

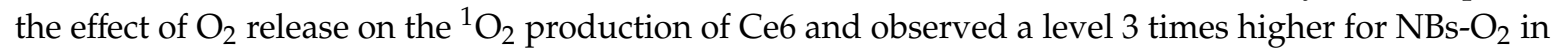
comparison with $\mathrm{Ce} 6$ alone. In vitro studies on $\mathrm{C} 6$ glioma showed that they were strongly accumulated 
in cytoplasm after endocytosis in comparison with Ce6 alone. In vivo studies were performed on glioma-bearing nude mice. They evaluated their ability to improve the PDT treatment and showed a significant decrease of tumour growth for mice treated with these nanobubbles and laser irradiation $\left(670 \mathrm{~nm}, 300 \mathrm{~mW} \cdot \mathrm{cm}^{-2}, 30 \mathrm{~min}\right)$ in comparison with the control group (Table 5).

Table 5. Summary of publications about $\mathrm{O}_{2}$ microbubbles as $\mathrm{O}_{2}$ vehicle.

\begin{tabular}{cccccccc}
\hline Ref & Application & $\mathbf{O}_{2}$ Source & PS & $\begin{array}{c}\text { Energy of } \\
\text { Excitation }\end{array}$ & $\begin{array}{c}\text { Type of } \\
\text { ROS }\end{array}$ & In Vitro & In Vivo \\
\hline [67] & $\begin{array}{c}\text { Hyperthermia/ } \\
\text { PDT }\end{array}$ & $\begin{array}{c}\mathrm{O}_{2} \text {-loaded } \\
\text { polymer } \\
\text { bubbles }\end{array}$ & $\mathrm{Ce} 6$ & $\begin{array}{c}660 \mathrm{~nm}, \\
100 \mathrm{~mW} \cdot \mathrm{cm}^{-2}, 10 \\
\mathrm{~min}\end{array}$ & $1 \mathrm{O}^{2}$ & $\begin{array}{c}\text { RAW } 264.7 \\
\text { cell line }\end{array}$ & $\begin{array}{c}\text { Tramp-C1 } \\
\text { tumour-bearing } \\
\text { C57BL/6JNarl mice }\end{array}$ \\
\hline [68] & PDT & $\begin{array}{c}\mathrm{O}_{2} \\
\text { nanobubbles }\end{array}$ & $\mathrm{Ce} 6$ & $\begin{array}{c}6700 \mathrm{~mW} \cdot \mathrm{cm}^{-2}, 30 \\
\mathrm{~min}\end{array}$ & ${ }^{1} \mathrm{O}_{2}$ & $\begin{array}{c}\mathrm{C} 6 \text { glioma } \\
\text { cell line }\end{array}$ & $\begin{array}{c}\mathrm{C} 6 \text { glioma } \\
\text { tumour-bearing mice }\end{array}$ \\
\hline
\end{tabular}

Ce6: Chlorin e6.

\subsection{Other}

Niu et al. [69] designed $\beta-\mathrm{NaGdF}_{4}: \mathrm{Yb}^{3+} / \mathrm{Er}^{3+}$ upconverting NPs (diameter $50 \mathrm{~nm}$ ) associated with gold oxide $\left(\mathrm{Au}_{2} \mathrm{O}_{3}\right)$, porous silica, $\mathrm{Ce} 6$, cyclo-RGD and PEG. Upon a NIR irradiation, $\mathrm{Au}_{2} \mathrm{O}_{3}$ is able to produce $\mathrm{O}_{2}$ assisted by UCNPs via (FRET). When FRET occurred between UCNPs and $\mathrm{Au} / \mathrm{Au}_{2} \mathrm{O}_{3}$ under NIR light, $\mathrm{Au}_{2} \mathrm{O}_{3}$ underwent a decomposition into $\mathrm{Au}$ and $\mathrm{O}_{2}$. The $\mathrm{O}_{2}$ production under NIR irradiation $\left(980 \mathrm{~nm}, 30 \mathrm{~min}, 0.5 \mathrm{~mW} \cdot \mathrm{cm}^{-2}\right)$ was demonstrated using a Ru probe. FRET was observed between the NP and $\mathrm{Au}_{2} \mathrm{O}_{3}$ for $\mathrm{O}_{2}$ production and between the NPs and Ce6 for a PDT effect. The phototoxicity of the NPs on human cervical cancer cells (HeLa) was demonstrated. The NPs were intravenous injected in nude mice inoculated with HeLa tumour cells. After NIR irradiation $(980 \mathrm{~nm}$, $30 \mathrm{~min}, 0.5 \mathrm{~mW} \cdot \mathrm{cm}^{-2}$ ), the relative tumour volume of the treated group stayed constant whereas it increased in the control group. The Ns presented also a photothermal effect that could be used for PA.

\section{Modification of Tumour Microenvironment (TME)}

The "normal" microenvironment is complex and dynamic. Its cellular component encompasses all neighbouring cells (adjacent cells belonging to the same tissue) and cells residing in their direct environment (fibroblasts, vascular cells, dendritic cells, immune system cells, etc.). The TME or stroma is defined as the cellular components, molecular components and mechanical stresses surrounding and interacting with tumour cells. It differs from the "normal" microenvironment by the biochemical composition of the extra cellular matrix and especially by the fact that the stromal cell populations, although not transformed, are subverted and controlled by the tumour cells to meet their own needs. It has been widely demonstrated that TME plays a major role in bone marrow clearance and tumour invasion, as well as resistance to chemotherapy [70]. By modifying the TME, it seems possible through specific response pathways, such as that of the proteins of the Hypoxia Inducible Factor (HIF) family, to induce the activation of several signalling pathways that regulate many cellular processes such as angiogenesis, metabolism, cell proliferation and apoptosis.

\section{1. $\mathrm{H}_{2} \mathrm{O}_{2}$ Decomposition}

It is known that cancer cells have higher levels of $\mathrm{H}_{2} \mathrm{O}_{2}$ than normal cells [71] because of the aberrant metabolism of cancer cell. The concentrations range from $10^{-4}$ to $10^{-3} \mathrm{M}$. One of the strategies to improve $\mathrm{O}_{2}$ levels in hypoxic areas is to design compounds that could degrade endogenous $\mathrm{H}_{2} \mathrm{O}_{2}$ to produce $\mathrm{O}_{2}$ inside the tumour. It is interesting to note that catalase is able to convert around 5 million $\mathrm{H}_{2} \mathrm{O}_{2}$ molecules per minute and catalase is explored nowadays to overcome tumour relief [72]. Moreover, another advantage of this strategy is that the decrease of $\mathrm{H}_{2} \mathrm{O}_{2}$ in the cells leads to a decrease of cancer cell proliferation [72-74]. 


\subsection{1. $\mathrm{MnO}_{2}$}

One advantage of $\mathrm{MnO}_{2}$ is that it can adsorb different kinds of small molecules via physisorption or Mn-N coordination links. $\mathrm{MnO}_{2}$ produces $\mathrm{O}_{2}$ by catalytic $\mathrm{H}_{2} \mathrm{O}_{2}$ decomposition under neutral conditions, but also under acidic conditions by reaction with $\mathrm{H}^{+}$. This strategy is very new. The first publication has been written in 2015, and then we can find three publications in 2016, seven in 2017, 14 in 2018 and three already in 2019 (before March). Moreover, the efficacy of PDT is not only limited by tumour hypoxia but also over-expressed glutathione (GSH) in cancer cells that consumes ROS.

$\mathrm{Xu}$ et al. [75] synthesized a photoactive $\mathrm{Mn}$ (II) complex of BODIPY derivatives ([(BDA) $\left.\mathrm{MnCl}_{2}\right]$, $\mathrm{Mn}_{1}$ ) as a $\mathrm{O}_{2}$ generator under irradiation (green LED, 500-600 nm, $10 \mathrm{~W}$ ) in water. $\mathrm{Mn}_{1}$ was loaded on graphene oxide $\left(\mathrm{Mn}_{1} @ \mathrm{GO}\right)$ and an in vitro biological evaluation for $\mathrm{Mn}_{1}$ and $\mathrm{Mn}_{1} @ G O$ on HepG-2 cells in normal and hypoxic conditions was performed. In normal conditions, both $\mathrm{Mn}_{1}$ and $\mathrm{Mn}_{1} @ G O$ after light illumination (green LED, 500-600 nm, $15 \mathrm{~min}$ ) were active against HepG-2 cells. It was also found that both compounds could be used as photoactivated anticancer materials since Mn1 and $\mathrm{Mn}_{1} @ \mathrm{GO}$ were able to exhibit inhibition on the proliferation of HepG-2 cells when light irradiation. In particular, $\mathrm{Mn}_{1} @ \mathrm{GO}$ reacted with $\mathrm{H}_{2} \mathrm{O}_{2}$ resulting in the formation of active species, and worked as $\mathrm{H}_{2} \mathrm{O}_{2}$ and light-activated anticancer NPs. Moreover, $\mathrm{Mn}_{1} @ G O$ could be an efficient anticancer material in hypoxic environments and $\mathrm{Mn}_{\mathrm{I}}$ could target mitochondria and had some effects on the expression of HIF- $1 \alpha$ in HepG-2 cells.

Multifunctional $\mathrm{MnO}_{2}$ NPs loaded with Ce6 and coated with PEG were designed (Ce6 @ $\mathrm{MnO}_{2}$-PEG) by $\mathrm{Zhu}$ et al. [76]. In vitro studies in an $\mathrm{O}_{2}$-deficient atmosphere have shown that $\mathrm{Ce} 6 @$ $\mathrm{MnO}_{2}$-PEG NPs can effectively increase the efficiency of light-induced PDT $\left(661 \mathrm{~nm}, 5 \mathrm{~mW} \cdot \mathrm{cm}^{-2}, 30 \mathrm{~min}\right)$ due to the increased intracellular level of $\mathrm{O}_{2}$. In vitro in 4T1 cells, it was found that $\mathrm{Ce} 6 @ \mathrm{MnO}_{2}-\mathrm{PEG}$ NPs were very effective, even under conditions of $\mathrm{O}_{2}$ deficiency. With systemic administration to mice bearing subcutaneous $4 \mathrm{~T} 1$ tumours, $\mathrm{Ce} 6 @ \mathrm{MnO}_{2}$-PEG NPs showed effective accumulation inside the tumour, in which the $\mathrm{MnO}_{2} \mathrm{NPs}$ gradually decomposed into $\mathrm{Mn}^{2+}$ ions. Meanwhile, as expected, the level of oxygenation of the tumour was significantly increased. Due to enhanced Ce6 uptake in the tumour and reversed tumour hypoxia, highly effective PDT treatment $\left(661 \mathrm{~nm}, 5 \mathrm{~mW} \cdot \mathrm{cm}^{-2}, 1 \mathrm{~h}\right)$ of cancer was implemented using Ce6@ $\mathrm{MnO}_{2}$-PEG NPs. Given the gradual decomposition of $\mathrm{MnO}_{2} \mathrm{NPs}$, easy filtration of $\mathrm{Mn}^{2+}$ in the kidneys, and the lack of obvious short-term in vivo toxicity observed in this study, $\mathrm{MnO}_{2}$ nanostructures could be a unique type of safe nanoplatform promising for cancer.

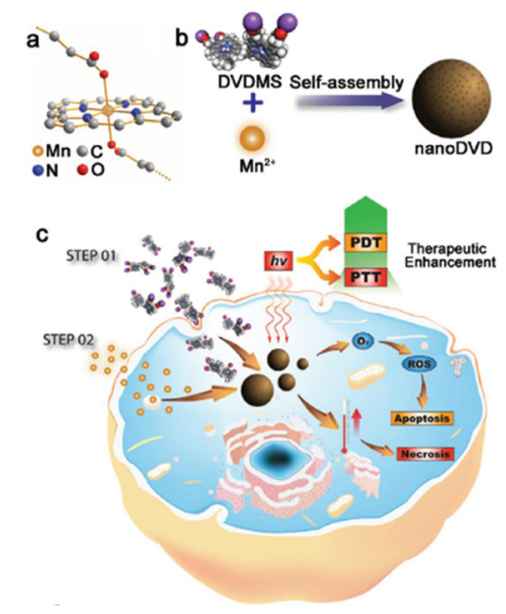

Figure 15. Schematic illustration showing a molecular model of the $\mathrm{Mn}^{2+}$ ion linking porphyrin ring and two carboxylate radicals of DVDMS molecules (a), the fabrication process of Mn/DVDMS (b), and photothermal/PDT (PTT/PDT) (c). Reprinted from Chu et al. [77] with permission from John Wiley and Sons, Copyright 2018. 
Chu et al. [77] developed an engineering nanoplatform that combined many functions, including imaging (fluorescence imaging, MRI and PA imaging), as well as a synergistic combination of phototherapy (PTT and PDT). The $\mathrm{MnO}_{2}$ nanosheets served as a highly efficient carrier for a sinoporphyrin sodium (DVDMS) PS and an in situ $\mathrm{O}_{2}$ and nano-DVD (Mn/DVDMS) generator, enhanced theranostic capability of $\mathrm{Mn}^{2+}$-assisted assembly of DVDMS ( $\mathrm{MnO}_{2} / \mathrm{DVDMS}$ ) (Figure 15).

$\mathrm{MnO}_{2}$ nanosheets served as a highly effective DVDMS carrier and in situ $\mathrm{O}_{2}$ and nanoDVD generator. In a tumour environment, $\mathrm{MnO}_{2}$ /DVDMS could be reduced by $\mathrm{GSH}$ and $\mathrm{H}_{2} \mathrm{O}_{2}$, which resulted in the release of $\mathrm{Mn}^{2+}$, DVDMS and $\mathrm{O}_{2}$. In addition, GSH consumption, $\mathrm{O}_{2}$ production, and nanoDVD formation demonstrated an overall improved efficacy of phototherapy in vitro $(630 \mathrm{~nm}$, $\left.75 \mathrm{~mW} \cdot \mathrm{cm}^{-2}, 5 \mathrm{~min}\right)$ and in vivo $\left(630 \mathrm{~nm}, 300 \mathrm{~mW} \cdot \mathrm{cm}^{-2}, 8 \mathrm{~min}\right)$ in MCF-7 tumour.

Gao et al. [78] developed an $\mathrm{O}_{2}$-generating PDT nanocomplex (IHM) by encapsulating $\mathrm{MnO}_{2}$ NP in HA NPs coupled to ICG. The $\mathrm{O}_{2}$ content in the tumour increased by $2.25 \pm 0.07$ times with IHM compared without IHM treatment. After laser irradiation in the IHM group, there was a significant inhibition of tumour growth compared to the group treated with NPs. Immunofluorescent staining confirmed a decrease in both HIF1-a and pimonidazole in the IHM group, implying that generating $\mathrm{O}_{2}$ in the tumour not only improved the efficiency of PDT, but also weakened tumour hypoxia. In vitro studies in murine squamous SCC-7 cells showed a high suppression of cell proliferation under PDT $\left(808 \mathrm{~nm}, 0.5 \mathrm{~W} \cdot \mathrm{cm}^{-2}, 10 \mathrm{~min}\right)$ treatment with IHM. In vivo in SCC-7 tumour-bearing mice highlighted a high inhibition of tumour growth with PDT treatment $\left(808 \mathrm{~nm}, 0.8 \mathrm{~W} \cdot \mathrm{cm}^{-2}, 10 \mathrm{~min}\right.$ ) with IHM.

Hao et al. [79] designed poly (lactide-co-glycolide) (PLGA) NPs loaded with hematoporphyrin monomethyl ether (HMME) and coated with multifunctional $\mathrm{MnO}_{2}$ shells, (PLGA/HMME@MnO $\mathrm{NPs}$ ). As expected, inside the tumour they could observe the generation of $\mathrm{O}_{2}$ and degradation of $\mathrm{MnO}_{2}$ into $\mathrm{Mn}^{2+}$ ions by glutathione. In vitro in MCF-7 cells, under illumination ( $\left.532 \mathrm{~nm}, 1.5 \mathrm{~W} \cdot \mathrm{cm}^{-2}, 2 \mathrm{~min}\right)$, the released HMME produced ROS that destroyed tumour cells. Furthermore, the decreased of GSH level further inhibited the consumption of the produced ROS, which greatly enhanced the PDT efficacy. These results were confirmed by in vivo studies in S180 tumour model after PDT treatment $(532 \mathrm{~nm}$, $1.5 \mathrm{~W} \cdot \mathrm{cm}^{-2}, 1.5 \mathrm{~min}$ ) with PLGA/HMME@ $\mathrm{MnO}_{2} \mathrm{NPs}$ with a significant decrease of tumour volume.

Kim et al. [80] developed biocompatible mesoporous silica NPs with $\mathrm{MnFe}_{2} \mathrm{O}_{4} \mathrm{NPs}$ (MFMSN) and Ce6 (MFMSN-Ce6). These results demonstrated the continuous generation of $\mathrm{O}_{2}$ by the Fenton catalyst under physiological conditions, improving the generation of ROS under hypoxic conditions. In vitro PDT efficiency in human glioblastoma cancer (U-87 MG) cells in both normoxic and hypoxic conditions was investigated. A significant cell death was observed in both conditions after incubation of cells with MFMSN-Ce6 and irradiated at $670 \mathrm{~nm}\left(0.5 \mathrm{~W} \cdot \mathrm{cm}^{-2}, 30 \mathrm{~s}\right)$, contrary to cells incubated with Ce6 alone and irradiated, which highlighted a low cell death in hypoxic conditions. In vivo in U87 MG-bearing mouse xenograft model, PDT treatment $\left(670 \mathrm{~nm}, 0.88 \mathrm{~W} \cdot \mathrm{cm}^{-2}, 5 \mathrm{~min}\right)$ with MFMSN-Ce6 showed the best efficiency.

Liu et al. [81] developed a bovine serum albumin (BSA) stabilized $\mathrm{MnO}_{2} \mathrm{NPs}$ on which TCC $(\mathrm{HPPH})$ was physisorbed (hydrodynamic size $60.52 \pm 25.61 \mathrm{~nm}$ ). In vitro studies in U87MG cells after $630 \mathrm{~nm}$ laser irradiation showed that the cells incubated with the NPs exhibited more reduced viability than those incubated with the PS alone $\left(10 \mathrm{~mW} \cdot \mathrm{cm}^{-2}, 1 \mathrm{~min}\right)$. In vivo $\left(630 \mathrm{~nm}, 10 \mathrm{~mW} \cdot \mathrm{cm}^{-2}, 10 \mathrm{~min}\right)$ in U87MG tumour bearing mice, a complete eradication of the tumour was observed after treatment with the NPs whereas no diminution was observed with the NP without HPPH and only a low decrease with HPPH. Thanks to pimonidazole hypoxyprobe kit, they proved the decrease of tumour hypoxia.

$\mathrm{Ma}$ Z. et al. [82] in 2017 developed a $\mathrm{H}_{2} \mathrm{O}_{2}$-activatable nanostructure $\left(\mathrm{SiO}_{2}-\mathrm{MB} @ \mathrm{MnO}_{2}\right)$ composed by a $\mathrm{SiO}_{2}-\mathrm{MB}$ core coated to a $\mathrm{MnO}_{2}$ shell. Under acidic hypoxic conditions, these NPs could release $\mathrm{MB}$ and generate $\mathrm{O}_{2}$ by decomposition of $\mathrm{H}_{2} \mathrm{O}_{2}$ of the TME. $\mathrm{SiO}_{2}-\mathrm{MB} @ \mathrm{MnO}_{2}$ exhibited a significant PDT efficiency $\left(650 \mathrm{~nm}, 100 \mathrm{~mW} \cdot \mathrm{cm}^{-2}, 15 \mathrm{~min}\right)$ in vitro in HeLa cells with $92 \%$ of cell death $(42 \%$ for $\mathrm{MB}$ alone and $64 \%$ for $\left.\mathrm{SiO}_{2}-\mathrm{MB}\right)$. Moreover, in TME conditions ( $\left.\mathrm{pH}=5.5\right)$, an efficient release of $\mathrm{MB}$ by $\mathrm{SiO}_{2}-\mathrm{MB} @ \mathrm{MnO}_{2}$ was observed after $5 \mathrm{~h}$ of incubation $(87 \%)$. The dramatic increase of PDT effect was also proven In vivo in U14 tumour-bearing mice with an important decrease of tumour 
volume in comparison with irradiation of $\mathrm{MB}$ alone or $\mathrm{SiO}_{2}-\mathrm{MB}$ and a decrease of $\mathrm{HIF}-1 \alpha$ showing an improvement of hypoxia.

Ai et al. [83] developed upconversion nanoconjugate (UCN) loaded with Ce6 and integrating $\mathrm{MnO}_{2}$ NPs and HA biopolymer (UCNs- $\left.\mathrm{MnO}_{2}-\mathrm{Ce} 6-\mathrm{HA}\right)$. Under NIR $808 \mathrm{~nm}$ light irradiation $\left(0.4 \mathrm{~W} \cdot \mathrm{cm}^{-2}\right.$, $60 \mathrm{~min}$ ), UCNs- $\mathrm{MnO}_{2}$-Ce6-HA produced high level of $\mathrm{O}_{2}$ by reaction of $\mathrm{MnO}_{2}$ with $\mathrm{H}_{2} \mathrm{O}_{2}$ of the microenvironment and thus led to an increase of the production of ${ }^{1} \mathrm{O}_{2}$ in hypoxic conditions. In vitro studies in murine melanoma cells (B16F10) confirmed this with an increase of cell death (49\%) by treatment with UCNs- $\mathrm{MnO}_{2}$-Ce6-HA under NIR irradiation $\left(0.4 \mathrm{~W} \cdot \mathrm{cm}^{-2}, 60 \mathrm{~min}\right)$ in hypoxic conditions.

$\mathrm{Gu}$ et al. [84] synthesized nanocomposites $\left(\mathrm{CaF}_{2}: \mathrm{Yb}, \mathrm{Er} @\right.$ silica/ $\left.\mathrm{MnO}_{2}-\mathrm{Ce} 6=\mathrm{C} @ \mathrm{MSN}-\mathrm{Ce} 6\right)$ constituted of $\mathrm{CaF}_{2}: \mathrm{Yb}$,Er crystals incorporated in mesoporous silica nanospheres (MSNs) coated with a thin layer of $\mathrm{MnO}_{2}$ and loaded with $\mathrm{Ce} 6$. The $\mathrm{MnO}_{2}$ coating modulated a hypoxic TME by generating in situ $\mathrm{O}_{2}$ through a reaction with an endogenous $\mathrm{H}_{2} \mathrm{O}_{2}$ tumour. In vitro tests in $4 \mathrm{~T} 1$ cells highlighted that C@MSN-Ce6 presented under light irradiation $\left(980 \mathrm{~nm}, 0.5 \mathrm{~W} \cdot \mathrm{cm}^{-2}, 10 \mathrm{~min}\right)$ an improvement of PDT efficiency, in comparison with NPs without $\mathrm{MnO}_{2}$, in both normoxic and hypoxic conditions confirmed by an elevation of intracellular ROS level. In 4T1 tumours on Balb/c mice, in vivo studies showed a decrease of hypoxia in tumour after injection of C@MSN-Ce6 by using pimonidazole probe. The highest efficiency of PDT treatment $\left(980 \mathrm{~nm}, 0.5 \mathrm{~W} \cdot \mathrm{cm}^{-2}, 30 \mathrm{~min}\right)$ was observed for C@MSN-Ce6 with a significant decrease of tumour growth.

Chen et al. [85] prepared successfully $\mathrm{pH} / \mathrm{H}_{2} \mathrm{O}_{2}$-responsive carbon dots $\mathrm{CDs} / \mathrm{MnO}_{2}-\mathrm{PEG}$ presenting interesting characteristics such as a low cyto toxicity and a complete clearance from the body and an increase of fluorescence and ${ }^{1} \mathrm{O}_{2}$ production in TME conditons. In vitro, in HeLa cells and in vivo, in $4 \mathrm{~T} 1$ tumour-bearing nude mice, analyses revealed that the low-toxic $\mathrm{CDs} / \mathrm{MnO}_{2}-\mathrm{PEG}$ nanohybrids could be applied as $\mathrm{pH} / \mathrm{H}_{2} \mathrm{O}_{2}$-driven, turn-on nanotheranostics for the concurrent bimodal $\mathrm{MR} / \mathrm{FL}$ imaging and $\mathrm{O}_{2}$-elevated PDT of solid tumours. In vitro PDT $\left(635 \mathrm{~nm}, 100 \mathrm{~mW} \cdot \mathrm{cm}^{-2}, 30 \mathrm{~min}\right)$ effect was investigated in HeLa cells under hypoxic and acidic conditions and $\mathrm{CDs} / \mathrm{MnO}_{2}-\mathrm{PEG}$ exhibited high efficiency to kill cancer cells. In vivo studies, under PDT treatment $\left(635 \mathrm{~nm}, 100 \mathrm{~mW} \cdot \mathrm{cm}^{-2}, 10 \mathrm{~min}\right)$ with $\mathrm{CDs} / \mathrm{MnO}_{2}-\mathrm{PEG}$, conduction a significant inhibition of tumour growth.

He et al. [86] synthesized large pore silica nanocomposites (LPMSNs) coupled to Ce6, AS1411 aptamer for the selectivity and $\mathrm{MnO}_{2}$, denoted as AS1411/Ce6-LPMSNs- $\mathrm{MnO}_{2}$. Due to the high reactivity of $\mathrm{MnO}_{2}$ with endogenous acidic $\mathrm{H}_{2} \mathrm{O}_{2}$, massive $\mathrm{O}_{2}$ molecules were formed, improving PDT efficiency $\left(660 \mathrm{~nm}, 100 \mathrm{~mW} \cdot \mathrm{cm}^{-2}, 10 \mathrm{~min}\right)$.

Kapri and Bhattacharyya [87] developed a p-n heterojunction nanofilm containing p-type $\mathrm{MoS}_{2}$ nanoplates and nitrogen-doped reduced graphene oxide (n-rGO) with a thickness of $\sim 5 \mathrm{~nm}$. Illumination at $980 \mathrm{~nm}$ led to an effective electron-hole separation through the heterojunction. The nanoplates were modified with functionalized lipoic acid poly(ethylene glycol) to ensure better biocompatibility and colloidal stability and surface-decorated 3-5 nm $\mathrm{MnO}_{2}$ NPs to finally obtain $\mathrm{pMoS}_{2} / \mathrm{n}$-rGO-MnO 2 -PEG nanosheets. $\mathrm{MnO}_{2}$ increased intracellular $\mathrm{O}_{2}$ by reacting with endogenous $\mathrm{H}_{2} \mathrm{O}_{2}$. In vitro studies in HeLa and HEK 293 (human embryonic kidney 293 cells) cells were performed highlighted an efficient PDT $\left(980 \mathrm{~nm}, 0.4 \mathrm{~W} \cdot \mathrm{cm}^{-2}, 5 \mathrm{~min}\right)$ effect of the nanosheets. Compared to p-MoS $2 / n-r G O-P E G$ and $\mathrm{MoS}_{2} / \mathrm{rGO}-\mathrm{PEG}, \mathrm{p}-\mathrm{MoS}_{2} / \mathrm{n}-\mathrm{rGO}-\mathrm{MnO}_{2}-\mathrm{PEG}$ nanoplates exhibit enhanced DCF fluorescence and they detected an increase of hypoxia due to increased apoptosis under the influence of NIR light.

Liang et al. [88] synthesized gold-coated NPs coupled to $\mathrm{MnO}_{2} \mathrm{NPs}\left(\mathrm{AuNC} @ \mathrm{MnO}_{2}, \mathrm{AM}\right)$. Sufficient oxygenation in the tumour site reduced local hypoxia. In addition, the $\mathrm{O}_{2}$-enhanced effect of PDT AM not only effectively destroyed the primary tumour in vivo, but also caused the death of immunogenic cells (ICD) with the release of damage-related molecular patterns (DAMP), which subsequently caused maturation of DC and activation of effector cells, thereby causing a systematic inducing antitumour immune responses against mTNBC. In vitro analyses in $4 \mathrm{~T} 1$ cells showed a high increase of ROS production and cell apoptosis after treatment with AM under NIR irradiation $\left(808 \mathrm{~nm}, 0.8 \mathrm{~W} \cdot \mathrm{cm}^{-2}, 3 \mathrm{~min}\right)$. In vivo studies in $4 \mathrm{~T} 1$ tumour-bearing mice showed a high inhibition of 
tumour growth after AM-PDT treatment. Moreover, they observed that AM could also destroy tumour metastasis. To enhance cancer PDT, a mitochondrial-directed multifunctional $\mathrm{MnO}_{2} \mathrm{NP}$ with a dye (IR808) was developed (IR808 @ MnO NP) by Zhou et al. [89] (Figure 16).

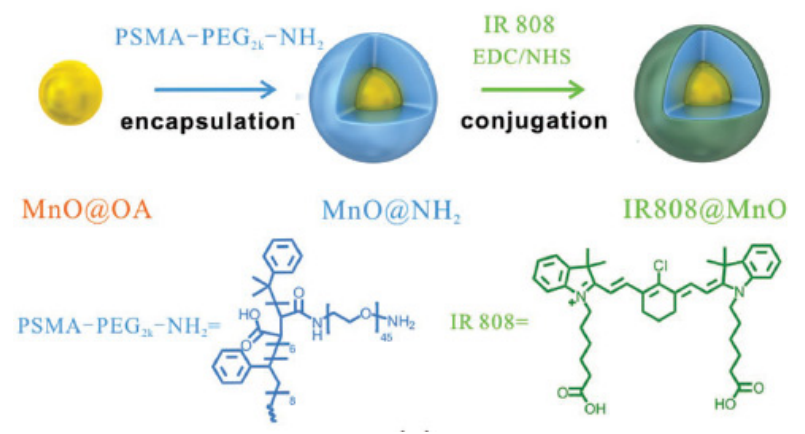

Figure 16. Synthetic route of $\mathrm{MnO} @ \mathrm{OA}, \mathrm{MnO} @ \mathrm{NH}_{2}$, and IR808@MnO. Reprinted from [89] with permission from John Wiley and Sons, Copyright 2018.

In this nanoplatform, IR808 acted as targeting ligand, eventually moving into mitochondria. Large amounts of ROS were formed during the reaction between $\mathrm{H}_{2} \mathrm{O}_{2}$ and $\mathrm{MnO}_{2} \mathrm{NPs}$. The results, in MCF-7 cancer cells, showed that IR808@MnO NPs improved the hypoxia environment of the tumour, generating a large amount of ROS. Moreover, a high in vitro PTT/PDT efficiency $\left(808 \mathrm{~nm}, 0.5 \mathrm{~W} \cdot \mathrm{cm}^{-2}\right.$, $5 \mathrm{~min}$ ) was observed by treatment with IR808@MnO NPs with a significant decrease of cell viability (6\%) under acidic conditions. In vivo in MCF-7 tumour-bearing mice, IR808@MnO NPs highlighted a significant phototoxicity with no tumour recurrence for all treated-mice and an improvement of hypoxia in tumour.

HSA- $\mathrm{MnO}_{2}-\mathrm{Ce} 6$ woofers were prepared by Lin et al. [90]. $\mathrm{HSA}-\mathrm{MnO}_{2}-\mathrm{Ce} 6 \mathrm{NPs}$ generated $\mathrm{O}_{2}$ when reacting with $\mathrm{H}_{2} \mathrm{O}_{2}$ at endogenous levels. In addition, ${ }^{1} \mathrm{O}_{2}$ generation was doubled due to the use of HSA- $\mathrm{MnO}_{2}-\mathrm{Ce} 6 \mathrm{NPs}$ instead of HSA-Ce6 NPs in the presence of $\mathrm{H}_{2} \mathrm{O}_{2}$ with $660 \mathrm{~nm}$ laser illumination. In vitro mouse bladder cancer cells (MB-49) viability tests showed that $\mathrm{HSA}-\mathrm{MnO}_{2}-\mathrm{Ce} 6 \mathrm{NPs}$ themselves were non-toxic, but significantly enhanced the effects of PDT on bladder cancer cells (MB-49) during laser irradiation $\left(660 \mathrm{~nm}, 5 \mathrm{~mW} \cdot \mathrm{cm}^{-2}, 30 \mathrm{~min}\right) . \mathrm{O}_{2}$ content in orthotopic bladder cancer increased by 3.5 times after the introduction of $\mathrm{HSA}-\mathrm{MnO}_{2}-\mathrm{Ce} 6 \mathrm{NPs}$ compared with the previous introduction of HSA-Ce6 NPs without $\mathrm{MnO}_{2}$. Given the superior tumour targeting and low toxicity, $\mathrm{HSA}-\mathrm{MnO}_{2}-\mathrm{Ce} 6$ NPs were then used for the PDT treatment of orthotopic bladder cancer $\left(660 \mathrm{~nm}, 200 \mathrm{~mW} \cdot \mathrm{cm}^{-2}, 15\right.$ min). PDA with HS of HSA-MnO $2-\mathrm{Ce} 6$ NPs showed significantly improved therapeutic efficacy and significantly increased the lifespan of mice compared with the control group.

Wang et al. [91] developed $\mathrm{pH} / \mathrm{H}_{2} \mathrm{O}_{2}$ responsive nanocomplexes composed of Si QDs linked by electrostatic interaction to BSA-Ce6 to form BSA-Ce6-Si QDs (BCS) coated with $\mathrm{MnO}_{2}$ on the surface of BSA to obtain blocked-cell shared-memory (BCSM NPs). In the same conditions as $\mathrm{TME}\left(\mathrm{H}_{2} \mathrm{O}_{2}\right.$, $\mathrm{pH}=6.5$ ), BCSM NPs showed a high production of $\mathrm{O}_{2}$ and thus of ${ }^{1} \mathrm{O}_{2}$ which was higher than Ce6 alone. PDT treatment $\left(638 \mathrm{~nm}, 5 \mathrm{~mW} \cdot \mathrm{cm}^{-2}, 30 \mathrm{~min}\right)$ with BCSM NPs in vitro in HeLa cells conducted to a significant decrease of cell viability (20\%) and a high production of ${ }^{1} \mathrm{O}_{2}$ was observed. In vivo PDT experiments in HeLa tumour-bearing mice showed that the growth of tumours was effectively inhibited under light exposure $\left(638 \mathrm{~nm}, 5 \mathrm{~mW} \cdot \mathrm{cm}^{-2}, 5 \mathrm{~min}\right)$.

Zhu et al. [92] synthesized hybrid semiconductor NPs (SPN-Ms) composed of semiconducting polymer NPs (SPN) as a core and $\mathrm{MnO}_{2}$ nanosheets as a shell. The SPN core served as the NIR agent for fluorescence imaging and PDT, while the $\mathrm{MnO}_{2}$ nanoribbons as $\mathrm{O}_{2}$ formation agent. SPNs were coated with different amounts of $\mathrm{MnO}_{2}$ and the SPN-M1 $\left(1_{w / w} \%\right.$ of $\left.\mathrm{MnO}_{2}\right)$ generated 2.68 times more ${ }^{1} \mathrm{O}_{2}$ than uncoated SPN (SPN-0) under hypoxic conditions under NIR laser irradiation $\left(0.44 \mathrm{~W} \cdot \mathrm{cm}^{-2}\right)$. In vitro and in vivo in $4 \mathrm{~T} 1$ cells model, SPN-M1 exhibited a high PDT $\left(808 \mathrm{~nm}, 5 \mathrm{~min}\right.$, in vitro: $0.44 \mathrm{~W} \cdot \mathrm{cm}^{-2}$ and in vivo: $0.3 \mathrm{~W} \cdot \mathrm{cm}^{-2}$ ) efficiency. 
Zhu et al. [93] designed a multifunctional theranostic NP (NMOFs@BSA/SDs@MnO ${ }_{2}$ ) with nanoscale metal organic frameworks (NMOFs, composed of TCPP as ligand and $\mathrm{Fe}^{3+}$ ), bovine serum albumin (BSA) and sulfadiazines (SDs), to provide actively targeting for the over-expressed carbonic anhydrase IX (CA IX) in tumour cells, and $\mathrm{MnO}_{2}$. NPs presented an average hydrodynamic diameter of $122 \mathrm{~nm}$ and its ability to produce $\mathrm{O}_{2}$ was also proved. In vitro in $4 \mathrm{~T} 1$ cells, nmOFs@BSA/SDs@ $\mathrm{MnO}_{2}$ under laser irradiation $\left(660 \mathrm{~nm}, 50 \mathrm{~mW} \cdot \mathrm{cm}^{-2}, 15 \mathrm{~min}\right)$ induced a high decrease of cell viability with a production of ROS due to $\mathrm{H}_{2} \mathrm{O}_{2}$ decomposition. In vivo in $4 \mathrm{~T} 1$ bearing mice highlighted a significant inhibition of tumour growth by PDT treatment $\left(660 \mathrm{~nm}, 50 \mathrm{~mW} \cdot \mathrm{cm}^{-2}, 15 \mathrm{~min}\right)$ with nmOFs@BSA/SDs@ $\mathrm{MnO}_{2}$.

Liu et al. [94] developed NPs based on black phosphorus nanocomposite as PS. The NPs ( $\left.\mathrm{R}-\mathrm{MnO}_{2}-\mathrm{FBP}\right)$ were composed by assembly of $\mathrm{MnO}_{2}$ encapsulating in Rhodamine $\mathrm{B}(\mathrm{RhB})\left(\mathrm{R}-\mathrm{MnO}_{2}\right)$ for $\mathrm{O}_{2}$ generator and fluorescein isothiocyanate (FITC)-labelled peptide-functionalized black phosphorus (FBP) as PS. It was shown that the $\mathrm{O}_{2}$ release was proportional to the liberation of $\mathrm{Mn}^{2+}$ and $\mathrm{RhB}$ in the $\mathrm{R}-\mathrm{MnO}_{2}-\mathrm{FBP}$ system. Under irradiation $(660 \mathrm{~nm}), \mathrm{R}-\mathrm{MnO}_{2}-\mathrm{FBP}$ presented $\phi_{\Delta}$ of $9.9 \%$ which remained stable in hypoxic conditions. After delivery of $\mathrm{R}-\mathrm{MnO}_{2}-\mathrm{FBP}$ into cancer cells in acidic and $\mathrm{H}_{2} \mathrm{O}_{2}$-rich environment, the generation of $\mathrm{O}_{2}$ was observed and PDT treatment in hypoxic cells conducted to $51.6 \%$ of cell (HeLa cells) apoptosis under laser irradiation $\left(660 \mathrm{~nm}, 150 \mathrm{~mW} \cdot \mathrm{cm}^{-2}, 3 \mathrm{~min}\right)$. In vivo experiments in HeLa-bearing mice with $\mathrm{R}-\mathrm{MnO}_{2}-\mathrm{FBP}$ highlighted the ability of $\mathrm{R}-\mathrm{MnO}_{2}-\mathrm{FBP}$ to enhance PDT treatment $\left(660 \mathrm{~nm}, 150 \mathrm{~mW} \cdot \mathrm{cm}^{-2}, 10 \mathrm{~min}\right)$.

Several teams have studied the use of $\mathrm{MnO}_{2} \mathrm{NPs}$ to improve combined therapies by designing self-oxygenated systems. We report three teams who described the interest of $\mathrm{MnO}_{2}$ to improve PTT/PDT synergistic therapy.

Cao et al. [95] developed intelligent NPs to overcome limitations of dual PDT and PTT treatment. The NPs were constituted by a $\mathrm{MnO}_{2}$ nanosheet decorating at the surface with $\mathrm{Cu}_{2-\mathrm{x}} \mathrm{S}\left(\mathrm{MnO}_{2} / \mathrm{Cu}_{2-\mathrm{x}} \mathrm{S}\right)$ and then loaded with siRNA (siRNA-small interfering RNA) to finally formed $\mathrm{MnO}_{2} / \mathrm{Cu}_{2-\mathrm{x}} \mathrm{S}$-siRNA. In an acidic microenvironment, the $\mathrm{MnO}_{2}$ tumour was reduced to the $\mathrm{Mn}^{2+}$ ion and triggered the decomposition of $\mathrm{H}_{2} \mathrm{O}_{2}$ to $\mathrm{O}_{2}$ to facilitate tumour hypoxia. Reduced $\mathrm{Mn}^{2+}$ ions significantly enhanced the contrast of MRI, and $\mathrm{Cu}_{2-x} \mathrm{~S}$ acted as a powerful PA and PT imaging agent, which led to accurate trimodal tumour-specific imaging and detection. In vitro studies in MCF-7 and A549 cells were performed. Under NIR irradiation $\left(980 \mathrm{~nm}, 0.72 \mathrm{~W} \cdot \mathrm{cm}^{-2}, 5 \mathrm{~min}\right), \mathrm{MnO}_{2} / \mathrm{Cu}_{2-\mathrm{x}} \mathrm{S} \mathrm{NPs}$ showed a high phototoxicity with a cell viability of only $29.68 \%$ due an effective synergistic PTT/PDT effect. In vivo studies in B16 tumour-bearing mice highlighted a high inhibition of tumour growth for mice treated with $\mathrm{MnO}_{2} / \mathrm{Cu}_{2-\mathrm{x}} \mathrm{S}$-siRNA and NIR irradiation $\left(\left(980 \mathrm{~nm}, 0.72 \mathrm{~W} \cdot \mathrm{cm}^{-2}, 5 \mathrm{~min}\right)\right.$ proving an enhancement of PTT/PDT treatment with a high increase of ${ }^{1} \mathrm{O}_{2}$ due to $\mathrm{H}_{2} \mathrm{O}_{2}$ decomposition by $\mathrm{MnO}_{2}$.

Yin et al. [96] coated uniformly carbon nanotubes (CNTs), as PTT agent with cross-linked $\mathrm{MnO}_{2}$ flakes, as $\mathrm{O}_{2}$ generator, $\mathrm{MnO}_{2} / \mathrm{CNTs}(\mathrm{MCs})$ and incubated with $\mathrm{Ce} 6$ to give $\mathrm{Ce} 6-\mathrm{MnO}_{2} / \mathrm{CNTs}(\mathrm{CMCs})$ for PTT/PDT therapy. This system could, in the TME, release $\mathrm{Ce} 6$ and CNTs while generating $\mathrm{O}_{2}$ by reaction of $\mathrm{MnO}_{2}$ with endogenous $\mathrm{H}_{2} \mathrm{O}_{2}$ and $\mathrm{H}^{+}$. In TME-mimetic conditions, the photothermal effect of CMCs and ${ }^{1} \mathrm{O}_{2}$ generation under laser irradiation (PTT: $808 \mathrm{~nm}, 1.0 \mathrm{~W} \cdot \mathrm{cm}^{-2}$ and PDT: $660 \mathrm{~nm}$, $0.5 \mathrm{~mW} \cdot \mathrm{cm}^{-2}$ ) was observed. In vitro in HeLa cells, CMCs showed a high phototoxicity and a strong production of ${ }^{1} \mathrm{O}_{2}$ under irradiation $\left(660 \mathrm{~nm}, 1.0 \mathrm{~W} \cdot \mathrm{cm}^{-2}, 5 \mathrm{~min}\right)$. The synergistic PTT/PDT effect of CMCs was highlighted in vivo in HeLa tumour-bearing mice irradiated with $808+660 \mathrm{~nm}\left(1.0 \mathrm{~W} \cdot \mathrm{cm}^{-2}\right.$, $10 \mathrm{~min}$ ) with eradication of tumours.

In 2019 Liu et al. proposed [97] new $\mathrm{MnO}_{2}$-based nanotherapeutic agents (honeycomb $\mathrm{MnO}_{2} /$ IR780/BSA NPs, HMIB NPs) for NIR-activatable and self-oxygenated PTT/PDT. HMIB NPs exhibited efficient ${ }^{1} \mathrm{O}_{2}$ production under NIR irradiation $\left(785 \mathrm{~nm}, 20 \mathrm{~mW} \cdot \mathrm{cm}^{-2}\right)$ and PT effect $(785 \mathrm{~nm}$, 0.3 and $1.0 \mathrm{~W} \cdot \mathrm{cm}^{-2}, 6 \mathrm{~min}$ ). In vitro in HepG2 and $3 \mathrm{~T} 3$ cells, the authors showed that the irradiation of cells with a higher power $\left(785 \mathrm{~nm}, 1 \mathrm{~W} \cdot \mathrm{cm}^{-2}\right)$ after incubation with HMIB NPs led to more cell death than irradiation at $785 \mathrm{~nm}$ and $50 \mathrm{~mW} \cdot \mathrm{cm}^{-2}$ due to the PT effect. In vivo, HepG2 tumours could be 
completely eliminated when increasing the laser power density from 0.3 to $1 \mathrm{~W} \cdot \mathrm{cm}^{-2}$, which could be attributed to the synergy of PDT and PTT.

We report two studies about the use of $\mathrm{MnO}_{2}$ to improve chemo-PDT synergistic therapy. Chen et al. [98] synthesized HSA- $\mathrm{MnO}_{2}-\mathrm{Ce} 6$ \& $\mathrm{Pt} \mathrm{NPs}$ ( $\mathrm{HMCP}$ ) constituted by $\mathrm{MnO}_{2}$ nanoclusters coated to HSA modified with $\mathrm{Ce} 6$ or with a prodrug of cis- $\mathrm{Pt}\left(\mathrm{c}, \mathrm{t}, \mathrm{c}-\left[\mathrm{Pt}\left(\mathrm{NH}_{3}\right)_{2}-\left(\mathrm{O}_{2} \mathrm{CCH}_{2} \mathrm{CH}_{2} \mathrm{COOH}\right)(\mathrm{OH}) \mathrm{Cl}_{2}\right]\right.$ (cis-Pt(IV)SA)). These NPs were sensitive to $\mathrm{pH} / \mathrm{H}_{2} \mathrm{O}_{2}$ using a simple one-step albumin-based biomineralization method for effective combination therapy. Once inside the tumour, $\mathrm{MnO}_{2}$ nanoclusters in HMCP NPs decreased hypoxia. Meanwhile, the reaction of $\mathrm{MnO}_{2}$ with $\mathrm{H}^{+}$and $\mathrm{H}_{2} \mathrm{O}_{2}$ in TME led to the gradual decomposition of these albumin- $\mathrm{MnO}_{2}$ NPs into separate therapeutic albumin complexes with sizes less than $10 \mathrm{~nm}$ in order to achieve significantly improved intra-tumour interstitial diffusion for optimized treatment of tumours. As a result of these effects, large in vitro antitumour therapeutic results in $4 \mathrm{~T} 1$ cells were achieved after combined PDT $\left(660 \mathrm{~nm}, 5 \mathrm{~mW} \cdot \mathrm{cm}^{-2}\right.$, $30 \mathrm{~min}$ ) and chemotherapy using HMCP NPs by a single treatment at a rather low dose. In vivo studies were performed in 4T1 tumours-bearing mice and a significant decrease of hypoxia was also observed in presence HMCP NPs by using pimonidazole. In vivo studies of the efficiency of HMCP combined to light irradiation $\left(660 \mathrm{~nm}, 5 \mathrm{~mW} \cdot \mathrm{cm}^{-2}, 1 \mathrm{~h}\right)$ highlighted an increase of tumour growth inhibition.

Zhang et al. [99] developed an $\mathrm{O}_{2}$-generating and $\mathrm{pH}$-sensitive nanoplatform, loading $\mathrm{MnO}_{2}$ for $\mathrm{O}_{2}$ generation, g- $\mathrm{C}_{3} \mathrm{~N}_{4}$ for PDT, ZIF-8 (zeolitic imidazolate frameworks) for drug encapsulation and doxorubicin hydrochloride for chemotherapy (Figure 17).

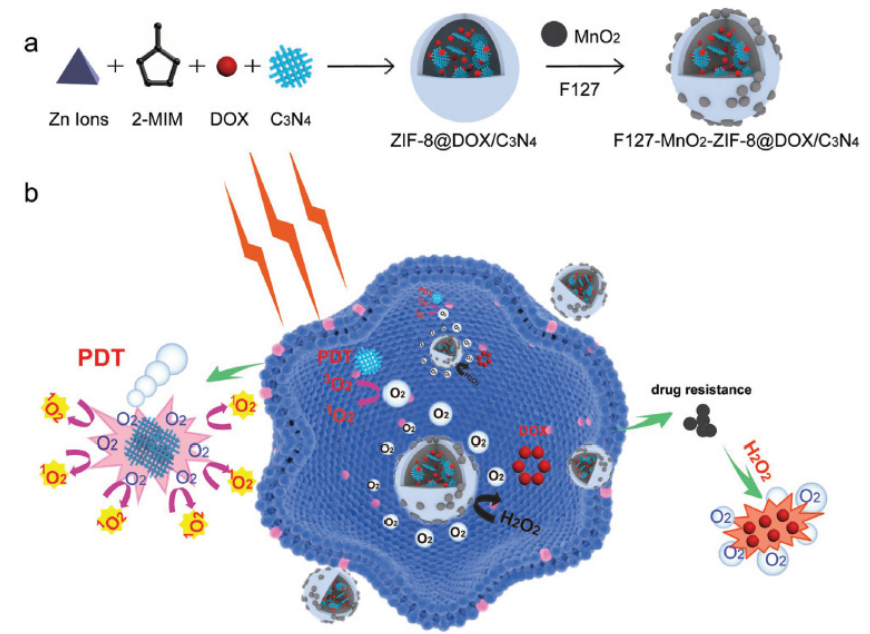

Figure 17. (a) Schematic illustration of the fabrication of FMZ/DC nanocomposites. The diagram is not drawn to scale. (b) Schematic illustration of FMZ/DC with $\mathrm{O}_{2}$ generation enhancing the chemo-PDT under $660 \mathrm{~nm}$ light irradiation. Reprinted from [99] with permission from John Wiley and Sons, Copyright 2018.

In vitro experiments in 4T1 cells showed a higher therapeutic effect using the NPs compared to therapy without $\mathrm{MnO}_{2}$ nanodot in hypoxic conditions or only with chemical and PDT (660 nm, $5 \mathrm{~mW} \cdot \mathrm{cm}^{-2}, 30 \mathrm{~min}$ ) with the presence of $\mathrm{MnO}_{2}$ nanodot. In vivo experiments also showed that NPs could reduce tumour hypoxia and improve the effect of photodynamic and chemotherapeutic treatment. 4T1 tumours could be very effectively eliminated using the developed NPs when irradiated with light $\left(660 \mathrm{~nm}, 5 \mathrm{~mW} \cdot \mathrm{cm}^{-2}, 30 \mathrm{~min}\right)$.

Two others studies about the use of $\mathrm{MnO}_{2}$ to improve combined therapies have been described.

Fan et al. [100] were the first to propose intelligent $\mathrm{MnO}_{2}$ nanosheets, anchored with UCNPs, to simultaneously visualize and treat solid tumours after X-ray/light excitation. After NIR illumination of the quenched UCNP, luminescence of the UCNPs was enhanced after the decomposition of $\mathrm{MnO}_{2}$ into $\mathrm{Mn}^{2+}$ by acidic $\mathrm{H}_{2} \mathrm{O}_{2}$ in the tumours (Figure 18). 


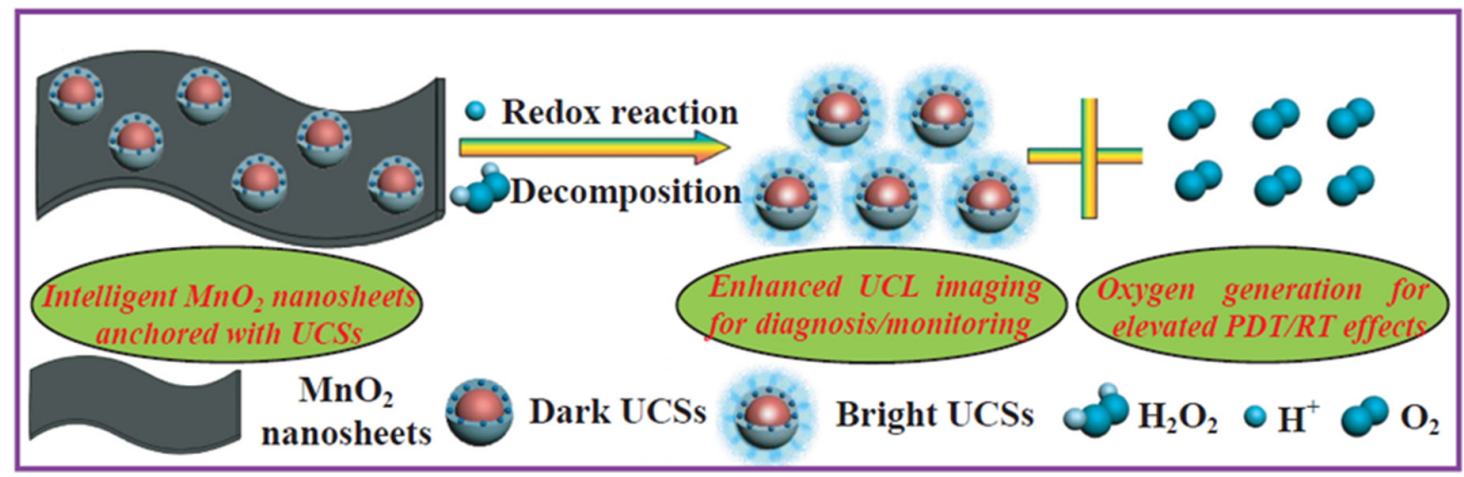

Figure 18. Schematic illustration of the decomposition of $\mathrm{MnO}_{2}$ nanosheets arising from the redox reaction between UCSMs and acidic $\mathrm{H}_{2} \mathrm{O}_{2}$, which led to the enhanced UCL imaging for diagnosis/monitoring as well as the massive $\mathrm{O}_{2}$ generation for improving the synergetic PDT/RT effects. Reprinted from [100] with permission from John Wiley and Sons, Copyright 2015.

Hypoxic murine breast cancer, hc-4T1 cells, were used. No killing could be observed after X-ray ( $5 \mathrm{~Gy}, 5 \mathrm{~min}$ ) or light irradiation (NIR, $1.5 \mathrm{~W} \cdot \mathrm{cm}^{-2}, 5 \mathrm{~min}$ ). After addition of the compound, cell death could be observed after PDT (UCSMs + NIR) and RT (UCSMs + RT) due to the $\mathrm{O}_{2}$ generation. Moreover, after NIR and X-ray, the lowest cell viability would be detected showing the synergetic $\mathrm{PDT} / \mathrm{RT}$ effects. The same effect was detected in vivo in $4 \mathrm{~T} 1$ solid tumour (PDT: NIR, $2 \mathrm{~W} \cdot \mathrm{cm}^{-2}, 10 \mathrm{~min}$ and RT: $8 \mathrm{~Gy}, 5 \mathrm{~min}$ ). In vivo PA imaging was performed to evaluate the vascular saturated $\mathrm{O}_{2}$ by evaluating oxygenated and deoxygenated $\mathrm{Hb}$. Injection of UCSMs increased the signal intensity of oxygenated/deoxygenated $\mathrm{Hb}$ but also enhanced $\mathrm{O}_{2}$ by about $7 \%$. Moreover, addition of UCSMs induced a down-expression of HIF- $1 \alpha$, due to the decreased hypoxia and increased oxygenation.

$\mathrm{He}$ et al. [101] proposed a glutathione-activatable and $\mathrm{O}_{2} / \mathrm{Mn}^{2+}$-Evolving NPs for both PDT and gene-silencing therapy (GAOME N). This system consisted of the $\mathrm{MnO}_{2}$ cellular nanocarrier $\left(\mathrm{hMnO}_{2}\right)$ loaded with catalase, $\mathrm{Ce} 6$, and foliar-tag DNAzyme. After endocytosis, $\mathrm{hMnO}_{2}$ carriers were reduced by overexpressed GSH to $\mathrm{Mn}^{2+}$ ions, which led to a decrease of GSH level and the breakdown of GAOME NC. Then, the released catalases triggered the cleavage of endogenous $\mathrm{H}_{2} \mathrm{O}_{2}$ with the formation of $\mathrm{O}_{2}$. The formation of $\mathrm{O}_{2}$ and the consumption of GSH effectively increased the efficiency of PDT. In addition, the DNAzyme was released to silence the genes in the presence of self-generated $\mathrm{Mn}^{2+}$ ions as cofactors. Rational synergy of enhanced PDT and gene therapy led to a significant increase in the effectiveness of cancer treatment in vitro (MCF-7 cell line, $635 \mathrm{~nm}, 30 \mathrm{~mW} \cdot \mathrm{cm}^{-2}, 5 \mathrm{~min}$ ) and in vivo (MCF-7 tumour-bearing mice, $635 \mathrm{~nm}, 100 \mathrm{~mW} \cdot \mathrm{cm}^{-2}, 5 \mathrm{~min}$ ).

Another type of NP was able to catalyse $\mathrm{H}_{2} \mathrm{O}_{2}$ to produce $\mathrm{O}_{2}$ as well as being a contrast agent for both MRI and fluorescence imaging: carbon dot [102]. Jia et al. synthesized Mn-carbon dots (CDs) by a solvothermal approach with $\mathrm{Mn}$ (II) phthalocyanines (Mn-Pc) and cooperative self-assembly with DSPE-PEG. The hydrodynamic diameter of this Mn-CD assembly was around $162 \mathrm{~nm}$. Mn(II) could be oxidized to $\mathrm{MnO}_{2}$ that led to the catalytic decomposition of $\mathrm{H}_{2} \mathrm{O}_{2}$. Formation of $\mathrm{O}_{2}$ was observed when Mn-CD was in acidic $\mathrm{H}_{2} \mathrm{O}_{2}$ solution whereas no $\mathrm{O}_{2}$ was produced in the absence of $\mathrm{H}_{2} \mathrm{O}_{2}$ or Mn-CD. In acidic media, the $\mathrm{O}_{2}$ bubbles were even more abundant. Mn-CD assembly totally disassembled in acidic $\mathrm{H}_{2} \mathrm{O}_{2}$ solution forming free Mn-CD. By ESR technique in solution and using SOSG probe in vitro in HeLa cells, they proved the formation of ${ }^{1} \mathrm{O}_{2}$ even in hypoxic conditions. For PDT experiments $\left(635 \mathrm{~nm}, 50 \mathrm{~mW} \cdot \mathrm{cm}^{-2}, 10 \mathrm{~min}\right)$ the cells were cultured in an acid medium $(\mathrm{pH}=6.5)$ with addition of $\mathrm{H}_{2} \mathrm{O}_{2} .99 \%$ mortality rate could be observed whereas with $\mathrm{CD}$ without $\mathrm{Mn}$, no PDT effect could be observed (no PS). In vivo PDT efficiency was evaluated in subcutaneous $4 \mathrm{~T} 1$ tumour-bearing female nude mice $\left(635 \mathrm{~nm}, 50 \mathrm{~mW} \cdot \mathrm{cm}^{-2}, 10 \mathrm{~min}\right)$. With $\mathrm{Mn}-\mathrm{CD}$ the tumour was completely inhibited and no recurrence could be observed. All the mice survived over 60 days (Table 6). 
Table 6. Summary of publication about the decomposition of $\mathrm{H}_{2} \mathrm{O}_{2}$ by $\mathrm{MnO}_{2}$.

\begin{tabular}{|c|c|c|c|c|c|c|c|c|}
\hline Ref & Application & Catalyst & $\mathrm{O}_{2}$ Source & PS & Energy of Excitation & Type of ROS & IN VITRO & In Vivo \\
\hline [75] & PDT & Mn (II) complex & $\mathrm{H}_{2} \mathrm{O}_{2}$ & BODIPY derivatives & $500-600 \mathrm{~nm}, 15 \mathrm{~min}$ & $\begin{array}{l}{ }^{1} \mathrm{O}_{2}, \cdot \mathrm{OH} \text { and } \\
\text { others ROS }\end{array}$ & HepG-2 cell line & \\
\hline [76] & PDT & $\mathrm{MnO}_{2}$ & $\mathrm{H}_{2} \mathrm{O}_{2}$ & Ce6 & $\begin{array}{l}\text { In vitro: } 661 \mathrm{~nm}, 5 \mathrm{~mW} \cdot \mathrm{cm}^{-2}, 30 \mathrm{~min} \\
\text { In vivo: } 661 \mathrm{~nm}, 5 \mathrm{~mW} \cdot \mathrm{cm}^{-2}, 1 \mathrm{~h}\end{array}$ & ${ }^{1} \mathrm{O}_{2}$ & $4 \mathrm{~T} 1$ cell line & $\begin{array}{l}4 \mathrm{~T} 1 \text { tumour-bearing } \\
\text { mice }\end{array}$ \\
\hline [77] & PDT & $\mathrm{MnO}_{2}$ & $\mathrm{H}_{2} \mathrm{O}_{2}$ & DVDMS & $\begin{array}{l}\text { In vitro: } 630 \mathrm{~nm}, 75 \mathrm{~mW} \cdot \mathrm{cm}^{-2}, 5 \mathrm{~min} \\
\text { In vivo: } 630 \mathrm{~nm}, 300 \mathrm{~mW} \cdot \mathrm{cm}^{-2}, 8 \mathrm{~min}\end{array}$ & ${ }^{1} \mathrm{O}_{2}$ & MCF-7 cell line & $\begin{array}{c}\text { MCF-7 } \\
\text { tumour-bearing mice }\end{array}$ \\
\hline [78] & PDT & $\mathrm{MnO}_{2}$ & $\mathrm{H}_{2} \mathrm{O}_{2}$ & ICG & $\begin{array}{l}\text { In vitro: } 808 \mathrm{~nm}, 0.5 \mathrm{~W} \cdot \mathrm{cm}^{-2}, 10 \mathrm{~min} \\
\text { In vivo: } 808 \mathrm{~nm}, 0.8 \mathrm{~W} \cdot \mathrm{cm}^{-2}, 10 \mathrm{~min}\end{array}$ & ${ }^{1} \mathrm{O}_{2}$ & SCC-7 cell line & $\begin{array}{l}\text { SCC7 tumour-bearing } \\
\text { mice }\end{array}$ \\
\hline [79] & PDT & $\mathrm{MnO}_{2}$ & $\mathrm{H}_{2} \mathrm{O}_{2}$ & HMME & $\begin{array}{l}\text { In vitro: } 532 \mathrm{~nm}, 1.5 \mathrm{~W} \cdot \mathrm{cm}^{-2}, 2 \mathrm{~min} \\
\text { In vivo: } 808 \mathrm{~nm}, 1.5 \mathrm{~W} \cdot \mathrm{cm}^{-2}, 1.5 \mathrm{~min}\end{array}$ & ${ }^{1} \mathrm{O}_{2}$ & MCF-7 cells line & S180 tumour model \\
\hline [80] & PDT & $\begin{array}{l}\text { manganese } \\
\text { ferrite NPs }\end{array}$ & $\mathrm{H}_{2} \mathrm{O}_{2}$ & Ce6 & $\begin{array}{l}\text { In vitro: } 670 \mathrm{~nm}, 0.5 \mathrm{~W} \cdot \mathrm{cm}^{-2}, 30 \mathrm{~s} \\
\text { In vivo: } 670 \mathrm{~nm}, 0.8 \mathrm{~W} \cdot \mathrm{cm}^{-2}, 5 \mathrm{~min}\end{array}$ & ${ }^{1} \mathrm{O}_{2}$ & U87 MG cell line & $\begin{array}{l}\text { U87 tumour-bearing } \\
\text { mice }\end{array}$ \\
\hline [81] & PDT & $\mathrm{MnO}_{2}$ & $\mathrm{H}_{2} \mathrm{O}_{2}$ & $\mathrm{HPPH}$ & $\begin{array}{l}\text { In vitro: } 10 \mathrm{~mW} \cdot \mathrm{cm}^{-2}, 1 \mathrm{~min} \\
\text { In vivo: } 630 \mathrm{~nm}, 10 \mathrm{~mW} \cdot \mathrm{cm}^{-2}, 10 \mathrm{~min}\end{array}$ & & U87MG cell line & $\begin{array}{c}\text { U87MG } \\
\text { tumour-bearing mice }\end{array}$ \\
\hline [82] & PDT & $\mathrm{MnO}_{2}$ & $\mathrm{H}_{2} \mathrm{O}_{2}$ and $\mathrm{H}^{+}$ & MB & $650 \mathrm{~nm}, 100 \mathrm{~mW} \cdot \mathrm{cm}^{-2}, 15 \mathrm{~min}$ & ${ }^{1} \mathrm{O}_{2}$ & HeLa cells line & $\begin{array}{l}\text { U14 tumour-bearing } \\
\text { mice }\end{array}$ \\
\hline [83] & PDT & $\begin{array}{c}\mathrm{MnO}_{2} \\
\text { nanosheets }\end{array}$ & $\mathrm{H}_{2} \mathrm{O}_{2}$ & Ce6 & $808 \mathrm{~nm}, 0.4 \mathrm{~W} \cdot \mathrm{cm}^{-2}, 60 \mathrm{~min}$ & ${ }^{1} \mathrm{O}_{2}$ & B16F10 cell line & No \\
\hline [84] & PDT & $\mathrm{MnO}_{2}$ & $\mathrm{H}_{2} \mathrm{O}_{2}$ & Ce6 & $\begin{array}{l}\text { In vitro: } 980 \mathrm{~nm}, 0.5 \mathrm{~W} \cdot \mathrm{cm}^{-2}, 10 \mathrm{~min} \\
\text { In vivo: } 660 \mathrm{~nm}, 0.5 \mathrm{~W} \cdot \mathrm{cm}^{-2}, 30 \mathrm{~min}\end{array}$ & ${ }^{1} \mathrm{O}_{2}$ & $4 \mathrm{~T} 1$ cell line & $\begin{array}{l}4 \mathrm{~T} 1 \text { tumour-bearing } \\
\text { mice }\end{array}$ \\
\hline [85] & PDT & $\mathrm{MnO}_{2}$ & $\mathrm{H}_{2} \mathrm{O}_{2}$ & $\mathrm{CD}$ & $\begin{array}{l}\text { In vitro: } 635 \mathrm{~nm}, 100 \mathrm{~mW} \cdot \mathrm{cm}^{-2}, 30 \mathrm{~min} \\
\text { In vivo: } 635 \mathrm{~nm}, 100 \mathrm{~mW} \cdot \mathrm{cm}^{-2}, 10 \mathrm{~min}\end{array}$ & ${ }^{1} \mathrm{O}_{2}$ & HeLa cell line & $\begin{array}{c}\text { 4T1-luc } \\
\text { tumour-bearing mice }\end{array}$ \\
\hline [86] & PDT & $\mathrm{MnO}_{2}$ & $\mathrm{H}_{2} \mathrm{O}_{2}$ & Ce6 & $660 \mathrm{~nm}, 100 \mathrm{~mW} \cdot \mathrm{cm}^{-2}, 10 \mathrm{~min}$ & ${ }^{1} \mathrm{O}_{2}$ & HeLa cells line & No \\
\hline [87] & PDT & $\mathrm{MnO}_{2}$ & $\mathrm{H}_{2} \mathrm{O}_{2}$ & $\begin{array}{l}\text { PEGylated } \mathrm{p}-\mathrm{n} \\
\text { heterojunction } \\
\text { nanosheets }\end{array}$ & $980 \mathrm{~nm}, 0.4 \mathrm{~W} \cdot \mathrm{cm}^{-2}, 5 \mathrm{~min}$ & ${ }^{1} \mathrm{O}_{2}$ & $\begin{array}{l}\text { HeLa cells and } \\
\text { HEK } \\
293 \text { cell lines }\end{array}$ & \\
\hline [88] & PDT & $\mathrm{MnO}_{2}$ & $\mathrm{H}_{2} \mathrm{O}_{2}$ & Gold nano-cage (AuNC) & $808 \mathrm{~nm}, 0.8 \mathrm{~W} \cdot \mathrm{cm}^{-2}, 3 \mathrm{~min}$ & ${ }^{1} \mathrm{O}_{2}$ & $4 \mathrm{~T} 1$ cell line & $\begin{array}{l}4 \mathrm{~T} 1 \text { tumour-bearing } \\
\text { mice }\end{array}$ \\
\hline [89] & PDT & $\mathrm{MnO} \mathrm{NP}$ & $\mathrm{H}_{2} \mathrm{O}_{2}$ & IR808 & $808 \mathrm{~nm}, 0.5 \mathrm{~W} \cdot \mathrm{cm}^{-2}, 5 \mathrm{~min}$ & ${ }^{1} \mathrm{O}_{2}$ & $\begin{array}{l}\text { MCF-7 cancer } \\
\text { cells }\end{array}$ & $\begin{array}{c}\text { MCF-7 } \\
\text { tumour-bearing mice }\end{array}$ \\
\hline [90] & PDT & $\mathrm{MnO}_{2}$ & $\mathrm{H}_{2} \mathrm{O}_{2}$ & Ce6 & $\begin{array}{l}\text { In vitro: } 660 \mathrm{~nm}, 5 \mathrm{~mW} \cdot \mathrm{cm}^{-2}, 30 \mathrm{~min} \\
\text { In vivo: } 660 \mathrm{~nm}, 200 \mathrm{~mW} \cdot \mathrm{cm}^{-2}, 15 \mathrm{~min}\end{array}$ & ${ }^{1} \mathrm{O}_{2}$ & MB-49 cells line & $\begin{array}{l}\text { Mice with orthotopic } \\
\text { bladder cells }\end{array}$ \\
\hline [91] & PDT & $\mathrm{MnO}_{2}$ & $\mathrm{H}_{2} \mathrm{O}_{2}$ & Ce6 & $\begin{array}{l}\text { In vitro: } 638 \mathrm{~nm}, 5 \mathrm{~mW} \cdot \mathrm{cm}^{-2}, 30 \mathrm{~min} \\
\text { In vivo: } 638 \mathrm{~nm}, 5 \mathrm{~mW} \cdot \mathrm{cm}^{-2}, 5 \mathrm{~min}\end{array}$ & ${ }^{1} \mathrm{O}_{2}$ & $\begin{array}{l}\text { HeLa and } \\
\text { HepG-2 cell } \\
\text { lines }\end{array}$ & $\begin{array}{c}\text { HeLa } \\
\text { tumour-bearing mice }\end{array}$ \\
\hline
\end{tabular}


Table 6. Cont

\begin{tabular}{|c|c|c|c|c|c|c|c|c|}
\hline Ref & Application & Catalyst & $\mathrm{O}_{2}$ Source & PS & Energy of Excitation & Type of ROS & IN VITRO & In Vivo \\
\hline [92] & PDT & $\mathrm{MnO}_{2}$ & $\mathrm{H}_{2} \mathrm{O}_{2}$ and $\mathrm{H}^{+}$ & $\begin{array}{l}\text { Poly(cyclopentadithiophene } \\
\text {-alt-benzothiadiazole) } \\
\text { (PCPDTBT) }\end{array}$ & $\begin{array}{l}\text { In vitro: } 808 \mathrm{~nm}, 0.44 \mathrm{~W} \cdot \mathrm{cm}^{-2}, 5 \mathrm{~min} \\
\text { In vivo: } 808 \mathrm{~nm}, 0.30 \mathrm{~W} \cdot \mathrm{cm}^{-2}, 5 \mathrm{~min}\end{array}$ & ${ }^{1} \mathrm{O}_{2}$ & $4 \mathrm{~T} 1$ cells line & $\begin{array}{l}\text { 4T1 tumour-bearing } \\
\text { mice }\end{array}$ \\
\hline [93] & PDT & $\mathrm{MnO}_{2}$ & $\mathrm{H}_{2} \mathrm{O}_{2}$ & $\begin{array}{l}\text { nmOFs composed by } \\
\text { TCPP and } \mathrm{Fe}^{3+}\end{array}$ & $660 \mathrm{~nm}, 50 \mathrm{~mW} \cdot \mathrm{cm}^{-2}, 15 \mathrm{~min}$ & $\cdot \mathrm{OH}$ & $4 \mathrm{~T} 1$ cells line & $\begin{array}{l}\text { 4T1 tumour-bearing } \\
\text { mice }\end{array}$ \\
\hline [94] & PDT & $\mathrm{MnO}_{2}$ & $\mathrm{H}_{2} \mathrm{O}_{2}$ and $\mathrm{H}^{+}$ & FBP & $\begin{array}{l}\text { In vitro: } 660 \mathrm{~nm}, 150 \mathrm{~mW} \cdot \mathrm{cm}^{-2}, 3 \mathrm{~min} \\
\text { In vivo: } 660 \mathrm{~nm}, 150 \mathrm{~mW} \cdot \mathrm{cm}^{-2}, 10 \mathrm{~min}\end{array}$ & ${ }^{1} \mathrm{O}_{2}$ & HeLa cell line & $\begin{array}{l}\text { HeLa tumour-bearing } \\
\text { mice }\end{array}$ \\
\hline [95] & PTT/PDT & $\mathrm{MnO}_{2}$ & $\mathrm{H}_{2} \mathrm{O}_{2}$ & $\mathrm{Cu}_{2-\mathrm{x}} \mathrm{S}$ & $980 \mathrm{~nm}, 0.72 \mathrm{~W} \cdot \mathrm{cm}^{-2}, 5 \mathrm{~min}$ & ${ }^{1} \mathrm{O}_{2}$ & $\begin{array}{l}\text { MCF-7 and } \\
\text { A549 cell lines }\end{array}$ & $\begin{array}{c}\text { B16 } \\
\text { tumour-bearing mice }\end{array}$ \\
\hline [96] & PTT/PDT & $\mathrm{MnO}_{2}$ & $\mathrm{H}_{2} \mathrm{O}_{2}$ and $\mathrm{H}^{+}$ & Ce6 & $808+660 \mathrm{~nm}, 1.0 \mathrm{~W} \cdot \mathrm{cm}^{-2}, 10 \mathrm{~min}$ & ${ }^{1} \mathrm{O}_{2}$ & HeLa cell line & $\begin{array}{l}\text { HeLa tumour-bearing } \\
\text { mice }\end{array}$ \\
\hline [97] & PTT/PDT & $\mathrm{MnO}_{2}$ & $\mathrm{H}_{2} \mathrm{O}_{2}$ and $\mathrm{H}^{+}$ & IR780 & $\begin{array}{c}785 \mathrm{~nm} \\
\text { PDT: } 50 \mathrm{~mW} \cdot \mathrm{cm}^{-2} \\
\text { PTT/PDT: } 0.3 \text { to } 1.0 \mathrm{~W} \cdot \mathrm{cm}^{-2}\end{array}$ & ${ }^{1} \mathrm{O}_{2}$ & $\begin{array}{l}\text { HepG2 and 3T3 } \\
\text { cell lines }\end{array}$ & $\begin{array}{l}\text { HepG2 } \\
\text { tumour-bearing mice }\end{array}$ \\
\hline [98] & Chemo-PDT & $\mathrm{MnO}_{2}$ & $\mathrm{H}_{2} \mathrm{O}_{2}$ & Ce6 & $\begin{array}{l}\text { In vitro: } 660 \mathrm{~nm}, 5 \mathrm{~mW} \cdot \mathrm{cm}^{-2}, 30 \mathrm{~min} \\
\text { In vivo: } 660 \mathrm{~nm}, 5 \mathrm{~mW} \cdot \mathrm{cm}^{-2}, 1 \mathrm{~h}\end{array}$ & ${ }^{1} \mathrm{O}_{2}$ & $4 \mathrm{~T} 1$ cell line & $\begin{array}{l}\text { 4T1 tumour-bearing } \\
\text { mice }\end{array}$ \\
\hline [99] & Chemo-PDT & $\mathrm{MnO}_{2}$ & $\mathrm{H}_{2} \mathrm{O}_{2}$ and $\mathrm{H}^{+}$ & $\mathrm{g}-\mathrm{C}_{3} \mathrm{~N}_{4}$ & $660 \mathrm{~nm}, 5 \mathrm{~mW} \cdot \mathrm{cm}^{-2}, 30 \mathrm{~min}$ & ${ }^{1} \mathrm{O}_{2}$ & 4T1 cell line & $\begin{array}{l}4 \mathrm{~T} 1 \text { tumour-bearing } \\
\text { mice }\end{array}$ \\
\hline [100] & PDT & $\begin{array}{c}\mathrm{MnO}_{2} \\
\text { nanosheets }\end{array}$ & $\mathrm{H}_{2} \mathrm{O}_{2}, \mathrm{H}^{+}$ & $\begin{array}{l}\text { Silicon phthalocyanine } \\
\text { dihydroxide (SPCD) }\end{array}$ & $\begin{array}{l}\text { In vitro: NIR, } 1.5 \mathrm{~W} \cdot \mathrm{cm}^{-2}, 5 \mathrm{~min} \\
\text { In vivo: NIR, } 2 \mathrm{~W} \cdot \mathrm{cm}^{-2}, 10 \mathrm{~min}\end{array}$ & ${ }^{1} \mathrm{O}_{2}$ & hc-4T1 cell line & $\begin{array}{c}4 \mathrm{~T} 1 \\
\text { tumour-bearing mice }\end{array}$ \\
\hline [101] & $\begin{array}{c}\text { PDT and } \\
\text { gene-silencing } \\
\text { therapy }\end{array}$ & $\begin{array}{l}\mathrm{O}_{2} / \mathrm{Mn}^{2+} \text {-evolving } \\
\text { nanocomposite }\end{array}$ & $\mathrm{H}_{2} \mathrm{O}_{2}$ & Ce6 & $\begin{array}{l}\text { In vitro: } 635 \mathrm{~nm}, 30 \mathrm{~mW} \cdot \mathrm{cm}^{-2}, 5 \mathrm{~min} \\
\text { In vivo: } 635 \mathrm{~nm}, 100 \mathrm{~W} \cdot \mathrm{cm}^{-2}, 5 \mathrm{~min}\end{array}$ & ${ }^{1} \mathrm{O}_{2}$ & MCF-7 cell line & $\begin{array}{l}\text { MCF-7 } \\
\text { tumour-bearing mice }\end{array}$ \\
\hline [102] & PDT & Mn-Carbon dot & $\mathrm{H}_{2} \mathrm{O}_{2}$ & $\mathrm{Mn}-\mathrm{Pc}$ & $635 \mathrm{~nm}, 50 \mathrm{~mW} \cdot \mathrm{cm}^{-2}, 10 \mathrm{~min}$ & ${ }^{1} \mathrm{O}_{2}$ & HeLa cell line & $\begin{array}{l}\text { 4T1 tumour-bearing } \\
\text { mice }\end{array}$ \\
\hline
\end{tabular}

BODIPY: 4,4-difluoro-4-bora-3a,a-diaza-s-indacene; Ce6: Chlorin e6; DVDMS: sinoporphyrin sodium; ICG: Indocyanine green; HMME: hematoporphyrin monomethyl ether; HPPH: 2-devinyl-2-(1-hexyloxiethyl)pyropheophorbide; MB: methylene blue; CD: carbon dot; nmOFs: nanoscale metal organic frameworks; TCPP: carboxyphenyl-porphyrin; FBP: fluorescein isothiocyanate (FITC)-labelled peptide-functionalized black phosphorus; $\mathrm{g}-\mathrm{C}_{3} \mathrm{~N}_{4}$ : Graphitic carbon nitrides; Mn-Pc: Mn(II) phthalocyanines. 


\subsubsection{Catalase}

Catalase is a natural enzyme. Catalase has a specific catalytic behaviour and is able to decompose endogenous $\mathrm{H}_{2} \mathrm{O}_{2}$ to produce $\mathrm{O}_{2}$ bubbles in the tumour tissue. It can then be used to regulate tumour hypoxia. However, it is not very stable in the presence of proteases in the blood circulation and systemic administration is compromised. In order to protect catalase, one solution can be its encapsulation or coupling to inorganic or organic NPs. That will be the aim of the next paragraph.

As far as we know, the first paper developing this strategy was written by Chen et al. [103]. They synthesized multifunctional NPs composed of catalase (encapsulation efficiency $13.1 \%$ ) into a PLGA (poly(D,L-lactic-co-glycolic acid) NP with MB as a PS (encapsulation efficiency 19.51\%), a black hole quencher-3 (BHQ-3) as an energy quencher of excited PS and a targeting unit (RGDfK) for $\alpha_{\mathrm{v}} \beta_{3}$ integrin targeting. The average hydrodynamic diameter of the HAOP NP was $205 \mathrm{~nm}$ measured by DLS. In the presence of $\mathrm{H}_{2} \mathrm{O}_{2}$, formation of $\mathrm{O}_{2}$ bubbles induced the destruction of the HAOP NPs shell and the release of MB. Using SOSG, they also demonstrated the formation of ${ }^{1} \mathrm{O}_{2}$ in the presence of $\mathrm{H}_{2} \mathrm{O}_{2}$ after $635 \mathrm{~nm}$ excitation $\left(100 \mathrm{~mW} \cdot \mathrm{cm}^{-2}, 5 \mathrm{~min}\right)$ of the HAOP NPs, which was negligible for HAOP NPs without $\mathrm{H}_{2} \mathrm{O}_{2}$ and NPs without catalase. PDT efficacy was performed with light of $635 \mathrm{~nm}$ $\left(100 \mathrm{~mW} \cdot \mathrm{cm}^{-2}, 5 \mathrm{~min}\right)$ on U87-MG cell line. After illumination, the apoptotic cells were $98.2 \%$ for cells treated with HAOP NPs and only $15.8 \%$ for cells treated with HAOP NPs without catalase. A lysosome-associated pathway could be concluded using acridine orange as a marker of lysosome integrity. A commercially available $\mathrm{O}_{2}$ probe $\left(\left[\mathrm{Ru}(\mathrm{dpp})_{3}\right] \mathrm{Cl}_{2}\right.$ ) allowed to detect intracellular $\mathrm{O}_{2}$ which increased after incubation with HAOP NPs. The group treated with HAOP NPs without catalase showed high level of HIF- $1 \alpha$ whereas the group treated by HAOP NPs showed very week level expression due to generated $\mathrm{O}_{2}$ that overcame the hypoxia. In vivo PDT was realized on BALB/c mice bearing U87-MG tumour. As expected after HAOP NPs injection, the tumour growth was totally inhibited which was not the case for all the control groups. After release from the NPs, catalase could generate high level of $\mathrm{O}_{2}$.

Zhang et al. in 2016 [104] designed core-shell gold nanorods (APMECR@MB NC) (diameter of $75 \mathrm{~nm}$ ) covered with phenyl mesoporous silica loaded with [Eu(THA) $($ phen)] to trigger MB via luminescence resonance transfer, a catalase was covalently coupled to the surface via its amino group and conjugated to a targeting peptide (cRGD). Thanks to the overlap between emission spectrum of $\mathrm{Eu}(\mathrm{THA})_{3}$ (phen) and absorption spectrum of $\mathrm{MB}$, high energy transfer could happen upon $808 \mathrm{~nm}$ excitation between $\mathrm{Eu}(\mathrm{THA})_{3}$ (phen) and MB estimated to be $96.1 \%$. With DPBF, it was possible to conclude to the formation of ${ }^{1} \mathrm{O}_{2}$. APMECR@MB NC produced $\mathrm{O}_{2}$ bubbles in the presence of $\mathrm{H}_{2} \mathrm{O}_{2}$. Prostatic cancer cell lines (PC-3) were cultured in hypoxic incubator. Using DCFH-DA, ${ }^{1} \mathrm{O}_{2}$ could be detected after incubation with APMECR@MB NC whereas little or no ${ }^{1} \mathrm{O}_{2}$ could be detected after incubation with free MB or APME@MB without catalase. Pork tissues of various thickness were used and placed between the excitation source $\left(808 \mathrm{~nm}, 1000 \mathrm{~mW} \cdot \mathrm{cm}^{-2}\right.$ for $\left.5 \mathrm{~min}\right)$ and the PC- 3 cells. The authors proved that there was a synergistic PTT/PDT of PC-3 cells with the use of APMECR@MB.

$\mathrm{Hu}$ et al. [105] used a zeolite with mesoporous structure $(531 \mathrm{~nm})$ as a nanocarrier to immobilize catalase and MB (ZCM NPs). The catalase loaded in the zeolite was still efficient and kept $90 \%$ of enzymatic activity compared to free catalase. As expected, in closed tubes, it was possible to detect $\mathrm{O}_{2}$ formation in the presence of ZCM NPs and $\mathrm{H}_{2} \mathrm{O}_{2}$. In vitro detection of ${ }^{1} \mathrm{O}_{2}$ with SOSG revealed that the ${ }^{1} \mathrm{O}_{2}$ formation was 3.7 higher for the $\mathrm{ZCM}$ treated group than the group's zeolite or zeolite-MB. Formation of $\mathrm{O}_{2}$ upon decomposition of in situ $\mathrm{H}_{2} \mathrm{O}_{2}$ thanks to the presence of the NPs was 4.8-fold higher than without NPs and allowed the release of MB. The PDT experiments were performed on athymic nude mice with SW1990 with laser at $635 \mathrm{~nm}, 50 \mathrm{~mW} \cdot \mathrm{cm}^{-2}$ for $10 \mathrm{~min}$. They could observe a total inhibition of tumour growth at 18 days, which was not possible under other conditions (control, light only, ZCM only) (Figure 19). 


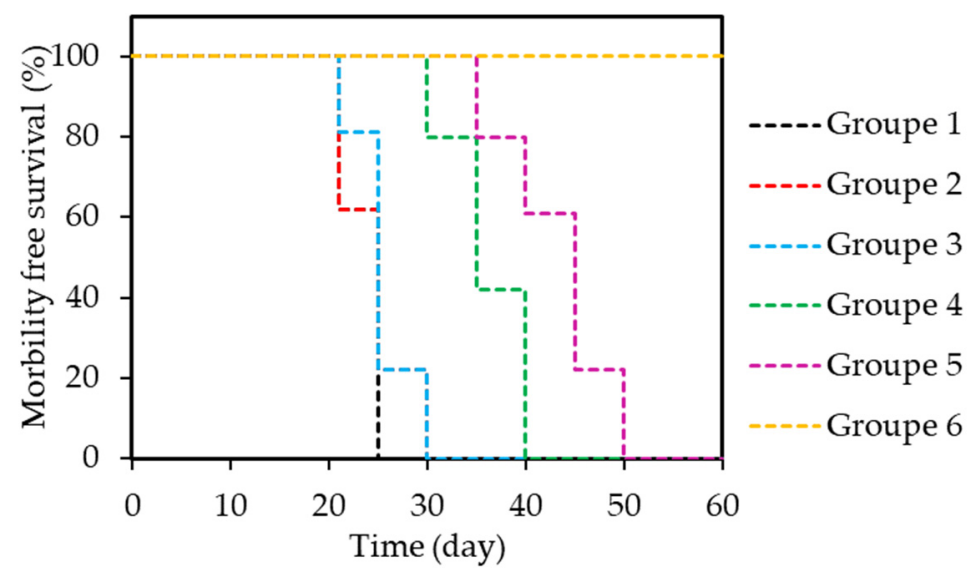

Figure 19. In vivo PDT in xenograft mice models with SW1990 PC. Survival rates of mice bearing SW1990 tumours after different treatments. $\left({ }^{*}\right) p<0.05,\left({ }^{* *}\right) p<0.01$. Group 1-PBS, Group 2-laser, Group 3-ZCM nanocapsule, Group 4-free MBlaser, Group 5-zeolite-MB-laser, and Group 6-ZCM nanocapsule-laser ( $n=5$ per group). Adapted from $\mathrm{Hu}$ et al. [105].

Cheng et al. [106] described catalase incorporated into a nanoscale metal-organic framework (NMOF) composed of a cancer cell membrane and a cytoskeleton-like porous zeolitic imidazole framework with $\mathrm{AlPcS}_{4}$ (Al(III) phthalocyanine chloride tetrasulfonic acid) (10.6\%). The core-shell structure had size of about $110 \mathrm{~nm}$ and an outer lipid bilayer shell of $7.2 \mathrm{~nm}$. After irradiation at $660 \mathrm{~nm}\left(30 \mathrm{~mW} \cdot \mathrm{cm}^{-2}, 1 \mathrm{~min}\right)$ of HeLa cells in presence of CAT-PS-ZIF@Mem, 75.6\% of the cells died whereas only $12.28 \%$ died when exposed to PS-ZIF@Mem without catalase. BALB/c-nu mice with HeLa cells were used as tumour model. HIF- $1 \alpha$ staining assay was used to evaluate the tumour hypoxic conditions. As expected the group treated with CAT-PS-ZIF@Mem presented low signal (low hypoxia) whereas the group treated with PS-ZIF@Mem without catalase presented high signal. For PDT experiments $\left(660 \mathrm{~nm}, 220 \mathrm{~mW} \cdot \mathrm{cm}^{-2}, 5 \mathrm{~min}\right)$ the tumour growth was significantly inhibited showing that the CAT-PS-ZIF@Mem NPs have a high phototoxicity and that the formation of $\mathrm{O}_{2}$ thanks to decomposition of $\mathrm{H}_{2} \mathrm{O}_{2}$ improved PDT efficiency.

Combination therapy is also possible. Chen et al. [72] described self-assembly of HSA in which they covalently coupled Ce6 $(2.6 \%)$ and encapsulated catalase and a chemotherapeutic drug the paclitaxel (PTX) (6.5\%). The NPs HSA-Ce6-Cat-PTX showed spherical structure of around $100 \mathrm{~nm}$ of diameter. They proved that HSA-Ce6-Cat-PTX NP produced more $\mathrm{O}_{2}$ in the presence of $\mathrm{H}_{2} \mathrm{O}_{2}$ than HSA-Ce6-Cat may be due to some loss of activity of the catalase in HSA-Ce6-Cat. In HSA-Ce6-Cat-PTX NPs, the entrapped catalase maintained around $70 \%$ of its initial enzymatic activity. Moreover, the generation of ${ }^{1} \mathrm{O}_{2}$ by HSA-Ce6-Cat-PTX detected with SOSG was higher in the presence of $\mathrm{H}_{2} \mathrm{O}_{2}$ due to the additional $\mathrm{O}_{2}$ supply. In vitro experiments were performed in $4 \mathrm{~T} 1$ cells with $660 \mathrm{~nm}$ light $\left(5 \mathrm{~mW} \cdot \mathrm{cm}^{-2}, 30 \mathrm{~min}\right)$. Compared with PDT alone, chemotherapy alone or both, the combination treatment under light irradiation proved to be the best. After light illumination, the release of PTX into the cytoplasm improved the PDT effect. Under nitrogen atmosphere and addition of HSA-Ce-cat was not able to induce PDT effect whereas HSA-Ce6-Cat-PTX had a very good cancer cell killing efficiency. Female nude mice bearing 4T1 tumours were used for in vivo tests. To check the hypoxia into the tumour, (HIF)- $1 \alpha$ and pimonidazole were used. Both HSA-Ce6-Cat-PTX and HSA-Ce6-Cat showed significant decreased hypoxia signals compared to the control. After PDT $\left(660 \mathrm{~nm}, 5 \mathrm{~mW} \cdot \mathrm{cm}^{-2}, 60 \mathrm{~min}\right)$ the most effective tumour growth inhibition was observed for mice treated with HSA-Ce6-Cat-PTX compared to PDT alone or chemotherapy alone. To sum up, HSA-Ce6-Cat-PTX NPs accumulated into the tumour then decomposed, PTX was released, catalase decomposed endogenous $\mathrm{H}_{2} \mathrm{O}_{2}$ to produce $\mathrm{O}_{2}$, PDT induced the disruption of lysosomes and the PTX distributed into cytoplasm.

Yang et al. [107] also designed a very smart multifunctional NPs in which they encapsulated catalase in hollow silica NPs, with covalently coupled Ce6, covalently coupled CTPP 
(3-carboxypropyl)triphenylphosphonium bromide) to target mitochondria and modified with an acidic $\mathrm{pH}$ responsive charge-convertible DPEG polymer (in acidic conditions, the DPEG polymer had positives charges that enhance tumour cell internalization) and programmed death-ligand 1 (PD-L1) antibody to promote the infiltration of T lymphocytes in metastasis. The obtained CAT@S/Ce6-CTPP/DPEG had a size of around $100 \mathrm{~nm}$ with a shell thickness of $12 \mathrm{~nm}$. Comparing $\mathrm{O}_{2}$ formation in solution in the presence of $\mathrm{H}_{2} \mathrm{O}_{2}$, they could observe a rapid $\mathrm{O}_{2}$ formation for CAT@S/Ce6-CTPP/DPEG compared to the control BSA@S/Ce6-CTPP/DPEG.CAT@S/Ce6-CTPP/DPEG kept 70\% of its initial activity compared to free catalase in the presence of protease. Thanks to SOSG, they also observed the increase in ${ }^{1} \mathrm{O}_{2}$ formation in solution with CAT@S/Ce6-CTPP/DPEG excited at $660 \mathrm{~nm}$ in the presence of $\mathrm{H}_{2} \mathrm{O}_{2}$ compared to the absence of $\mathrm{H}_{2} \mathrm{O}_{2}$. $4 \mathrm{~T} 1$ cells were used for in vitro tests $\left(660 \mathrm{~nm}, 5 \mathrm{~mW} \cdot \mathrm{cm}^{-2}, 60 \mathrm{~min}\right)$. The cell killing efficiency was higher after incubation with CAT@S/Ce6-CTPP/DPEG compared to BSA@S/Ce6-CTPP/DPEG. Confocal microscopy imaging revealed a specific intracellular targeting of mitochondria. Oxygenation level was increased with CAT@S/Ce6-CTPP/DPEG compared to the control and the use of pimonidazole proved the decrease of hypoxia. PDT efficiency was also the best for CAT@S/Ce6-CTPP/DPEG $\left(660 \mathrm{~nm}, 5 \mathrm{~mW} . \mathrm{cm}^{-2}, 60 \mathrm{~min}\right)$. Very interestingly, thanks to the programmed death-ligand 1 (PD-L1) antibody, they showed that PDT plus anti-PD-L1 treatment was able to stop the progression of tumours that were not irradiated (1-2 cm away).

Shen et al. [108] synthesized pH-responsive aerobic NPs made of interaction of negatively charged catalase with positively charged chitosan. The resulting micelles $(C \& C)$ were used to encapsulate Ce6 and the size of the C\&C-Ce 6 was $68.5 \mathrm{~nm}$. In acidic environment, the disassembly of the NP led to the release of Ce6 $(75 \%$ after $80 \mathrm{~h})$ as well as the release of catalase. They showed that the formation of ${ }^{1} \mathrm{O}_{2}$ after addition of $\mathrm{H}_{2} \mathrm{O}_{2}$ was higher in acidic media due to the release of both $\mathrm{Ce} 6$ and catalase in contact of $\mathrm{H}_{2} \mathrm{O}_{2}$. In vitro phototoxicity was evaluated in squamous cell carcinoma CAL-27 $(650 \mathrm{~nm}$, $\left.100 \mathrm{~mW} \cdot \mathrm{cm}^{-2}, 10 \mathrm{~min}\right)$. IC 50 was found to be $15.33 \mathrm{mg} \cdot \mathrm{mL}^{-1}$ for free Ce6 and $12.02 \mathrm{mg} \cdot \mathrm{mL}^{-1}$ for catalase + Ce6 mixture and only $4.03 \mathrm{mg} \cdot \mathrm{mL}^{-1}$ for C\&C-Ce6. The percentage of apoptotic cell after PDT treatment for PBS, Ce6, chitosan + Ce6, catalase + Ce6 and C\&C-Ce6 NPs were respectively $9.38 \%, 78.57 \%, 76.7 \%, 86.09 \%$ and $94.31 \%$ showing the important role of catalase that induced higher formation of ${ }^{1} \mathrm{O}_{2}$. Female BALB/c mice bearing CAL-27 tumour $\left(650 \mathrm{~nm}, 100 \mathrm{~mW} \cdot \mathrm{cm}^{-2}, 10 \mathrm{~min}\right)$ were chosen for in vivo experiments. After 14 days after the treatment, the tumour volumes for PBS, Ce6, chitosan + Ce6, catalase + Ce6 and C\&C-Ce6 NPs were respectively $1.87 \pm 0.14 \mathrm{~cm}^{3}, 1.04 \pm 0.09 \mathrm{~cm}^{3}$, $0.99 \pm 0.15 \mathrm{~cm}^{3}, 0.96 \pm 0.12 \mathrm{~cm}^{3}$ and $0.52 \pm 0.11 \mathrm{~cm}^{3}$, in good agreement with in vitro results. The lowest amount of hypoxia-inducible factor HIF- $1 \alpha$ was found as expected for the C\&C-Ce6 NPs treated mice.

Zhao et al. [109] described graphitic-phase mesoporous carbon nitride nanosheet $\left(m p g-C_{3} N_{4}\right.$, $\mathrm{MCNs}$ ) in which hematoporphyrin monomethyl ether (HMME) and catalase were wrapped into the $5 \mathrm{~nm}$ pores. HA was covalently coupled to the nanosheet. They checked that catalase still kept its activity when it was encapsulated. The best HMME loading was obtained with a feed rate HMME/MCNs of 3/1. A strong incorporation of HA@mgp- $\mathrm{C}_{3} \mathrm{~N}_{4}$-HMME/CAT into murine melanoma B16-F10 cell lines could be observed by confocal microscopy and the apoptosis rate was higher than all the others conditions ((HA@mgp- $\mathrm{C}_{3} \mathrm{~N}_{4}+\mathrm{LED}$, HMME, HA@mgp- $\mathrm{C}_{3} \mathrm{~N}_{4}$-HMME, HA@mgp- $\mathrm{C}_{3} \mathrm{~N}_{4}$-HMME/CAT) after light illumination (LED, $3000 \mathrm{~mW} \cdot \mathrm{cm}^{-2}$ for $2 \mathrm{~min}$ ). In female $\mathrm{C} 57$ mice, the in vivo results were in good agreement with the in vitro ones, the authors could detect enhanced inhibition of tumour growth after injection (i.v.) of $\mathrm{HA} @ m g p-\mathrm{C}_{3} \mathrm{~N}_{4}$-HMME/CAT, and light illumination compared to all the others groups. Using pimonidazole, reduced hypoxia could be detected in tumours from mice injected with HA@mgp- $\mathrm{C}_{3} \mathrm{~N}_{4}$-HMME/CAT thanks to the formation of $\mathrm{O}_{2}$ through the decomposition of $\mathrm{H}_{2} \mathrm{O}_{2}$ compared to mice injected with HA@mgp- $\mathrm{C}_{3} \mathrm{~N}_{4}$-HMME and irradiated.

Another idea is to target proinflammatory-activated macrophages that are involved in chronic inflammation and also known to generate $\mathrm{H}_{2} \mathrm{O}_{2}$ to destroy undesirable invaders [110]. Lu et al. [111] developed selenium NPs (SeNPs) coated with a first layer of chitosan(CS)-RB-GSH, a thiolate catalase (CAT) covalently coupled to this first layer and a second layer of HA-ethylene diamine(EDA)-folic acid(FA). HA and FA were respectively CD44 and FR-b targeting agent over-expressed on cell surfaces 
of activated macrophages. The size of the NPs was $148.4 \pm 7.2 \mathrm{~nm} .{ }^{1} \mathrm{O}_{2}$ detection was performed by electronic paramagnetic resonance (EPR) and using 9,10-diphenylanthracene (DPA) and was more important in the presence of $\mathrm{H}_{2} \mathrm{O}_{2}$. The NPs presented high specificity for activated macrophages compared to normal macrophage. In RAW 264.7 (mouse macrophages) and under light illumination (green LED array, $\left.40 \mathrm{~mW} \cdot \mathrm{cm}^{-2}, 10 \mathrm{~min}\right)$ a decrease of cell viability could be observed $(43.3 \%$ cell viability) with SeNPs and $32.8 \%$ with CAT/SeNPs. Using CAT/SeNPs led to $\mathrm{H}_{2} \mathrm{O}_{2}$ depletion and inhibition of activation and proliferation of macrophages.

Ouyang et al. [112] proposed the use of thylakoid membrane which was able to catalycally decompose $\mathrm{H}_{2} \mathrm{O}_{2}$ to produce $\mathrm{O}_{2}$ thanks to its membrane-related catalase [113]. With mechanical grinding, chloroplasts were extracted from spinach leaves. They underwent hypotonic lysis to release thylakoids. After extrusion, nanovesicle biomimetic nanothylakoids (NT) were obtained with a membrane thickness of around $9 \mathrm{~nm}$ and a size of around $50 \mathrm{~nm}$. In hypoxic conditions and in the presence of $\mathrm{H}_{2} \mathrm{O}_{2}$ the dissolved $\mathrm{O}_{2}$ concentration increased in solution and $\mathrm{H}_{2} \mathrm{O}_{2}$ was catalytically decomposed. Using SOSG, after $660 \mathrm{~nm}$ light excitation $\left(1 \mathrm{~W} \cdot \mathrm{cm}^{-2}, 5 \mathrm{~min}\right), 7.8 \mathrm{more}^{1} \mathrm{O}_{2}$ was produced within $5 \mathrm{~min}$. NP without catalase (LP) was synthesized as a control. In hypoxic environment, NPs produced larger amount of ${ }^{1} \mathrm{O}_{2}$ than LP. In $4 \mathrm{~T} 1$ cancer cells, $\left[\mathrm{Ru}(\mathrm{dpp})_{3}\right] \mathrm{Cl}_{2}$ quenched fluorescence in hypoxic environment proved the formation of $\mathrm{O}_{2}$ and SOSG the formation of ${ }^{1} \mathrm{O}_{2}$. In vivo studies on tumour-bearing mice injected with NT or LP were performed. The expression of HIF1-a decreased after NT treatment which was not the case with LP injection, suggesting that tumour hypoxia disappeared after NT treatment. After PDT $\left(660 \mathrm{~nm}, 1 \mathrm{~W} \cdot \mathrm{cm}^{-2}, 10 \mathrm{~min}\right)$ the tumour growth was totally inhibited after injection of NT whereas with LPs, the tumour growth was only delayed within the first 4 days and even recurred later.

An original strategy was developed by Wang et al. [114]. Catalase could lose a part of its activity when encapsulated into NPs. In this paper, they used the acrylate onto the surface of the protein to enable free radical polymerization of a small PEG as the drafting moiety and Meso-tetra( $p$-hydroxyphenyl)porphine (THPP) as a cross linker. The CAT-THPP-PEG nanocapsules showed spherical morphology with a size of around $25 \mathrm{~nm}$ and $30 \mathrm{~nm}$ by DLS (Figure 20).

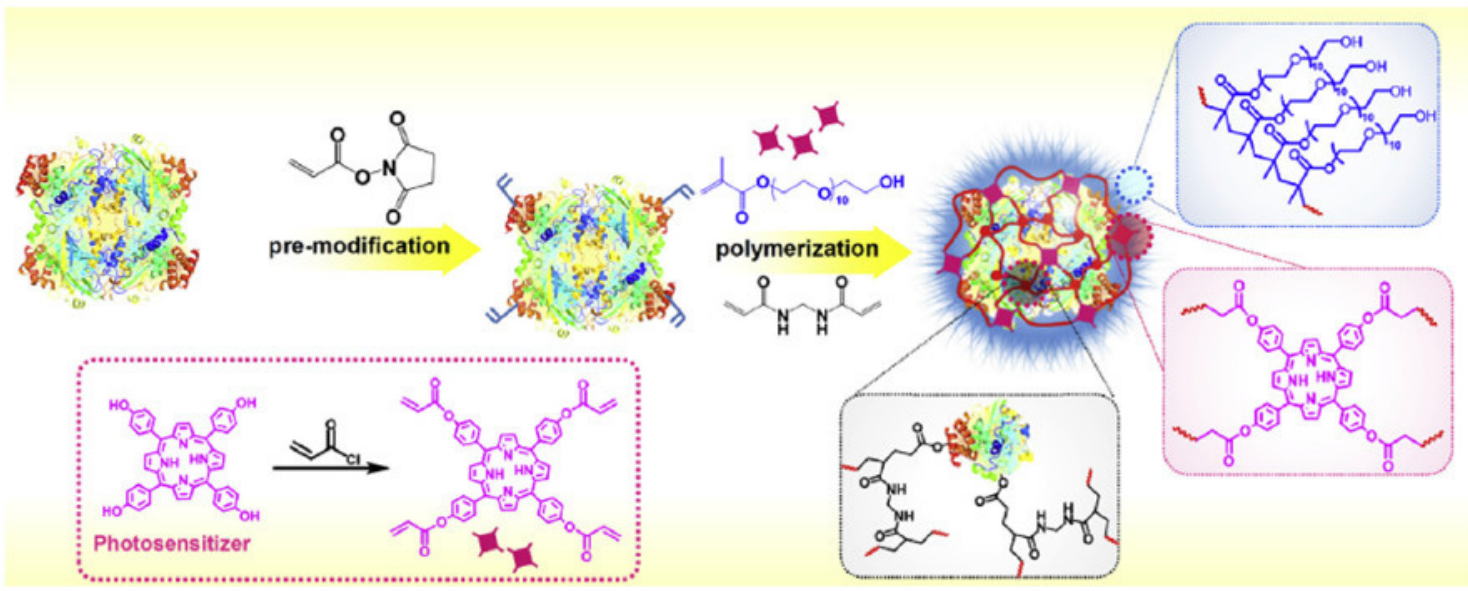

Figure 20. Schematic illustration of the preparation and structure of CAT-THPP-PEG. Hydrodynamic diameters of catalase, BSA-THPP-PEG and CAT-THPP-PEG in water, PBS and FBS. Reprinted [114] with permission from Elsevier Ltd, Copyright 2018.

Using SOSG, after light illumination $\left(660 \mathrm{~nm}, 5 \mathrm{~mW} \cdot \mathrm{cm}^{-2}, 30 \mathrm{~min}\right)$ they could detect in solution a high production of ${ }^{1} \mathrm{O}_{2}$ in the presence of $\mathrm{H}_{2} \mathrm{O}_{2}$ both in normoxic and hypoxic media due to the formation of extra $\mathrm{O}_{2}$. In vitro experiments in $4 \mathrm{~T} 1$ cells were performed $\left(660 \mathrm{~nm}, 5 \mathrm{~mW} \cdot \mathrm{cm}^{-2}, 30 \mathrm{~min}\right)$. As expected, cell killing increased under hypoxic conditions in presence of CAT-THPP-PEG and not in presence of the control BAS-THPP-PEG. Antipimonidazole antibody was used to detect hypoxia zones on tumour slices and revealed a large decrease of tumour hypoxia after CAT-THPP-PEG treatment 
compared to BSA-THPP-PEG treatment. In vivo studies in BALB/c mice bearing $4 \mathrm{~T} 1$ tumours $(660 \mathrm{~nm}$, $5 \mathrm{~mW} \cdot \mathrm{cm}^{-2}, 60 \mathrm{~min}$ ) confirmed the in vitro studies with a large inhibitory effect of the tumour growth after CAT-THPP-PEG injection.

Another strategy is not to use natural enzyme but nanomaterial-based artificial enzyme. They are called nanozyms. The advantage is that the requirement of enzyme encapsulation is not needed neither the controllable release.

In 2017 Liu et al. [115] developed peroxidase amine-terminated PAPAM dendrimer-encapsulated gold NP with catalase like activity (AuNCs-NH$)$ and coupled to Protoporphyrin IX (PpIX). They proved that the AuNCs- $\mathrm{NH}_{2}$ NPs possessed catalase-like activity at $\mathrm{pH}$ 4.8-7.4 that could allow $\mathrm{H}_{2} \mathrm{O}_{2}$ consumption to form $\mathrm{O}_{2}$ in cytoplasm $(\mathrm{pH}=7.4)$, endosomes $(\mathrm{pH}=5.5)$ or lysosomes $(\mathrm{pH}=$ 4) Evidence of $\mathrm{O}_{2}$ formation was obtained in lung cancer $\mathrm{H} 460$ cells. PDT efficiency (532 nm, $200 \mathrm{~mW} \cdot \mathrm{cm}^{-2}, 5 \mathrm{~J}$ per well) in hypoxic and normoxic conditions with AuNCs- $\mathrm{NH}_{2}$ and PPIX showed that AuNCs- $\mathrm{NH}_{2}$ overcome cancer cell hypoxia and induced a better PDT efficacy.

Yang et al. [116] in 2018 described a new kind of catalase-mimeting DNAzyme function NP with AN1411 DNA G-quadruplex/hemin (iron-containing porphyrin)-Ce6 coordinated to calcium ions and surrounding by poly(L-histidine)polyethylene glycol. AS1411/Ce6 (AC) and AS1411/hemin (AH) complexes had a size of $10 \mathrm{~nm}$. Thanks to $\mathrm{Ca}^{2+}$ coordination, and poly(L-histidine)- polyethylene glycol (pHis-PEG) as stabilizing agent, the CACH-PEG NP was elaborated with a size of $70 \mathrm{~nm}$. CACH and CACH-PEG NP were more efficient in producing ${ }^{1} \mathrm{O}_{2}$ in the presence of $\mathrm{H}_{2} \mathrm{O}_{2}$ under $660 \mathrm{~nm}$ light irradiation than free Ce6. At acidic $\mathrm{pH}$ (5.5), the hydrodynamic size of CACH-PEG NP decreased to $12 \mathrm{~nm}$ showing the formation of smaller G-quadruplex. In 4T1 cells, the CACH-PEG NP internalized via endocytosis and Ce6 localized in the nuclei. PDT treatment $\left(660 \mathrm{~nm}, 5 \mathrm{~mW} \cdot \mathrm{cm}^{-2}, 30 \mathrm{~min}\right)$ with or without $\mathrm{H}_{2} \mathrm{O}_{2}$ was conducted and as expected, the level of ${ }^{1} \mathrm{O}_{2}$ produced was higher in the presence of $\mathrm{H}_{2} \mathrm{O}_{2}$. In BALB/c mice bearing $4 \mathrm{~T} 1$ tumours, ${ }^{99 \mathrm{~m}}$ Tc CACH-PEG NPs showed tumour retention $(5.4 \%$ of injected dose per gram of tissue $(\% \mathrm{ID} / \mathrm{g}))$. Using pimonidazole proved that hypoxia was reduced in the mice that have been injected with PEG CACH-PEG NPs. After PDT $\left(660 \mathrm{~nm}, 5 \mathrm{~mW} \cdot \mathrm{cm}^{-2}, 60 \mathrm{~min}\right)$ the best inhibition of tumour growth was observed for mice treated with CACH-PEG NP.

Ruan et al. [117] synthesized manganese-iron layered double oxide (MnFe-LDH) that possessed catalase-like activity and was loaded with MB. The particle size was about $200 \mathrm{~nm}$ and thickness of $2.8 \mathrm{~nm}$ with 2-3 layers. Under $808 \mathrm{~nm}$ laser with high irradiance $\left(1000 \mathrm{~mW} \cdot \mathrm{cm}^{-2}\right)$ for $10 \mathrm{~min}$, the temperature increased rapidly. In HeLa cells incubated with MnFe-LDH, they detected the formation of $\mathrm{O}_{2}$ by checking the quenched fluorescence of $\left[\mathrm{Ru}(\mathrm{dpp})_{3}\right] \mathrm{Cl}_{2}$. In solution using $\mathrm{DPBF},{ }^{1} \mathrm{O}_{2}$ formation after $650 \mathrm{~nm}$ light excitation of MnFe-LDH/MB could be detected and addition of $\mathrm{H}_{2} \mathrm{O}_{2}$ in the solutions increased ${ }^{1} \mathrm{O}_{2}$ formation. With SOSG in HeLa cells, the same results were obtained. The irradiation of HeLa cells $\left(650 \mathrm{~nm}, 100 \mathrm{~mW} \cdot \mathrm{cm}^{-2}\right.$ for $10 \mathrm{~min}$ ) with free $\mathrm{MB}$ and $\mathrm{MnFe}-\mathrm{LDH} / \mathrm{MB}$ led to respectively $15 \%$ and $40 \%$ of cell death. After irradiation at $808 \mathrm{~nm}, 51 \%$ cell death was observed. After $650 \mathrm{~nm}$ and $808 \mathrm{~nm}$ irradiation, cells treated with MnFe-LDH/MB all died showing the synergistic effect of PTT and PDT. In female Kunming mice with murine cervical cancer cells (U14) $\left(650 \mathrm{~nm}, 100 \mathrm{~mW} \cdot \mathrm{cm}^{-2}\right.$ for $15 \mathrm{~min}$ and $808 \mathrm{~nm} 1000 \mathrm{~mW} \cdot \mathrm{cm}^{-2} 10 \mathrm{~min}$ ) tumour growth inhibition was moderate after PTT or PDT, whereas the dual treatment induced an almost total destruction of the tumour. HIF-1 $\alpha$ was very low.

Two papers utilized Prussian Blue (PB) NPs that are known for their catalase-like activity and were FDA approved for clinical application [118,119]. In the first one, Yang et al. [119] described periodic mesoporous organosilica coated with PB NPs and loaded with Ce6. TESPTS (1,4-bis(triethoxysily)propane tetrasulfide was used as organosilica molecule to coat PB NPs. The hydrodynamic diameter of PB@PMO-Ce6 NPs was about $170 \mathrm{~nm}$. In solution, the mixing of PB@PMO-Ce6 and $\mathrm{H}_{2} \mathrm{O}_{2}$ resulted in the formation of $\mathrm{O}_{2}$ bubbles showing the catalase-like activity of PB@PMO-Ce6 NPs. In U87MG cells, after irradiation at $660 \mathrm{~nm}\left(1000 \mathrm{~mW} \cdot \mathrm{cm}^{-2}, 5 \mathrm{~min}\right)$, total amount of formed ${ }^{1} \mathrm{O}_{2}$ was higher for PB@PMO-Ce6 in the presence of $\mathrm{H}_{2} \mathrm{O}_{2}$ than with PB@PMO-Ce6 alone. PDT in vivo was investigated in U87MG tumour-bearing mice by intratumoural injection of PB@PMO-Ce6 or Ce6 alone and $660 \mathrm{~nm}$ light $\left(1000 \mathrm{~mW} \cdot \mathrm{cm}^{-2}, 2 \mathrm{~min}\right)$. Higher formation of ${ }^{1} \mathrm{O}_{2}$ and apoptotic cells 
were observed after PB@PMO-Ce6 treatment than Ce6 treatment. Tumour growth presented a slower rate after Ce6 treatment and was totally broken after PB@PMO-Ce6 treatment.

The second paper concerns Wang's work [118] who used mesoporous silica to coat PB, coated by PEG and loaded by Zinc phthalocyanine (ZnPc) (Figure 21). The NPs with a PB core and $\mathrm{SiO}_{2}$ shell surrounding by PEG had a hydrodynamic diameter of around $140 \mathrm{~nm}$ (PSP NCs). More than 50\% $\mathrm{H}_{2} \mathrm{O}_{2}$ was degraded in the presence of PSP NCs within $1 \mathrm{~h}$ at $25^{\circ} \mathrm{C}$ with the apparition of $\mathrm{O}_{2}$ bubble and increased at $43{ }^{\circ} \mathrm{C}$. The concentration of $\mathrm{O}_{2}$ formed was 1.95 time higher at $43^{\circ} \mathrm{C}$ than at $25^{\circ} \mathrm{C}$.

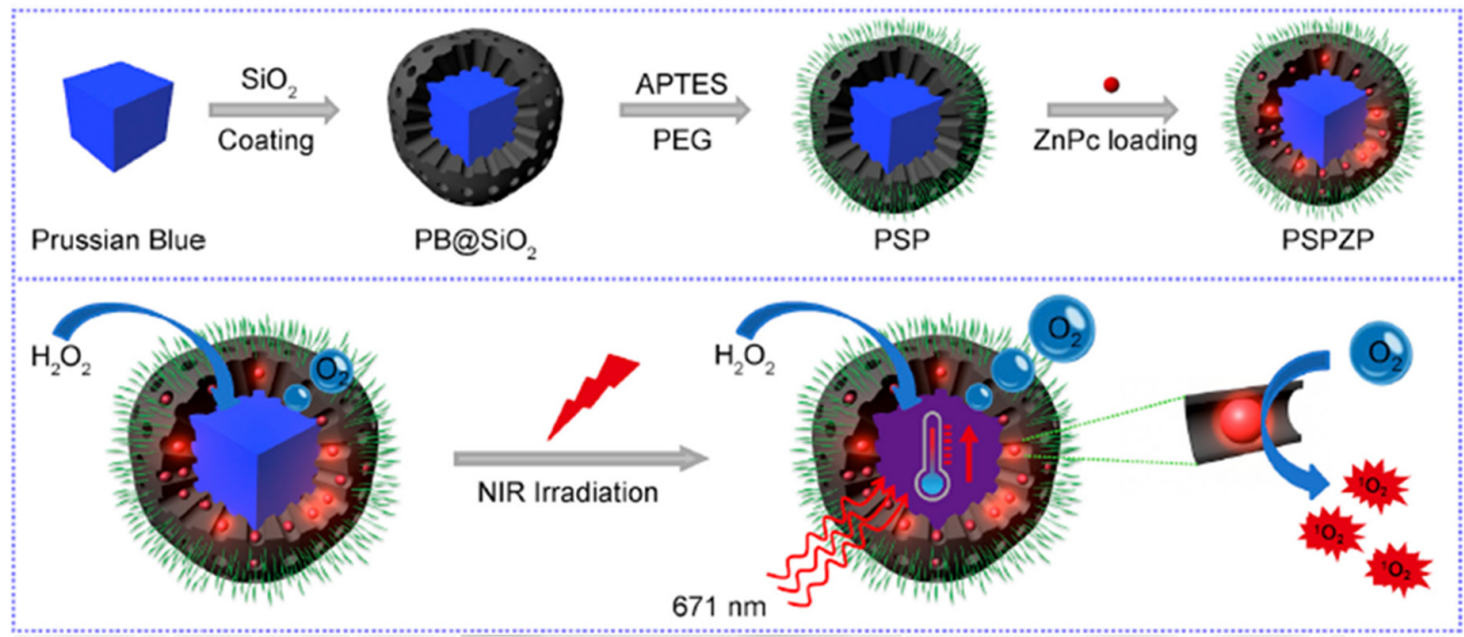

Figure 21. Schematic of the synthetic procedure and photo-enhanced therapy of the PSPZP NCs. Reprinted from [118] with permission from Elsevier Ltd, Copyright 2018.

For each PSP particle, it was possible to load 18,800 ZnPc (PSPZP). Using DPBF in hypoxic condition a significant increase of ${ }^{1} \mathrm{O}_{2}$ formation was observed after addition of $\mathrm{H}_{2} \mathrm{O}_{2}$. $4 \mathrm{~T} 1$ cells were incubated under hypoxia conditions with $\left(\left[\mathrm{Ru}(\mathrm{dpp})_{3}\right] \mathrm{Cl}_{2}\right.$. After being treated with PSP NCs, the decrease of the fluorescence of ([Ru(dpp) 3$] \mathrm{Cl}_{2}$ proved the formation of $\mathrm{O}_{2}$. HeLa, A549 (Human lung cancer cells) and $4 \mathrm{~T} 1$ cells were selected for PDT experiments $\left(671 \mathrm{~nm}, 400 \mathrm{~mW} \cdot \mathrm{cm}^{-2}\right.$ for $\left.5 \mathrm{~min}\right)$. After incubation with PSPZP, the cytotoxicity was higher in normoxic than hypoxic conditions. Addition of $\mathrm{H}_{2} \mathrm{O}_{2}$ in hydroxic condition increased cytotoxicity that was even enhanced at $43{ }^{\circ} \mathrm{C}$. In vivo experiments were performed in $4 \mathrm{~T} 1$ tumour-bearing mice $\left(671 \mathrm{~nm}, 400 \mathrm{~mW} \cdot \mathrm{cm}^{-2}, 5 \mathrm{~min}\right)$ after intravenous injection of PSPZP. The growth of the tumour stopped which was not the case for PSPZP without light, light, $\mathrm{ZnPc}+$ light, PSP + light. The reduced pimonidazole fluorescence in tumour slices extracted from mice treated with PSPZP showed that the tumour hypoxia disappeared. The drawbacks were the low accumulation and the lack of targeting unit.

Two papers have described the use of Fe(III) for its catalase like-activity. Ma et al. showed that $\mathrm{Fe}(\mathrm{III})$ could have catalase-like activity and could decompose $\mathrm{H}_{2} \mathrm{O}_{2}$ to create $\mathrm{O}_{2}$ [120]. They elaborated $\mathrm{Fe}(\mathrm{III})$ doped Graphitic-phase $\mathrm{C}_{3} \mathrm{~N}_{4}$ nanosheet covalently coupled to a mitochondria- targeting moiety-(4-carboxybutyl)triphenylphosphonium bromide (TPP)—and loaded with MB on the surface. The $\mathrm{C}_{3} \mathrm{~N}_{4}$-Fe-TPP NF/MB NPs in water had a size of $110 \mathrm{~nm}$ that moved to $116 \mathrm{~nm}$ after 5 days. Fluorescence of $\left[\mathrm{Ru}(\mathrm{dpp})_{3}\right] \mathrm{Cl}_{2}$ after addition of $\mathrm{H}_{2} \mathrm{O}_{2}$ to $\mathrm{C}_{3} \mathrm{~N}_{4}$-Fe-TPP NF/MB NPs solution suggested an increase of local $\mathrm{O}_{2}$ concentration. With $\mathrm{DPBF}$, formation of ${ }^{1} \mathrm{O}_{2}$ was proven under $650 \mathrm{~nm}$ light illumination $\left(100 \mathrm{~mW} \cdot \mathrm{cm}^{-2}\right)$ and in vivo in HeLa cells $\left(650 \mathrm{~nm}, 100 \mathrm{~mW} \cdot \mathrm{cm}^{-2}, 15 \mathrm{~min}\right)$ with DCHF-DA. PDT experiments in vitro in HeLa cells showed a slight decrease of cell viability with free MB and $\mathrm{C}_{3} \mathrm{~N}_{4}$-NS/MB NPs without Fe(III) whereas a strong decrease of cell viability was observed after incubation with $\mathrm{C}_{3} \mathrm{~N}_{4}$-Fe NF/MB NPs and $\mathrm{C}_{3} \mathrm{~N}_{4}$-Fe-TPP NF/MB NPs. The in vivo efficiency was determined in U14 cervical cancer in Kunming mice $\left(650 \mathrm{~nm}, 100 \mathrm{~mW} \cdot \mathrm{cm}^{-2}\right.$, 15 min each day, 2 days interval). $\mathrm{C}_{3} \mathrm{~N}_{4}$-Fe-TPP NF/MB NPs proved to be very efficient and led to almost complete elimination 
of the tumour with no regrowth during the 15 days of the experiment. HIF- $1 \alpha$ indicated a higher $\mathrm{O}_{2}$ concentration in the group treated with $\mathrm{C}_{3} \mathrm{~N}_{4}-\mathrm{Fe} \mathrm{NF} / \mathrm{MB}$ and $\mathrm{C}_{3} \mathrm{~N}_{4}$-Fe-TPP NF/MB NPs.

Few months later, Zhen et al. [121] also used the catalase-like activity of Fe(III) and developed BSA that coordinated with $\mathrm{Fe}^{3+}$ through different active groups such as carboxyl, thiol amino. MB was then added and loaded in BSA through amide bond and/or hydrophobic interaction. The monodispersed MB-BSA-Fe(III)NP had a hydrodynamic size of $28.21 \mathrm{~nm}$. In solution, the production of $\mathrm{O}_{2}$ was measured in the presence of MB-BSA-Fe(III)NP and $\mathrm{H}_{2} \mathrm{O}_{2}$ suggesting that MB-BSA-Fe(III) possessed catalase-like activity. In solution under light illumination $\left(650 \mathrm{~nm}, 100 \mathrm{~mW} \cdot \mathrm{cm}^{-2} 10 \mathrm{~min}\right)$ the absorbance of DPBF (proportional to ${ }^{1} \mathrm{O}_{2}$ formation) decreased to $79 \%$ with $\mathrm{H}_{2} \mathrm{O}_{2}$ and only $60 \%$ without $\mathrm{H}_{2} \mathrm{O}_{2}$. In HeLa cells, the fluorescence of $\mathrm{Ru}(\mathrm{dpp})_{3} \mathrm{JCl}_{2}$ disappeared after $24 \mathrm{~h}$ in cells treated with MB-BSA-Fe(III)NP suggesting that NPs could overcome the hypoxia. After PDT $(650 \mathrm{~nm}$, $100 \mathrm{~mW} \cdot \mathrm{cm}^{-2}, 15 \mathrm{~min}$ ) viability was $83.3 \%$ after MB incorporation whereas a high decrease of $33.7 \%$ was observed with MB-BSA-Fe(III)NP.

Metal-organic frameworks (MOFs) are self-assembled molecules that have nanometric size and present excellent properties such as high surface-to-volume ratio, large pore size and pore windows. Two papers in 2018 used MOFs. Hu et al. [122] used iron(III) carboxylate MOF (MIL-100 (Fe); MIL stands for Materials Institutes Lavoisier) as a carrier for three kinds of PS: Ce6, 2-((4'-(2,2-bis(4-methoxy- phenyl)-1-phenylvinyl)-1,1'-biphenyl-4-yl)(phenyl)methylene)malonitrile (TPEDC) and (E)-2-(4-(4-(2,2-bis(4-methoxyphenyl)-1-phenylvinyl)styryl)-3-cyano-5,5-dimethyl- furan2(5H)-ylidene)malonitrile (TPETCF). To improve the water dispersibility, they coated the NPs with a nonionic amphiphilic block copolymer F127. The average hydrodynamic size was $140 \mathrm{~nm}$ (size distribution 90-400 nm). In solution and in the presence of $\mathrm{H}_{2} \mathrm{O}_{2}$, a catalytic reaction occurred thanks to $\mathrm{Fe}(\mathrm{III})$ leading to the release of free $\mathrm{Fe}(\mathrm{III})$ that will decomposed rapidly $\mathrm{H}_{2} \mathrm{O}_{2}$ to produce $\mathrm{O}_{2}$. 9,10-Diphenylanthracenediyl-bis(methylene) dimalonic acid (ABDA) was used to prove that PSs did not produce ${ }^{1} \mathrm{O}_{2}$ when trapped into the MOF, but were still able to produce ${ }^{1} \mathrm{O}_{2}$ when they escaped. F127-TPETCF@MIL-100 was chosen to study the activatable PDT effect in vitro on 4T1 cells. By confocal microscopy with DCHF-DA in the presence of $\mathrm{H}_{2} \mathrm{O}_{2}$ the photosensitization capability of F127-TPETCF@MIL-100 was demonstrated. After light excitation (white light excitation, $50 \mathrm{~mW} \cdot \mathrm{cm}^{-2}$, $5 \mathrm{~min}$ ) in the presence of $\mathrm{H}_{2} \mathrm{O}_{2}$ cell death was observed, which was not the case without $\mathrm{H}_{2} \mathrm{O}_{2}$. If TPETCF could induce nonspecifically apoptosis in both normal and tumour cells, F127-TPETCF@MIL-100 specifically induced cell death in the tumour. In vivo experiments in subcutaneous 4T1 tumour-bearing mice both TPETCF and F127-TPETCF@MIL-100 injected into the tumour could inhibit tumour growth after light illumination $\left(50 \mathrm{~mW} \cdot \mathrm{cm}^{-2}, 10 \mathrm{~min}\right.$ ) but the tumour treated with F127-TPETCF@MIL-100 had a slower growing rate. The hydroxyprobe- 1 kit was used to show that the hypoxia was weaker in the tumour treated with F127-TPETCF@MIL-100. After intravenous injection, F127-TPETCF@MIL-100 localized mainly in liver and tumour and could still inhibit the tumour growth.

The same year, Lan et al. [123] proposed also a nanoscale MOF elaborated from $\mathrm{Fe}_{3} \mathrm{O}$ clusters and 5,10,15,20-tetra(p-benzoato)porphyrin (TBP). The Fe-TBP had a length of $100 \mathrm{~nm}$ and was able to catalyze the decomposition of $\mathrm{H}_{2} \mathrm{O}_{2}$ to produce $\mathrm{O}_{2}$. Incubation in CT26 cells under low $\mathrm{O}_{2}$ conditions led to the accumulation of HIF- $1 \alpha$, but when heated with Fe-TBP, the signal decreased significantly showing the decrease of hypoxia thanks to the production of $\mathrm{O}_{2}$. After irradiation $\left(650 \mathrm{~nm}, 20 \mathrm{~mW} \cdot \mathrm{cm}^{-2}\right.$, $15 \mathrm{~min}$ ) under hypoxic conditions and using SOSG in solution, they proved that after addition of $\mathrm{H}_{2} \mathrm{O}_{2} \mathrm{Fe}-\mathrm{TBP}$ was able to produce ${ }^{1} \mathrm{O}_{2}$ similar than the production in normoxic conditions whereas the control $\mathrm{H}_{4}$ TBP or Hf-TBP without $\mathrm{Fe}(\mathrm{III})$ generated only traces of ${ }^{1} \mathrm{O}_{2} . \mathrm{IC}_{50}$ in normoxic conditions were $2.60 \pm 1.59,11.33 \pm 6.75,25.13 \pm 6.83 \mathrm{mM}$ for Fe-TBP, Hf-TBP and $\mathrm{H}_{4} \mathrm{TBP}$. In hypoxic conditions, Fe-TBP presented an $\mathrm{IC}_{50}$ of $3.10 \pm 1.66$ whereas $\mathrm{H}_{4} \mathrm{TBP}$ or $\mathrm{Hf}-\mathrm{TBP}$ were totally ineffective $\left(\mathrm{IC}_{50}\right.$ superior to $50 \mathrm{mM}$ ). In vivo experiments were performed in mouse model of CT26 colorectal adenocarcinoma $\left(650 \mathrm{~nm}, 100 \mathrm{~mW} \cdot \mathrm{cm}^{-2}, 7.5 \mathrm{~min}\right)$ and PDT was effective in both normoxic and hypoxic conditions. Interestingly, they studied the effect of PDT in immunotherapy. A bilateral model of CT26 tumours was built. 
One of the tumours was treated with Fe-TBP and illuminated and the other tumour did not receive any treatment. Then an $\alpha$-PD-L1 treatment was performed. Both tumours decreased (more than 90\%) with a very low dose of Fe-TBP $\left(0.2 \mathrm{mM}\right.$ and $\left.45 \mathrm{~J} \cdot \mathrm{cm}^{-2}\right)$. They also demonstrated that PDT together with $\alpha$-PD-L1 treatment induced formation of cytotoxic T cells that could infiltrate in distant tumour.

A very sophisticated system has been developed by Liu et al. [124]. They designed black phosphorus nanosheeta (BPNSa) on which they coupled FA by non-covalent interaction to target FA receptor as well as a DNA duplex made of Cy5-aptamer-heme (H1) and 3'-heme-labelled oligo-nucleotide (H2) (Cy5-dHeme-BPNS-FA). The idea was that after endocytosis the strong affinity between intracellular ATP and the aptamer would induce the release of $\mathrm{H} 1$ and $\mathrm{H} 2$ that would be able to concert $\mathrm{H}_{2} \mathrm{O}_{2}$ to $\mathrm{O}_{2}$. In solution in presence of Cy5-dHeme-BPNS-FA and ATP, the fluorescence of $\mathrm{Cy} 5$ increased proving the release of $\mathrm{Cy} 5$ labelled $\mathrm{H} 1$. When $\mathrm{H}_{2} \mathrm{O}_{2}$ was added, the formation of $\mathrm{O}_{2}$ was detected. Using DPBF, Cy5-dHeme-BPNS-FA produced ${ }^{1} \mathrm{O}_{2}$ mainly due to BPNS. In normal air atmosphere, ${ }^{1} \mathrm{O}_{2}$ formation of Cy5-dHeme-BPNS-Fa in presence of ATP was $44.6 \%$ higher than without ATP. Under hypoxic conditions, after $20 \mathrm{~min}$ irradiation $\left(660 \mathrm{~nm}, 150 \mathrm{~mW} \cdot \mathrm{cm}^{-2}\right)$ in vitro, ${ }^{1} \mathrm{O}_{2}$ formation was even 16.0- and 6.8-fold higher with and without ATP. In HeLa cells, $\left[\mathrm{Ru}(\mathrm{dpp})_{3}\right] \mathrm{Cl}_{2}$ was used to show that activated heme was essential in $\mathrm{O}_{2}$ formation in hydroxic and normoxic HeLa cells. Thanks to SOSG, it was also possible to demonstrate in vitro production of ${ }^{1} \mathrm{O}_{2}$. Cell death after PDT $\left(660 \mathrm{~nm}, 150 \mathrm{~mW} \cdot \mathrm{cm}^{-2}, 3 \mathrm{~min}\right)$ in normoxic conditions treated with Cy5-BPNS-FA was $35.8 \%$ whereas it was $79.1 \%$ for cells treated with Cy5-dHeme-BPNS-FA due to higher concentration of $\mathrm{O}_{2}$ after decomposition of $\mathrm{H}_{2} \mathrm{O}_{2}$. In vivo in subcutaneous $4 \mathrm{~T} 1$ tumour-bearing female nude mice $\left(660 \mathrm{~nm}, 150 \mathrm{~mW} \cdot \mathrm{cm}^{-2}, 10 \mathrm{~min}\right)$, the tumour volume decreased to $6 \%$ for the group treatment with Cy5-BPNS-FA and 45\% for the group treatment with Cy5-dHeme-BPNS-FA in good agreement with in vitro experiments (Table 7). 
Table 7. Summary of publications about the decomposition of $\mathrm{H}_{2} \mathrm{O}_{2}$ by catalase.

\begin{tabular}{|c|c|c|c|c|c|c|c|c|}
\hline Ref & Application & Catalyst & $\mathrm{O}_{2}$ Source & PS & Energy of Excitation & Type of ROS & In Vitro & In Vivo \\
\hline [103] & PDT & Catalase & $\mathrm{H}_{2} \mathrm{O}_{2}$ & MB & $635 \mathrm{~nm}, 100 \mathrm{~mW} \cdot \mathrm{cm}^{-2}, 5 \mathrm{~min}$ & ${ }^{1} \mathrm{O}_{2}$ & $\begin{array}{l}\text { HaCaT, U87-MG, } \\
\text { MCF-7 and SKOV-3 } \\
\text { cell lines }\end{array}$ & $\begin{array}{l}\text { U87-MG tumour bearing } \\
\text { mice }\end{array}$ \\
\hline [104] & PDT & Catalase & $\mathrm{H}_{2} \mathrm{O}_{2}$ & MB & $808 \mathrm{~nm}, 1 \mathrm{~W} \cdot \mathrm{cm}^{-2}, 5 \mathrm{~min}$ & ${ }^{1} \mathrm{O}_{2}$ & $\begin{array}{l}\text { PC-3 and bMSCs } \\
\text { cell lines }\end{array}$ & No \\
\hline [105] & PDT & Catalase & $\mathrm{H}_{2} \mathrm{O}_{2}$ & MB & In vivo: $635 \mathrm{~nm}, 50 \mathrm{~mW} \cdot \mathrm{cm}^{-2}, 10 \mathrm{~min}$ & ${ }^{1} \mathrm{O}_{2}$ & $\begin{array}{l}\text { SW1990 and } 293 \mathrm{~T} \\
\text { cell lines }\end{array}$ & $\begin{array}{l}\text { SW1990 tumour-bearing } \\
\text { mice }\end{array}$ \\
\hline [106] & PDT & Catalase & $\mathrm{H}_{2} \mathrm{O}_{2}$ & $\mathrm{AlPcS}_{4}$ & $\begin{array}{l}\text { In vitro: } 660 \mathrm{~nm}, 30 \mathrm{~mW} \cdot \mathrm{cm}^{-2}, 1 \mathrm{~min} \\
\text { In vivo: } 660 \mathrm{~nm}, 220 \mathrm{~mW} \cdot \mathrm{cm}^{-2}, 5 \mathrm{~min}\end{array}$ & ${ }^{1} \mathrm{O}_{2}$ & $\begin{array}{l}\text { HeLa, COS7, SCC-7 } \\
\text { and } 4 \mathrm{~T} 1 \text { cell lines }\end{array}$ & $\begin{array}{l}\text { HeLa tumour-bearing } \\
\text { mice }\end{array}$ \\
\hline$[72]$ & PDT & Catalase & $\mathrm{H}_{2} \mathrm{O}_{2}$ & Ce6 & $\begin{array}{l}\text { In vitro: } 660 \mathrm{~nm}, 5 \mathrm{~mW} \cdot \mathrm{cm}^{-2}, 30 \mathrm{~min} \\
\text { In vivo: } 660 \mathrm{~nm}, 5 \mathrm{~mW} \cdot \mathrm{cm}^{-2}, 60 \mathrm{~min}\end{array}$ & ${ }^{1} \mathrm{O}_{2}$ & $4 \mathrm{~T} 1$ cell line & 4T1 tumour-bearing mice \\
\hline [107] & PDT & Catalase & $\mathrm{H}_{2} \mathrm{O}_{2}$ & Ce6 & $660 \mathrm{~nm}, 5 \mathrm{~mW} \cdot \mathrm{cm}^{-2}, 60 \mathrm{~min}$ & ${ }^{1} \mathrm{O}_{2}$ & $4 \mathrm{~T} 1$ cell line & 4T1 tumour-bearing mice \\
\hline [108] & PDT & Catalase & $\mathrm{H}_{2} \mathrm{O}_{2}$ & Ce6 & $\begin{array}{l}\text { In vitro: } 650 \mathrm{~nm}, 100 \mathrm{~mW} \cdot \mathrm{cm}^{-2}, 10 \mathrm{~min}, \\
25 \mathrm{~J} \cdot \mathrm{cm}^{-2} \\
\text { In vivo: } 650 \mathrm{~nm}, 100 \mathrm{~mW} \cdot \mathrm{cm}^{-2}, 10 \mathrm{~min}\end{array}$ & ${ }^{1} \mathrm{O}_{2}$ & $\begin{array}{l}\text { CAL-27, HeLa, L929 } \\
\text { cell lines }\end{array}$ & $\begin{array}{l}\text { CAL-27 tumour-bearing } \\
\text { mice }\end{array}$ \\
\hline [109] & PDT & Catalase & $\mathrm{H}_{2} \mathrm{O}_{2}$ & HMME & $\mathrm{LED}, 3000 \mathrm{~mW} \cdot \mathrm{cm}^{-2}$ for $2 \mathrm{~min}$ & ${ }^{1} \mathrm{O}_{2}$ & B16-F10 cell line & Female C57 mice \\
\hline [111] & PDT & $\begin{array}{l}\text { Thiolate catalase } \\
\text { (CAT) }\end{array}$ & $\mathrm{H}_{2} \mathrm{O}_{2}$ & $\mathrm{RB}$ & Green LED array, $40 \mathrm{~mW} \cdot \mathrm{cm}^{-2}, 10 \mathrm{~min}$ & ${ }^{1} \mathrm{O}_{2}$ & RAW 264.7 cell line & No \\
\hline [112] & PDT & $\begin{array}{c}\text { Biomimetic } \\
\text { nanothylakoid }\end{array}$ & $\mathrm{H}_{2} \mathrm{O}_{2}$ & chlorophyll & $660 \mathrm{~nm} 1 \mathrm{~W} \cdot \mathrm{cm}^{-2}, 10 \mathrm{~min}$ & ${ }^{1} \mathrm{O}_{2}$ & $4 \mathrm{~T} 1$ cell line & 4T1 tumour-bearing mice \\
\hline [114] & PDT & Catalase & $\mathrm{H}_{2} \mathrm{O}_{2}$ & THPP & $\begin{array}{l}\text { In vitro: } 660 \mathrm{~nm}, 5 \mathrm{~mW} \cdot \mathrm{cm}^{-2}, 30 \mathrm{~min} \\
\text { In vivo: } 660 \mathrm{~nm}, 5 \mathrm{~mW} \cdot \mathrm{cm}^{-2}, 60 \mathrm{~min}\end{array}$ & ${ }^{1} \mathrm{O}_{2}$ & $4 \mathrm{~T} 1$ cell line & 4T1 tumour-bearing mice \\
\hline [115] & $\begin{array}{l}\text { PDT/lung } \\
\text { cancer }\end{array}$ & AuNCs-NH ${ }_{2}$ & $\mathrm{H}_{2} \mathrm{O}_{2}$ & PpIX & $532 \mathrm{~nm}, 200 \mathrm{~mW} \cdot \mathrm{cm}^{-2}, 5 \mathrm{~J}$ per well & ${ }^{1} \mathrm{O}_{2}$ & H 460 cell line & No \\
\hline [116] & PDT & $\begin{array}{l}\text { G-quadruplex-hemin } \\
\text { DNAzyme }\end{array}$ & $\mathrm{H}_{2} \mathrm{O}_{2}$ & Ce6 & $\begin{array}{l}\text { In vitro: } 660 \mathrm{~nm}, 5 \mathrm{~mW} \cdot \mathrm{cm}^{-2}, 30 \mathrm{~min} \\
\text { In vivo: } 660 \mathrm{~nm}, 5 \mathrm{~mW} \cdot \mathrm{cm}^{-2}, 60 \mathrm{~min}\end{array}$ & & $4 \mathrm{~T} 1$ cell line & 4T1 tumour-bearing mice \\
\hline [117] & PDT & MnFe-LDH & $\mathrm{H}_{2} \mathrm{O}_{2}$ & MB & $\begin{array}{l}\text { In vitro: } 650 \mathrm{~nm}, 100 \mathrm{~mW} \cdot \mathrm{cm}^{-2}, 10 \mathrm{~min} \\
\text { In vivo: } 650 \mathrm{~nm}, 100 \mathrm{~mW} \cdot \mathrm{cm}^{-2}, 15 \mathrm{~min}\end{array}$ & ${ }^{1} \mathrm{O}_{2}$ & HeLa cell line & U14 tumour-bearing mice \\
\hline [118] & PDT & PB NPs & $\mathrm{H}_{2} \mathrm{O}_{2}$ & $\mathrm{ZnPc}$ & $671 \mathrm{~nm}, 400 \mathrm{~mW} \cdot \mathrm{cm}^{-2}, 5 \mathrm{~min}$ & ${ }^{1} \mathrm{O}_{2}$ & $\begin{array}{l}\text { HeLa, A549 and 4T1 } \\
\text { cell lines }\end{array}$ & 4T1 tumour-bearing mice \\
\hline [119] & PDT & PB NPs & $\mathrm{H}_{2} \mathrm{O}_{2}$ & Ce6 & $\begin{array}{l}\text { In vitro: } 660 \mathrm{~nm}, 1.0 \mathrm{~W} \cdot \mathrm{cm}^{-2}, 5 \mathrm{~min} \\
\text { In vivo: } 660 \mathrm{~nm}, 1.0 \mathrm{~W} \cdot \mathrm{cm}^{-2}, 2 \mathrm{~min}\end{array}$ & ${ }^{1} \mathrm{O}_{2}$ & $\begin{array}{l}\text { U87MG and } \\
\text { HUVEC cell lines }\end{array}$ & $\begin{array}{l}\text { U87MG tumour-bearing } \\
\text { mice }\end{array}$ \\
\hline [120] & PDT & $\mathrm{Fe}(\mathrm{III})$ & $\mathrm{H}_{2} \mathrm{O}_{2}$ & MB & $650 \mathrm{~nm}, 100 \mathrm{~mW} \cdot \mathrm{cm}^{-2}, 15 \mathrm{~min}$ & ${ }^{1} \mathrm{O}_{2}$ & HeLa cell line & U14 tumour-bearing mice \\
\hline
\end{tabular}


Table 7. Cont.

\begin{tabular}{|c|c|c|c|c|c|c|c|c|}
\hline Ref & Application & Catalyst & $\mathrm{O}_{2}$ Source & PS & Energy of Excitation & Type of ROS & In Vitro & In Vivo \\
\hline [121] & PDT & $\mathrm{Fe}(\mathrm{III})$ & $\mathrm{H}_{2} \mathrm{O}_{2}$ & MB & $\begin{array}{l}\text { In vitro: } 650 \mathrm{~nm}, 100 \mathrm{~mW} \cdot \mathrm{cm}^{-2}, 10 \mathrm{~min} \\
\text { In vivo: } 650 \mathrm{~nm}, 100 \mathrm{~mW} \cdot \mathrm{cm}^{-2}, 15 \mathrm{~min}\end{array}$ & ${ }^{1} \mathrm{O}_{2}$ & HeLa cell line & - \\
\hline [122] & PDT & $\mathrm{Fe}(\mathrm{III})$ & $\mathrm{H}_{2} \mathrm{O}_{2}$ & $\begin{array}{l}\text { Ce6, TPEDC, } \\
\text { TPETCF }\end{array}$ & $\begin{array}{l}\text { In vitro: white light excitation, } \\
50 \mathrm{~mW} \cdot \mathrm{cm}^{-2} 5 \mathrm{~min} \\
\text { In vivo: white light excitation, } \\
50 \mathrm{~mW} \cdot \mathrm{cm}^{-2}, 10 \mathrm{~min}\end{array}$ & ${ }^{1} \mathrm{O}_{2}$ & $4 \mathrm{~T} 1$ cell line & 4T1 tumour-bearing mice \\
\hline [123] & Immuno-PDT & $\mathrm{Fe}(\mathrm{III})$ & $\mathrm{H}_{2} \mathrm{O}_{2}$ & TBP & $\begin{array}{l}\text { In vitro: } 650 \mathrm{~nm}, 20 \mathrm{~mW} \cdot \mathrm{cm}^{-2}, 15 \mathrm{~min} \\
\text { In vivo: } 650 \mathrm{~nm}, 100 \mathrm{~mW} \cdot \mathrm{cm}^{-2}, 7.5 \mathrm{~min}\end{array}$ & ${ }^{1} \mathrm{O}_{2}$ & CT26 cell line & $\begin{array}{l}\text { CT26 tumour-bearing } \\
\text { mice }\end{array}$ \\
\hline [124] & PDT & $\begin{array}{c}\text { Cy5- } \\
\text { aptamer-heme } \\
\text { (H1) and 3'-heme } \\
\text { labelled } \\
\text { oligonucleotide } \\
\text { (H2) }\end{array}$ & $\mathrm{H}_{2} \mathrm{O}_{2}$ & BPNS & $\begin{array}{l}\text { In vitro: } 660 \mathrm{~nm}, 150 \mathrm{~mW} \cdot \mathrm{cm}^{-2}, 3 \mathrm{~min} \\
\text { In vivo: } 660 \mathrm{~nm}, 150 \mathrm{~mW} \cdot \mathrm{cm}^{-2}, 10 \mathrm{~min}\end{array}$ & ${ }^{1} \mathrm{O}_{2}$ & HeLa cell line & 4T1 tumour-bearing mice \\
\hline $\begin{array}{l}\text { MB: Me } \\
\text { 20-tetra } \\
\text { double } \\
\text { TPETC } \\
\text { phosph }\end{array}$ & $\begin{array}{l}\text { lene Blue; Al } \\
\text { ydroxypheny } \\
\text { le; PB NPs: P } \\
\text { )-2-(4-(4-(2,2 } \\
\text { s nanosheet. }\end{array}$ & $\begin{array}{l}\mathrm{PcS}_{4}: \mathrm{Al}(\mathrm{III}) \text { phthalc } \\
\text { l) porphyrin; AuNC } \\
\text { cussian Blue nanopa } \\
\text {-bis(4-methoxypher }\end{array}$ & $\begin{array}{l}\text { nine chlo } \\
\mathrm{H}_{2} \text { : perox } \\
\text { es; ZnPc: } \\
\text { 1-phenyl }\end{array}$ & $\begin{array}{l}\text { etrasulfoni } \\
\text { amine-term } \\
\text { phthalocyar } \\
\text { styryl)-3-c }\end{array}$ & $\begin{array}{l}\text { id; Ce6: Chlorin e6; HMME: Hematop } \\
\text { ted PAPAM dendrimer-encapsulated g } \\
\text {; TPEDC: 2-((4'-(2,2-bis(4-methoxyphe } \\
\text { lo-5,5-dimethylfuran-2(5H)-ylidene)m }\end{array}$ & $\begin{array}{l}\text { lyrin monon } \\
\text { JP; PPIX: Pro } \\
\text { 1-phenylvin } \\
\text { hitrile; TBP: }\end{array}$ & $\begin{array}{l}\text { ether; RB: Ros } \\
\text { hyrin IX; MnFF } \\
\text {-biphenyl-4-yl) } \\
\text { 20-tetra( } p \text {-ber }\end{array}$ & $\begin{array}{l}\text { gal; THPP: meso-5, 10, } 15 \\
\text { H: Manganese-iron layered } \\
\text { nyl)methylene)malonitrile } \\
\text { o)porphyrin. BPNS: black }\end{array}$ \\
\hline
\end{tabular}




\subsubsection{Platinum (Pt) NPs}

$\mathrm{Pt}$ NPs are other types of artificial catalases. They can also be used as catalysts and are well-known to possess good peroxidase-like properties. They can indeed catalyze in situ the intracellular $\mathrm{H}_{2} \mathrm{O}_{2}$ to produce large amounts of $\mathrm{O}_{2}$ thanks to the decomposition of $\mathrm{H}_{2} \mathrm{O}_{2}$. In the literature, we found five publications describing the use of Pt NPs all in 2018 and four of them reported in vivo experiments. In all of them, Pt NPs are associated with others NPs. Pt NP converts $\mathrm{H}_{2} \mathrm{O}_{2}$ into $\mathrm{O}_{2}$.

Zhang et al. [125] developed Pt NP (approximately $2 \mathrm{~nm}$ ) in a metal-organic framework (average diameter of about $90 \mathrm{~nm}$ ) coated with PEG. The dynamic diameter of the NP was $160.1 \mathrm{~nm}$. They chose the TCPP as the PS. Thanks to dichlorodihydrofluorescein diacetate (DCFH-DA) and DPBF they proved that the NP could efficiently produce ${ }^{1} \mathrm{O}_{2}$ in hypoxic conditions in the presence of $\mathrm{H}_{2} \mathrm{O}_{2}$. After intravenous injection in hepatoma 22 (H22) tumour-bearing mice after light illumination $(638 \mathrm{~nm}$, $1 \mathrm{~W} \cdot \mathrm{cm}^{-2}, 10 \mathrm{~min}$ ), the tumour growth of the group treated with the NP and light was significantly different from the groups with only light and only NP (around six times less).

Wei et al. [126] decided to develop 2D Pd-based nanoplates as a carrier. They coupled SH-PEG-COOH to improve the stability and coupled Ce6 onto the carboxylic acid group (10 $\mathrm{wt} \%$ ). The resulting Pd@Pt-PEG-Ce6 nanoplates have a hydrodynamic size of about $80 \mathrm{~nm}$. Using DPBF, they proved that Pd@Pt-PEG-Ce6 and Ce6 produced the same amount of ${ }^{1} \mathrm{O}_{2}$. Adding $\mathrm{H}_{2} \mathrm{O}_{2}$, only Pd@Pt-PEG-Ce6 was able to increase the production of ${ }^{1} \mathrm{O}_{2}$. In vitro experiments in A4T1 cell lines, in $\mathrm{N}_{2}$ atmosphere addition of exogenous $\mathrm{H}_{2} \mathrm{O}_{2}$ under $660 \mathrm{~nm}$ laser irradiation $\left(5 \mathrm{~min}, 150 \mathrm{~mW} \cdot \mathrm{cm}^{-2}\right.$ ) produced a diminution of PDT effect with Ce6 but not with Pd@Pt-PEG-Ce6 compared that in air atmosphere, proving the production of $\mathrm{O}_{2}$. Under $808 \mathrm{~nm}$ irradiation $\left(0.5 \mathrm{~W} \cdot \mathrm{cm}^{-2}, 5 \mathrm{~min}\right)$, Pd@Pt-PEG-Ce6 exhibited a moderate photothermal effect, which could lead to an enhancement of PDT treatment. In vivo studies in Balb/v mice with 4T1 tumour showed that Pd@Pt-PEG-Ce6 under both $660 \mathrm{~nm}$ and $808 \mathrm{~nm}$ illumination led to the best tumour growth inhibition compared to the others groups (Ce6 alone, light alone, only Pd@Pt-PEG-Ce6).

Wang et al. [127] synthesized hybrid core-shell NPs composed of a polydopamine (pda) core, $\mathrm{Pt}$ NP interlayer, zirconium-TCPP (PCN) porphyrin shell and a coordination between $\mathrm{Zr}_{6}$ and the carboxyl group of folic acid. The size of Pda-Pt@PCN was $250 \mathrm{~nm}$ with a thickness of the shell of about $30 \mathrm{~nm}$. With ADPA and Pda-Pt@PCN, in solution saturated with $\mathrm{N}_{2}$, formation of ${ }^{1} \mathrm{O}_{2}$ was higher after addition of $\mathrm{H}_{2} \mathrm{O}_{2}$ revealing the formation of $\mathrm{O}_{2}$ via the decomposition of $\mathrm{H}_{2} \mathrm{O}_{2}$. The incorporation of Pda-Pt@PCN-FA into FAR over-expressed CT26 cells was higher than that into FAR-negative COS7 cell line demonstrating the FA targeting effect. PDT efficacy was investigated under both normoxia and hypoxia conditions. In normoxic conditions, no difference could be observed between Pda-Pt@PCN-FA and Pda@PCN-FA whereas in hypoxia conditions, Pda@PCN-FA presented higher phototoxicity (nearly $80 \%$ ). Using a wound-healing test, they also proved that cells treated with Pda-Pt@PCN-FA were less capable of moving compared with cells without treatment demonstrating the advantage of these NPs for the metastatic process. In a CT26-cell-bearing mice modeltumour hypoxia had been improved (hypoxia-inducible factors staining assay), $660 \mathrm{~nm}$ illumination $\left(220 \mathrm{~mW} \cdot \mathrm{cm}^{-2}, 5 \mathrm{~min}\right)$ induced a significant tumour suppression effect as well as an inhibition of tumour metastasis.

Cai et al. [128] designed 3D-dendritic mesoporous silica NP (3D-dentritic MSNs DMSNs) in which were incorporated Pt NPs. They coupled $\mathrm{NH}_{2}-\mathrm{PEG}-\mathrm{NH}_{2}$ to improve the biocompatibility, triphenylphosphine (TPP) to target mitochondria and loaded Ce6 as a PS (13\% $(w / w))$. Pt-DMSNs$\mathrm{TPP} / \mathrm{Ce} 6 \mathrm{had}$ an average diameter of around $113.5 \mathrm{~nm}$. An important increase of ${ }^{1} \mathrm{O}_{2}$ production by Pt-DMSNs-TPP/Ce6 was noticed with addition of $\mathrm{H}_{2} \mathrm{O}_{2}$ using ADBA. A549 cells treated with free Ce6, DMSNs/Ce6, Pt-DMSNs/Ce6 and Pt-DMSNs-TPP/Ce6. As expecting, mitochondria-triggered apoptosis and therapeutic PDT $\left(660 \mathrm{~nm}, 50 \mathrm{~mW} \cdot \mathrm{cm}^{-2}, 5 \mathrm{~min}\right)$ in vivo efficacy was higher in the cells treated with Pt-DMSNs-TPP/Ce6 than the others conditions.

Ouyang et al. [129] used 2D semiconductor NPs namely BPNS with an average diameter of $200 \mathrm{~nm}$ on which Pt NP of $4.2 \mathrm{~nm}$ were uniformly placed. BP nanosheet did not induce decomposition of $\mathrm{H}_{2} \mathrm{O}_{2}$ whereas Pt@BP nanohydrids did. Formation of ${ }^{1} \mathrm{O}_{2}$ was observed thanks to DPBF whose 
absorption decreased less than 10\% under NIR illumination for Pt@BP but by $35 \%$ after adding $\mathrm{H}_{2} \mathrm{O}_{2}$. In vitro antitumour studies were performed on $4 \mathrm{~T} 1$ cells; after incorporation and light illumination $\left(660 \mathrm{~nm}, 1 \mathrm{~W} \cdot \mathrm{cm}^{-2}, 10 \mathrm{~min}\right)$, the cell viability decreased of $26 \%$ with BP and $65 \%$ with Pt@BP, with a dysfunction of mitochondria. In vivo in mice bearing subcutaneous 4T1 tumours, PDT treatment led to total regression of the tumour (Table 8).

\subsubsection{Others}

In order to produce $\mathrm{O}_{2}$ inside the hypoxic zones of the tumours, three others strategies have been developed. Three studies focused on the decomposition of $\mathrm{H}_{2} \mathrm{O}_{2}$ but not endogenous $\mathrm{H}_{2} \mathrm{O}_{2}$ of tumour cells. In these strategies, the authors encapsulated $\mathrm{H}_{2} \mathrm{O}_{2}$ in nanostructures.

$\mathrm{Li}$ et al. [130] designed light-triggered polymeric vesicle coupled to $\mathrm{Ce} 6$ and encapsulating $\mathrm{H}_{2} \mathrm{O}_{2}$. Briefly, PAMAM dendrimer coupled to Ce6/cypate and $\mathrm{H}_{2} \mathrm{O}_{2}$ were co-assembled with a block copolymer that could be cleaved upon ROS production into polymeric vesicles (HC@P1-vesicle) $(155.2 \pm 21.5 \mathrm{~nm})$. Upon $808 \mathrm{~nm}$ excitation, $\mathrm{H}_{2} \mathrm{O}_{2}$ was decomposed in $\mathrm{O}_{2}$. Upon $660 \mathrm{~nm}$ illumination, excitation of $\mathrm{Ce} 6$ induced the formation of ${ }^{1} \mathrm{O}_{2}$ that disrupted the copolymer and destabilized the vesicle leading to the release of Ce6/cypate into the tumour. One cycle of 660/805 nm illumination induced the fast release of $\mathrm{H}_{2} \mathrm{O}_{2}$ due to cleavage of the copolymer and disruption of the vesicle. $808 \mathrm{~nm}$ excitation of HC@P1-vesicle did not lead to high formation of ${ }^{1} \mathrm{O}_{2}$ but $660 \mathrm{~nm}$ excitation did. One cycle of 660/805 nm illumination induced an increased amount of ${ }^{1} \mathrm{O}_{2}$. In human pancreatic BxPC-3 cancer cells, the cellular uptake of CC-PAPAM was five times higher with light irradiation of HC@P1-vesicle than without light. A higher PDT effect $\left(805 \mathrm{~nm}, 1000 \mathrm{~mW} \cdot \mathrm{cm}^{-2}, 3 \mathrm{~min}-660 \mathrm{~nm}, 100 \mathrm{~mW} \cdot \mathrm{cm}^{-2}, 10 \mathrm{~min}\right)$ was observed for HC@P1-vesicle than for the same vesicles without $\mathrm{H}_{2} \mathrm{O}_{2}$. In vivo experiments in BxPC-3 tumour-bearing mice $\left(805 \mathrm{~nm}, 1000 \mathrm{~mW} \cdot \mathrm{cm}^{-2}, 3 \mathrm{~min}-660 \mathrm{~nm}, 100 \mathrm{~mW} \cdot \mathrm{cm}^{-2}, 10 \mathrm{~min}\right)$ showed that HC@P1-vesicle preferably accumulated into the tumour compared to CC-PAMAM. After one cycle of 660/805 nm illumination, CC-PAPAM released from the vesicle deeply distributed into the tumour. 
Table 8. Summary of publications about $\mathrm{H}_{2} \mathrm{O}_{2}$ decomposition by Pt NPs.

\begin{tabular}{|c|c|c|c|c|c|c|c|c|}
\hline Ref & Application & Catalyst & $\mathrm{O}_{2}$ Source & PS & Energy of Excitation & Type of ROS & In Vitro & In Vivo \\
\hline [125] & PDT & Pt NP & $\mathrm{H}_{2} \mathrm{O}_{2}$ & ТСРР & $\begin{array}{l}\text { In vitro: } 638 \mathrm{~nm}, 1.0 \mathrm{~W} \cdot \mathrm{cm}^{-2}, 10 \mathrm{~min} \\
\text { In vivo: } 638 \mathrm{~nm}, 1.0 \mathrm{~W} \cdot \mathrm{cm}^{-2}, 8 \mathrm{~min}\end{array}$ & ${ }^{1} \mathrm{O}_{2}$ & $\begin{array}{l}\text { HeLa and 4T1 } \\
\text { cell lines }\end{array}$ & $\begin{array}{l}\mathrm{H} 22 \text { tumour-bearing } \\
\text { mice }\end{array}$ \\
\hline [126] & PDT & Pt NP & $\mathrm{H}_{2} \mathrm{O}_{2}$ & Ce6 & $\begin{array}{c}660 \mathrm{~nm}, 150 \mathrm{~mW} \cdot \mathrm{cm}^{-2}, 5 \mathrm{~min}+808 \mathrm{~nm}, \\
500 \mathrm{~mW} \cdot \mathrm{cm}^{-2}, 5 \mathrm{~min}\end{array}$ & ${ }^{1} \mathrm{O}_{2}$ & $4 \mathrm{~T} 1$ cell line & $\begin{array}{l}\text { 4T1 tumour-bearing } \\
\text { mice }\end{array}$ \\
\hline [127] & PDT & Pt NP & $\mathrm{H}_{2} \mathrm{O}_{2}$ & zirconium-ТCPP & $\begin{array}{l}\text { In vitro: } 660 \mathrm{~nm}, 30 \mathrm{~mW} \cdot \mathrm{cm}^{-2}, 3 \mathrm{~min} \\
\text { In vivo: } 660 \mathrm{~nm}, 200 \mathrm{~mW} \cdot \mathrm{cm}^{-2}, 5 \mathrm{~min}\end{array}$ & ${ }^{1} \mathrm{O}_{2}$ & CT26 cell line & $\begin{array}{l}\text { CT26 tumour-bearing } \\
\text { mice }\end{array}$ \\
\hline$[128]$ & PDT & Pt NP & $\mathrm{H}_{2} \mathrm{O}_{2}$ & Ce6 & $660 \mathrm{~nm}, 50 \mathrm{~mW} \cdot \mathrm{cm}^{-2} ; 5 \mathrm{~min}$ & ${ }^{1} \mathrm{O}_{2}$ & A549 cell line & No \\
\hline [129] & PDT & Pt NP & $\mathrm{H}_{2} \mathrm{O}_{2}$ & BPNS & $660 \mathrm{~nm}, 1.0 \mathrm{~W} \cdot \mathrm{cm}^{-2}, 10 \mathrm{~min}$ & ${ }^{1} \mathrm{O}_{2}$ & $4 \mathrm{~T} 1$ cell line & $\begin{array}{l}4 \mathrm{~T} 1 \text { tumour-bearing } \\
\text { mice }\end{array}$ \\
\hline
\end{tabular}

TCPP: carboxyphenylporphyrin; BPNS: black phosphorus nanosheet. 
Thanks to pimonidazole, after treatment with HC@P1-vesicle and one cycle of 660/805 nm illumination it was proved that the hypoxia decreased in the tumour. Multiple cycles of 660/805 nm illumination were then performed. After five cycles, in vivo, tumour treated with HC@P1-vesicle had less than $20 \%$ hypoxic areas compared to more than $70 \%$ for tumour treated with only $660 \mathrm{~nm}$ light. A total ablation of hypoxic hypopermeable pancreatic tumour was observed.

Wang et al. [131] developed NPs (PLGA-FA/IR780- $\mathrm{H}_{2} \mathrm{O}_{2}$ NPs) composed of a core-shell (poly(lactic-co-glycolic acid) (PLGA) and $\mathrm{H}_{2} \mathrm{O}_{2} /$ poly(vinylpyrrolidone) complex $\left(\mathrm{O}_{2}\right.$ source)) convalently conjugating folic acid (targeting) and entrapping in the shell IR780 diodide (PTT/PDT agent) (Figure 22). The authors proved the photothermal effect of these NPs as well as their ability to produce ROS to kill cancer cells in vitro in HepG2 cell line after laser irradiation $\left(808 \mathrm{~nm}, 0.5 \mathrm{~W} \cdot \mathrm{cm}^{-2}\right.$, $60 \mathrm{~s}$ ) with a decrease of cell viability of $80 \%$. The phothermal effect conducted to an efficient release of $\mathrm{H}_{2} \mathrm{O}_{2}$ to increase the $\mathrm{O}_{2}$ concentration. These observations were confirmed in vivo in Hep-G2 tumour-bearing mice with a significant inhibition of tumour growth.

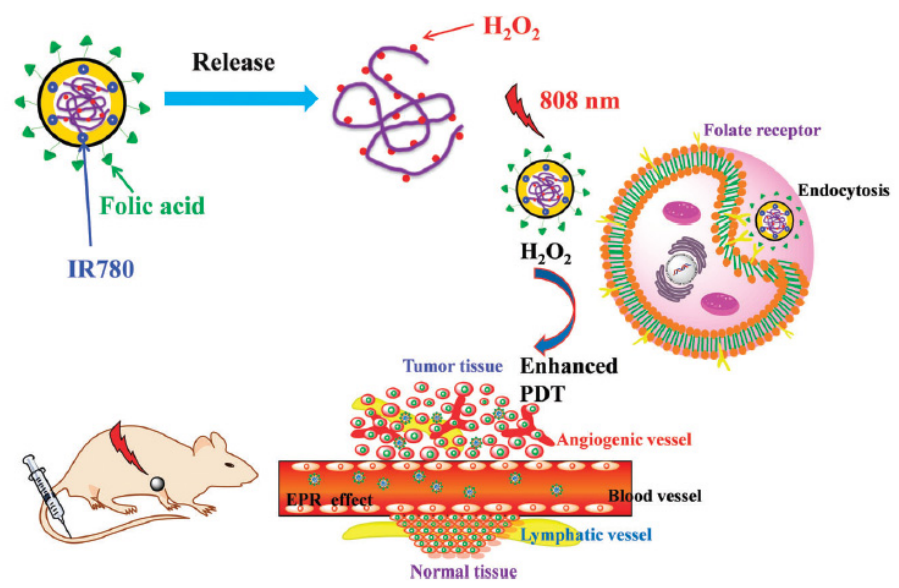

Figure 22. Illustrations of $\mathrm{O}_{2}$ self-enriched PLGA-FA/IR780- $\mathrm{H}_{2} \mathrm{O}_{2}$ NPs and their application for PTT and enhanced PDT against tumours. Republished from [131] with permission of the Royal Society of Chemistry, Copyright 2018.

In 2011, Manifold et al. [132] described a preliminary study on the influence of topical application of $\mathrm{H}_{2} \mathrm{O}_{2}$ cream on the potential photodynamic reaction (PDR) by 5-ALA methyl ester (MAL) on skin diseases. In this study, the aim was to investigate the possible side effects of $\mathrm{H}_{2} \mathrm{O}_{2}$ cream (Crystacide ${ }^{\circledR}$ ), of MAL cream under different $\mathrm{pO}_{2}$. Forty healthy volunteers participated in the protocol and each of them wore a patch on the right forearm. The patch was constituted of four sites: i.e. (a) normal skin without any treatment, (b) a positive control with MAL cream and further illumination after removal of excess of PS, (c) same as (b) in hypoxic condition, and (d) same of (b) with $\mathrm{H}_{2} \mathrm{O}_{2}$ cream. Another patch on the left forearm was devoted to control the different factors taken alone (light, MAL cream, Crystacide $\left.{ }^{\circledR}\right)$. An evaluation by the naked eye was carried out to highlight the presence of erythema or oedema on the cutaneous sites. Laser Doppler perfusion imaging quantified the change in cutaneous blood flow in vivo. The first results indicated a great variability in terms of appearance of erythema as a function of time and $25 \%$ of volunteers showed strong response. Regarding oedema, this side effect was much less problematic. In summary, further investigation should be necessary before topical administration of Crystacide ${ }^{\circledR}$ for cutaneous PDR applications.

Two others studies have described two other systems to decompose endogenous $\mathrm{H}_{2} \mathrm{O}_{2}$. Zhen et al. synthesized a $\mathrm{BiOI} / \mathrm{BiOIO}_{3}$ nanocomposite $(\mathrm{BB} \mathrm{NCs})(108 \mathrm{~nm})$ [133]. The photogenerated electrons ( $\mathrm{e}^{-}$) under $650 \mathrm{~nm}$ light irradiation reacted with $\mathrm{H}_{2} \mathrm{O}_{2}$ to produce ${ }^{\bullet} \mathrm{OH}$ and slit $\mathrm{H}_{2} \mathrm{O}$ to produce $\mathrm{O}_{2}$ then ${ }^{1} \mathrm{O}_{2}$ both in hypoxic and normoxic conditions. ${ }^{\bullet} \mathrm{OH}$ was detected thanks to hydroxyphenyl fluorescein probe (HPF) after $650 \mathrm{~nm}$ illumination and its concentration was even higher after addition of $\mathrm{H}_{2} \mathrm{O}_{2} \cdot{ }^{1} \mathrm{O}_{2}$ was detected thanks to SOSG probe even in hypoxic conditions. In HeLa cells, the use of 
SOSG probe also proved the formation of ${ }^{1} \mathrm{O}_{2}$ even in hypoxic cells. DCHF-DA presented the same fluorescence in normoxic or hypoxic cells showing the equal amount of ROS production. Fluorescence of $\left(\left[\mathrm{Ru}(\mathrm{dpp})_{3}\right] \mathrm{Cl}_{2}\right.$ was quenched even in hypoxic conditions in the presence of irradiated BB NCs. In vivo $\left(650 \mathrm{~nm}, 500 \mathrm{~mW} \cdot \mathrm{cm}^{-2}, 15 \mathrm{~min}\right)$, the tumour in the $\mathrm{BB} \mathrm{NCs} /$ laser group was totally destroyed and a low level of HIF- $1 \alpha$ was detected.

Wu et al. [134] synthesized an UCNP containing Ce6 and Ferric Hydroxide $\mathrm{Fe}(\mathrm{OH})_{3}$, biocompatible and acting as a synergetic agent between PDT and chemotherapy. When irradiated at $808 \mathrm{~nm}$ in presence of $\mathrm{H}_{2} \mathrm{O}_{2}$, these UCNPs (176 nm diameter) excited Ce6 which generated ${ }^{1} \mathrm{O}_{2}$, using $\mathrm{O}_{2}$ produced by the Fenton-like reaction of $\mathrm{Fe}(\mathrm{OH})_{3}$ with $\mathrm{H}_{2} \mathrm{O}_{2}$. In vitro, $4 \mathrm{~T} 1$ and 293T human embryonic kidney cells viability was tested in normoxia or hypoxia, in presence or in absence of $\mathrm{H}_{2} \mathrm{O}_{2}$ with or without irradiation $\left(808 \mathrm{~nm}, 1 \mathrm{~W} \cdot \mathrm{cm}^{-2}, 10 \mathrm{~min}\right)$. They clearly showed the amplified effect of using these UCNPs in presence of $\mathrm{H}_{2} \mathrm{O}_{2}$ and irradiation (Figure 23).
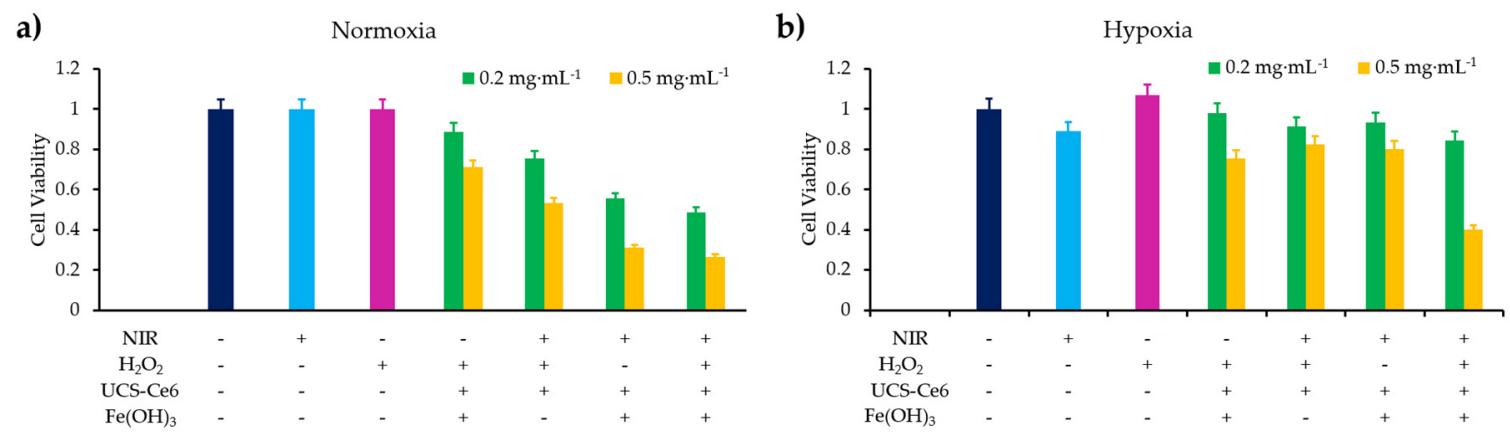

Figure 23. $(\mathbf{a}, \mathbf{b})$ CCK-8 assay of $4 \mathrm{~T} 1$ cells after incubating in a normoxia/hypoxia environment and treated by different methods. Adapted from Wu et al. [134]

In vivo, the $4 \mathrm{~T} 1$ mouse tumour model was irradiated at $808 \mathrm{~nm}\left(1 \mathrm{~W} \cdot \mathrm{cm}^{-2}, 30 \mathrm{~min}\right)$ and 14 days after treatment with UCPs, not only the growth of tumour dramatically decreased, but also the tumour nearly disappeared (Table 9).

\subsection{Water Splitting}

Until 2010, water splitting was essentially studied for $\mathrm{H}_{2}$ production as it appears a potentiate solution to the energy and environmental issues. Numerous active photocatalysts such as metaloxides, sulfides, nitrides, nanocomposites, and doped materials have been proposed for the generation of $\mathrm{H}_{2}$ (and concomitant $\mathrm{O}_{2}$ generation) [135]. However, it is well known that nature (and especially plants) is able to use light to catalyse the synthesis of $\mathrm{O}_{2}$ from $\mathrm{H}_{2} \mathrm{O}$ in chloroplasts with high yields. Inspired by this and, as water is the most abundant element in the human body, scientists have thought of using light-driven water splitting for in situ $\mathrm{O}_{2}$ formation at the tumour site and thus decrease hypoxia. For this, some teams have developed various $\mathrm{O}_{2}$ generators based on oxides $\left(\mathrm{CaO}, \mathrm{ZnO}, \mathrm{Bi}_{2} \mathrm{WO}_{6} \ldots\right)$, carbon nitride NPs and other materials such as nanorods or nanosheets.

$\mathrm{CaO}_{2}$ is an $\mathrm{O}_{2}$-generating material that can be used to suppress hypoxia. It has many advantages such as highly compatible, efficient $\mathrm{O}_{2}$ generator and rapidly metabolized in cells. When it reacts with water or weak acid, it can release $\mathrm{O}_{2}$ and can alleviate tumour hypoxia:

$$
2 \mathrm{CaO}_{2}+4 \mathrm{H}_{2} \mathrm{O} \rightarrow 2 \mathrm{Ca}(\mathrm{OH})_{2}+2 \mathrm{H}_{2} \mathrm{O}_{2} \rightarrow 2 \mathrm{Ca}(\mathrm{OH})_{2}+2 \mathrm{H}_{2} \mathrm{O}+\mathrm{O}_{2}
$$

Hu et al. [136] developed an " optical battery » based on UCNP associated with RB by electrostatic interactions in biocompatible PDMS (polydimethylsiloxane) which was able to produce ${ }^{1} \mathrm{O}_{2}$ after NIR irradiation $\left(980 \mathrm{~nm}, 2 \mathrm{~W} \cdot \mathrm{cm}^{-2}, 5 \mathrm{~s}\right)$. The persistent luminescence of the battery allowed to irradiate during a short time (5 s) and to induce a PDT effect without continuous irradiation. This avoided photothermal effects. 
Table 9. Summary of publications about $\mathrm{H}_{2} \mathrm{O}_{2}$ decomposition by others ways.

\begin{tabular}{|c|c|c|c|c|c|c|c|c|}
\hline Ref & Application & Catalyst & $\mathrm{O}_{2}$ Source & PS & Energy of Excitation & Type of ROS & In Vitro & In Vivo \\
\hline [130] & PDT & $\begin{array}{c}\text { Light-triggered } \\
\text { polymeric vesicle } \\
\text { coupled to Ce6 and } \\
\text { encapsulating } \mathrm{H}_{2} \mathrm{O}_{2} \text {. }\end{array}$ & $\mathrm{H}_{2} \mathrm{O}_{2}$ & Ce6 & $\begin{array}{c}805 \mathrm{~nm}, 1000 \mathrm{~mW} \cdot \mathrm{cm}^{-2}, \\
3 \mathrm{~min}-660 \mathrm{~nm} \\
100 \mathrm{~mW} \cdot \mathrm{cm}^{-2}, 10 \mathrm{~min}\end{array}$ & ${ }^{1} \mathrm{O}_{2}$ & BxPC-3 cell line & $\begin{array}{l}\text { BxPC-3 tumour-bearing } \\
\text { mice }\end{array}$ \\
\hline [131] & PTT/PDT & $\begin{array}{c}\text { Hydrophilic } \\
\mathrm{H}_{2} \mathrm{O}_{2} / \text { poly(vinylpyrrolidone) } \\
\text { complex }\end{array}$ & $\mathrm{H}_{2} \mathrm{O}_{2}$ & IR780 & $808 \mathrm{~nm}, 0.5 \mathrm{~W} \cdot \mathrm{cm}^{-2}, 3 \mathrm{~min}$ & ROS & HepG2 cell line & $\begin{array}{l}\text { HepG2 tumour-bearing } \\
\text { mice }\end{array}$ \\
\hline [132] & PDT & Cream & $\mathrm{H}_{2} \mathrm{O}_{2}$ & $\begin{array}{l}\text { 5-ALA methyl } \\
\text { ester (MAL, } \\
\text { Metvix }{ }^{\circledR} \text { ) }\end{array}$ & $\begin{array}{c}570-670 \mathrm{~nm}, 105 \mathrm{~mW} \cdot \mathrm{cm}^{-2} \\
16 \mathrm{~min}, \text { in vvo }\end{array}$ & nd & $\begin{array}{l}\text { Erithema cell } \\
\quad \text { line }\end{array}$ & 40 healthy volunteers \\
\hline [133] & PDT & $\begin{array}{c}\mathrm{BiOI} / \mathrm{BiOIO}_{3} \\
\text { nanocomposite }\end{array}$ & $\mathrm{H}_{2} \mathrm{O}_{2}$ & $\mathrm{BiOI} / \mathrm{BiOIO}_{3}$ & $\begin{array}{c}650 \mathrm{~nm}, 500 \mathrm{~mW} \cdot \mathrm{cm}^{-2}, \\
15 \mathrm{~min}\end{array}$ & ${ }^{1} \mathrm{O}_{2}$ and $\bullet \bullet H$ & HeLa cell line & $\begin{array}{l}4 \mathrm{~T} 1 \text { tumour-bearing } \\
\text { mice }\end{array}$ \\
\hline [134] & Chemo-PDT & $\begin{array}{l}\mathrm{Fe}(\mathrm{OH}) \text {-modified } \\
\text { UCNP }\end{array}$ & $\mathrm{H}_{2} \mathrm{O}_{2}$ & Ce6 & $\begin{array}{l}\text { In vitro: } 808 \mathrm{~nm}, 1 \mathrm{~W} \cdot \mathrm{cm}^{-2}, \\
10 \mathrm{~min} \\
\text { In vivo: } 808 \mathrm{~nm}, 1 \mathrm{~W} \cdot \mathrm{cm}^{-2} \\
30 \mathrm{~min}\end{array}$ & $\stackrel{{ }^{1} \mathrm{O}_{2},}{\bullet}$ & $4 \mathrm{~T} 1$ cell line & $\begin{array}{l}\text { 4T1 tumour-bearing } \\
\text { mice }\end{array}$ \\
\hline
\end{tabular}

nd: not determined; Ce6: chlorin e6; 5-ALA: 5-sminolevulinic acid; UCNP: Up-conversion nanoparticles. 
The battery was implemented under different thicknesses of pork tissue. The NIR irradiation $(980 \mathrm{~nm})$ induced ${ }^{1} \mathrm{O}_{2}$ production at a thickness of $4 \mathrm{~mm}$, whereas UV light $(365 \mathrm{~nm})$ was efficient at only $1 \mathrm{~mm}$. The battery was biocompatible in a human colon adenocarcinoma cell line HT29 and presented phototoxicity under light illumination. $\mathrm{CaO}_{2}$ was encapsulated in the battery and a higher molecular $\mathrm{O}_{2}$ concentration and hypoxia inhibition was observed. Finally, the device was implanted subcutaneously onto a HT29 solid tumour. The PDT effect of the battery after NIR irradiation $(660 \mathrm{~nm}$, $30 \mathrm{~mW} \cdot \mathrm{cm}^{-2}, 30+60 \mathrm{~s}$ ) during 15 days (two times each day) led to a better oxygenation and a tumour volume decrease (Figure 24).

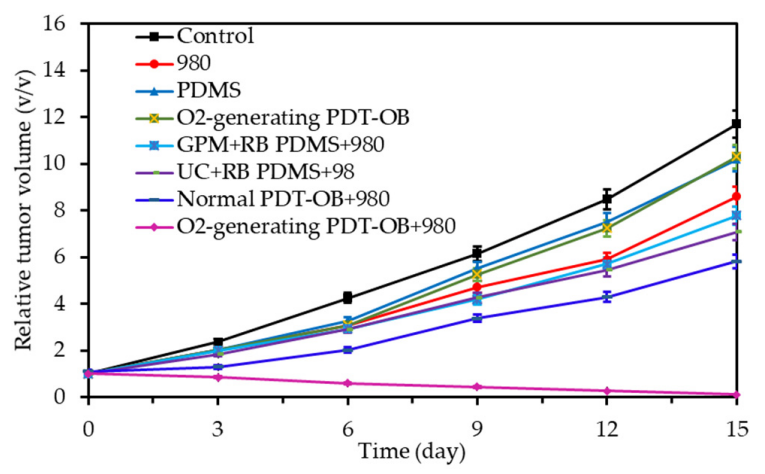

Figure 24. Tumour volumes evolution in different treatments groups. PDT-OB $=\mathrm{O}_{2}$ generating optical battery; GPM: Green luminescent material Adapted from Hu et al. [136].

A liposome-based NP containing $\mathrm{MB}$ and the $\mathrm{O}_{2}$ supplier $\mathrm{CaO}_{2}$ were synthetized by Liu et al. [137]. After a short irradiation time (30 s), photobleaching of the NPs occurred inducing the formation of $\mathrm{O}_{2}$ by release of $\mathrm{CaO}_{2}$ in water. After a long irradiation time (60 s), hypoxia in the tumour environment was regulated and a PDT effect was observed. The NPs were tested on $4 \mathrm{~T} 1$ cells. The regulation of hypoxia was demonstrated using a ROS detection kit. Dual-stage irradiation $\left(660 \mathrm{~nm}, 30 \mathrm{~mW} \cdot \mathrm{cm}^{-2}\right.$, $1 \mathrm{~min}$ and $5 \mathrm{~min}$ ) led to improved phototoxicity compared to single irradiation. The NPs were tested on subcutaneously 4T1 solid tumour bearing mouse. Tumour inhibition was observed after light illumination $\left(658 \mathrm{~nm}, 280 \mathrm{~mW} \cdot \mathrm{cm}^{-2}, 2+8 \mathrm{~min}\right)$ whereas negligible effect appeared in the dark group (Figure 25).

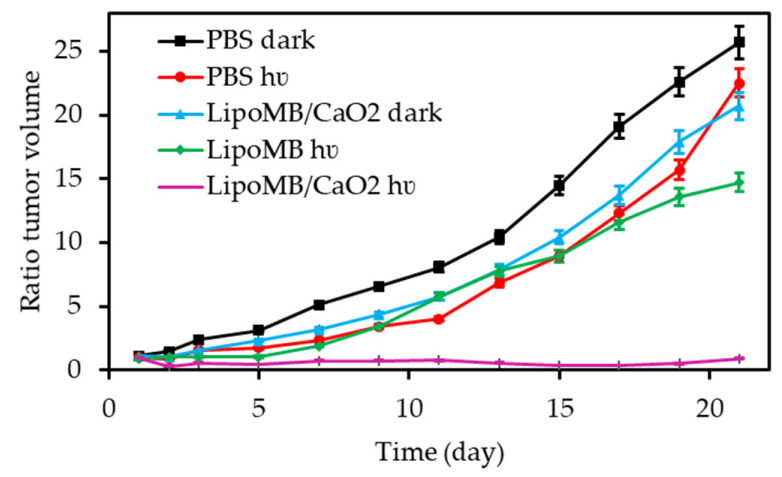

Figure 25. Relative tumour volume after different treatments. Adapted from Liu et al. [137].

Sheng et al. [138] synthesized a core shell NP with a $\mathrm{CaO}_{2}$ core coated with a $\mathrm{pH}$ sensitive methacrylate based copolymer that could undergo a dissolution at $\mathrm{pH}$ lower than 7.4, leading to the exposure of the $\mathrm{CaCO}_{2}$ to aqueous medium. The authors prepared a de-oxygenated PBS solution containing SOSG and RB and added $\mathrm{CaO}_{2} \mathrm{NPs}$ and irradiated (white light, $5 \mathrm{~min}$ ). The results revealed a significant increase $(324.8 \%, p<0.001)$ of SOSG fluorescence compared to the control experiments, indicating the ability of the NPs to provide $\mathrm{O}_{2}$ during PDT, to enhance the formation of ${ }^{1} \mathrm{O}_{2}$. The injection of NP in a BxPC-3 human pancreatic cancer cell line demonstrated an enhancement 
of the PDT effect. In vivo experiments were performed in Mia-PaCa 2 xenograft mice, $(3 * 3$ min Fenix LD01 LED50 $\mathrm{mW}, 205 \mathrm{~J} \cdot \mathrm{cm}^{-2}$ ) which is a model known to form hypoxic tumours. No significant difference in tumour volume for mice treated with PDT alone or $\mathrm{CaO}_{2} \mathrm{NPs}$ alone 5 days after treatment was observed whereas a significant reduction of $70.5 \%$ was observed for animals treated with the $\mathrm{CaO}_{2}$ NPs and PDT.

$\mathrm{C}_{3} \mathrm{~N}_{4}$ is known as a water splitting material biocompatible but presents limit efficiency in the red light region. Carbon-dot (CD)-doped carbon nitride $\left(\mathrm{C}_{3} \mathrm{~N}_{4}\right)$ NPs were designed by Zheng et al. [139] to enhance red light absorption and allow $\mathrm{O}_{2}$ production via water splitting. To overcome the limit efficiency in red light region, carbon dots have been added. PpIX-PEG-RGD was grafted on the NP. The association showed an enhanced $\mathrm{O}_{2}$ production compared to $\mathrm{C}_{3} \mathrm{~N}_{4}$ alone, allowing the decrease of hypoxia. ROS production after light illumination $\left(630 \mathrm{~nm}, 80 \mathrm{~mW} \cdot \mathrm{cm}^{-2}, 10 \mathrm{~min}\right)$ was measured in a 4T1 cell line. An enhancement could be observed with the NP, and not for PpIX or $\mathrm{C}_{3} \mathrm{~N}_{4}$ without CDs. After laser irradiation at $630 \mathrm{~nm}$, NP displayed the same phototoxicity in hypoxic and normoxic medium, contrary to PpIX. The NPs were tested in subcutaneously 4T1 solid tumour bearing mouse. NP injection and irradiation showed remarkable tumour growth inhibition contrary to PpIX or $C_{3} N_{4}$ without CDs.

Li et al. [140] associated Fe- $\mathrm{C}_{3} \mathrm{~N}_{4}$ NPs with tris(bipyridyl)cationic Ru complexes $\left(\mathrm{Ru}(\mathrm{bpy})_{3}{ }^{2+}\right.$ ) which enhance photocatalytic activity and act as PS. Ru complex absorption of near infrared light enhanced the charge transfer to $\mathrm{C}_{3} \mathrm{~N}_{4}$ and photocatalytic water splitting. The NPs irradiated at $800 \mathrm{~nm}$ $(2.7 \mathrm{~W}, 5 \mathrm{~min})$ allowed more $\mathrm{O}_{2}$ generation than $\mathrm{C}_{3} \mathrm{~N}_{4}$ or $\left(\mathrm{Ru}(\mathrm{bpy})_{3}{ }^{2+}\right)$ alone. The ROS production was also confirmed by using DCFH-DA and ESR. The NP biocompatibility, cellular uptake and phototoxicity $(800 \mathrm{~nm}, 2.7 \mathrm{~W}, 3 \mathrm{~min})$ were demonstrated on a $4 \mathrm{~T} 1 \mathrm{cell}$ line. Experiments on $4 \mathrm{~T} 1$ tumour bearing mice after intravenous injection of NPs and light irradiation (800 nm, $2.7 \mathrm{~W}, 5 \mathrm{~min})$ showed significant tumour inhibition.

Yang et al. [141] developed a theranostic platform that associated UCNPs $\left(\mathrm{NaGdF}_{4}: \mathrm{Yb}, \mathrm{Tm} @ \mathrm{NaGdF}_{4}\right)$ graphic- $\mathrm{C}_{3} \mathrm{~N}_{4}$ nanosheets (one PS) and carbon dots (another PS) incorporated in a ZIF-8 metal-organic framework (MOF) shell. The combination of g- $\mathrm{C}_{3} \mathrm{~N}_{4}$ and CDs could induce stepwise water splitting: (1) ${ }_{2} \mathrm{H}_{2} \mathrm{O} \rightarrow \mathrm{H}_{2} \mathrm{O}_{2}+\mathrm{H}_{2}$; (2) $2 \mathrm{H}_{2} \mathrm{O}_{2} \rightarrow 2 \mathrm{H}_{2} \mathrm{O}+\mathrm{O}_{2}$. The phototoxicity was observed on HeLa cells after NIR irradiation $\left(980 \mathrm{~nm}, 500 \mathrm{~mW} \cdot \mathrm{cm}^{-}{ }^{2}, 5 \mathrm{~min}\right)$ (Figure 26). The NPs injected in U14 tumour-bearing mice irradiated at $980 \mathrm{~nm}\left(0.5 \mathrm{~W} \cdot \mathrm{cm}^{-2}, 10 \mathrm{~min}\right)$ induced a delayed tumour growth.
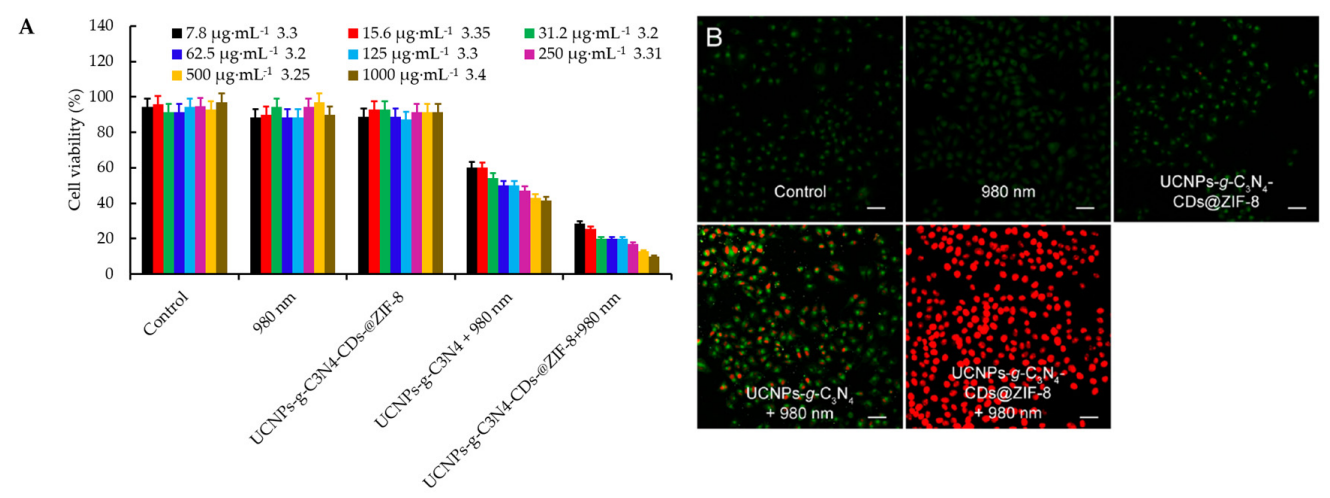

Figure 26. (A) In vitro cell viabilities of HeLa cells incubated with cell culture (control), $980 \mathrm{~nm}$ light, UCNPs-g-C3N4 with 980 nm laser irradiation, and UCNPs-g-C3N4-CDs@ZIF-8 at varied concentrations with and without $980 \mathrm{~nm}$ laser irradiation. Adapted from Yang et al. [141] (B) CLSM images of HeLa cells incubated with different conditions corresponding to the toxicity test in vitro, and all the cells are marked with calcein AM and PI. Reprinted from [141] with permission from the American Chemical Society, Copyright 2017. 
Zheng et al. [142] designed a platform assembling an $\mathrm{O}_{2}$-generated thylakoid membrane from plants (spinach, lettuce, carbage) fused with synthetic $\mathrm{NP}\left(\mathrm{Ag}, \mathrm{SiO}_{2}, \mathrm{ZnO}\right)$. This idea come from the fact that in nature, plants possess a very oxygenic photosynthesis system that allow the photocatalyzed formation of $\mathrm{O}_{2}$. These platforms exhibited good $\mathrm{O}_{2}$ generation that could reverse the tumour hypoxia. This $\mathrm{O}_{2}$ production proved to be higher compared to $\mathrm{CaO}_{2}$ or $\mathrm{MnO}_{2}$. The in vivo generation of $\mathrm{O}_{2}$ was proven in CT26 tumour bearing Balb/C mice. The authors observed enhanced PDT when they added the platform to $\mathrm{MB}\left(660 \mathrm{~nm}, 155 \mathrm{~mW} \cdot \mathrm{cm}^{-2}, 2 \mathrm{~min}\right)$.

In 2015, Zhou et al. [143] synthesized of a monolayer of $\mathrm{Bi}_{2} \mathrm{WO}_{6}$ with highly active surface that could generate photocatalytic oxidation reactions, leading to the oxidation of $\mathrm{H}_{2} \mathrm{O}$ (or $\mathrm{OH}^{-}$) to ${ }^{\bullet} \mathrm{OH}$ upon laser irradiation. Indeed, $\mathrm{Bi}_{2} \mathrm{WO}_{6}$ could produce $\mathrm{ROS}$ without the need of $\mathrm{O}_{2}$. Zhang et al. [144] demonstrated that small $\mathrm{Bi}_{2} \mathrm{WO}_{6} \mathrm{NPs}(5 \mathrm{~nm})$ grafted with carboxylic acid groups could efficiently generate ${ }^{\bullet} \mathrm{OH}$ after irradiation in the NIR grange $\left(808 \mathrm{~nm}, 1 \mathrm{~W} \cdot \mathrm{cm}^{-2}, 5\right.$ to $\left.20 \mathrm{~min}\right)$. The in vivo injection of the NP in HeLa tumour bearing nude mice showed a photothermal effect until $47^{\circ} \mathrm{C}$ after $8 \mathrm{~min}$ irradiation $\left(808 \mathrm{~nm}, 1 \mathrm{~W} \cdot \mathrm{cm}^{-2}\right)$ because of their strong Plasmon resonance. The ROS production was evaluated both by the SOSG for ${ }^{1} \mathrm{O}_{2}$ and by EPR for ${ }^{\bullet} \mathrm{OH}$ radicals. Formation of ${ }^{\bullet} \mathrm{OH}$ played a dominant role. The in vivo PDT (HeLa tumour bearing mouse model, $808 \mathrm{~nm}, 1 \mathrm{~W} \cdot \mathrm{cm}^{-2}, 8 \mathrm{~min}$ ) showed that $\mathrm{Bi}_{2} \mathrm{WO}_{6} \mathrm{NPs}$ induced photodynamic killing in a hypoxia-free manner resulting in tumour continuous decrease of the tumour volume (Figure 27). It was not the case for ICG and $\mathrm{W}_{18} \mathrm{O}_{49} \mathrm{NPs}$, which could react, with $\mathrm{O}_{2}$ absorbed onto the NP to generate ROS in an $\mathrm{O}_{2}$ independent manner.

a)

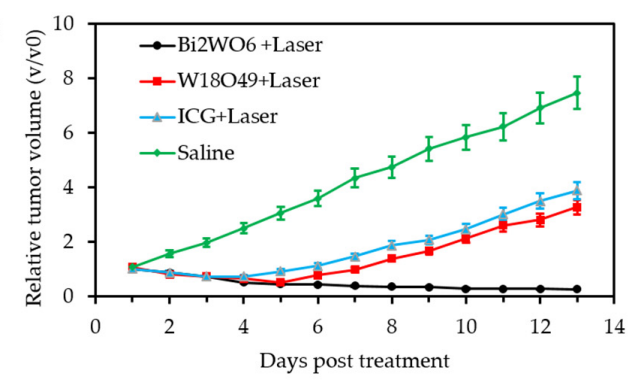

c)

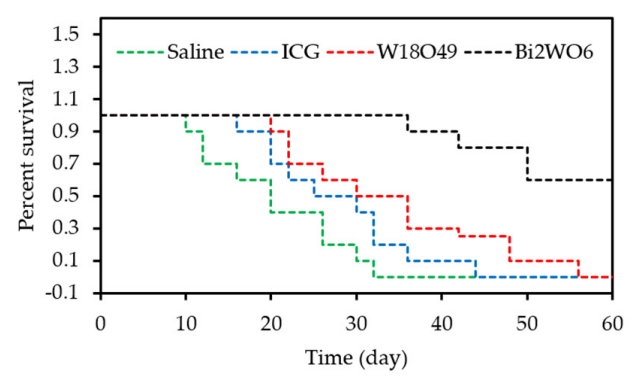

b)

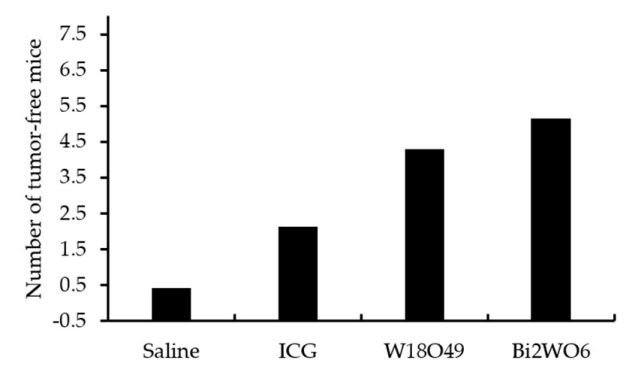

d)

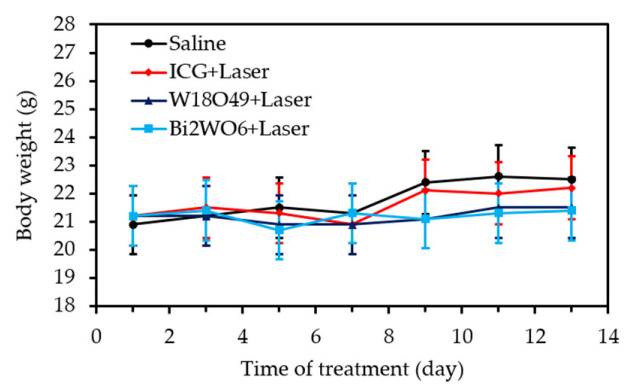

Figure 27. (a) Tumour volumes of HeLa-tumour-bearing mice that received different treatments as displayed. (b) Number of tumour-free mice after treatment during the observation. (c) Survival curves of HeLa-tumour bearing mice that received different treatments as displayed. (d) Body weight of HeLa-tumour-bearing mice that received different treatments as indicated. Adapted from Zhang et al. [144].

Fan et al. in 2017 [145] developed semiconductor materials with broadband light response in $\mathrm{UV}$ and visible region. Usually photocatalytic reaction produce $\mathrm{O}_{2}$ by splitting water, in vivo, but not enough to produce ROS in sufficient quantity by PDT. To improve the efficiency, such nanorods (CdSe-seeded/Cds) were doped with deposited Au, forming a hybrid nanocomposite (HNC) (Figure 28). RGD peptide was coupled to target $\alpha_{\mathrm{v}} \beta_{3}$ receptors. Under visible excitation, the nanorods induced charge separation and delocalized electrons, which were transferred to $\mathrm{Au}$, increasing the ROS generation by water splitting. 


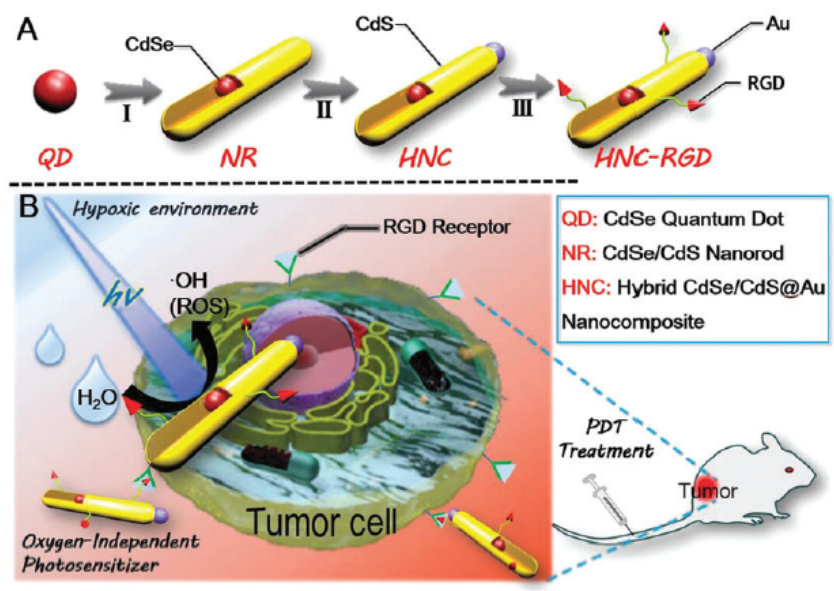

Figure 28. (A) Structure of HNCs: (I) anisotropic growth of NRs; (II) gold deposition on top of NRs; (III) RGD modification of HNCs; (B) schematic diagram of visible light driven water splitting to generate ROS for PDT treatment. Republished from [145] with permission from the Royal Society of Chemistry, Copyright 2017.

In vitro, excitation was performed with a blue LED $\left(450 \mathrm{~nm}, 500 \mathrm{~mW} \cdot \mathrm{cm}^{-2}, 10 \mathrm{~min}\right)$. A significant increase of intracellular ROS was observed in COS-7 and HeLa cells with HNC in normoxic conditions. Moreover, cytotoxicity assays have been performed on $4 \mathrm{~T} 1$ cells, with irradiation by blue LED during 1 , 2 and $3 \mathrm{~min}$. 20\% viability of cells was observed in normoxic and hypoxic conditions, to be compared to the $80 \%$ obtained with non-modified nanorods (CdSe-seeded/Cds). In vivo model was the murine $4 \mathrm{~T} 1$ breast-adenocarcinoma mouse on female balb/c mice. Obvious tumour growth inhibition was observed when NCNs-RGD were used under blue light irradiation (30 $\mathrm{min})$, indicating the excellent accumulation of these nanorods in the tumour and improvement of the PDT effect in hypoxic media (Table 10).

\subsection{Destruction of Tumour Extracellular Matrix (ECM)}

Proteins such as collagen, glycoproteins, elastin, and proteoglycans are constituents of normal connective tissues. The tumour-associated proteases are likely to destroy some of these proteins inducing, by the way, the invasive process and thus metastasis. However, destruction of the extracellular matrix may be useful if it is cleverly applied. Indeed, it can lead to better vascularization and therefore to an excess supply of $\mathrm{O}_{2}$, thus reducing hypoxia.

In 2016, Gong et al. [146] investigated the effect of the administration of hyaluronidase (HAase) before PDT with nanomicelles containing Ce6 (NM-Ce6). The HAase treatment could degrade ECM by breaking down hyaluronan leading to an increase of the blood vessel density and the perfusion of the tumour. The accumulation of nm-Ce6, with an average size of $33 \mathrm{~nm}$, in tumours was studied after administration of different doses of HAase $(0,375,750,1500$ and $3000 \mathrm{U})$ and a significant increase in the tumour uptake of nm-Ce6 ( 2-fold) was observed with the HAase treatment with an optimal dose at $1500 \mathrm{U}$. The significant decrease of HIF-1 $\alpha$ after this HAase administration proved an improvement of hypoxia conditions in the tumour. In vivo PDT studies were performed in balb/c mice bearing 4T1 tumours. No effect on the tumour growth was observed with the administration of HAase alone but in combination with PDT treatment with $\mathrm{nm}-\mathrm{Ce} 6$ under light irradiation at $660 \mathrm{~nm}\left(2 \mathrm{~mW} \cdot \mathrm{cm}^{-2}, 1 \mathrm{~h}\right)$, there was an almost total inhibition of the tumour growth. The authors also investigated the effect of HAase administration on PDT efficiency against lymphatic metastasis since HAase presented the ability to move in drainage lymph nodes and thus increased the EPR effect of nm-Ce6 and relieved the hypoxia in both the tumour and the metastases sites. To reduce invasiveness of local injection of HAase, this last one was PEGylated to form HAase-PEG for systemic local injection and the same EPR and hypoxia effects were observed. 
Table 10. Summary of publication about water splitting.

\begin{tabular}{|c|c|c|c|c|c|c|c|c|}
\hline Ref & Application & Catalyst & $\mathrm{O}_{2}$ Source & PS & Energy of Excitation & Type of ROS & In Vitro & In Vivo \\
\hline [136] & PDT & $\mathrm{CaO}_{2}$ & Water splitting & $\mathrm{RB}$ & $980 \mathrm{~nm}, 2 \mathrm{~W} \cdot \mathrm{cm}^{-2}, 5 \mathrm{~s}$ & ${ }^{1} \mathrm{O}_{2}$ & HT29 cell line & $\begin{array}{l}\text { HT29 tumour-bearing } \\
\text { mice }\end{array}$ \\
\hline [137] & PDT & $\mathrm{CaO}_{2}$ & Water splitting & MB & $\begin{array}{c}\text { In vitro: } 660 \mathrm{~nm}, 30 \mathrm{~mW} \cdot \mathrm{cm}^{-2} \\
30+60 \mathrm{~s} \\
\text { In vivo: } 658 \mathrm{~nm}, 280 \mathrm{~mW} \cdot \mathrm{cm}^{-2} \\
2+8 \mathrm{~min}\end{array}$ & ${ }^{1} \mathrm{O}_{2}$ & $4 \mathrm{~T} 1$ cell line & $\begin{array}{l}\text { 4T1 tumour-bearing } \\
\text { mice }\end{array}$ \\
\hline [138] & PDT & $\mathrm{CaO}_{2}$ & Water splitting & $\mathrm{RB}$ & White light, $205 \mathrm{~J} \cdot \mathrm{cm}^{-2}, 5 \mathrm{~min}$ & ${ }^{1} \mathrm{O}_{2}$ & BxPC-3 cell line & $\begin{array}{c}\text { MIAPaCa-2 } \\
\text { tumour-bearing mice }\end{array}$ \\
\hline [139] & PDT & $\mathrm{C}_{3} \mathrm{~N}_{4} \mathrm{NPs}$ & Water splitting & PpIX & $630 \mathrm{~nm}, 80 \mathrm{~mW} \cdot \mathrm{cm}^{-2}, 10 \mathrm{~min}$ & nd & $4 \mathrm{~T} 1$ cell line & $\begin{array}{l}4 \mathrm{~T} 1 \text { tumour-bearing } \\
\text { mice }\end{array}$ \\
\hline [140] & PDT & $\mathrm{Fe}-\mathrm{C}_{3} \mathrm{~N}_{4} \mathrm{NPs}$ & Water splitting & $\mathrm{Ru}(\mathrm{bpy})_{3}{ }^{2+}$ & $\begin{array}{c}\text { In vitro: } 800 \mathrm{~nm}-2 \text { photons, } \\
2.7 \mathrm{~W}, 3 \text { or } 5 \text { min } \\
\text { In vivo: } 800 \mathrm{~nm}-2 \text { photons, } 2.7 \\
\mathrm{~W}, 5 \mathrm{~min}\end{array}$ & ${ }^{1} \mathrm{O}_{2}$ & $4 \mathrm{~T} 1$ cell line & $\begin{array}{c}\text { 4T1 tumour bearing } \\
\text { Balb/ } \\
\text { c mice }\end{array}$ \\
\hline [141] & PDT & $\mathrm{C}_{3} \mathrm{~N}_{4}$ nanosheets & Water splitting & $\mathrm{CD}$ & $\begin{array}{c}\text { In vitro: } 980 \mathrm{~nm}, \\
500 \mathrm{~mW} \cdot \mathrm{cm}^{-2}, 5 \mathrm{~min} \\
\text { In vivo: } 980 \mathrm{~nm}, 500 \mathrm{~mW} \cdot \mathrm{cm}^{-2} \\
10 \mathrm{~min}\end{array}$ & $\begin{array}{l}\bullet \mathrm{OH}^{-} \\
\mathrm{O}_{2}^{-} \bullet\end{array}$ & HeLa cell line & $\begin{array}{l}\text { U14 tumour-bearing } \\
\text { mice }\end{array}$ \\
\hline [142] & PDT & $\begin{array}{l}\text { Thylakoid } \\
\text { membrane from } \\
\text { plants }\end{array}$ & Water splitting & $\begin{array}{c}\mathrm{Ag}, \mathrm{SiO}_{2} \text { or } \mathrm{ZnO} \\
\mathrm{NPs}\end{array}$ & $660 \mathrm{~nm}, 155 \mathrm{~mW} \cdot \mathrm{cm}^{-2}, 2 \mathrm{~min}$ & ROS & CT26 cell line & $\begin{array}{l}\text { CT26 tumour-bearing } \\
\text { mice }\end{array}$ \\
\hline [144] & PTT/PDT & $\mathrm{Bi}_{2} \mathrm{WO}_{6} \mathrm{NPs}$ & Water splitting & $\mathrm{Bi}_{2} \mathrm{WO}_{6} \mathrm{NPs}$ & $808 \mathrm{~nm}, 1 \mathrm{~W} \cdot \mathrm{cm}^{-2}, 5$ to $20 \mathrm{~min}$ & $\bullet \mathrm{OH}$ & HeLa cell line & $\begin{array}{c}\text { HeLa tumour-bearing } \\
\text { mice }\end{array}$ \\
\hline [145] & PDT & $\begin{array}{l}\text { Au-semiconductor } \\
\text { nanocomposite }\end{array}$ & Water splitting & & $\begin{array}{c}\text { In vitro: } 450 \mathrm{~nm}, \\
500 \mathrm{~mW} \cdot \mathrm{cm}^{-2}, 10 \mathrm{~min} \\
\text { In vivo: } 450 \mathrm{~nm}, 500 \mathrm{~mW} \cdot \mathrm{cm}^{-2} \\
30 \mathrm{~min}\end{array}$ & nd & $4 \mathrm{~T} 1$ cell line & $\begin{array}{l}\text { 4T1 tumour-bearing } \\
\text { mice }\end{array}$ \\
\hline
\end{tabular}

nd: not determined; RB: Rose Bengal; MB: Methylene Blue; $\mathrm{C}_{3} \mathrm{~N}_{4}$ : Carbon nitride; PPIX: Protoporphyrin IX; Ru(bpy) ${ }_{3}^{2+}$ : tris(bipyridyl)cationic Ru complexes; $\mathrm{CD}$ : Carbon dot. 
Liu et al. [147] described another strategy, based on two steps to enhance PDT treatment: a first injection of NPs containing collagenase (CLG) to destroy tumour ECM by degradation of collagen and a second injection of liposomes containing Ce6 for PDT treatment. The $\mathrm{pH}$-sensitive NPs were composed of $\mathrm{Mn}^{2+}$ coordinated with benzoic-imine (BI)-linker to form nanoscale coordination polymers (NCPs) encapsulating CLG (CLG@NCP). CLG@NCP NPs were surrounded by a lipid PEG shell to finally formed CLG@NCP-PEG NPs possessing a hydrodynamic size of $106 \mathrm{~nm}$. The pH-sensitive relapse of CLG by CLG@NCP-PEG NPs was investigated by changing the $\mathrm{pH}$ of a solution containing CLG@NCP-PEG NPs, from 7.4 to 6.5 and after $24 \mathrm{~h}$ of incubation a release of $\sim 90 \%$ was observed. Moreover, a recovery of $\sim 80 \%$ of CLG enzyme activity was highlighted for a $\mathrm{pH}$ 6.5. In vivo in $4 \mathrm{~T} 1$ tumour bearing mice, a high tumour uptake was observed $24 \mathrm{~h}$ after injection of CLG@NCP-PEG NPs as well as a significant decrease of the collagen level in the tumours leading to an ECM degradation and thus an enhancement of blood flow perfusion. As a consequence of these effects of the level of tumour oxygenation, a significant increase over time was observed after treatment with CLG@NCP-PEG NPs (Figure 29) as well as a high decrease of hypoxia signals.

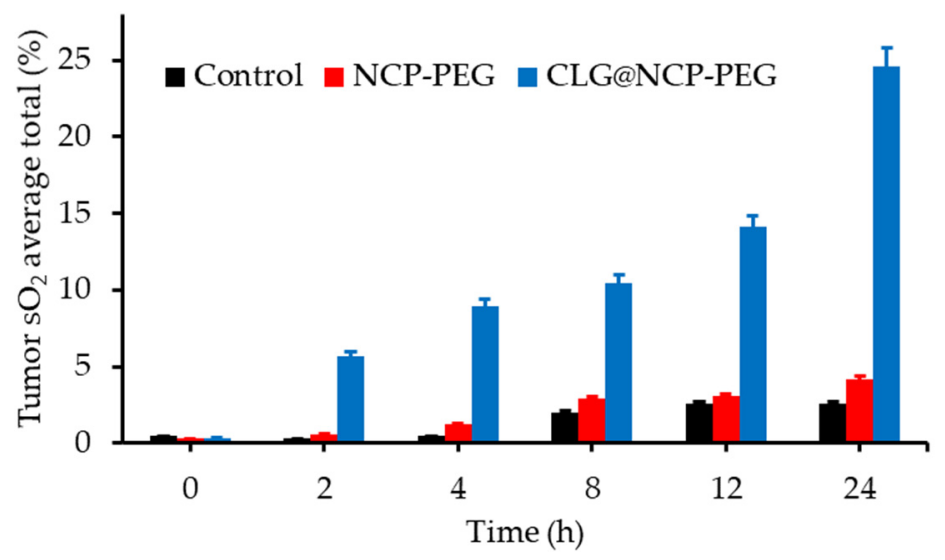

Figure 29. Quantification of the oxyhemoglobin saturation in the tumour from different groups over time. Adapted from Liu et al. [147].

The effect of a pretreatment with CLG@NCP-PEG NPs before PDT treatment with liposomes containing Ce6 (liposome@Ce6) was finally studied. The therapeutic PDT effect was dramatically improved with an effective tumour growth inhibition when mice where pretreated with CLG@NCP-PEG NPs $24 \mathrm{~h}$ before injection of liposome@Ce6 and irradiated $\left(660 \mathrm{~nm}, 5 \mathrm{~mW} \cdot \mathrm{cm}^{-2}, 60 \mathrm{~min}\right)$ after again 24 h. Moreover, CLG@NCP-PEG NPs showed no cytotoxicity over time (14 days) (Table 11).

\subsection{Decrease of Tumour $\mathrm{O}_{2}$ Consumption}

A recent strategy consists to decrease the tumour cells' demand for $\mathrm{O}_{2}$ by inhibiting mitochondrial respiration ((via NADH dehydrogenase). Several mitochondrial receptors can be targeted such as papaverine's or metformin's complexes and others. The expected reduced $\mathrm{O}_{2}$ consumption induces an increased oxygenation concentration. Since 2015, some drugs with potential ability to decrease the hypoxic fraction have been developed in the field of PDT and/or PTT. Nevertheless, some requirements must be taken into account to obtain a significant improvement in the treatment of cancer. Normally oxygenated tissues should not be affected, uptake by tumour cells should be rapid, minimal side effects and optimal clearance should be observed. Two teams have reported the use of metformin (Met) which is known to reduce tumour $\mathrm{O}_{2}$ consumption and thus increase tumour oxygenation. 
Table 11. Summary of publications about the destruction of ECM to modify TME.

\begin{tabular}{|c|c|c|c|c|c|c|c|c|}
\hline Ref & Application & Target & $\begin{array}{l}\text { Additional } \\
\text { Compound }\end{array}$ & PS & Energy of Excitation & Type of ROS & In Vitro & In Vivo \\
\hline [146] & PDT & $\begin{array}{l}\text { Hyaluronan of } \\
\text { ECM }\end{array}$ & Hyaluronidase & Ce6 & $\begin{array}{c}660 \mathrm{~nm}, 2 \mathrm{~mW} \cdot \mathrm{cm}^{-2} \\
60 \mathrm{~min}\end{array}$ & $\begin{array}{c}{ }^{1} \mathrm{O}_{2} \text { and others } \\
\text { ROS }\end{array}$ & No & $\begin{array}{l}4 \mathrm{~T} 1 \text { tumour-bearing } \\
\text { mice }\end{array}$ \\
\hline [147] & PDT & $\begin{array}{l}\text { Collagen of } \\
\text { ECM }\end{array}$ & Collagenase & Ce6 & $\begin{array}{c}660 \mathrm{~nm}, 5 \mathrm{~mW} \cdot \mathrm{cm}^{-2} \\
60 \mathrm{~min}\end{array}$ & nd & No & $\begin{array}{l}4 \mathrm{~T} 1 \text { tumour-bearing } \\
\text { mice }\end{array}$ \\
\hline
\end{tabular}


In 2017, Song et al. [148] incorporated in PEG liposomes, HCe6 (hydrophobic Ce6) and a hypoglycemic agent, Met. The resulting NPs exhibited a ${ }^{1} \mathrm{O}_{2}$ generation under $660 \mathrm{~nm}$ light excitation. In vitro studies were performed in 4T1 cells to evaluate the PDT efficiency of Met-HCe6-liposomes in comparison with HCe6-liposomes and Met or Ce6 alone. After a $660 \mathrm{~nm}$ light irradiation for $10 \mathrm{~min}$, all Ce6 formulations showed almost the same PDT effect in normoxic conditions. In vivo tests were performed in mice bearing 4T1 tumours injected with Met-HCe6-liposomes. The authors used PA to evaluate the tumour oxygenation in presence of Met alone or Met-liposomes by following the level of oxygenated $\mathrm{Hb}$ (oxyhemoglobin) in tissues. A high increase was observed for both after $2 \mathrm{~h}$ with a decrease over time, after $2 \mathrm{~h}$, for Met alone. However, for Met-liposomes, the increase of oxyhemoglobin subsists over time due to a continuous release of Met. After injection of Met-HCe6-liposomes, a significant reduction of hypoxia was observed $2 \mathrm{~h}$ and $24 \mathrm{~h}$ after injection $(57 \%$ to $27 \%$ and $15 \%$ respectively), by using pimonidazole hydrochloride. The improvement of tumour oxygenation with this compound was also proved in two other tumour models (CT26 colon cancer and SCC-7). Finally, the improvement of PDT efficiency was confirmed by in vivo studies in a 4T1 tumour model. After injection of Met-HCe6-liposomes or HCe6-liposomes 24h before a $660 \mathrm{~nm}$ light irradiation $\left(0.035 \mathrm{~W} \cdot \mathrm{cm}^{-2}, 30 \mathrm{~min}\right)$, the tumour growth was highly decreased for both in comparison with PDT treatment with Ce6 alone. Moreover, the most significant inhibition of tumour growth was observed for group treated with Met-HCe6-liposomes-mediated PDT (Table 12).

Zuo et al. [149] designed NPs (PM-W ${ }_{18} \mathrm{O}_{49}$-Met NPs) composed by $\mathrm{W}_{18} \mathrm{O}_{49}$ NPs (PDT and PTT application) and Met encapsulated in platelet membranes (PM) for a better biocompatibility. They first evaluated the properties of $\mathrm{W}_{18} \mathrm{O}_{49}$ NPs and PM- $\mathrm{W}_{18} \mathrm{O}_{49}$ NPs without Met and found respective mean diameter of $5 \mathrm{~nm}$ and $115 \mathrm{~nm}$. Under an $808 \mathrm{~nm}$ laser irradiation $\left(1 \mathrm{~W} \cdot \mathrm{cm}^{-2}, 10 \mathrm{~min}\right)$, a solution of $\mathrm{PM}-\mathrm{W}_{18} \mathrm{O}_{49} \mathrm{NPs}$ showed an increase of temperature from 24.2 to $61.6{ }^{\circ} \mathrm{C}$ over time. Moreover, they observed ${ }^{1} \mathrm{O}_{2}$ production and of the ability to transform laser energy to heat for PM- $\mathrm{W}_{18} \mathrm{O}_{49}$ NPs contrary to $\mathrm{W}_{18} \mathrm{O}_{49}$ NPs alone indicating a protecting effect of PM. The introduction of Met in $\mathrm{PM}-\mathrm{W}_{18} \mathrm{O}_{49}$ NPs did not affect its characteristics (size, morphologic, optical) and PM-W $\mathrm{W}_{18} \mathrm{O}_{49}-\mathrm{Met}_{\mathrm{NPs}}$ allowed an effective release of Met in the tumour. The efficiency of PM- $\mathrm{W}_{18} \mathrm{O}_{49}$-Met NPs to reduce tumour $\mathrm{O}_{2}$ consumption was evaluated in Raji cells and compared to that of Met alone. For both compounds, a significant decrease $(70 \%)$ of $\mathrm{O}_{2}$ consumption rate was observed after $24 \mathrm{~h}$ incubation. An induction of hypoxia simultaneously to increase of ROS production was observed for $\mathrm{PM}-\mathrm{W}_{18} \mathrm{O}_{49}$ NPs whereas a higher level of ROS production was observed for PM- $\mathrm{W}_{18} \mathrm{O}_{49}$-Met NPs with a decrease

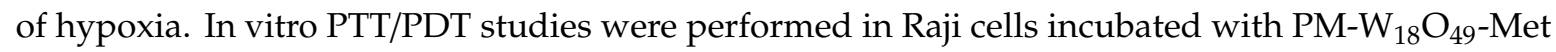
$\mathrm{NPs}, \mathrm{PM}-\mathrm{W}_{18} \mathrm{O}_{49} \mathrm{NPs}$ or $\mathrm{W}_{18} \mathrm{O}_{49} \mathrm{NPs}$ and irradiated at $808 \mathrm{~nm}\left(1 \mathrm{~W} \cdot \mathrm{cm}^{-2}, 10 \mathrm{~min}\right)$. A highly decrease of cell viability was observed for all these compounds but $\mathrm{PM}-\mathrm{W}_{18} \mathrm{O}_{49}-$ Met NPs presented the highest cytotoxicity with a level of viability inferior at $20 \%$. The antitumour efficacy was confirmed by in vivo tests in mice bearing Raji-lymphoma xenografts injected with the same compounds and irradiated at $808 \mathrm{~nm}$ (10 min).

Two others systems based on two different compounds (tamoxifen, TAM, and atovaquone, Ato) able to reduce $\mathrm{O}_{2}$ consumption have been described. In 2018, Yang et al. [150] developed a system based on the use of TAM. They combined in solution Ce6-modified HSA (HSA-Ce6) with TAM to induce a self-assembly of NPs which could be dissociated under acidic $\mathrm{pH}$. They also synthesized as a control covalently cross-linked HSA-Ce6 NPs (C-HSA-Ce6 NPs). The NPs formed: HSA-Ce6/TAM NPs and C-HSA-Ce6 NPs presented a hydrodynamic size of $130 \mathrm{~nm}$ and $80 \mathrm{~nm}$ respectively. When the environment became acidic, the TAM molecules were protonated, which could induce NPs dissociation. They found that the presence of TAM and HSA did not affect the ${ }^{1} \mathrm{O}_{2}$ generation induce by Ce6. In vitro PDT efficiency was evaluated in 4T1 cells incubated with HSA-Ce6/TAM NPs $6 \mathrm{~h}$ before $660 \mathrm{~nm}$ light irradiation $\left(5 \mathrm{~mW} \cdot \mathrm{cm}^{-2}, 30 \mathrm{~min}\right)$. The HSA-Ce6/TAM NPs showed a photocytotoxicity similar as that observed for C-HSA-Ce6 NPs or Ce6 alone. By performing in vivo studies, in mice bearing 4T1 tumours, the authors observed a tumour uptake of HSA-Ce6/TAM NPs significantly higher than C-HSA-Ce6 NPs or Ce6 alone due to the pH-induced dissociation of HSA-Ce6/TAM NPs in HSA-Ce6 
allowing an intratumoural penetration more efficient. Moreover, they investigated the evolution of tumour oxygenation after injection of HSA-Ce6/TAM NPs by using PA imaging and observed an increase of tumour oxygenation from $0.91 \%$ to $10.9 \%$. By using pimonidazole they found a reduction of hypoxia from $21.6 \%$ to $2.04 \%$ for mice treated with HSA-Ce6/TAM NPs. The in vivo PDT efficiency was evaluated by injection in mice of HSA-Ce6/TAM NPs and C-HSA-Ce6 NPs following by $660 \mathrm{~nm}$ light irradiation. A high phototoxic effect was highlighted for mice treated HSA-Ce6/TAM NPs and light with some complete eradication of the tumour whereas for the control groups (C-HSA-Ce6 + Light or HSA-Ce6/TAM NPs alone), any inhibition of tumour growth was observed.

Xia et al. [151] described another vehicle with a reducible size based on gelatin for a better tumour uptake encapsulating a PS (ICG-BSA nanocomplex) and Ato. The gelatin NPs thus formed were denoted Ato-ICG-GNPs $(437 \pm 52 \mathrm{~nm}$ ). These NPs could be reduced in the tumour by enzymes (matrix metallopeptidase, MMP-2) and thus highly release in the tumour site Ato and ICG-BSA after only $2 \mathrm{~h}$ (Figure 30).

a)

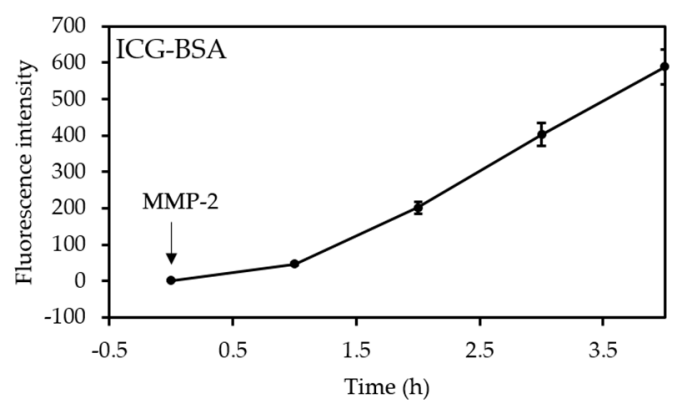

b)

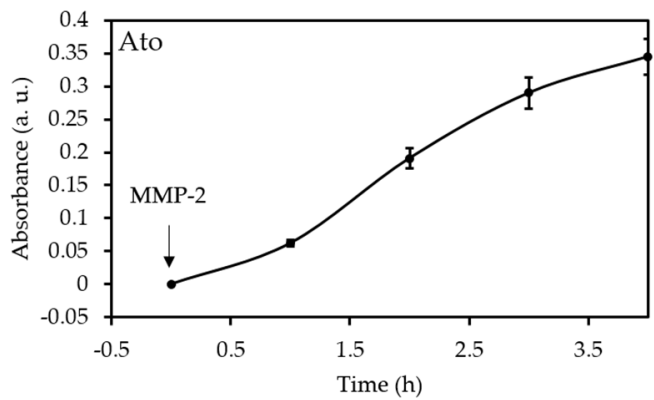

Figure 30. MMP-2-triggered shape remodelling and cell uptake behaviour of Ato-ICG-GNPs. (a) Fluorescence intensity of ICG-BSA $(795 \mathrm{~nm})$ in the supernatant. (b) Absorbance of Ato $(490 \mathrm{~nm})$ in the supernatant. Adapted from Xia et al. [151].

The ability of Ato-ICG-GNPs to reduce tumour $\mathrm{O}_{2}$ consumption was investigated in HeLa cells and compare to Ato alone. The $\mathrm{O}_{2}$ consumption rate was significantly reduced by $50 \%$, after incubation of cells with $2 \mu \mathrm{M}$ of Ato or Ato-ICG-GNPs and no difference was observed between the two compounds. The evaluation of OCR was done in both normoxic $\left(21 \%\right.$ of $\left.\mathrm{O}_{2}\right)$ and hypoxic $\left(2 \%\right.$ of $\left.\mathrm{O}_{2}\right)$ conditions and any influence of $\mathrm{O}_{2}$ on Ato efficiency was highlighted. It was also observed that in presence of Ato-ICG-GNPs, the cell proliferation slowed down (Figure 31 and Table 12).

a)

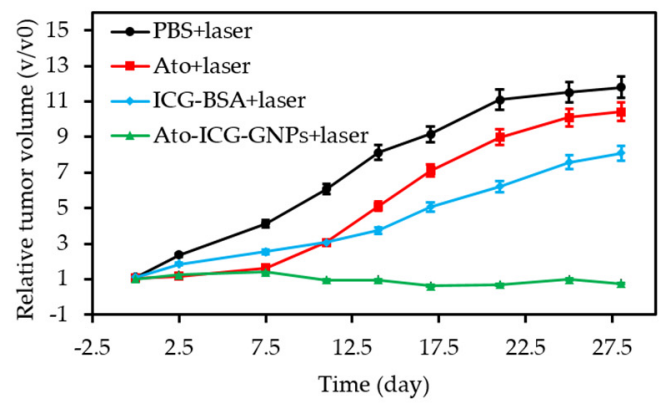

b)

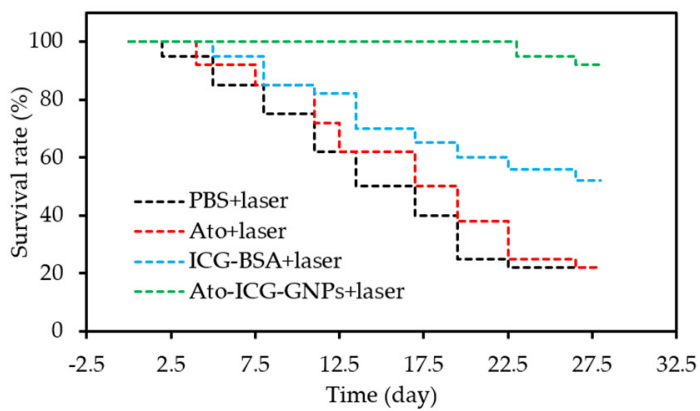

Figure 31. In vivo therapeutic outcome. (a) Relative tumour growth curves of mice received different treatments within a total of 28 days. Control ( $0.1 \mathrm{~mL}$ per mouse, PBS); Ato ( $0.1 \mathrm{~mL}$ per mouse, containing $330.15 \mu \mathrm{g} \cdot \mathrm{mL}^{-1}$ Ato); ICG-BSA $\left(0.1 \mathrm{~mL}\right.$ per mouse, containing $\left.37.44 \mu \mathrm{g} \cdot \mathrm{mL}^{-1} \mathrm{ICG}\right)$; Ato-ICG-GNPs ( $0.1 \mathrm{~mL}$ per mouse, containing $330.15 \mu \mathrm{g} \cdot \mathrm{mL}^{-1}$ Ato and $37.44 \mu \mathrm{g} \cdot \mathrm{mL}^{-1} \mathrm{ICG}$ ). The tumour region was irradiated by a $808 \mathrm{~nm}$ laser with a power density of $1 \mathrm{~W} \cdot \mathrm{cm}^{-2}$ for a duration of $5 \mathrm{~min}$ at 4 h post injection. ( $\mathrm{n}=18$ in each group). (b) Survival profiles as represented by the calculated rate of survival. Adapted from Xia et al. [151]. 
Table 12. Summary of publications about the reduction of tumour $\mathrm{O}_{2}$ consumption to modify TME.

\begin{tabular}{|c|c|c|c|c|c|c|c|}
\hline Ref & Application & $\begin{array}{l}\text { Additional } \\
\text { Compound }\end{array}$ & PS & Energy of Excitation & Type of ROS & In Vitro & In Vivo \\
\hline [148] & PDT & Met & HCe6 & $\begin{array}{c}\text { In vitro: } 660 \mathrm{~nm}, 10 \mathrm{~min} \\
\text { In vivo: } 660 \mathrm{~nm}, 30 \mathrm{~min} \text {, } \\
0.035 \mathrm{~W} \cdot \mathrm{cm}^{-2}\end{array}$ & nd & $4 \mathrm{~T} 1$ cell line & 4T1 tumour-bearing mice \\
\hline [149] & PDT & Met & $\mathrm{W}_{18} \mathrm{O}_{49}$ & $808 \mathrm{~nm}, 1 \mathrm{~W} \cdot \mathrm{cm}^{-2}, 10 \mathrm{~min}$ & ${ }^{1} \mathrm{O}_{2}$ & Raji cell line & Raji lymphoma-bearing mice \\
\hline [150] & PDT & TAM & Ce6 & $660 \mathrm{~nm}, 5 \mathrm{~mW} \cdot \mathrm{cm}^{-2}, 30 \mathrm{~min}$ & ${ }^{1} \mathrm{O}_{2}$ & 4T1 cell line & 4T1 tumour-bearing mice \\
\hline [151] & PDT & Ato & $\begin{array}{c}\text { ICG-BSA } \\
\text { nanocomplex }\end{array}$ & $808 \mathrm{~nm}, 1 \mathrm{~W} \cdot \mathrm{cm}^{-2}, 5 \mathrm{~min}$ & ROS & HeLa cell line & HeLa tumour-bearing mice \\
\hline
\end{tabular}

nd: not determined; Met: Metformin; HCe6: Hydrophobic Chlorin e6; TAM: Tamoxifen; Ato: Atovaquone; ICG-BSA: Indocyanine Green-Bovine Serum Albumin. 
The PDT efficiency of Ato-ICG-GNPs in comparison with ICG-BSA was investigated in vitro in HeLa cells incubated with Ato-ICG-GNPs or ICG-BSA and irradiated with an $808 \mathrm{~nm}$ laser $\left(1.0 \mathrm{~W} \cdot \mathrm{cm}^{-2}\right.$, $5 \mathrm{~min}$ ). A high decrease of cell viability was observed for both with a significantly better phototoxicity for Ato-ICG-GNPs. In vivo studies in mice bearing HeLa-xenograft confirmed the results observed in vitro with a high decrease of tumour growth for mice treated with Ato-ICG-GNPs and laser irradiation (treatment repeated four times) (Figure 31a) and a survival rate of $90 \%$ after 3 weeks of treatment (Figure 31b).

\subsection{Others}

Two others ways to modify the TME have been reported. Gui et al. [152] explored a new strategy consisting in finding a way to deplete ATP in hypoxic cells. They synthesized a metal-organic framework NP with $\mathrm{Cu}^{2+}$ and $\mathrm{ZnPc}-(\mathrm{COOH})_{8}$ leading to a 3D architecture $\left(\left(\mathrm{Cu}_{8}\left(\mathrm{ZnPc}-(\mathrm{COOH})_{8}\right)_{n}\right.\right.$, $\mathrm{ZPCN}) . \mathrm{ZnPc}-(\mathrm{COOH})_{8}$ was aggregated into the NPs and ROS production was not efficient. The authors showed that addition of ATP led to the formation of ATP-Cu complex and free $\mathrm{ZnPc}-(\mathrm{COOH})_{8}$ could then produce again ${ }^{1} \mathrm{O}_{2}$. In A549 cells after PDT $(665 \mathrm{~nm})$ incubation with $\mathrm{Cu}^{2+}$ only did not decrease the survival, whereas with the PS survival was $55.4 \%$ and with ZPCN $23.7 \%$. They showed also that cells treated with ZPCN caused an important decrease in ATP concentration, arrested in the S phase, suggesting that DNS replication was stopped in the cells, a decrease in GSH level and high production of ROS and induced mitochondrial transmembrane potential depolarization of $68.72 \%$. In vivo in A549 tumour xenografts in nude mice, PDT $(665 \mathrm{~nm})$ induced the suppression of tumour growth.

In 2016, Lv et al. [153] designed two PS based on iridium (III) complexes: $\operatorname{Ir}\left(\mathrm{P}(\mathrm{ph})_{3}\right.$ and Ir-alkyl (Figure 32) for the specific targeting of mitochondria and lysosomes, respectively, to enhance the PDT effect.

a)

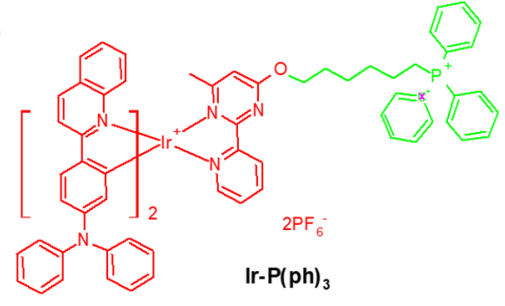

b)

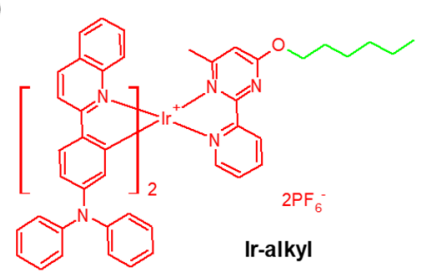

Figure 32. Chemical structures of (a) Ir-P(ph) 3 and (b) Ir-alkyl. Adapted from Lv et al. [153].

The authors treated HeLa cells with both complexes at different $\mathrm{O}_{2}$ levels and found that even under hypoxic conditions, the intracellular $\mathrm{O}_{2}$ concentration remains high for $\operatorname{Ir}\left(\mathrm{P}(\mathrm{ph})_{3}\right.$. They attributed this finding to an inhibition of respiration in mitochondria due to the PS. The PSs exhibited $\phi_{\Delta}$ of 0.17 for $\operatorname{Ir}\left(\mathrm{P}(\mathrm{ph})_{3}\right.$ and 0.21 for Ir-alkyl. After incubation with $\operatorname{Ir}\left(\mathrm{P}(\mathrm{ph})_{3}\right.$ or Ir-alkyl, under hypoxic conditions, a high intracellular $\mathrm{O}_{2}$ concentration was observed with $\operatorname{Ir}\left(\mathrm{P}(\mathrm{ph})_{3}(11 \%\right.$ against $3 \%$ for Ir-alkyl). Under a $475 \mathrm{~nm}$ irradiation $\left(22 \mathrm{~mW} \cdot \mathrm{cm}^{-2}, 30 \mathrm{~min}\right)$, for both compounds, cell death occurred in $4 \mathrm{~h}$ whereas in hypoxic conditions, $\operatorname{Ir}\left(\mathrm{P}(\mathrm{ph})_{3}\right.$ was more efficient to kill cells. Moreover, the irradiation of $\operatorname{Ir}\left(\mathrm{P}(\mathrm{ph})_{3}\right.$ induced more ROS generation than Ir-alkyl under both normoxic and hypoxic conditions.

\section{Combined Therapies}

In many diseases, a single treatment is often not effective or selective enough. One solution is to add a second therapy to the usual treatment. As a result, there are many opportunities for clinicians to improve the healing and comfort of patients. The combination of two or more simultaneous or consecutive modes of action may result in an additive or synergistic effects, i.e. creative cooperation. For example, one often speaks of "cocktail effect" in the case of complex mixtures of chemicals. In the field of cancer, various modalities can be applied $[154,155]$ and combining several interventions can minimize drug resistance, or fight against expected resistance. 
In this section, recent advancements of PDT associated with various other modalities (chemo-, antiangiogenic-, immuno-, or photothermal therapies) will be addressed.

\subsection{Chemo-PDT}

Chemotherapy is still the major treatment for many cancers. However, cancer cells can develop drug resistance, decreasing the effectiveness of the protocol, or even generating recurrence of cancer. The combination of chemotherapy and PDT as an adjuvant therapy can bring a synergistic effect that can lead to a decrease in drug doses and reduced systemic toxicity.

\subsubsection{Tirapazamine (TPZ)}

TPZ belongs to the class of benzotiazine-di-N-oxides of hypoxic cytotoxin. Thanks to a one-electron reduction of the molecule, free radical species are formed and induce single and double-strand breaks. Hypoxic microenvironment triggers TPZ. It was the first molecule not based on nitro or quinone functionalities to induce ROS in hypoxic conditions.

Liu et al. [156] designed double silica-shelled UCNP able of co-delivering silicon phthalocyanine dihydroxide (SPCD) and TPZ to afford TPZ-UC/SPCD for the NIR-induced synergetic therapy of tumours, by combining PDT and hypoxia-activated chemotherapy. Under $980 \mathrm{~nm}$ laser irradiation $\left(1.4 \mathrm{~W} \cdot \mathrm{cm}^{-2}, 5 \mathrm{~min}\right), \mathrm{TPZ}-\mathrm{UC} / \mathrm{SPCD}$ generated a large amount of ROS, and therefore high PDT efficacy against HeLa cells was achieved, resulting in a severe hypoxia which would further facilitate the activation of TPZ. Furthermore, according to the in vivo studies performed on tumour-bearing nude mice under $980 \mathrm{~nm}$ laser light $\left(1.4 \mathrm{~W} \cdot \mathrm{cm}^{-2}, 15 \mathrm{~min}\right)$, TPZ-UC/SPCD showed remarkably suppressed tumour growth compared to UC-PDT alone, which confirmed that the combined TPZ-PDT treatment could lead to marked cell apoptosis, further demonstrating the synergistic effects (Table 13).

Guo et al. [157] designed an angiogenesis vessel-targeting NPs (AVT-NPs) that consisted of a PS (5-(4-carboxyphenyl)-10, 15, 20- tris(3-hydroxyphenyl)chlorin, TPC), angiogenic vessel-targeting peptide (GX1 cyclopeptides), and TPZ (Figure 33).

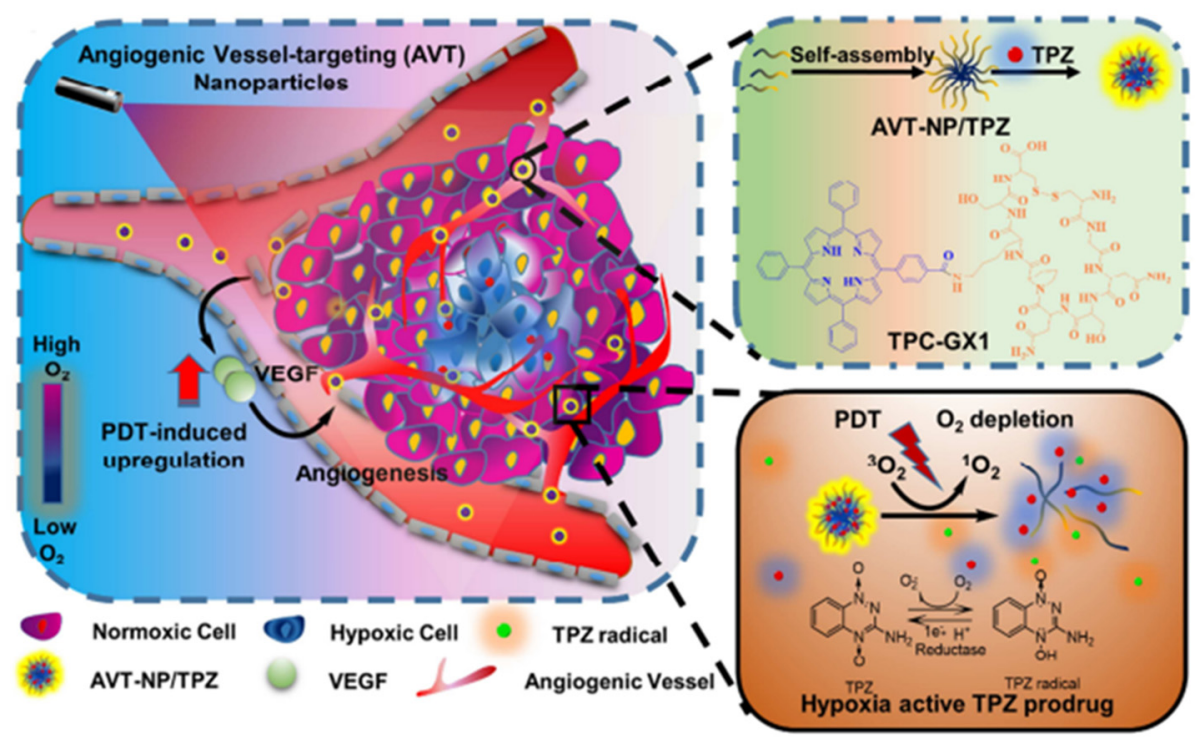

Figure 33. Schematic illustration and characterizations of AVT-NPs. The formation of AVT-NP, generation of cytotoxic TPZ radical under hypoxic conditions in cancer cells, and illustration of AVT-NP/TPZ based PDT that induces a local hypoxic environment and promoted angiogenesis for targeted drug delivery and synergistic chemo-photo therapy. Reprinted from [157] with permission from Elsevier Ltd, Copyright 2017.

The designed AVT-NPs showed high accumulation efficiency at the tumour site, resulting in a large production of ROS under laser $\left(650 \mathrm{~nm}, 1.2 \mathrm{~W} \cdot \mathrm{cm}^{-2}, 10 \mathrm{~min}\right)$ irradiation, and therefore high 
PDT efficacy was achieved which resulted in a severe hypoxia and increased angiogenesis. In the meantime, the exaggerated hypoxia further activated the bioreductive prodrug TPZ to also release highly cytotoxic radicals, leading to an enhanced antitumour efficacy both in vitro and in vivo (MCF-7 cells, $650 \mathrm{~nm}, 1.2 \mathrm{~W} \cdot \mathrm{cm}^{-2}, 10 \mathrm{~min}$ ) compared to free drug or non-targeted nanodrugs.

Li et al. [158] demonstrated a novel biomimetic nanoplatform (TPZ@PCN@Mem) for tumourtargeted combination therapy. TPZ@PCN@Mem was elaborated by loading the hypoxia-activated prodrug TPZ in a PCN-224 porphyrinic metal organic framework and then coating with the homotypic cancer cell membranes. The authors found that PCN-224 present in the nanoplatform generated large amounts of cytotoxic ROS once exposed to laser irradiation $\left(660 \mathrm{~nm}, 30 \mathrm{~mW} \cdot \mathrm{cm}^{-2}, 30 \mathrm{~s}\right)$ and the resulting hypoxia in the tumour aggravated by the photochemical $\mathrm{O}_{2}$ depletion further facilitated the activation of TPZ for successive bioreductive chemotherapy. Thus, according to the both in vitro $(660 \mathrm{~nm}$, $\left.30 \mathrm{~mW} \cdot \mathrm{cm}^{-2}, 5 \mathrm{~min}\right)$ and in vivo $\left(660 \mathrm{~nm}, 220 \mathrm{~mW} \cdot \mathrm{cm}^{-2}, 10 \mathrm{~min}\right)$ investigations, TPZ@PCN@Mem exhibited highly efficient therapeutic effect against a 4T1 tumour model with negligible side effects.

Wang et al. [159] reported the development of hybrid PLGA/lipid NPs able of codelivering ICG and TPZ to solid tumours by combining PDT and hypoxia-activated chemotherapy against metastatic breast cancer. Further conjugation of the NPs to iRGD (CRGDKGPDC) peptide provided NPs (iNP/IT) studied in both 3D tumour spheroids in vitro and orthotopic breast tumours in vivo. Upon near-IR laser $\left(808 \mathrm{~nm}, 2 \mathrm{~W} \cdot \mathrm{cm}^{-2}, 3 \mathrm{~min}\right)$, the NPs showed a high ROS production and therefore an important antitumour efficacy against metastatic $4 \mathrm{~T} 1$ tumour model under normal $\mathrm{O}_{2}$ conditions. Meanwhile, the hypoxic microenvironment in tumours triggered TPZ for synergistic cell-killing effect. Furthermore, according to the in vivo results (4T1 tumour-bearing mice, $808 \mathrm{~nm}, 2 \mathrm{~W} \cdot \mathrm{cm}^{-2}, 5 \mathrm{~min}$ ), iNP/IT could inhibit both primary tumour growth and metastasis with minimal side effects contrary to a mixture of NPs containing individual drugs

Chen et al. [160] have successfully developed photolabile HSA-based NPs modified with diazirine (DA) and loaded with ICG and TPZ (ICG/TPZ@HSA dNMs). Such photoresponsive ICG/TPZ@HSA dNMs were able to form aggregates via crosslinking of surface DA groups upon $405 \mathrm{~nm}\left(1.0 \mathrm{~W} \cdot \mathrm{cm}^{-2}\right)$ laser irradiation, thus causing enhanced tumour site accumulation and prolonged retention time. A successive laser exposure $\left(808 \mathrm{~nm}, 1.0 \mathrm{~W} \cdot \mathrm{cm}^{-2}, 7 \mathrm{~min}\right)$ of the ICG/TPZ@HSA dNMs at the tumour area enabled to trigger a cascade of synergistic therapeutic events by generation of ROS, hyperthermia, and consequent hypoxia microenvironment, which activated the initially nontoxic TPZ. Following systemic administration to mice bearing 4T1 tumours, ICG/TPZ@HSA dNMs eradicated efficiently the tumours by sequential irradiation of lasers $\left(405 \mathrm{~nm}, 0.75 \mathrm{~W} \cdot \mathrm{cm}^{-2}, 5 \mathrm{~min}\right.$ and $808 \mathrm{~nm}, 1.0 \mathrm{~W} \cdot \mathrm{cm}^{-2}, 10$ $\min )$.

Liu et al. [161] designed a multifunctional (Hf/TCPP) nmOF platform, denoted Hf/TCPP loaded with TPZ. Thanks to their porous surface nature, the Hf/TCPP nmOFs possess a high TPZ loading capacity $(80 \%)$. In addition, further surface PEGylation with DOPA-PIMA-mPEG enhanced their dispersibility and stability in physiological media and, significantly controlled the release rate of TPZ within TPZ/Hf/TCPP/PEG. Exposure of TPZ/Hf/TCPP/PEG nmOFs to laser irradiation $(635 \mathrm{~nm}$, $12 \mathrm{~mW} \cdot \mathrm{cm}^{-2}, 9 \mathrm{~min}$ ) provoked an efficient ROS production, triggered the activation of TPZ and as consequently a great cytotoxic effect against both HeLa and $4 \mathrm{~T} 1$ cells. Finally, the in vivo studies $\left(635 \mathrm{~nm}, 0.1 \mathrm{~W} \cdot \mathrm{cm}^{-2}, 30 \mathrm{~min}\right)$ confirmed the prominent antitumour efficacy against $4 \mathrm{~T} 1$ tumours.

Yang et al. [162] developed another drug delivery system for synergistic breast cancer treatment. The lipid carrier denoted Lip(IR780\&TPZ) was successfully prepared by encapsulating the lipophilic IR780 in the phospholipid bilayer of liposome while TPZ was loaded in the hydrophilic core. According to both in vitro and in vivo results, (Figure 34), the lipidic carrier Lip(IR780\&TPZ) could exert PDT by generating ${ }^{1} \mathrm{O}_{2}$ once exposed to laser irradiation $\left(808 \mathrm{~nm}, 1.0 \mathrm{~W} \cdot \mathrm{cm}^{-2}, 3 \mathrm{~min}\right)$ in $4 \mathrm{~T} 1$ tumour, leading to the formation of a hypoxic microenvironment which activated TPZ. 
a)

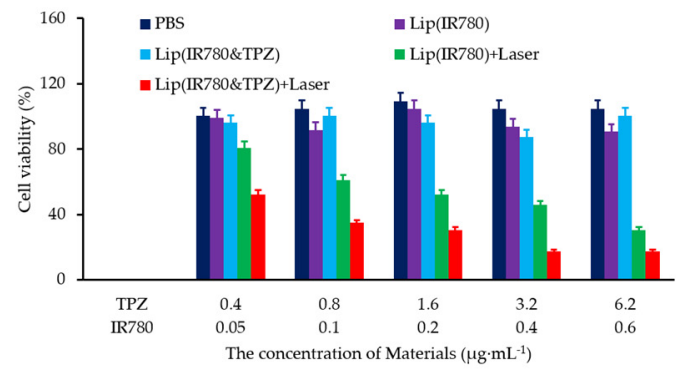

b)

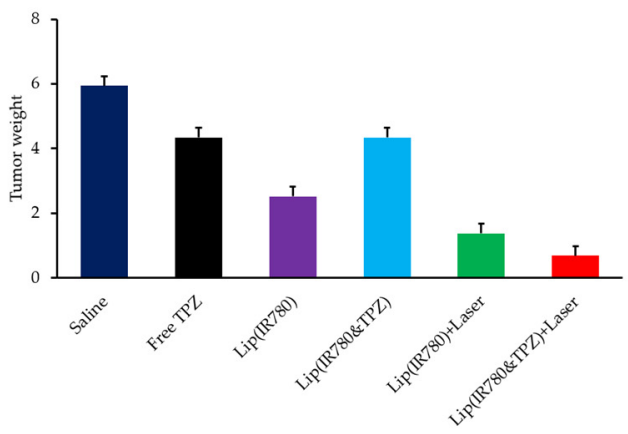

Figure 34. (a): Survival of 4T1 cells after photo-thermal treatment: Viability of cells treated with different formulations under an $808 \mathrm{~nm}$ laser for $3 \mathrm{~min}$ with a sequence of $10 \mathrm{~s}$ irradiation and $10 \mathrm{~s}$ break. (b): Toxicity of Lip (IR780\&TPZ) in 4T1 tumour-bearing mice: Tumour weights in the different groups of mice after the indicated treatments. Adapted from Yang et al. [162].

Zhang et al. [163] reported the synthesis of an innovative hypoxia-responsive 2-nitroimidazole (NI) derivative conjugated with PEG amphoteric polymer-based liposomes (PEG-NI) co-encapsulating Ce6, TPZ and a gene probe $\left(\mathrm{P}_{\text {miRNA }}\right)$ for synergistic PDT-chemotherapy. Exposition of the multifunctional liposomes (Lip/Ce6/TPZ-P miRNA $)$ to laser irradiation $\left(670 \mathrm{~nm}, 0.48 \mathrm{~W} \cdot \mathrm{cm}^{-2}, 10 \mathrm{~min}\right)$ caused Ce6-mediated PDT and severe hypoxia, leading to the disassembly of the liposome and activation of the TPZ. A greatly improved anti-cancer activity compared to conventional PDT was achieved upon laser irradiation $\left(670 \mathrm{~nm}, 0.48 \mathrm{~W} \cdot \mathrm{cm}^{-2}, 10 \mathrm{~min}\right)$ for both in vitro and in vivo studies in MCF-7 cell lines, indicating the benefit of the hypoxia-activated chemotherapy combined PDT of the as prepared multifunctional liposomes for synergistic treatment.

Wang et al. [164] elaborated a multifunctional supramolecular vesicles based on the recognition of water-soluble pillar [5]arene (WP5) and NIR-absorbing diketopyrrolopyrrole (DPP)-based guest (G) for combined photothermal/photodynamic/hypoxia-activated chemotherapy. These supramolecular vesicles were able to highly encapsulate TPZ. The photothermal conversion efficiency and ROS generation ability of the vesicles were investigated $\left(660 \mathrm{~nm}, 1.5 \mathrm{~W} \cdot \mathrm{cm}^{-2}, 7 \mathrm{~min}\right)$. The results revealed that such vesicles could efficiently convert $\mathrm{O}_{2}$ to ${ }^{1} \mathrm{O}_{2}$ for PDT. Meanwhile, the continuous $\mathrm{O}_{2}$ consumption during the PDT process resulted in hypoxic microenvironment, which triggered antitumour activity of the TPZ-loaded vesicles for synergistic enhancement of anticancer efficacy in vitro against MCF-7 cancer cells (Figure 35).

a)

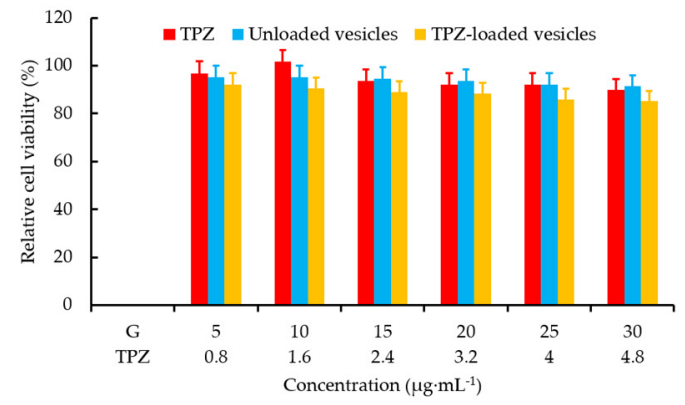

b)

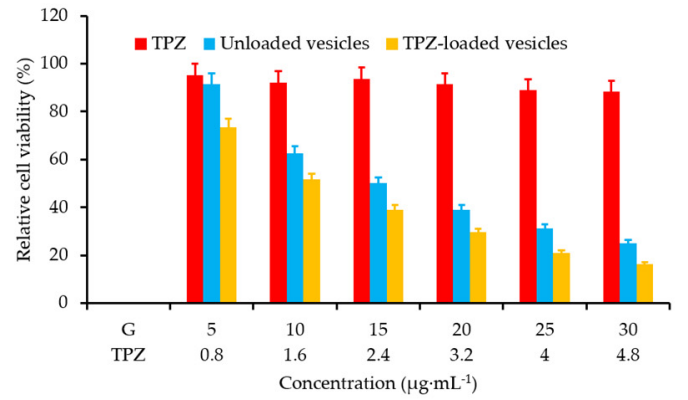

Figure 35. In vitro cytotoxicity of MCF-7 cancer cells incubated for $24 \mathrm{~h}$ with free TPZ, unloaded vesicles, and TPZ-loaded vesicles in the dark (a) and in light (b). Adapted from Wang et al. [164]. 
Table 13. Summary of publications about the use of TPZ for Chemo-PDT.

\begin{tabular}{|c|c|c|c|c|c|c|c|c|}
\hline Ref & Application & $\begin{array}{l}\text { Supplementary } \\
\text { Therapy Used }\end{array}$ & Chemo-Drug & PS & Energy of Excitation & Type of ROS & In Vitro & In Vivo \\
\hline [156] & Chemo-PDT & Chemotherapy & TPZ & SPCD & $\begin{array}{l}\text { In vitro: } 980 \mathrm{~nm}, 0.7 \mathrm{~W} \cdot \mathrm{cm}^{-2}, 5 \mathrm{~min} \\
\text { In vivo: } 980 \mathrm{~nm}, 1.4 \mathrm{~W} \cdot \mathrm{cm}^{-2}, 15 \mathrm{~min}\end{array}$ & $\begin{array}{l}{ }^{1} \mathrm{O}_{2} \text { and others } \\
\text { ROS }\end{array}$ & HeLa cell line & $\begin{array}{l}\text { HeLa tumour-bearing } \\
\text { mice }\end{array}$ \\
\hline [157] & Chemo-PDT & Chemotherapy & $\mathrm{TPZ}$ & $\mathrm{TPC}$ & $650 \mathrm{~nm}, 1.2 \mathrm{~W} \cdot \mathrm{cm}^{-2}, 10 \mathrm{~min}$ & ${ }^{1} \mathrm{O}_{2}$ & MCF-7 cell line & $\begin{array}{c}\text { MCF-7 } \\
\text { tumour-bearing mice }\end{array}$ \\
\hline [158] & Chemo-PDT & Chemotherapy & $\mathrm{TPZ}$ & PCN-224 & $\begin{array}{l}\text { In vitro: } 660 \mathrm{~nm}, 30 \mathrm{~mW} \cdot \mathrm{cm}^{-2}, 5 \mathrm{~min} \\
\text { In vivo: } 660 \mathrm{~nm}, 220 \mathrm{~mW} \cdot \mathrm{cm}^{-2}, 10 \mathrm{~min}\end{array}$ & ${ }^{1} \mathrm{O}_{2}$ & $\begin{array}{l}4 \mathrm{~T} 1 \text { and COS7 } \\
\text { cell line }\end{array}$ & $\begin{array}{l}\text { 4T1 tumour-bearing } \\
\text { mice }\end{array}$ \\
\hline [159] & Chemo-PDT & Chemotherapy & $\mathrm{TPZ}$ & ICG & $\begin{array}{l}\text { In vitro: } 808 \mathrm{~nm}, 2 \mathrm{~W} \cdot \mathrm{cm}^{-2}, 3 \mathrm{~min} \\
\text { In vivo: } 808 \mathrm{~nm}, 2 \mathrm{~W} \cdot \mathrm{cm}^{-2}, 5 \mathrm{~min}\end{array}$ & ${ }^{1} \mathrm{O}_{2}$ & $4 \mathrm{~T} 1$ cell line & $\begin{array}{l}\text { 4T1 tumour-bearing } \\
\text { mice }\end{array}$ \\
\hline [160] & Chemo-PDT & Chemotherapy & TPZ & ICG & $\begin{array}{c}405 \mathrm{~nm}, 0.75 \mathrm{~W} \cdot \mathrm{cm}^{-2}, 5 \mathrm{~min} \text { and } 808 \mathrm{~nm} \\
1.0 \mathrm{~W} \cdot \mathrm{cm}^{-2}, 10 \mathrm{~min}\end{array}$ & ${ }^{1} \mathrm{O}_{2}$ & 4T1 cell line & $\begin{array}{l}4 \mathrm{~T} 1 \text { tumour-bearing } \\
\text { mice }\end{array}$ \\
\hline [161] & Chemo-PDT & Chemotherapy & TPZ & ТСРP & $\begin{array}{l}\text { In vitro: } 635 \mathrm{~nm}, 12 \mathrm{~mW} \cdot \mathrm{cm}^{-2}, 9 \mathrm{~min} \\
\text { In vivo: } 635 \mathrm{~nm}, 0.1 \mathrm{~W} \cdot \mathrm{cm}^{-2}, 30 \mathrm{~min}\end{array}$ & ${ }^{1} \mathrm{O}_{2}$ & $4 \mathrm{~T} 1$ cell line & $\begin{array}{l}\text { 4T1 tumour-bearing } \\
\text { mice }\end{array}$ \\
\hline [162] & Chemo-PDT & Chemotherapy & TPZ & IR780 & $808 \mathrm{~nm}, 1 \mathrm{~W} \cdot \mathrm{cm}^{-2}, 3 \mathrm{~min}$ & ${ }^{1} \mathrm{O}_{2}$ & $4 \mathrm{~T} 1$ cell line & $\begin{array}{l}\text { 4T1 tumour-bearing } \\
\text { mice }\end{array}$ \\
\hline [163] & Chemo-PDT & Chemotherapy & TPZ & Ce6 & $670 \mathrm{~nm}, 0.48 \mathrm{~W} \cdot \mathrm{cm}^{-2}, 10 \mathrm{~min}$ & ${ }^{1} \mathrm{O}_{2}$ & MCF-7 cell line & $\begin{array}{c}\text { MCF-7 } \\
\text { tumour-bearing mice }\end{array}$ \\
\hline [164] & Chemo-PDT & Chemotherapy & TPZ & $\begin{array}{l}\text { Diketopyrrolopyrrole } \\
\text { (DPP)-based } \\
\text { compound }\end{array}$ & $660 \mathrm{~nm}, 1.5 \mathrm{~W} \cdot \mathrm{cm}^{2}, 10 \mathrm{~min}$ & ${ }^{1} \mathrm{O}_{2}$ & MCF-7 cell line & No \\
\hline
\end{tabular}

TPZ: Tirapazamine; SPCD: silicon phthalocyanine dihydroxide; TPC: 5-(4-carboxyphenyl)-10, 15, 20-tris(3-hydroxyphenyl) chlorin; PCN-224: porphyrinic metal organic framework; ICG: Indocyanine green; TCPP: Carboxyphenyl-porphyrin; Ce6: Chlorin e6 


\subsubsection{Doxorubicin (Dox)}

DOX is an anthracycline that slows or stops the growth of cancer cells by poisoning TOP-2. Qian et al. [165] reported the synthesis of light-activated hypoxia-responsive NPs by combining the PDT and hypoxia responsive chemotherapy. Such a conjugated polymer-based delivery system denoted as DOX/CP-NI NPs were designed based on three components, i.e., 2-nitroimidazole-grafted conjugated polymer (CP-NI), polyvinyl alcohol (PVA) and DOX (Figure 36).

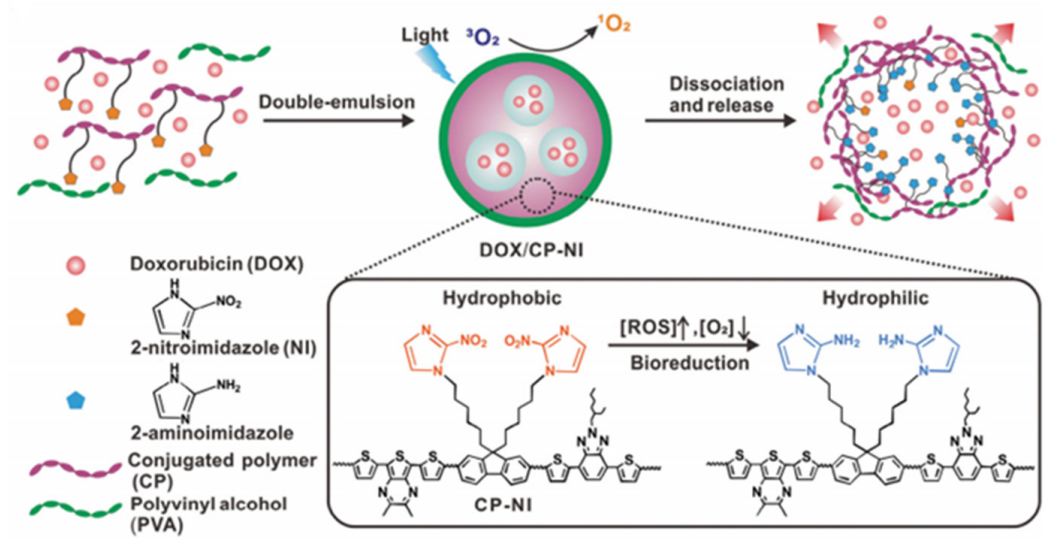

Figure 36. Schematic of the light-activated hypoxia-responsive drug-delivery system. Formation and mechanism of DOX/CP-NI NPs. Reprinted from [165] with permission from John Wiley and Sons, Copyright 2016.

According to both in vitro and in vivo studies on HeLa cells, DOX/CP-NI NPs could efficiently generate ROS when exposed to light irradiation $\left(532 \mathrm{~nm}, 0.1 \mathrm{~W} \cdot \mathrm{cm}^{-2}, 20 \mathrm{~min}\right)$. Meanwhile, the continuous $\mathrm{O}_{2}$ consumption for PDT facilitate generation of hypoxic conditions which promoted the disassembly of DOX/CP-NI, and thus an efficient DOX release which resulted in enhanced anticancer effect.

$\mathrm{Hu}$ et al. [166] synthesized multifunctional polymeric Ce6-DOX- $\mathrm{MnO}_{2}$ NPs (CDM NPs) for combined chemo and PDT enhanced by $\mathrm{O}_{2}$ generation. The CDM NPs were fabricated by hierarchically assembling DOX, Ce6 and colloidal $\mathrm{MnO}_{2}$ with poly ( $\varepsilon$-caprolactone-co-lactide)- $\beta$ poly(ethyleneglycol)- $\beta$-poly( $\varepsilon$-caprolactone colactide). Once administrated through systemic injection, the CDM NPs passively accumulated in the tumour, induced decomposition of endogenous tumour $\mathrm{H}_{2} \mathrm{O}_{2}$ under laser irradiation $\left(660 \mathrm{~nm}, 100 \mathrm{~mW} \cdot \mathrm{cm}^{-2}, 5 \mathrm{~min}\right)$ to generate $\mathrm{O}_{2}$ and $\mathrm{Mn}^{2+}$ for T1-weighted MRI. More importantly, CDM NPs dramatically improved antitumour efficiency against MCF-7 tumour-bearing mouse mode. Luo et al. [167] elaborated tumour-targeted hybrid protein $\mathrm{O}_{2}$ carriers loaded with DOX and Ce6 (ODC-HPOCs) (Figure 37).

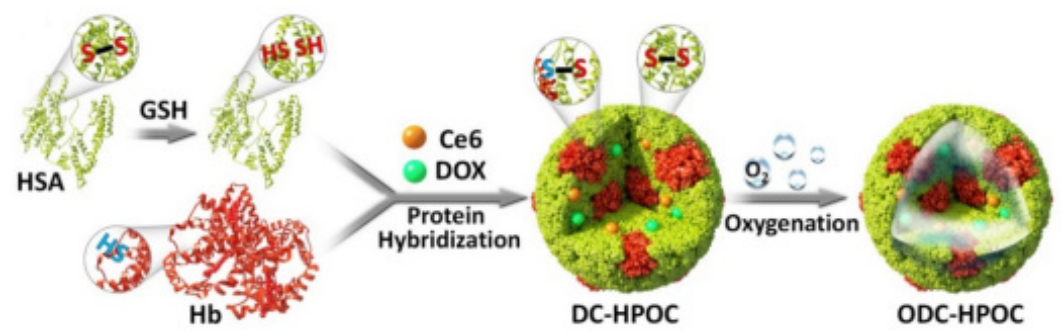

Figure 37. Schematic illustration of the fabrication of the ODC-HPOCs [167].

Laser irradiation $\left(660 \mathrm{~nm}, 100 \mathrm{~mW} \cdot \mathrm{cm}^{-2}, 2 \mathrm{~min}\right)$ of tumour-targeted ODC-HPOCs allowed outstanding performance in tumour accumulation of $\mathrm{O}_{2}$, DOX and Ce6. The high $\mathrm{O}_{2}$ affinity of ODC-HPOCs guaranteed sufficient tumour oxygenation, which was able to break hypoxia-induced chemoresistance through inhibiting the expressions of HIF- $1 \alpha$, multidrug resistance 1 (MDR1) and 
P-glycoprotein (P-gp). Meanwhile, the abundant $\mathrm{O}_{2}$ enhanced the ROS generation in PDT, and the enhanced chemo-PDT $\left(660 \mathrm{~nm}, 100 \mathrm{~mW} \cdot \mathrm{cm}^{-2}, 2 \mathrm{~min}\right)$ managed to offer a single-dose treatment with minimized concentration of DOX and Ce6.

$\mathrm{Xu}$ et al. [168] designed mesoporous $\mathrm{MnO}_{2}\left(\mathrm{mMnO}_{2}\right)$-coated UCNPs for TME-enhanced chemo-PDT and multiple imaging under NIR light excitation. The mesoporous silica shell covalently loaded with Ce6 were coated on the core-shell structured UCNPs $\left(\mathrm{NaGdF}_{4}: \mathrm{Yb}, \mathrm{Er} @ \mathrm{NaGdF}_{4}: \mathrm{Yb}\right)$. Subsequently, $\mathrm{mMnO}_{2}$ was coated on silica shell and then modified with PEG and loaded with DOX to obtain UCNPs@Ce6@mSiO ${ }_{2} @ \mathrm{mMnO}_{2}$-PEG-DOX (UCSM-PEG-DOX). Upon 980 nm irradiation $\left(0.5 \mathrm{~W} \cdot \mathrm{cm}^{-2}, 5 \mathrm{~min}\right)$, the fast degradation of $\mathrm{mMnO}_{2}$ shell in TME resulted in markedly enhanced T1-contrast MRI signals, an efficient DOX release, and greatly relieved tumour hypoxia by in situ generation of $\mathrm{O}_{2}$.

Xie et al. [169] developed a novel $\mathrm{O}_{2}$-loaded $\mathrm{pH}$-responsive multifunctional nanodrug carrier UC@mSiO ${ }_{2}$-RB@ZIF-O2-DOX-PEGFA (URODF) for an improved chemo-PDT efficiency. $\mathrm{NaYF}_{4}: \mathrm{Yb} / \mathrm{Er} @ \mathrm{NaYbF}_{4}: \mathrm{Nd} @ \mathrm{NaGdF}_{4} \mathrm{NPs}_{\mathrm{UC}}$ ) were employed for dual-modal upconversion/MR imaging. Meanwhile, the core-shell structure allowed UC NPs to activate RB in the mesoporous silica shell $\left(\mathrm{mSiO}_{2}\right)$ for PDT in $808 \mathrm{~nm}$ laser irradiation. Thus, under acidic conditions, the outmost $\mathrm{O}_{2}$ reservoir ZIF-90 shell would decompose, allowing quick release of $\mathrm{O}_{2}$ and DOX at low pH TME, and therefore achieving improved synergetic therapy and alleviating tumour hypoxia. Finally, according to the in vitro $\left(808 \mathrm{~nm}, 0.5 \mathrm{~W} \cdot \mathrm{cm}^{-2}, 10 \mathrm{~min}\right)$ cytotoxicity against $4 \mathrm{~T} 1$ and HeLa cells and in vivo $(808 \mathrm{~nm}$, $0.5 \mathrm{~W} \cdot \mathrm{cm}^{-2}, 5 \mathrm{~min}$ ) tumour inhibition studies against $\mathrm{H} 22$ cancer cells, the URODF NPs demonstrated remarkably enhanced tumour inhibition effect.

He et al. [170] reported a cancer-targeting vehicle characterized by cascaded reactivity to external (light) and internal (hypoxia) triggers for selective release of the cancer drug. The hypoxia- responsive drug delivery was prepared from self-assembled polyethylenimine-nitroimidazole (PEI-NI) micelles loaded with DOX that were further co-assembled with HA-conjugated Ce6 (HC) to form NPs. Upon internalization into mouse Lewis lung carcinoma (LLC) cells via CD44-mediated endocytosis, the hypoxia-responsive HC/PN/DOX NPs generated high levels of ROS under light irradiation $(660 \mathrm{~nm}$, $10 \mathrm{~mW} \cdot \mathrm{cm}^{-2}, 30 \mathrm{~min}$ ) The continuous $\mathrm{O}_{2}$ consumption provoked the disassembly of the DOX-loaded PEI-NI micelles which maximized the DOX release.

Yang et al. [171] developed a multifunctional NP composed of an iron oxide $\left(\mathrm{Fe}_{3} \mathrm{O}_{4}\right)$ core coated to a combined shell of $\mathrm{MnO}_{2}$ and polypyrrole (PPy), which was both the photothermal agent and PS, to formed $\mathrm{Fe}_{3} \mathrm{O}_{4} @ \mathrm{MnO}_{2} @ P P y$. Magnetic $\mathrm{Fe}_{3} \mathrm{O}_{4}$ was used to increase the intracellular $\mathrm{O}_{2}$ concentration. DOX was loaded on the $\mathrm{Fe}_{3} \mathrm{O}_{4} @ \mathrm{MnO}_{2} @ P P y$ nanocomposite to finally obtain $\mathrm{Fe}_{3} \mathrm{O}_{4} @$ $\mathrm{MnO}_{2} @ P P y-D O X N$ Ns. The increase of $\mathrm{O}_{2}$ concentration was proven in presence of $\mathrm{H}_{2} \mathrm{O}_{2}$ with these NPs. In vitro experiments were performed on HepG2 and Chinese hamster ovary (CHO) cells to

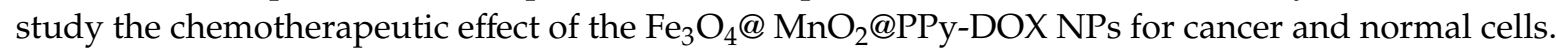
An acidic environment-dependent of DOX release was highlighted for the NPs as well as synergistic effects of chemotherapy and PTT/PDT improved by the increase of $\mathrm{O}_{2}$ tumour level. An enhancement of cellular uptake and an increase of cell death was observed with the combined chemo-PTT/PDT $\left(638 \mathrm{~nm}, 1 \mathrm{~mW} \cdot \mathrm{cm}^{-2}, 10 \mathrm{~min}\right)$ treatment using $\mathrm{Fe}_{3} \mathrm{O}_{4} @ \mathrm{MnO}_{2} @ P P y-D O X ~ N P s$.

Deng et al. [172] reported the synthesis of multifunctional nitroimidazole (NI)-bearing polymeric micelles to co-deliver DOX and Ce6 for dually hypoxia- and ${ }^{1} \mathrm{O}_{2}$-responsive integration of chemotherapy and PDT. As proof of concept, in vitro and in vivo studies were investigated on 4T1 cells and 4T1 tumour-bearing mouse model, respectively. It was found, that upon $660 \mathrm{~nm}$ laser irradiation $\left(100 \mathrm{~mW} \cdot \mathrm{cm}^{-2}, 10 \mathrm{~min}\right)$, the NCs/Dox + Ce6 produced large amount of ${ }^{1} \mathrm{O}_{2}$, which caused oxidation of NI, provoking micelle collapse, triggered payload release, and the production of aldehyde which results in high PDT effect. Meanwhile, the continuous consumption of ${ }^{1} \mathrm{O}_{2}$ resulted in a hypoxic environment, which triggered the micelle disassembly, DOX release, and thus caused glutathione GSH depletion that provided a supplementary anti-tumour efficacy (Table 14). 
Table 14. Summary of publications about the use of DOX for chemo-PDT.

\begin{tabular}{|c|c|c|c|c|c|c|c|c|}
\hline Ref & Application & $\begin{array}{l}\text { Supplementary } \\
\text { Therapy Used }\end{array}$ & Drug & PS & Energy of Excitation & Type of ROS & In Vitro & In Vivo \\
\hline [165] & Chemo-PDT & Chemotherapy & DOX & $\begin{array}{l}\text { 2-nitroimidazole } \\
\text { (NI) }\end{array}$ & $\begin{array}{l}\text { In vitro: light, } 0.1 \mathrm{~W} \cdot \mathrm{cm}^{-2}, 5 \text { or } 20 \mathrm{~min} \\
\text { In vivo: } 532 \mathrm{~nm}, 0.1 \mathrm{~W} \cdot \mathrm{cm}^{-2}, 5 \mathrm{~min} \text { or } \\
\quad 635 \mathrm{~nm}, 0.1 \mathrm{~W} \cdot \mathrm{cm}^{-2}, 5 \mathrm{~min}\end{array}$ & ${ }^{1} \mathrm{O}_{2}$ & HeLa cell line & $\begin{array}{l}\text { HeLa tumour-bearing } \\
\text { mice }\end{array}$ \\
\hline [166] & Chemo-PDT & Chemotherapy & DOX & Ce6 & $\begin{array}{l}\text { In vitro: } 660 \mathrm{~nm}, 100 \mathrm{~mW} \cdot \mathrm{cm}^{-2}, 5 \mathrm{~min} \\
\text { In vivo: } 660 \mathrm{~nm}, 100 \mathrm{~mW} \cdot \mathrm{cm}^{-2}, 10 \mathrm{~min}\end{array}$ & ${ }^{1} \mathrm{O}_{2}$ & MCF-7 cell line & $\begin{array}{l}\text { MCF-7 tumour-bearing } \\
\text { mice }\end{array}$ \\
\hline [167] & Chemo-PDT & Chemotherapy & DOX & Ce6 & $\begin{array}{l}\text { In vitro: } 660 \mathrm{~nm}, 100 \mathrm{~mW} \cdot \mathrm{cm}^{-2}, 2 \mathrm{~min} \\
\text { In vivo: } 660 \mathrm{~nm}, 100 \mathrm{~mW} \cdot \mathrm{cm}^{-2}, 20 \mathrm{~min}\end{array}$ & ${ }^{1} \mathrm{O}_{2}$ & MCF-7 cell line & $\begin{array}{l}\text { Female BALB/c nude } \\
\text { mice }\end{array}$ \\
\hline [168] & Chemo-PDT & Chemotherapy & DOX & Ce6 & $980 \mathrm{~nm}, 0.5 \mathrm{~W} \cdot \mathrm{cm}^{-2}, 5 \mathrm{~min}$ & ROS & HeLa cell line & $\begin{array}{l}\text { U14 tumour-bearing } \\
\text { mice }\end{array}$ \\
\hline [169] & Chemo-PDT & Chemotherapy & DOX & $\mathrm{RB}$ & $\begin{array}{l}\text { In vitro: } 808 \mathrm{~nm}, 0.5 \mathrm{~W} \cdot \mathrm{cm}^{-2}, 10 \mathrm{~min} \\
\text { In vivo: } 808 \mathrm{~nm}, 0.5 \mathrm{~W} \cdot \mathrm{cm}^{-2}, 5 \mathrm{~min}\end{array}$ & ${ }^{1} \mathrm{O}_{2}$ & L929 cell line & $\begin{array}{l}\text { H22 tumour bearing } \\
\text { mice }\end{array}$ \\
\hline [170] & Chemo-PDT & Chemotherapy & DOX & Ce6 & $\begin{array}{l}\text { In vitro: } 660 \mathrm{~nm}, 2 \mathrm{~mW} \cdot \mathrm{cm}^{-2}, 30 \mathrm{~min} \\
\text { In vivo: } 660 \mathrm{~nm}, 10 \mathrm{~mW} \cdot \mathrm{cm}^{-2}, 30 \mathrm{~min}\end{array}$ & ${ }^{1} \mathrm{O}_{2}$ & LLC cell line & $\begin{array}{l}\text { LLC tumour bearing } \\
\text { mice }\end{array}$ \\
\hline$[171]$ & Chemo-PDT & Chemotherapy & DOX & PPy & $638 \mathrm{~nm}, 1 \mathrm{~W} \cdot \mathrm{cm}^{-2}, 10 \mathrm{~min}$ & ${ }^{1} \mathrm{O}_{2}$ & HepG2 cell line & No \\
\hline [172] & Chemo-PDT & Chemotherapy & DOX & Ce6 & $660 \mathrm{~nm}, 100 \mathrm{~mW} \cdot \mathrm{cm}^{-2}, 10 \mathrm{~min}$ & ${ }^{1} \mathrm{O}_{2}$ & 4T1 cell line & $\begin{array}{l}4 \mathrm{~T} 1 \text { tumour-bearing } \\
\text { mice }\end{array}$ \\
\hline
\end{tabular}

DOX: Doxorubicin; Ce6: Chlorin e6; RB: Rose Bengal; PPy: Polypyrrole. 


\subsubsection{AQ4N}

AQ4N is a banoxantrone (Figure 38) and a hypoxia-activated prodrug (HAP) which can be reduced by endogenous isozymes (inducible nitric oxide synthase (iNOS) and cytochrome P450 (CYP) in hypoxia conditions.<smiles>C[N+](C)(C)CCNC1=CC=C(NCC[N+](C)(C)[O-])C2C(=O)c3c(O)ccc(O)c3C(=O)C12</smiles>

Figure 38. Structure of AQ4N.

Feng et al. [173] prepared a liposome (AQ4N-64 $\mathrm{Cu}-h$ Ce6-liposome) encapsulating hydrophilic $\mathrm{AQ} 4 \mathrm{~N}$ and hydrophobic hexadecylamine conjugated $h \mathrm{Ce} 6 \mathrm{cHeLated}$ with a ${ }^{64} \mathrm{Cu}$ isotope for in vivo positron emission tomography (PET) and a combined hypoxia-activated chemo-PDT. In vitro fluorescence imaging showed an efficient accumulation of these liposomes after intravenous injection in $4 \mathrm{~T} 1$ cells. Moreover, an effective cell killing ability was observed after illumination $(660 \mathrm{~nm}, 30 \mathrm{~min})$ of cells treated with AQ4N-64 Cu- $h$ Ce6-liposome. In vivo PDT experiments $\left(660 \mathrm{~nm}, 2 \mathrm{~mW} \cdot \mathrm{cm}^{-2}, 1 \mathrm{~h}\right)$ were performed in $4 \mathrm{~T} 1$ tumour-bearing mice injected with $\mathrm{AQ} 4 \mathrm{~N}-{ }^{64} \mathrm{Cu}-h \mathrm{Ce} 6$-liposome and a severe tumour hypoxia was observed triggering the activation of $\mathrm{AQ} 4 \mathrm{~N}$ and thus improved the inhibition of tumour growth.

A graphene oxide (GO)-based NP was designed by Luan et al. [174] for a trimodal cancer therapy. This NP was composed of verteporfin (VP) and the peptide c(RGDfK) for vascular-targeted PDT, AQ4N as hypoxia-activated prodrug (HAP), and HIF- $1 \alpha$ siRNA (siHIF- $1 \alpha$ ) to suppress the HIF- $1 \alpha$ expression upon hypoxia and thus increase the AQ4N activation. These NPs significantly hindered the growth of tumours in PC-3 models in vivo after illumination $\left(690 \mathrm{~nm}, 30 \mathrm{~mW} \cdot \mathrm{cm}^{-2}, 10 \mathrm{~min}\right)$ compared to the control groups (Table 15).

He et al. [175] engineered NPs for hypoxia-activated chemo-PDT composed of pegylated UiO-66 nmOFs co-anchoring a PS photochlor (HPPH) and an azide group and encapsulating AQ4N (Figure 39).

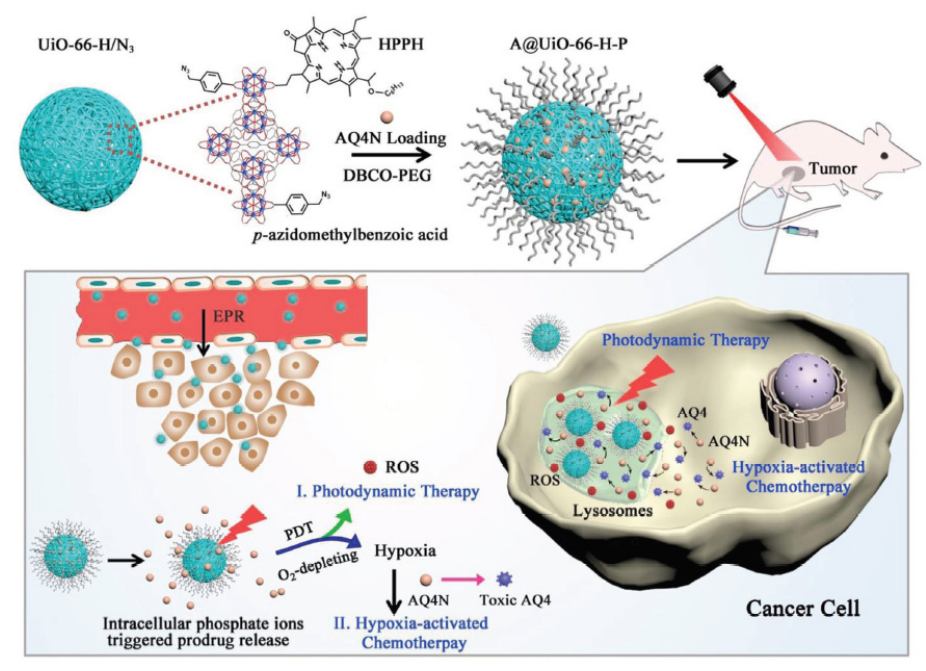

Figure 39. Schematic illustration showing the synthetic procedure of A@UiO-66-H-P NPs and the mechanism of PDT and hypoxia-activated cascade chemotherapy. Reprinted from [175] with permission from John Wiley and Sons, Copyright 2018. 
Table 15. Summary of publications about the use of AQ4N for chemo-PDT.

\begin{tabular}{|c|c|c|c|c|c|c|c|c|}
\hline Ref & Application & $\begin{array}{l}\text { Supplementary } \\
\text { Therapy Used }\end{array}$ & Drug & PS & Energy of Excitation & Type of ROS & In Vitro & In Vivo \\
\hline [173] & Chemo-PDT & Chemotherapy & $\mathrm{AQ} 4 \mathrm{~N}$ & Ce6 & $\begin{array}{l}\text { In vitro: } 660 \mathrm{~nm}, 2 \mathrm{~mW} \cdot \mathrm{cm}^{-2}, 30 \mathrm{~min} \\
\text { In vivo: } 660 \mathrm{~nm}, 2 \mathrm{~mW} \cdot \mathrm{cm}^{-2}, 1 \mathrm{~h}\end{array}$ & ${ }^{1} \mathrm{O}_{2}$ & $4 \mathrm{~T} 1$ cell line & $\begin{array}{l}4 \mathrm{~T} 1 \text { tumour-bearing } \\
\text { mice }\end{array}$ \\
\hline [174] & Chemo-PDT & Chemotherapy & $\mathrm{AQ} 4 \mathrm{~N}$ & Verteporfin & $\begin{array}{l}\text { In vitro: } 690 \mathrm{~nm}, 30 \mathrm{~mW} \cdot \mathrm{cm}^{-2}, 10 \mathrm{~min} \\
\text { In vivo: } 690 \mathrm{~nm}, 50 \mathrm{~mW} \cdot \mathrm{cm}^{-2}, 20 \mathrm{~min}\end{array}$ & ${ }^{1} \mathrm{O}_{2}$ & PC-3 cell line & $\begin{array}{l}\text { PC-3 tumour-bearing } \\
\text { mice }\end{array}$ \\
\hline [175] & Chemo-PDT & Chemotherapy & $\mathrm{AQ} 4 \mathrm{~N}$ & $\begin{array}{l}\text { Photochlor } \\
\text { (HPPH) }\end{array}$ & $\begin{array}{l}\text { In vitro: } 671 \mathrm{~nm}, 100 \mathrm{~mW} \cdot \mathrm{cm}^{-2}, 6 \mathrm{~min} \\
\text { In vivo: } 671 \mathrm{~nm}, 100 \mathrm{~mW} \cdot \mathrm{cm}^{-2}, 10 \mathrm{~min}\end{array}$ & ROS & $\begin{array}{l}\text { U87MG cell } \\
\text { line }\end{array}$ & $\begin{array}{c}\text { U87MG } \\
\text { tumour-bearing mice }\end{array}$ \\
\hline
\end{tabular}


In both in vitro and in vivo studies (U87MG cells and tumour, $671 \mathrm{~nm}, 100 \mathrm{~mW} \cdot \mathrm{cm}^{-2}, 6 \mathrm{~min}$ ) the authors observed that the $\mathrm{O}_{2}$-depleting PDT with these NPs conducted to an intracellular/tumour hypoxia leading to the activation of $A Q 4 \mathrm{~N}$ and thus an efficient synergistic chemo-PDT therapy (Table 15).

\subsubsection{Platinium drugs}

Platinium (IV) complexes are prodrugs which can be reduced in toxic $\mathrm{Pt}$ (II), by UV light irradiation or reducing agents. These species act as drugs for chemotherapy. Guo et al. [176] reported a Pt(IV) complex-based photoactivatable polyprodrug able to simultaneously generate highly toxic $\mathrm{Pt}(\mathrm{II})$ species for chemotherapy and a high level of ROS. This chemo-PDT concept did not rely on the use of a PS and the consumption of $\mathrm{O}_{2}$. The polyprodrug was obtained by co-polymerizing $\mathrm{Pt}(\mathrm{IV})$ complex-based prodrug monomer (PPM) with 2-methacryloyloxyethyl phosphorylcholine (MPC), nanosized hydrogel-like polyprodrug. Under light exposure, a reduction of $\mathrm{Pt}(\mathrm{IV})$ moieties contained in this photoactivatable polyprodrug was observed leading to the generation of $\mathrm{Pt}$ (II) species. In vitro experiments were performed in A549 cancer cells and in vivo in nude mice bearing A 549 cells and $\mathrm{IC}_{50}$ values for polyPPM of $2.6 \mathrm{mM}$ and $2.9 \mathrm{mM}$ against A549 and cisplatin-resistant A549R cells respectively were observed under irradiation $\left(396 \mathrm{~nm}, 5 \mathrm{~mW} \cdot \mathrm{cm}^{-2}, 5 \mathrm{~min}\right)$. In vivo A549 tumourbearing mice were treated with polyPPM and light irradiation $\left(0.4 \mathrm{~W} \cdot \mathrm{cm}^{-2}, 10 \mathrm{~min}\right)$ and resulted in the decrease in tumour growth.

The same strategy was described by $\mathrm{Xu}$ et al. [177]. They developed a NP containing Pt(IV) and Ce6, loading with UCNPs for the conversion of $980 \mathrm{~nm}$ near-infrared light into $365 \mathrm{~nm}$ and $660 \mathrm{~nm}$ emissions. After tumour accumulation, the NPs were triggered by a $980 \mathrm{~nm}$ laser to generate $\mathrm{O}_{2}$ and could also release active $\mathrm{Pt}(\mathrm{II})$. Results suggested that NPs generated $\mathrm{O}_{2}$ inside HeLa and L929 cells ( $980 \mathrm{~nm}, 0.85 \mathrm{~W} \cdot \mathrm{cm}^{-2}, 5 \mathrm{~min}$ ). In vivo in HeLa, B16 (Murine tumour cell line skin cancer), HCT116 (Human colon cancer cell line) and MDA-MB-231 tumour model, the capability of NPs to improve tumour hypoxia was demonstrated $\left(980 \mathrm{~nm}, 0.80 \mathrm{~W} \cdot \mathrm{cm}^{-2}, 10 \mathrm{~min}\right)$.

A new kind of compounds (covalent-organic polymers, COPs) which are able to cross-linked differents organic molecules by covalent bond to form organic network structures have been used in various fields. Wang et al. [178] cross-linked a PS, mesotetra(p-hydroxyphenyl) porphine (THPP), to a chemotherapeutic pro-drug, cis-Pt (IV) and conjugated to PEG to obtain THPP-Pt-PEG COPs. Cis-Pt(IV) was also used as a reduction-responsive linker. The ability of THPP-Pt-PEG COPs to kill cancer cells after PDT $\left(660 \mathrm{~nm}, 5 \mathrm{~mW} \cdot \mathrm{cm}^{-2}, 20 \mathrm{~min}\right)$ was observed in $4 \mathrm{~T} 1$ cells and a reduction-responsive degradation/drug release was highlighted. After injection of THPP-Pt-PEG COPs in 4T1 tumour-bearing mice, the combined chemo-PDT ( $660 \mathrm{~nm}, 5 \mathrm{~mW} \cdot \mathrm{cm}^{-2}, 45 \mathrm{~min}$ ) of the COPs showed a $\mathrm{n}$ improvement of therapeutic outcome in comparison with PDT and chemotherapy taken separately (Table 16).

\subsection{Antiangiogenic-PDT}

PDT also induces expression of angiogenic and survival molecules including VEGF, cyclooxygenase-2 (COX-2), and MMPs. The founding member of the hypoxia-inducible factor (HIF) family, HIF- $1 \alpha$, regulates a broad array of genes in response to $\mathrm{O}_{2}$ deprivation.

\subsubsection{HIF- $1 \alpha$ inhibitors}

The expression of HIF- $1 \alpha$ is increased after PDT treatment of cancer cells, which induces PDT resistance. The inhibition of HIF- $1 \alpha$ combined to PDT can lead to an improvement of the PDT efficiency. Chen et al. [179] developed anisamide-targeted lipid-calcium-phosphate (LCP) NPs encapsulating HIF- $1 \alpha$ siRNA to reduce the expression of HIF- $1 \alpha$ prior to PDT treatment with Photosan ${ }^{\circledR}$. In vitro in SCC4 and SAS cells, targeted LCP with anisamide showed an efficient release of HIF- $1 \alpha$ siRNA 2.5 or 3.5 fold higher than observed for LCP without anisamide. 
Table 16. Summary of publications about the use of Pt(IV) drugs for chemo-PDT.

\begin{tabular}{|c|c|c|c|c|c|c|c|c|}
\hline Ref & Application & $\begin{array}{l}\text { Supplementary } \\
\text { Therapy Used }\end{array}$ & Drug & PS & Energy of Excitation & Type of ROS & In Vitro & In Vivo \\
\hline [176] & Chemo-PDT & Chemotherapy & Pt (IV) complex & No & $\begin{array}{l}\text { In vitro: } 396 \mathrm{~nm}, 5 \mathrm{~mW} \cdot \mathrm{cm}^{-2}, 5 \mathrm{~min} \\
\text { In vivo: } 396 \mathrm{~nm}, 0.4 \mathrm{~W} \cdot \mathrm{cm}^{-2}, 10 \mathrm{~min}\end{array}$ & ${ }^{\bullet} \mathrm{OH}$ and ${ }^{1} \mathrm{O}_{2}$ & A549 cell line & $\begin{array}{l}\text { A549 tumour- bearing } \\
\text { mice }\end{array}$ \\
\hline [177] & Chemo-PDT & Chemotherapy & $\begin{array}{c}\mathrm{Pt}(\mathrm{IV}) \\
\text { Up conversion } \\
\text { NP }\end{array}$ & Ce6 & $\begin{array}{l}980 \mathrm{~nm} \text { near-infrared light convert into } \\
365 \mathrm{~nm} \text { and } 660 \mathrm{~nm} \text { emissions } \\
\text { In vitro: } 0.85 \mathrm{~W} \cdot \mathrm{cm}^{-2}, 5 \mathrm{~min} \\
\text { In vivo: } 0.80 \mathrm{~W} \cdot \mathrm{cm}^{-2}, 10 \mathrm{~min}\end{array}$ & ${ }^{1} \mathrm{O}_{2}$ & L929 cell line & $\begin{array}{l}\text { HeLa, B16, HCT116 } \\
\text { or MDA-MB-231 } \\
\text { tumour-bearing mice }\end{array}$ \\
\hline [178] & Chemo-PDT & Chemotherapy & cis-Pt (IV) & THPP & $\begin{array}{l}\text { In vitro: } 660 \mathrm{~nm}, 5 \mathrm{~mW} \cdot \mathrm{cm}^{-2}, 20 \mathrm{~min} \\
\text { In vivo: } 660 \mathrm{~nm}, 5 \mathrm{~mW} \cdot \mathrm{cm}^{-2}, 45 \mathrm{~min}\end{array}$ & ${ }^{1} \mathrm{O}_{2}$ & 4T1 cell line & $\begin{array}{l}\text { 4T1 tumour-bearing } \\
\text { mice }\end{array}$ \\
\hline
\end{tabular}

Ce6: Chlorin e6; THPP: mesotetra(p-hydroxyphenyl)porphine. 
Treatment with these NPs prior to photosan-PDT $\left(640 \mathrm{~nm}, 320 \mathrm{~mW} \cdot \mathrm{cm}^{-2}, 100 \mathrm{~J} \cdot \mathrm{cm}^{-2}\right)$ led to a significant decrease of cell viability in comparison with PDT alone. In vivo in SCC4 and SAS tumour-bearing mice, the combination of HIF- $1 \alpha$ siRNA and PDT led to a significant decrease of tumour volume (40\%) after 10 days.

Sun et al. [180] designed a multifunctional compound (siHIF@CpMB) constituted by cationic porphyrin lipip microbubbles (CpMBs), elaborated from cationic porphyrin lipip NPs, and loading HIF-1 $\alpha$ siRNA (siHIF) on the surface by electronic adsorption. In vitro in MDA-MB-231 cells, the authors observed an efficient release of siHIF after ultrasound exposure $(1.03 \mathrm{MHz}, 50 \%$ duty, $\left.1 \mathrm{~W} \cdot \mathrm{cm}^{-2}, 1 \mathrm{~min}\right)$ and production of ${ }^{1} \mathrm{O}_{2}$ after irradiation $\left(650 \mathrm{~nm}, 200 \mathrm{~mW} \cdot \mathrm{cm}^{-2}, 10 \mathrm{~min}\right)$. Moreover, the combinaison of siHIF treatment and PDT led to significant effect to kill cancer cells in both in vitro and in vivo models.

Broekgaarden et al. [181,182] elaborated a strategy relying on the use of acriflavine (ACF) to inhibit the expression of HIF- $1 \alpha$ in combinaison with PDT treatment with ZnPC-ETLs (Zinc Phthalocyanine in endothelium-targeting liposomes). An increase of HIF-1 $\alpha$ expression has been observed with PDT alone. The authors observed an increase of PDT effect $\left(500 \mathrm{~mW}, 15 \mathrm{~J} \cdot \mathrm{cm}^{-2}\right)$ with the addition of ACF before PDT in both normoxic and hypoxic conditions in vitro in human perihilar cholangiocarcinoma models (SK-ChA-1 cells). They reproduced the experience in A431 cells and observed an increase of cell death in hypoxic conditions after combination of ACF and PDT $\left(671 \mathrm{~nm}, 500 \mathrm{~mW} \cdot \mathrm{cm}^{-2}, 15 \mathrm{~J} \cdot \mathrm{cm}^{-2}\right)$ whereas no adjuvant effect of ACF was highlighted in normoxic conditions. (Table 17).

\subsubsection{VEGF Inhibitors}

Vascular endothelial growth-factor (VEGF) is overexpressed in tumour after PDT treatment and is involved in the neovascularisation of tumours which can induce PDT resistance. The inhibition of VEGF during PDT can lead to an enhancement of its efficiency.

Ferrario et al. [183] studied the overexpression of HIF-1 $\alpha$ and VEGF after PDT treatment (570-650 $\mathrm{nm}, 0.35 \mathrm{~mW} \cdot \mathrm{cm}^{-2}$ ) with Photofrin of BA tumours (mouse mammary carcinoma). To reduce this overexpression and thus improving the efficiency of PDT, they combined antiangiogenic therapy with PDT by treating mice with an angiogenic synthetic dipeptide (IM862) or an endothelial-activating polypeptide (EMAP-II) to inhibit VEGF production. The authors observed a decrease of VEGF level after combined antiangiogenic-PDT therapy $\left(630 \mathrm{~nm}, 75 \mathrm{~mW} \cdot \mathrm{cm}^{-2}, 200 \mathrm{~J} \cdot \mathrm{cm}^{-2}\right)$ with IM862 or EMAP-II and Photofrin as well as an increase of the tumoricidal action of PDT.

Zhou et al. [184] examined the influence of antiangiogenic coumpounds (VEGF inhibitors: SU5416 and SU6668) in combination with PDT with hypericin. In vivo studies in CNE2 tumour-bearing mice (poorly differentiated nasopharyngeal carcinoma) showed a significant inhibition of tumour growth for mice treated with SU5416 or SU6668 in combination with PDT (halogen light source, $47.7 \mathrm{~J} \cdot \mathrm{cm}^{-2}$, $60 \mathrm{~mW} \cdot \mathrm{cm}^{-2}$ ) with a better enhancement of the tumour response to PDT with SU6668.

Weiss et al. [185] compared the used of two types of compounds: an anti-VEGF antibody (bevatizumab) and angiostatic tyrosine kinase inhibitors (TKIs, sunitinib, sorafenib and axitinib) to inhibit VEGF receptor for an antiangiogenic treatment in combinaison with PDT using visudyne. They chose two tumour models (A278 human ovarian carcinoma cells and HCT-116 human colorectal carcinoma cells) implanted in chorioallantoic membrane of the chicken embryo. They observed the best improvement of PDT $\left(35 \mathrm{~mW} \cdot \mathrm{cm}^{-2}, 5 \mathrm{~J} \cdot \mathrm{cm}^{-2}\right)$ by combination with TKIs especially sorafenib and axitinib, the last one leading to a complete suppression of VEGFR-2 receptors expression in the vasculature of the tumour. The use of bevacizumab did not lead to any improvement of PDT. 
Table 17. Summary of publications about the use of HIF- $1 \alpha$ inhibitors for antiangiogenic-PDT.

\begin{tabular}{|c|c|c|c|c|c|c|c|c|}
\hline Ref & Application & Therapy Used & Drug & PS & Energy of Excitation & Type of ROS & In Vitro & In Vivo \\
\hline [179] & Antiangiogenic-PDT & Antiangiogenic & HIF- $1 \alpha$ siRNA & Photosan & $\begin{array}{c}640 \mathrm{~nm}, 320 \mathrm{~mW} \cdot \mathrm{cm}^{-2} \\
100 \mathrm{~J} \cdot \mathrm{cm}^{-2}\end{array}$ & nd & $\begin{array}{l}\text { SCC4 and SAS cell } \\
\text { lines }\end{array}$ & $\begin{array}{c}\text { SCC4 and SAS } \\
\text { tumour bearing nude } \\
\text { mice. }\end{array}$ \\
\hline [180] & Antiangiogenic-PDT & Antiangiogenic & HIF- $1 \alpha$ siRNA & $\begin{array}{c}\text { Cationic } \\
\text { porphyrin-grafed } \\
\text { lipid }\end{array}$ & $650 \mathrm{~nm}, 200 \mathrm{~mW}, 10 \mathrm{~min}$ & ${ }^{1} \mathrm{O}_{2}$ & $\begin{array}{l}\text { MDA-MB-231 cell } \\
\text { line }\end{array}$ & $\begin{array}{l}\text { MDA-MB-231 } \\
\text { tumour-bearing mice }\end{array}$ \\
\hline [181] & Antiangiogenic-PDT & Antiangiogenic & Acriflavine & $\mathrm{ZnPc}$ & $671 \mathrm{~nm}, 500 \mathrm{~mW}, 15 \mathrm{~J} \cdot \mathrm{cm}^{-2}$ & nd & A431 cell line & No \\
\hline [182] & Antiangiogenic-PDT & Antiangiogenic & Acriflavine & $\mathrm{ZnPc}$ & $671 \mathrm{~nm}, 500 \mathrm{~mW}, 15 \mathrm{~J} \cdot \mathrm{cm}^{-2}$ & ROS & SK-ChA-1 cell line & No \\
\hline
\end{tabular}

nd: not determined; HIF-1 $\alpha$ siRNA: hypoxia-inducible factor- $1 \alpha$ small interfering RNA; ZnPc: zinc phthalocyanine. 
Lecaros et al. [186] combined PDT using Photosan ${ }^{\circledR}$ with lipid-calcium-phosphate NPs (LCP NPs) delivering VEGF-A small interfering RNA (siVEGF-A) in cells to enhance the PDT effect by decreasing VEGF-A expression. In vivo studies in human oral squamous cancer cell (HOSCC), SCC4 and SAS models were performed and the combinaison of siVEGF-A and PDT $\left(640 \mathrm{~nm}, 320 \mathrm{~mW} \cdot \mathrm{cm}^{-2}\right.$, $100 \mathrm{~J} \cdot \mathrm{cm}^{-2}, 11 \mathrm{~min}$ ) induced a significant reduction of tumour volume in both models.

Liang et al. [187] synthesized pH-responsive direct-acting-antiviral (DAA) NPs with an average diameter of $55 \pm 2 \mathrm{~nm}$ and composed of dimethylxanthenone-4-acetic acid (DMXAA) as active-targeting VEGF receptor and diketopyrrolopyrrole (DPP-4) as PTT/PDT agent to improve combined PTT/PDT treatment by the destruction of the vascular region of tumours (Figure 40). Under acidic conditions of the TME, there was an effective release of DMXAA and an increase of ${ }^{1} \mathrm{O}_{2}$ generation as well as a good photothermal effect in comparison with $\mathrm{pH}$ of 7.4. In vitro and in vivo studies in HeLa tumour model highlighted an efficient synergitic effect of antivascular activity of DMXAA and PTT/PDT $(660 \mathrm{~nm}$, $0.8 \mathrm{~W} \cdot \mathrm{cm}^{-2}, 4 \mathrm{~min}$ ) to kill cancer cells with a complete ablation of tumour (Table 18).

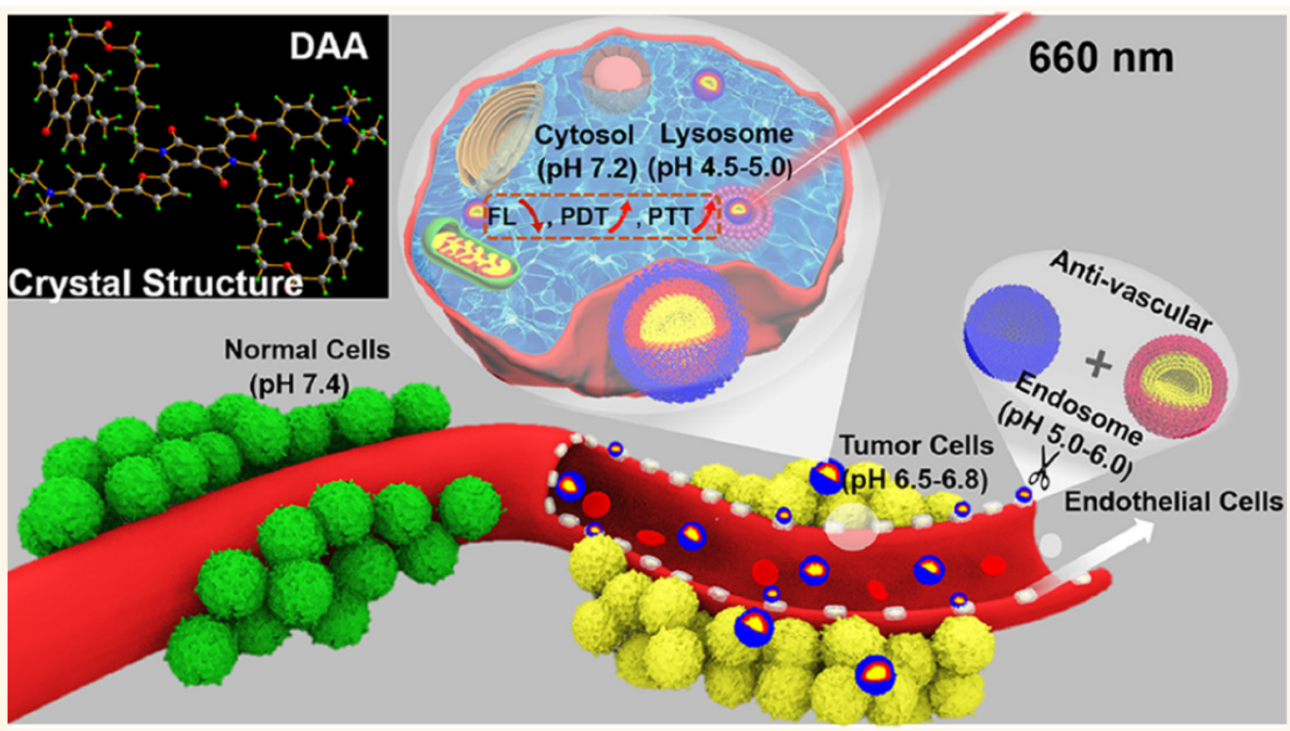

Figure 40. Antivascular and pH-Responsive Cancer PTT/PDT of DAA NPs at the tumour site. Reprinted from [187] with permission from the American Chemical Society, Copyright 2018.

\subsubsection{Others}

Cyclooxygenase 2 (COX-2) expression is induced by PDT treatment and it is involved in the progression of cancer. In 2005, Ferrario et al. [188] evaluated the effect of COX-2 inhibitors (celecoxib, a COX-2 selective nonsteroidal anti-inflammatory drug or NS-398, a COX-2 inhibitor) combined to PDT with Photofrin on cancer cell death in comparison with PDT alone. In vitro in BA cells, they observed a light dose-dependent increase of apoptosis of cancer cells after combined PDT (570-650 nm, $0.35 \mathrm{~mW} \cdot \mathrm{cm}^{-2}, 0$ to $525 \mathrm{~J} \cdot \mathrm{cm}^{-2}, 0$ to $\left.150 \mathrm{~s}\right)$ with COX-2 inhibitors. In vivo $\left(630 \mathrm{~nm}, 75 \mathrm{~mW} \cdot \mathrm{cm}^{-2}, 0\right.$ to $200 \mathrm{~J} \cdot \mathrm{cm}^{-2}$ ) injection of COX-2 inhibitors decreased angiogenesis and inflammation and increased PDT efficiency.

Tuncel et al. [189] synthesized a phthalocyanine-chalcone conjugate composed of chalcones holding properties of vascular disrupting agents (VDA) and a phthalocyanine as the PS. They observed a moderate inhibition of HUVEC (human umbilical vein endothelial cell) proliferation after treatment with the conjugate lower than those observed with chalcone alone as well as a lower ${ }^{1} \mathrm{O}_{2}$ for the conjugate in comparison with the PS alone (55\% against $83 \%$ ). However, PDT treatment (red light, $3.6 \mathrm{~J} \cdot \mathrm{cm}^{-2}$ ) with the conjugate in vitro in human colon adenocarcinoma cells (HT-29) led to the best efficiency, which could be explained by a better cellular uptake thanks to its amphiphilic character. 
Table 18. Summary of publications about the use of VEGF inhibitor for antiangiogenic-PDT.

\begin{tabular}{|c|c|c|c|c|c|c|c|c|}
\hline Ref & Application & Therapy Used & Drug & PS & Energy of Excitation & Type of ROS & In Vitro & In Vivo \\
\hline [183] & Antiangiogenic-PDT & Antiangiogenic & EMAP-II or IM862 & Photofrin & $\begin{array}{c}\text { In vitro: } 570-650 \mathrm{~nm}, \\
0.35 \mathrm{~mW} \cdot \mathrm{cm}^{-2} \\
\text { In vivo: } 630 \mathrm{~nm}, 75 \mathrm{~mW} \cdot \mathrm{cm}^{-2} \\
200 \mathrm{~J} \cdot \mathrm{cm}^{-2}\end{array}$ & nd & BA cell line & $\begin{array}{l}\text { BA tumour-bearing } \\
\text { mice }\end{array}$ \\
\hline [184] & Antiangiogenic-PDT & Antiangiogenic & SU5416 and SU6668 & hypericin & $\begin{array}{l}\text { Halogen light with red acetate } \\
\text { filter, } 47.7 \mathrm{~J} \cdot \mathrm{cm}^{-2}, 60 \mathrm{~mW} \cdot \mathrm{cm}^{-2}\end{array}$ & nd & No & $\begin{array}{c}\text { CNE2 } \\
\text { tumour-bearing } \\
\text { mice }\end{array}$ \\
\hline [185] & Antiangiogenic-PDT & Antiangiogenic & $\begin{array}{l}\text { sunitinib, sorafenib and } \\
\text { axitinib/bevacizumab }\end{array}$ & Visudyne & $420 \mathrm{~nm}, 5 \mathrm{~J} \cdot \mathrm{cm}^{-2}, 35 \mathrm{~mW} \cdot \mathrm{cm}^{-2}$ & nd & No & $\begin{array}{c}\text { A2780 } \\
\text { tumour-bearing } \\
\text { mice }\end{array}$ \\
\hline [186] & Antiangiogenic-PDT & Antiangiogenic & VEGF-A siRNA & Photosan & $\begin{array}{c}640 \mathrm{~nm} \\
\text { In vitro: } 10 \mathrm{~J} \cdot \mathrm{cm}^{-2}, 159 \mathrm{~s} \\
\text { In vivo: } 320 \mathrm{~mW} \cdot \mathrm{cm}^{-2}, 100 \mathrm{~J} \cdot \mathrm{cm}^{-2} \\
11 \mathrm{~min}\end{array}$ & nd & $\begin{array}{l}\text { SCC } 4 \text { and SAS } \\
\text { cell lines }\end{array}$ & $\begin{array}{l}\text { SCC4 and SAS } \\
\text { tumour bearing } \\
\text { nude mice } \\
.\end{array}$ \\
\hline [187] & Antiangiogenic-PDT & Antiangiogenic & $\begin{array}{l}\text { 5,6-dimethylxanthenone- } \\
\text { 4-acetic acid }\end{array}$ & DPP-4 & $660 \mathrm{~nm}, 0.8 \mathrm{~W} \cdot \mathrm{cm}^{-2}, 4 \mathrm{~min}$ & $\begin{array}{c}{ }^{1} \mathrm{O}_{2} \text { and } \\
\text { others } \\
\text { ROS }\end{array}$ & $\begin{array}{l}\text { HeLa and } \\
\text { HUVEC cell } \\
\text { lines }\end{array}$ & $\begin{array}{c}\text { HeLa } \\
\text { tumour-bearing } \\
\text { mice }\end{array}$ \\
\hline
\end{tabular}


The activation of the nuclear factor-kappa B (NF-kB) is induced by PDT treatment and has a negative role for this last one. $\mathrm{Li}$ et al. $[190,191]$ studied the combination of dihydroartemisinin (DHA), which could inactivate NF- $\mathrm{kB}$ and displayed an anticancer activity, with PDT using 5-ALA in comparison with PDT alone. In vitro and in vivo in human oesophageal cancer models (Eca109 and Ec9706), they showed a better tumour inhibition with a reduction of NF-kB expression for the combined treatement with DHA and PDT $\left(630 \mathrm{~nm}, 20-25 \mathrm{~J} \cdot \mathrm{cm}^{-2}\right)$ as compared to each treatment alone.

Carbonic anhydrase IX (CAIX) is overexpressed in tumour and is involved in the tumour survival and invasion. Jung et al. [192] synthesized an acetazolamide-functionalized boron dipyrromethene PS (AZ-BPS) (Figure 41) to combine antiangiogenic therapy by inhibiting CAIX with PDT.

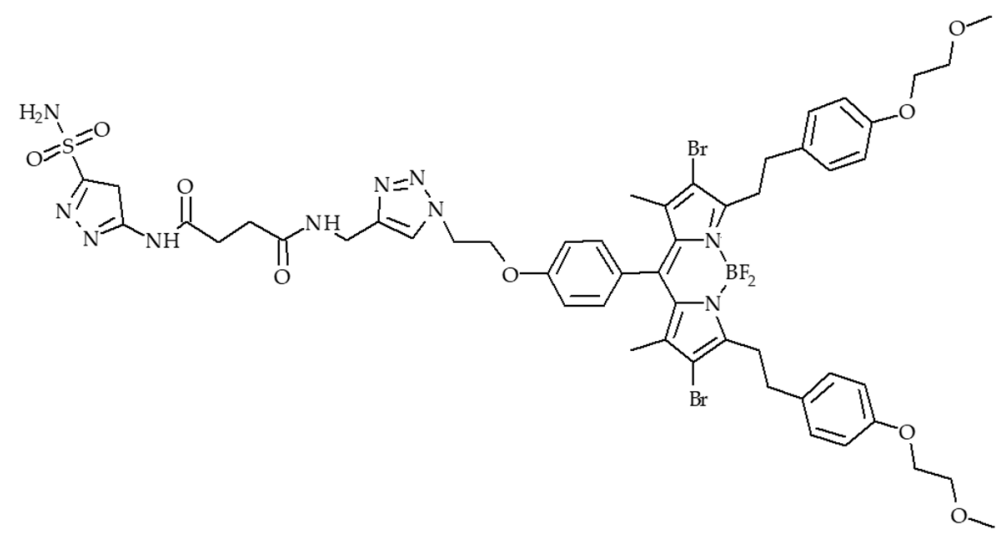

Figure 41. Structure of AZBPS. Adapted from Jung et al. [192].

In vitro in aggressive cancer MDA-MB-231 cells, they evaluated the phototoxicity $(660 \mathrm{~nm}$, $2 \mathrm{~W} \cdot \mathrm{cm}^{-2}, 30 \mathrm{~min}$ ) of AZ-BPS in comparison with BPS alone and observed an enhancement of phototoxicity. The same observation was done in vivo in MDA-MB-231 tumour-bearing mice, which may be due to the inhibition of tumour angiogenesis combined to PDT (Table 19).

\subsection{PTT/PDT}

Photothermic therapy is a technique to destroy cancer cells by burning them selectively. This technology uses a low-power laser beam that is directed to the tumour containing small amount of molecules capable of absorbing near-infrared rays (between 800 and $1300 \mathrm{~nm}$ ), and which efficiently convert this energy into heat. Since this technique uses irradiation, some teams considered associating PTT with PDT and proposed targeted hybrid nano-objects capable of being excited to produce both heat and ROS. This dual PTT/PDT modality offers the advantage of using only one NP for a double effect by involving only light. In contrary to PDT, PTT does not require $\mathrm{O}_{2}$ to be efficient.

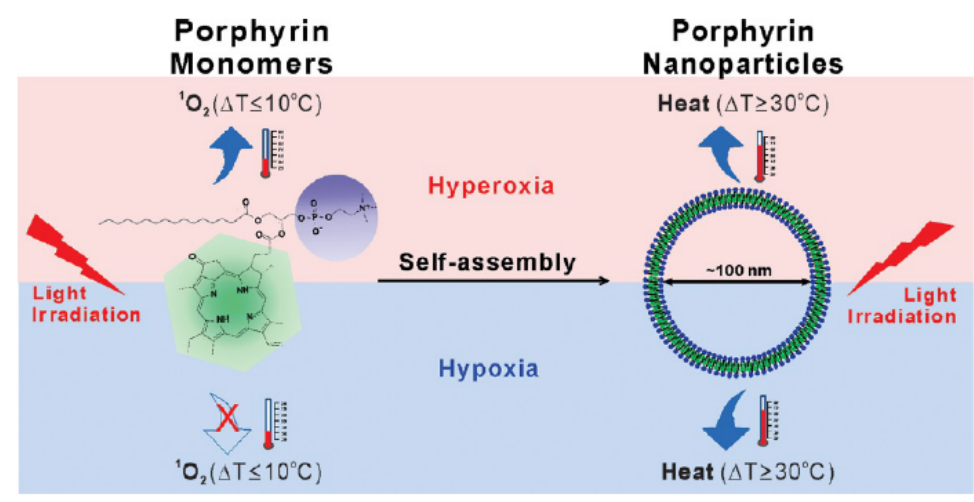

Figure 42. Schematic illustration of the study rationale and design. Reprinted from [193] with permission from the American Chemical Society, Copyright 2013. 
Table 19. Summary of publications about the use of others inhibitors for antiangiogenic-PDT.

\begin{tabular}{|c|c|c|c|c|c|c|c|c|}
\hline Ref & Application & Therapy Used & Drug & PS & Energy of Excitation & Type of ROS & In Vitro & In Vivo \\
\hline [188] & Antiangiogenic-PDT & Antiangiogenic & celecoxib or NS-398 & Photofrin & $\begin{array}{c}570-650 \mathrm{~nm}, 0.35 \mathrm{~mW} \cdot \mathrm{cm}^{-2}, 0 \text { to } \\
525 \mathrm{~J} \cdot \mathrm{cm}^{-2}, 0 \text { to } 150 \mathrm{~s}\end{array}$ & nd & BA cell line & $\begin{array}{l}\text { BA tumour-bearing } \\
\text { mice }\end{array}$ \\
\hline [189] & Antiangiogenic-PDT & Antiangiogenic & Chalcone & phthalocyanine & red light $(>600 \mathrm{~nm}), 3.6 \mathrm{~J} \cdot \mathrm{cm}^{-2}$ & ${ }^{1} \mathrm{O}_{2}$ & HT29 cell line & No \\
\hline [190] & Antiangiogenic-PDT & Antiangiogenic & DHA & 5-ALA & $630 \mathrm{~nm}, 25 \mathrm{~W} \cdot \mathrm{cm}^{-2}$ & nd & Eca109 cell line & $\begin{array}{c}\text { Eca109 } \\
\text { tumour-bearing } \\
\text { mice }\end{array}$ \\
\hline [191] & Antiangiogenic-PDT & Antiangiogenic & DHA & 5-ALA & $630 \mathrm{~nm}, 20$ or $25 \mathrm{~W} \cdot \mathrm{cm}^{-2}$ & nd & $\begin{array}{l}\text { Eca109 and Ec9706 } \\
\text { cell lines }\end{array}$ & No \\
\hline [192] & Antiangiogenic-PDT & Antiangiogenic & acetazolamide & AZBPS & $660 \mathrm{~nm}, 2 \mathrm{~W} \cdot \mathrm{cm}^{-2}, 30 \mathrm{~min}$ & ${ }^{1} \mathrm{O}_{2}$ & $\begin{array}{l}\text { MDA-MB-231 and } \\
\text { MCF7 cell line }\end{array}$ & $\begin{array}{l}\text { MDA-MB-231 } \\
\text { tumour-bearing } \\
\text { nude mice }\end{array}$ \\
\hline
\end{tabular}

nd: not determined; AZBPS: acetazolamide conjugated BODIPY; 5-ALA: 5-aminolevulinic acid. 
Nanostructured self-quenched porphysome NPs (Figure 42) have been developed by Jin et al. [193]. PDT with Photofrin $(633 \mathrm{~nm}, 200 \mathrm{~mW}$ with a spot size of $9 \mathrm{~mm}$ diameter for $318 \mathrm{~s})$ in treating mice bearing KB xenograft under hyperoxic conditions induced $100 \%$ reduction of tumour volume 2 days after treatment and $100 \%$ survival over 50 days. When molecules of Photofrin were assembled in the bilayer of self-quenched porphysome NPs, no PDT effect could be observed $(671 \mathrm{~nm}, 200 \mathrm{~mW}, 5 \mathrm{~min}$ $18 \mathrm{~s})$. Porphysomes proved in fact to be photothermal enhancers that induced rapid and significant tumour temperature increase (T final $>60^{\circ} \mathrm{C}$ in $85 \mathrm{~s}$ ) upon PTT irradiation (PTT: $671 \mathrm{~nm}, 750 \mathrm{~mW}$, $100 \mathrm{~J} \cdot \mathrm{cm}^{-2}, 85 \mathrm{~s}$ ) for a complete $\mathrm{KB}$ tumour elimination regardless of cellular $\mathrm{O}_{2}$ amount in both hyperoxic and hypoxic conditions.

Zhu et al. [194] designed a NP (BSA/SAs-NMOF NPs) based on nmOFs (TCPP as organic ligands and iron ions as metal center) as PTT/PDT agent, covalently conjugated to BSA/SA complexes (bovine serum albumin/sulfonamides) for biocompatibility. In vitro in $4 \mathrm{~T} 1$ cell line, the authors observed a photothermal conversion efficiency of $40.53 \%\left(660 \mathrm{~nm}, 50 \mathrm{~mW} \cdot \mathrm{cm}^{-2}, 10 \mathrm{~min}\right)$ and a efficient ROS generation $\left(660 \mathrm{~nm}, 50 \mathrm{~mW} \cdot \mathrm{cm}^{-2}, 10 \mathrm{~min}\right.$ then $\left.1.0 \mathrm{~W} \cdot \mathrm{cm}^{-2}, 5 \mathrm{~min}\right)$ in both normoxic and hypoxic conditions under laser irradiation. The synergistic effect of PTT/PDT $\left(660 \mathrm{~nm}, 50 \mathrm{~mW} \cdot \mathrm{cm}^{-2}, 10 \mathrm{~min}\right.$ then $1.0 \mathrm{~W} \cdot \mathrm{cm}^{-2}, 5 \mathrm{~min}$ ) to kill cancer cells was desmontrated in both in vitro and in vivo $4 \mathrm{~T} 1$ tumour models and appeared to be significantly better than PTT or PDT alone.

In 2016, Hu et al. [195] developed an original strategy based on the increase of temperature to improve circulation of the blood, blood $\mathrm{O}_{2}$ concentration in tumour tissue. This strategy is different from PTT since it does not base on a conversion of energy into heat but on an external change of the temperature of mice. They synthesized a human serum albumin loaded with Ce6 cHeLated with $\mathrm{Mn}^{2+}$ (HSA-Ce6 NAs) with an average hydrodynamic diameter of $100 \pm 2.4 \mathrm{~nm}$. Reduced GSH could induce the cleavage of intermolecular disulfide bonds of HSA-Ce6 NAs and the release of Ce6. In vitro in 4T1 cells, they showed that PDT $\left(660 \mathrm{~nm}, 50 \mathrm{~mW} \cdot \mathrm{cm}^{-2}, 5 \mathrm{~min}\right)$ led to cell viability of $25.7 \%$ at $37^{\circ} \mathrm{C}$ and $5.8 \%$ at $43^{\circ} \mathrm{C}$. In vivo in $4 \mathrm{~T} 1$ tumour-bearing mice, PDT was also performed $\left(660 \mathrm{~nm}, 200 \mathrm{~mW} \cdot \mathrm{cm}^{-2}\right.$, $20 \mathrm{~min}$ ). The designed a warm water bath to simulate « hot spring » bath. By changing the temperature from $37^{\circ} \mathrm{C}$ to $43^{\circ} \mathrm{C}$, blood flow velocity increased from $17.3 \mathrm{~cm} \cdot \mathrm{s}^{-1}$ to $32.4 \mathrm{~cm} \cdot \mathrm{s}^{-1}, \mathrm{O}_{2}$ saturation in tumour tissue also increased from $52 \%$ to $79 \%$. After PDT, mice treated with Ce6 at $37^{\circ} \mathrm{C}$ showed a tumour growth delay, with HSA-Ce6 NAs at $37^{\circ} \mathrm{C}$ a partly inhibition of tumour growth whereas with HSA-Ce6 NAs at $43^{\circ} \mathrm{C}$ they could observe significant tumour regression with no tumour recurrence.

In 2017, Feng et al. [196] described liposomes activatable by NIR light to relieve tumour hypoxia and to be an efficient PDT-agent while protecting skin. The liposomes (DiR- $h$ Ce6-liposomes) were composed by a PEG shell and encapsulated hexylamine conjugated Ce6 ( $h \mathrm{Ce} 6)$ and 1,1'-dioctadecyl-3,3,30,3'-tetramethylindotricarbocyanine iodide (DiR) as a NIR dye quenching the photophysical properties of $h$ Ce6. In the absence of NIR light, $h$ Ce6 contained in DiR-hCe6-liposome presented a quenching of its photophysical properties and under a $785 \mathrm{~nm}$ NIR irradiation, a photobleaching of DiR induced a recovery of $h$ Ce6 properties but also a photothermal heating leading to a reduction of tumour hypoxia. A quenching of $97 \%$ of $h$ Ce6 fluorescence in DiR-hCe6-liposomes was observed and a recovery of fluorescence was observed after NIR irradiation $\left(785 \mathrm{~nm}, 1 \mathrm{~W} \cdot \mathrm{cm}^{-2}\right.$, $10 \mathrm{~min})$. The ${ }^{1} \mathrm{O}_{2}$ generation was also evaluated under light excitation $\left(660 \mathrm{~nm}, 2 \mathrm{~mW} \cdot \mathrm{cm}^{-2}, 30 \mathrm{~min}\right)$ and the production by DiR- $h$ Ce6-liposomes was significantly lower than Ce6 alone and $h$ Ce6-liposomes but under NIR irradiation followed by $660 \mathrm{~nm}$ irradiation, DiR- $h$ Ce6-liposomes recovered this ability. In vitro PDT efficiency was investigated in $4 \mathrm{~T} 1$ cells. Under light irradiation $\left(660 \mathrm{~nm}, 2 \mathrm{~mW} \cdot \mathrm{cm}^{-2}\right.$, $30 \mathrm{~min}$ ), DiR-hCe6-liposomes showed a slight phototoxicity but a succession of NIR and $660 \mathrm{~nm}$ irradiation, a high phototoxic effect was observed similar to that observed for $h$ Ce6-liposomes. In vivo studies in balb/c mice bearing 4T1 tumours under NIR irradiation, an increase of temperature over time was observed corresponding to a photothermal heating. A significant reduction of tumour hypoxia from $38 \%$ to $12 \%$ was also observed after NIR irradiation (Figure 43 ). 


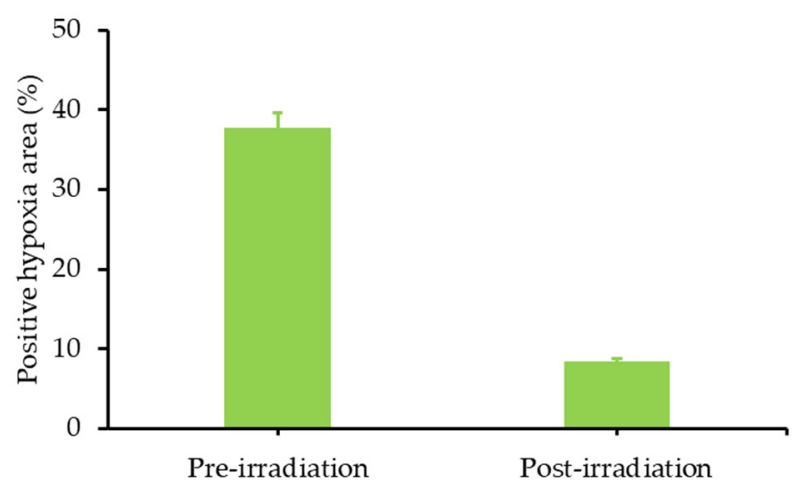

Figure 43. In vivo activation of DiR-hCe6-liposome by NIR laser irradiation and the followed tumour Oxygenation. Semi-quantitative analysis of the percentage of positive hypoxia region before and after laser irradiation. Adapted from Feng et al. [196].

Finally, the in vivo PDT effect of DiR-hCe6-liposomes after successive irradiations $(785 \mathrm{~nm}$, $0.7 \mathrm{~W} \cdot \mathrm{cm}^{-2}$ for $20 \mathrm{~min}$ followed by $660 \mathrm{~nm}, 2 \mathrm{~mW} \cdot \mathrm{cm}^{-2}$ for $1 \mathrm{~h}$ ) was studied and a high inhibition of tumour growth was observed whereas for mice injected with $h \mathrm{Ce} 6$ and irradiated at $660 \mathrm{~nm}$, only a moderate effect was observed (Figure 44 and Table 20).

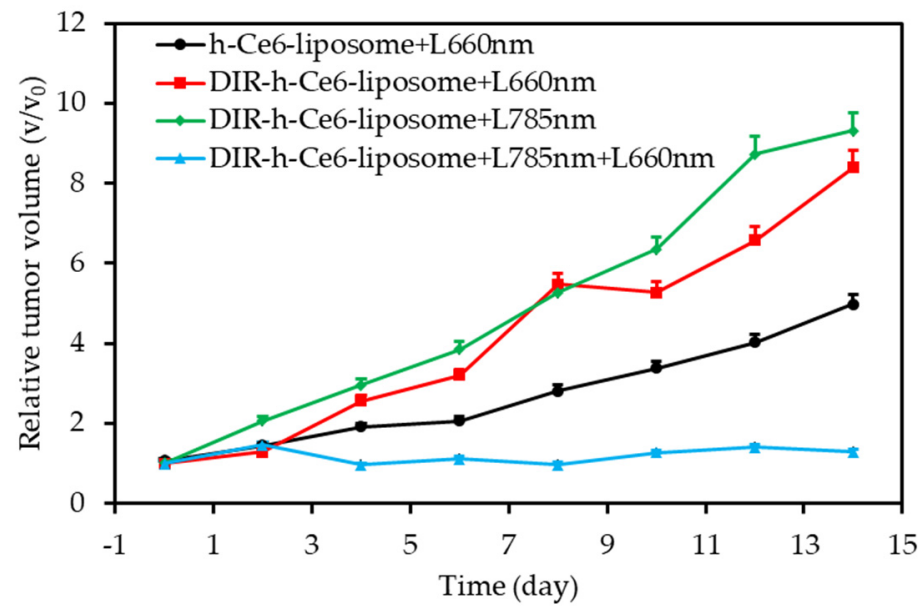

Figure 44. In vivo NIR light activated synergistic cancer phototherapy. Relative tumour volume $\left(\mathrm{V} / \mathrm{V}_{0}\right)$ changing curves of mice after various different treatments at indicated for 14 days. $\mathrm{V}$ and $\mathrm{V}_{0}$ stood for the tumour volumes after and before the treatment, respectively. Adapted from Feng et al. [196].

\subsection{Imuno-PDT}

Cancer cells undergo profound genetic rearrangements that allow them to acquire their malignant properties. Thus, they begin to express on their surface specific molecules (tumoural antigens) that distinguish them from healthy cells and are able to induce immune reactions. Immunotherapy is a therapeutic approach that acts on the immune system of a patient to fight against his disease. This technique relies on the injection of specific proteins to the targeted tumour, the goal being to teach the patient's immune cells to identify tumour and eliminate it. PDT may be a synergistic adjunct to this type of treatment as shown by the following example. 
Table 20. Summary of publications about PTT/PDT.

\begin{tabular}{|c|c|c|c|c|c|c|c|}
\hline Ref & Application & $\begin{array}{l}\text { Supplementary } \\
\text { Therapy Used }\end{array}$ & PS & Energy of Excitation & Type of ROS & In Vitro & In Vivo \\
\hline [193] & PTT/PDT & PTT & $\begin{array}{l}\text { Photofrin and } \\
\text { Porphysome }\end{array}$ & $\begin{array}{l}\text { Photofrin: } 635 \mathrm{~nm}, 200 \mathrm{~mW}, 318 \mathrm{~s} \\
\text { Porphysome: } 671 \mathrm{~nm}, 200 \mathrm{~mW}, 18 \mathrm{~s} \\
\text { PTT: } 671 \mathrm{~nm}, 750 \mathrm{~mW}, 85 \mathrm{~s}\end{array}$ & nd & No & KB tumour-bearing mice \\
\hline [194] & PTT/PDT & PTT & Iron porphyrin & $\begin{array}{c}600 \mathrm{~nm}, \\
\text { PDT: } 50 \mathrm{~mW} \cdot \mathrm{cm}^{-2}, 10 \mathrm{~min} \\
\text { PTT: } 1.0 \mathrm{~W} \cdot \mathrm{cm}^{-2} \text { for } 5 \mathrm{~min},\end{array}$ & ROS & $4 \mathrm{~T} 1$ cell line & 4T1 tumour-bearing mice \\
\hline [195] & PDT & External heating & Ce6 & $\begin{array}{c}\text { In vitro: } 660 \mathrm{~nm}, 50 \mathrm{~mW} \cdot \mathrm{cm}^{-2}, 5 \mathrm{~min} \\
\text { In vivo: } 660 \mathrm{~nm}, 200 \mathrm{~mW} \cdot \mathrm{cm}^{-2} \\
20 \mathrm{~min}\end{array}$ & ${ }^{1} \mathrm{O}_{2}$ & $4 \mathrm{~T} 1$ cell line & 4T1 tumour-bearing mice \\
\hline [196] & PTT/PDT & PTT & $h$ Ce6 & $\begin{array}{c}\text { NIR irradiation: } 785 \mathrm{~nm}, 1 \mathrm{~W} \cdot \mathrm{cm}^{-2} \\
10 \mathrm{~min} \\
\text { Light irradiation: } 660 \mathrm{~nm} \\
2 \mathrm{~mW} \cdot \mathrm{cm}^{-2}, 30 \mathrm{~min}\end{array}$ & nd & $4 \mathrm{~T} 1$ cell line & 4T1 tumour-bearing mice \\
\hline
\end{tabular}

nd: not determined; Ce6: Chlorin e6; $h$ Ce6: hexylamine conjugated chlorin e6. 
Im et al. [197] developed hypoxia-responsive Ce6-doped-azobenzene-glycol chitosan(GC)-PEG mesoporous silica NPs (CAGE) to enhance cancer immunotherapy (CIT) with PDT by modulation of dendritic cells and destruction of cancer cells (Figure 45). The effective generation of ROS by CAGE under laser irradiation was confirmed using SOSG. Biocompatibility and photoinduced cytotoxicity $\left(660 \mathrm{~nm}, 150 \mathrm{~mW} \cdot \mathrm{cm}^{-2}, 15 \mathrm{~min}\right)$ of carriers was validated in vitro in a murine melanoma cell line (B16.F1). In vivo studies in B16.F1 tumour bearing mice showed an efficient inhibition of tumour growth for mice treated with CAGE and irradiated at $660 \mathrm{~nm}\left(200 \mathrm{~mW} \cdot \mathrm{cm}^{-2}, 15 \mathrm{~min}\right)$.

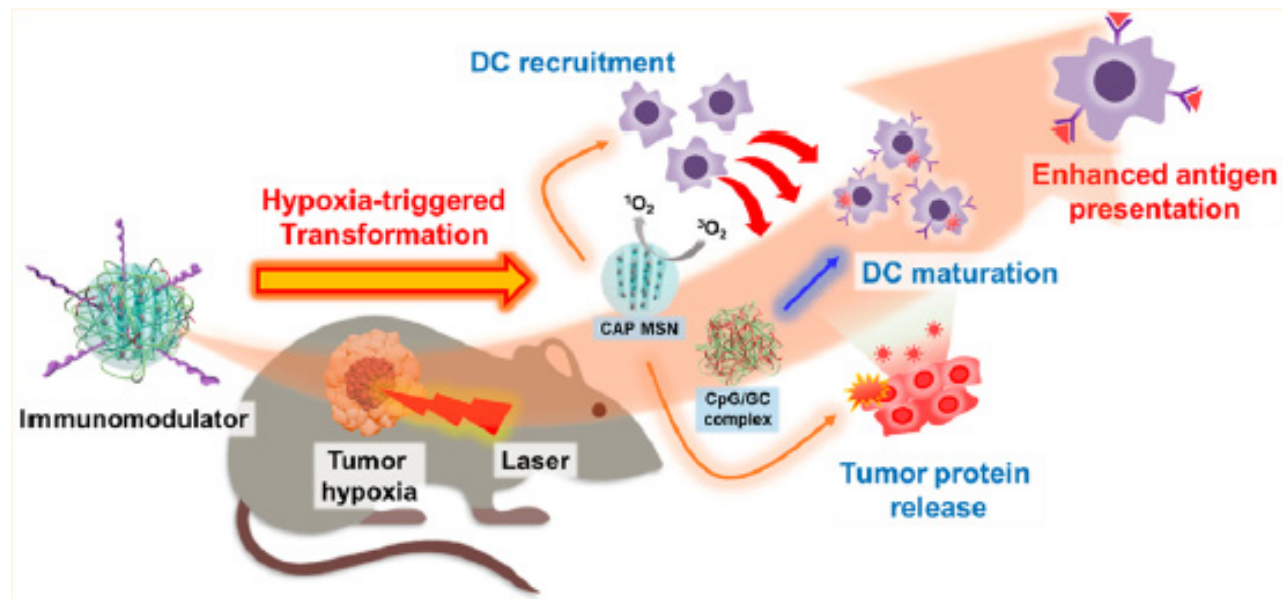

Figure 45. Schematic representation of Immuno-PDT concept of the study. Reprinted from [197] with permission from the American Chemical Society, Copyright 2019.

\section{Hypoxia-Independent PDT}

Intratumoural hypoxia is one of the major limitations in clinical use of PDT owing to insufficient generation of ${ }^{1} \mathrm{O}_{2}$. This hypoxic environment is further aggravated by consumption of oxygen during PDT limiting the therapeutic outcome $[193,198]$. To overcome that problem, various oxygen-sufficient materials or oxygen-independent PSs to produce ROS are developed and presented in this section.

\subsection{PDT Type I}

The principle of PDT is based on a PS excitation at a specific wavelength enabling PS to move to its triplet excited state and leading to the formation of cytotoxic ROS. These ROS can be produced by Type I (i.e. free radicals such as ${ }^{\bullet} \mathrm{OH}$ ) or Type II (i.e. ${ }^{1} \mathrm{O}_{2}$ ) photochemical reactions simultaneously. Most of the clinical applications relating to PDT are based on Type II PDT and suffering badly from the insufficient $\mathrm{O}_{2}$ supply in TME. One of the approaches being explored to circumvent this problem is the use of Type I PDT for more cytotoxic free radicals' generation to reduce dependence on intracellular oxygen content.

Ding et al. (2011) [199] designed micelles with 5,10,15,20-tetrakis-(meso-hydroxyphenyl)porphyrin) (mTHPP) effective under both normoxic $\left(50 \mathrm{~mm} \mathrm{Hg} \mathrm{O}_{2}\right.$ ) and hypoxic (less than $20 \mathrm{~mm} \mathrm{Hg} \mathrm{\textrm {O } _ { 2 }}$ ) conditions by modulation of photoactivation mechanism. Diameter of such micelles were $57 \mathrm{~nm}$ (electron rich: $\beta$-poly(2-(diisopropylamino)ethyl methacrylate (mTHPP-PDPA) micelles), $49 \mathrm{~nm}$ (electron deficient: poly(D,L-lactide)) micelles (mTHPP-(PEG-b)PLA) (Figure 46). 


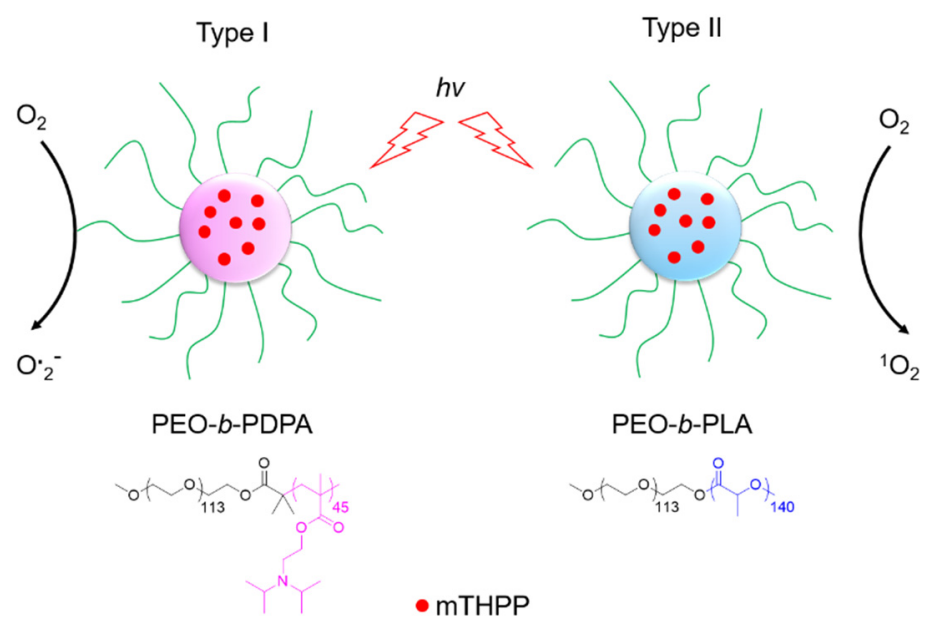

Figure 46. Modulation of photoactivation mechanism of a model PS, mTHPP, by the micelle microenvironment. Electron-rich PDPA micelles led to increased type I reactions producing superoxide radical anions, while electron-deficient PLA micelles generated ${ }^{1} \mathrm{O}_{2}$ as predominant species by type II reactions. Adapted from Ding et al. [199].

In vivo experiments were performed with various cancer cells (H2009, A549 and PC-3) in hypoxic conditions, irradiated at $532 \mathrm{~nm}\left(20 \mathrm{~mW} \cdot \mathrm{cm}^{-2}, 10 \mathrm{~min}\right)$ and cell survivals was observed 2 days after treatment. PDPA micelles generate less ${ }^{1} \mathrm{O}_{2}$ (relative quantum yield of 0.46) than PLA micelles in air saturated solution but about three time more others ROS. As example, survival of $\mathrm{H} 2009$ cells were two folds lower with PDPA micelles than with PLA micelles and three folds lower than with free mTHPP.

In 2014, Usacheva et al. [16] designed MB-loaded alginate NPs $(275 \pm 30 \mathrm{~nm})$ to study the PDT efficiency under normoxic and hypoxic conditions. The authors compared the ROS and ${ }^{1} \mathrm{O}_{2}$ production with free MB and MB NPs after irradiation under different concentration of $\mathrm{O}_{2}$. The ${ }^{1} \mathrm{O}_{2}$ production and fluorescence were systematically higher for MB NPs than free MB even at low $\mathrm{O}_{2}$ concentration. More interesting was a higher production of ROS with the NPs than free MB. Nitroblue tetrazolium (NBT) assay clearly indicated a high level of $\mathrm{O}_{2}^{-\bullet}$. Cytotoxicity of MB and MB NP-mediated PDT was studied in various breast cancer cells (MDAMB231, 4T1, SKBR3, and MCF7 cells) under ambient conditions and NPs showed a better efficacy for the MB. A similar study in normoxia and hypoxia led to the same result. The authors investigated the MB-mediated PDT $\left(660 \mathrm{~nm}, 6 \mathrm{~mW} \cdot \mathrm{cm}^{-2}\right)$ on mammospheres induced by MCF-7 cancer stem cells (CSCs) and showed that MB NPs effectively disrupted the formation of mammospheres as well colonies of cells under hypoxic conditions.

$\mathrm{Li}$ et al. (2018) [200] developed a molecular superoxide radical generator (ENBS-B) (Figure 47) that excited by near infrared light produced through type I reaction $\mathrm{O}_{2}{ }^{-\bullet}$. A significant part of this $\mathrm{O}_{2}{ }^{-\bullet}$ was transformed in $\bullet$ OH after formation of $\mathrm{H}_{2} \mathrm{O}_{2}$ (Figure 48).

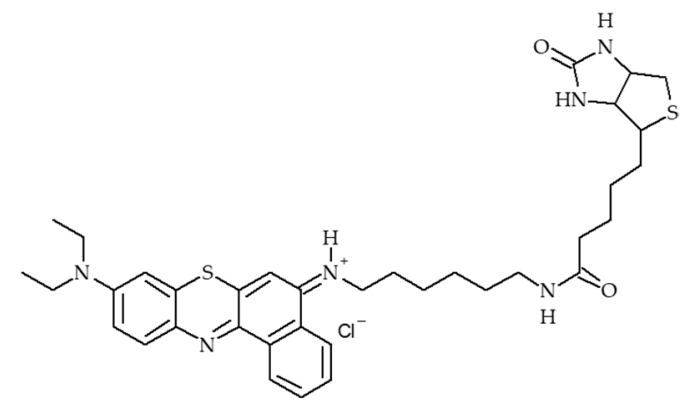

ENBS-B

Figure 47. Structure of ENBS-B. Adapted from Li et al. [200]. 


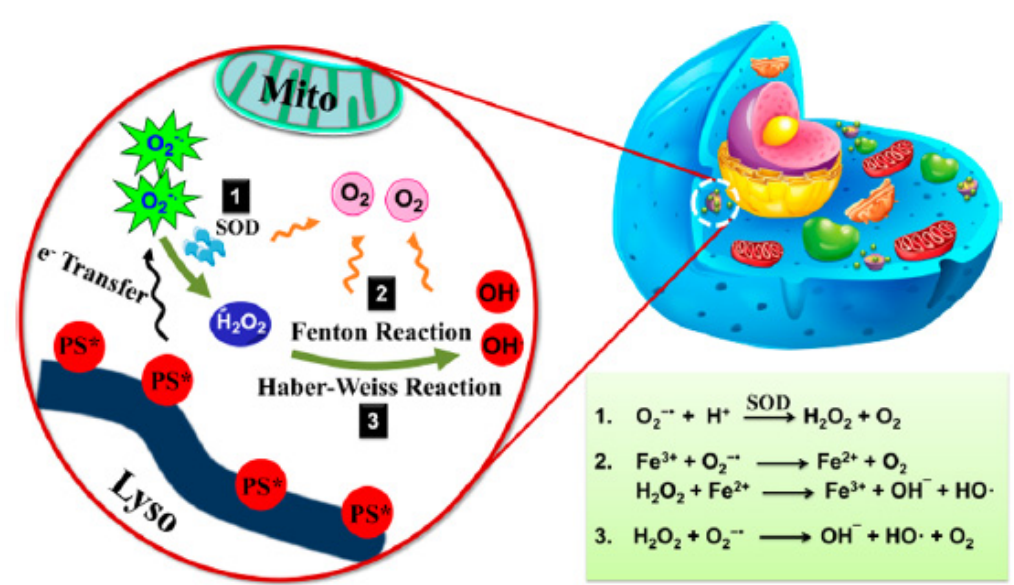

Figure 48. Schematic Illustration of Photo-Induced Radical Generation Mechanism of ENBS-B. Reprinted from [200] with permission from the American Chemical Society, Copyright 2018.

In vitro cytotoxicity of HepG2 cells under normoxic and hypoxic conditions was increased at equal time up to $94 \%$ at low concentration of ENBS-B. In vivo studies were performed on tumour bearing BALB/c mice with light irradiation $\left(660 \mathrm{~nm}, 15 \mathrm{~min}, 14.4 \mathrm{~J} \cdot \mathrm{cm}^{-2}\right)$ after injection of ENBS-B A They could observed the suppression of tumour growth. This was probably due to a better targeting on biotin receptors and also to the overcoming of traditional PDT involving $\mathrm{O}_{2}$ consumption.

Liu et al. (2018) [201] irradiated copper ferrite nanosphere (CFNs) (Figure 49) with $650 \mathrm{~nm}$ laser, in synergy with PTT. PDT and Fenton reaction together allowed the theranostic nanoplatform to generate cytotoxic $\bullet \mathrm{OH}$ and $\mathrm{O}_{2}^{-} \bullet$ by electron/hole pairs of CFN. This platform was synthesized using BSA as biocompatible surfactant and had a diameter of $70 \mathrm{~nm}$.

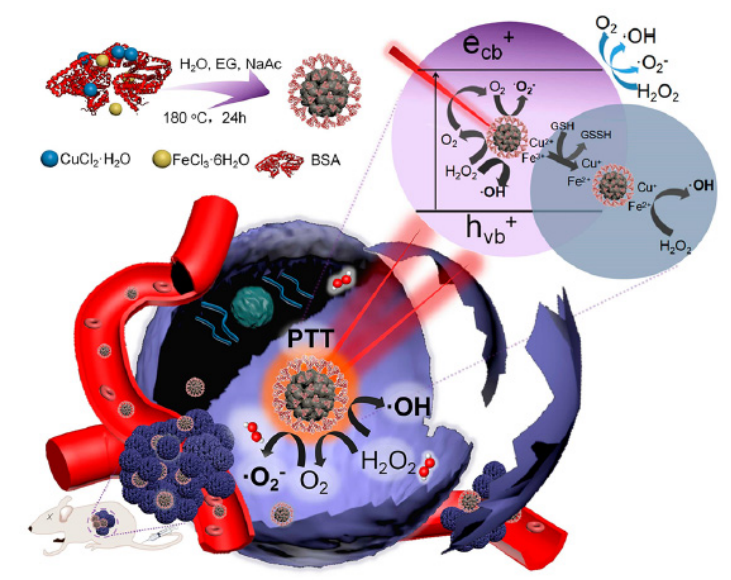

Figure 49. Schematic illustration of synthetic process and therapeutic mechanism of CFNs. Reprinted from [201] with permission from the American Chemical Society, Copyright 2018.

In vitro in HeLa cells treated with CFNs and light illumination $\left(650 \mathrm{~nm}, 15 \mathrm{~min}, 0.469 \mathrm{~W} \cdot \mathrm{cm}^{-2}\right)$ of CFNs induced ROS formation, with higher concentration than with light alone or CFNs alone. The CFNs were proven to regulate the TME via the catalysis of $\mathrm{H}_{2} \mathrm{O}_{2}$ producing $\mathrm{O}_{2}$ and consuming GSH. The authors observed the decrease of tumour hypoxia using $\left(\left[\mathrm{Ru}(\mathrm{dpp})_{3}\right] \mathrm{Cl}_{2}\right.$. Cell viability decreased nearly to zero when concentration of CFNs increased after two different illuminations $\left(650 \mathrm{~nm}, 15 \mathrm{~min}, 0.469 \mathrm{~W} \cdot \mathrm{cm}^{-2}\right.$ and $\left.808 \mathrm{~nm}, 10 \mathrm{~min}, 1.3 \mathrm{~W} \cdot \mathrm{cm}^{-2}\right)$. In vivo experiments were performed on U14 tumour bearing mice, leading to a complete ablation of tumour when both PDT and PTT were in synergy.

Lv et al. [202] synthetized type I PSs based on ruthenium (II) complexes with different cyclometaled ligands, one with 2,4-difluorophenylpyridine (Ru1) and the other with a coumarin (Ru2). In both 
normoxic and hypoxic conditions, experiments showed a strong effect attributed to charge transfer followed by type I reaction, leading to ROS production. It was found that ROS production $(475 \mathrm{~nm}$, $10 \mathrm{~mW} \cdot \mathrm{cm}^{-2}$ ) by Ru2 was 6.7 time larger than by Ru1. In vitro PDT effect was evaluated in HeLa cells irradiated in the visible region $\left(400-800 \mathrm{~nm}, 30 \mathrm{~mW} \cdot \mathrm{cm}^{-2}\right)$ during $10 \mathrm{~min}$. Ru2 was clearly more aggressive than Ru1 even at low concentration (Figure 50). Moreover, under hypoxia, the quantity of apoptotic cells after treatment was $2.83 \%$ for Ru1 and $54 \%$ for Ru2.

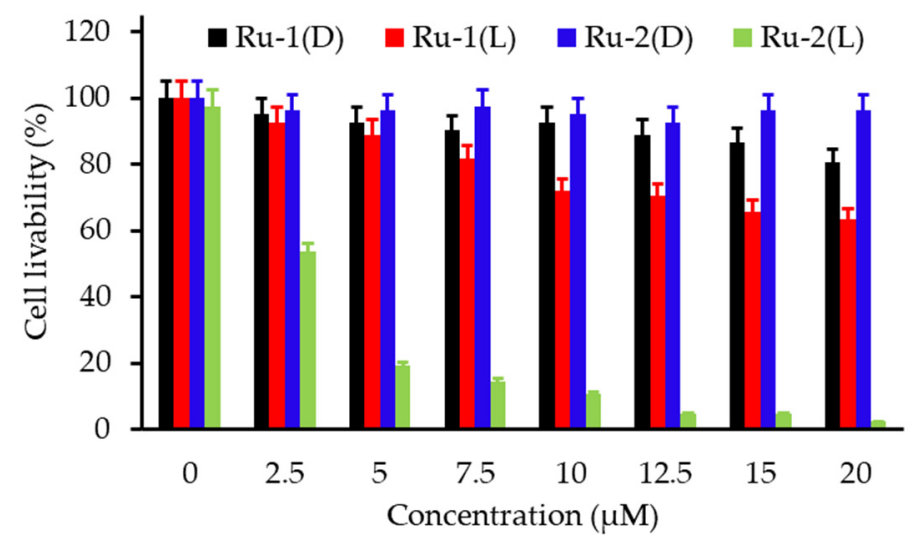

Figure 50. Dose-dependent curves for cell viability of HeLa cells treated with Ru1 and Ru2 using a typical MTT assay under light irradiation (L) or in the dark (D). Cells were irradiated with white light $\left(400-800 \mathrm{~nm}, 30 \mathrm{~mW} \cdot \mathrm{cm}^{-2}, 10 \mathrm{~min}\right)$. Adapted from Lv et al. [202].

In vivo PDT treatment (Xe lamp) on HeLa tumour bearing mice using Ru2 as PS indicate a tumour weight going from about $2 \mathrm{~g}$ to less than $0.1 \mathrm{~g}$ after 14 days.

Wang et al. (2018) [203] designed another nanoplatform $\mathrm{Fe}_{3} \mathrm{O}_{4} @ M I L-100(\mathrm{Fe})-\mathrm{UCNP}$ (FMU) (MIL, Material of Institute Lavoisier) which generate ${ }^{\bullet} \mathrm{OH}$ species in large amount due to a photo Fenton reaction. PEGylated FMU were also synthesized (FMUP) (Figure 51). In vitro cytotoxicity was measured on HeLa cells excited by $980 \mathrm{~nm}$ laser $\left(0.9 \mathrm{~W} \cdot \mathrm{cm}^{-2}, 10 \mathrm{~min}\right)$ and the cell viability was about $10 \%$.

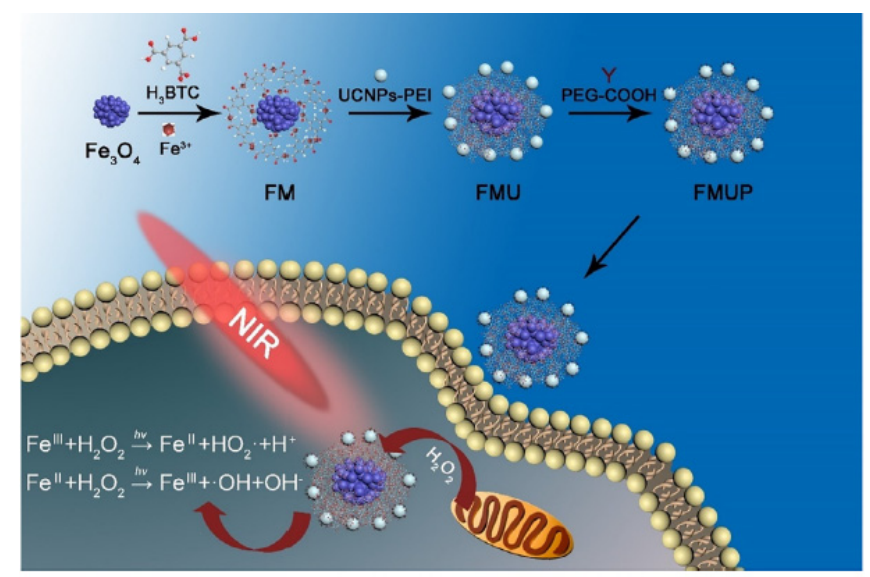

Figure 51. Schematic illustration of the synthesis process of FMUP, and the intracellular photon-Fenton reaction of FMUP with intracellular $\mathrm{H}_{2} \mathrm{O}_{2}$ under the irradiation of $980 \mathrm{~nm}$. Reprinted from [203] with permission from Elsevier Ltd, Copyright 2018.

In vivo experiments were performed on mice transplanted with carcinoma cells U14. Starting from a tumour of about $6 \mathrm{~mm}$ of diameter, illumination during $15 \mathrm{~min}$ at $980 \mathrm{~nm}\left(0.9 \mathrm{~W} \cdot \mathrm{cm}^{-2}\right)$ was followed after 14 days of treatment by a significant inhibition of growth and even a small decrease of 
the initial tumour diameter. Synergy between PDT and Fenton photoreaction was clearly the reason of such a result.

Tian et al. (2018) [204] integrated chloromethyl group into a Ru(II)-bipyridine complex leading to three chemical structures showed in Figure 52. Known to accumulate easily into mitochondria these complexes generate radicals in presence of nicotinamide adenine dinucleotide (NADH) abundant in such organelles. These radicals induced strong damages on DNA even in hypoxic conditions, leading to apoptosis. In vitro, the cytotoxicity toward SKOV-3 was evaluated, after incubation at different concentrations and irradiation at $470 \mathrm{~nm}$ (LED) during $30 \mathrm{~min}$. Complex 3 induced the highest cytotoxicity (between 50 and $10 \%$ of viability). Under hypoxic condition $\left(3 \% \mathrm{O}_{2}\right)$, this complex induced $21.1 \%$ of apoptotic cells after $30 \mathrm{~min}$ of irradiation $\left(470 \mathrm{~nm}, 22.5 \mathrm{~mW} \cdot \mathrm{cm}^{-2}\right)$. A disadvantage of this method is clearly that complexes were consumed during the PDT treatment, which could be solved by integration of Ru complexes into a drug delivery platform.
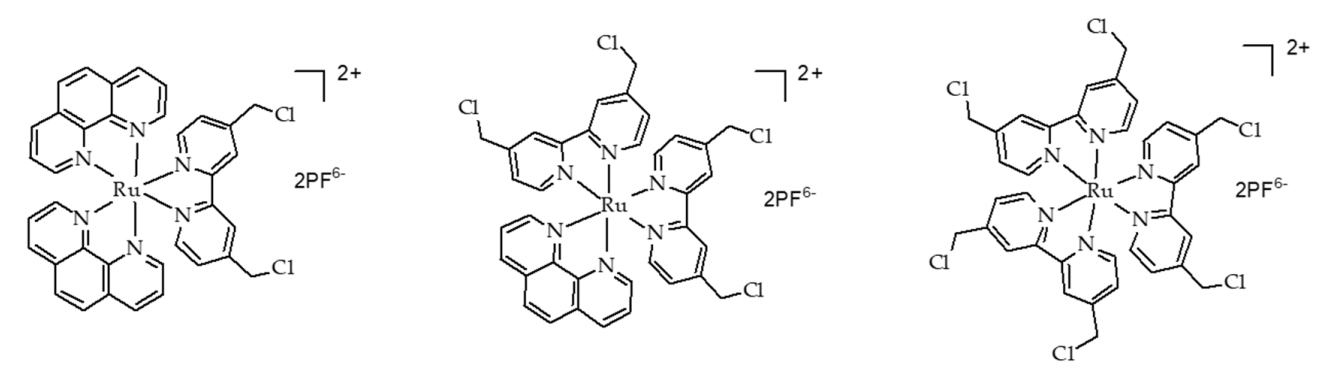

Figure 52. Chemical structures of complexes Ru (II) complexes. Adapted from Tian et al. [204].

Lazic et al. [205] developed three panchromatic PSs (TLD1822, TLD1829 and TLD1824) based on osmium complexes containing different 2,2'-biquinoline (biq) ligands (Figure 53) for PDT applications in both normoxic and hypoxic environment. These compounds presented the particularity to be activatable from 200 to $900 \mathrm{~nm}$ and the evaluation of ${ }^{1} \mathrm{O}_{2}$ generation by these compounds showed very low $\phi_{\Delta}(\sim 4 \%)$ for TLD1822 and TLD1829 and no production of ${ }^{1} \mathrm{O}_{2}$ was observed for TLD1824 indicating PDT effect with these molecules was not mediated by ${ }^{1} \mathrm{O}_{2}$ but by other ROS.

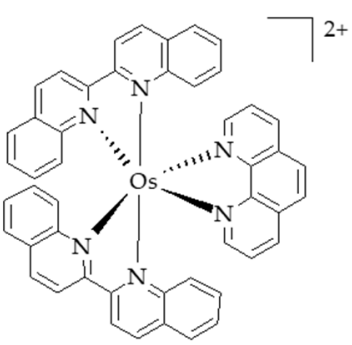

TLD1822

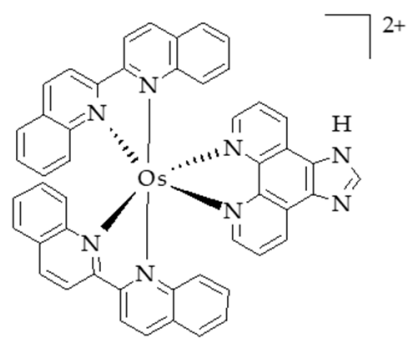

TLD1829

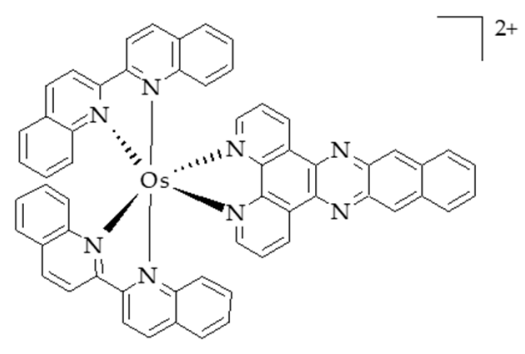

TLD1824

Figure 53. Molecular structures of the osmium-based PSs. Adapted from Lazic et al. [205].

In vitro PDT efficiency was evaluated in both HT1376 (human bladder cells) and U87 (human glioblastoma cells) under NIR $\left(808 \mathrm{~nm}, 900 \mathrm{~mW} \cdot \mathrm{cm}^{-2}\right.$ for $\left.667 \mathrm{~s}\right)$ or red $\left(625 \mathrm{~nm}, 450 \mathrm{~mW} \cdot \mathrm{cm}^{-2}\right.$ for $\left.200 \mathrm{~s}\right)$ light irradiation. The workers first evaluated PDT efficiency in normoxic conditions and observed that all PSs under both irradiations, TLD1829 displayed the highest cytotoxicity in U87 cells whereas for TLD1822 highest cytotoxicity was found in HT1376 cells. Moreover, no significant influence of the type of irradiation was highlighted. In hypoxic conditions, the cytoxicity of TLD1822 under irradiation was similar to that observed in normoxic conditions contrary to a PS of reference (PPIX) and TLD1829, which losted all their cytotoxicity in hypoxic media. In vivo studies were performed in a subcutaneously colon carcinoma tumour model and the PDT efficiency was evaluated for TLD1829 only under both red $\left(192\right.$ or $\left.266 \mathrm{~J} \cdot \mathrm{cm}^{-2}\right)$ and NIR irradiation $\left(600 \mathrm{~J} \cdot \mathrm{cm}^{-2}\right)$. Under red light illumination 
$\left(266 \mathrm{~J} \cdot \mathrm{cm}^{-2}\right)$, a significant tumour regression was observed with a majority of complete regression. Under NIR light, similar observations could be done (Table 21) 
Table 21. Summary of publications about the use of PDT type I strategy for a PDT Hypoxia-independent.

\begin{tabular}{|c|c|c|c|c|c|c|c|}
\hline Ref & Application & $\begin{array}{l}\text { Hypoxia-Independent } \\
\text { Strategy }\end{array}$ & PS & Energy of Excitation & Type of ROS & In Vitro & In Vivo \\
\hline [199] & PDT & $\begin{array}{c}\text { Modulation of the } \\
\text { mechanism of } \\
\text { photoactivation by micelles }\end{array}$ & mTHPP & $532 \mathrm{~nm}, 20 \mathrm{~mW} \cdot \mathrm{cm}^{-2}, 10 \mathrm{~min}$ & $\begin{array}{c}{ }^{1} \mathrm{O}_{2} \text { and others } \\
\text { ROS }\end{array}$ & $\begin{array}{l}\text { H2009, A549 and } \\
\text { PC-3 cell lines }\end{array}$ & No \\
\hline [16] & PDT & $\begin{array}{l}\text { Alginate formulation to } \\
\text { switch photochemistry of } \\
\text { PS from type II to type I }\end{array}$ & $\mathrm{MB}$ & $600 \mathrm{~nm}, 6 \mathrm{~mW} \cdot \mathrm{cm}^{-2}$ & $\begin{array}{c}\mathrm{O}_{2}^{-\bullet} \text { and others } \\
\text { ROS }\end{array}$ & $\begin{array}{l}\text { MDAMB231, 4T1, } \\
\text { SKBR3, and MCF7 } \\
\text { cell lines }\end{array}$ & \\
\hline [200] & PDT & $\begin{array}{l}\text { Superoxide radical } \\
\text { generator }\end{array}$ & ENBS-B & $660 \mathrm{~nm}, 14.4 \mathrm{~J} \cdot \mathrm{cm}^{-2}, 15 \mathrm{~min}$ & $\mathrm{O}_{2}^{-\bullet}, \bullet \mathrm{OH}$ & HepG2 cell line & $\begin{array}{c}\text { HepG2 } \\
\text { tumour-bearing } \\
\text { mice }\end{array}$ \\
\hline [201] & $\mathrm{PTT} / \mathrm{PDT}$ & Fenton reaction & CFNs & $\begin{array}{c}650 \mathrm{~nm}, 0.49 \mathrm{~W} \cdot \mathrm{cm}^{-2}, 15 \mathrm{~min} \text { and } \\
808 \mathrm{~nm} 1.3 \mathrm{~W} \cdot \mathrm{cm}^{-2}, 10 \mathrm{~min}\end{array}$ & $\bullet \mathrm{OH}, \mathrm{O}^{2-\bullet}$ & HeLa cell line & $\begin{array}{c}\text { U14 } \\
\text { tumour-bearing } \\
\text { mice }\end{array}$ \\
\hline [202] & PDT & Type I PSs & $\mathrm{Ru}$ (II) complexes & $\begin{array}{l}\text { In vitro: white light }(400-800 \mathrm{~nm}) \\
30 \mathrm{mWcm}{ }^{-2}, 10 \mathrm{~min} \\
\text { In vivo: xenon lamp, } 250 \mathrm{~mW} \cdot \mathrm{cm}^{-2} \text {, } \\
15 \mathrm{~min}\end{array}$ & $\begin{array}{l}{ }^{1} \mathrm{O}_{2} \text { and others } \\
\text { ROS }\end{array}$ & HeLa cell line & $\begin{array}{c}\text { HeLa } \\
\text { tumour-bearing } \\
\text { mice }\end{array}$ \\
\hline [203] & PDT & Fenton reaction & $\mathrm{Fe}_{3} \mathrm{O}_{4} @ \mathrm{MIL}-100(\mathrm{Fe})-\mathrm{UCNP}$ & $\begin{array}{l}\text { In vitro: } 980 \mathrm{~nm} \text { laser } \\
0.9 \mathrm{Wcm}^{-2}, 10 \mathrm{~min} \\
\text { In vivo: } 980 \mathrm{~nm} \text { laser } \\
0.9 \mathrm{Wcm}^{-2}, 15 \mathrm{~min}\end{array}$ & $\bullet \mathrm{OH}$ & HeLa cell line & $\begin{array}{c}\text { U14 } \\
\text { tumour-bearing } \\
\text { mice }\end{array}$ \\
\hline [204] & PDT & Carbon radical generator & $\mathrm{Ru}(\mathrm{III})$ complexes & $470 \mathrm{nl}$ LED & Carbon radicals & SKOV-3 cell line & No \\
\hline [205] & PDT & Type I reaction & $\begin{array}{l}\left.\mathrm{Os}(\mathrm{biq})_{2}(\mathrm{phen})\right]\left(\mathrm{PF}_{6}\right)_{2} \\
\left.\mathrm{Os}(\mathrm{biq})_{2}(\mathrm{IP})\right]\left(\mathrm{PF}_{6}\right)_{2} \text { and } \\
\left.\mathrm{Os}(\mathrm{biq})_{2}(\mathrm{dppn})\right]\left(\mathrm{PF}_{6}\right)_{2}\end{array}$ & $\begin{array}{c}625 \mathrm{~nm}\left(90 \mathrm{~J} \cdot \mathrm{cm}^{-2}=450 \mathrm{~mW} \cdot \mathrm{cm}^{-2},\right. \\
200 \mathrm{~s}) \text { or } 808 \mathrm{~nm} \mathrm{light}\left(600 \mathrm{~J} \cdot \mathrm{cm}^{-2}=\right. \\
\left.900 \mathrm{~mW} \cdot \mathrm{cm}^{-2}, 667 \mathrm{~s}\right)\end{array}$ & $\begin{array}{l}{ }^{1} \mathrm{O}_{2} \text { and } \\
\text { oxygen-independent } \\
\text { pathways }\end{array}$ & $\begin{array}{l}\text { HT1376 and U87 } \\
\text { cell lines }\end{array}$ & $\begin{array}{c}\text { CT26.CL25 } \\
\text { tumour-bearing } \\
\text { mice }\end{array}$ \\
\hline
\end{tabular}

$m$ THPP: 5,10,15,20-Tetrakis(meso-hudroxyphenyl)porphyrin; MB: Methylene Blue; CFNs: copper ferrite nanosphere. 


\section{2. $\mathrm{O}_{2}$ independent Cytotoxic Compounds}

Some other teams have developed compounds which could be photoactivated and do not need $\mathrm{O}_{2}$ to be cytotoxic. Babii et al. (2016) [206] used a light sensitive diarylethene-derived peptidomimetic (Figure 54), which did not need $\mathrm{O}_{2}$ to be cytotoxic since it was itself a toxic molecule in its isomeric form, appearing after irradiation by UV or visible light. A new photoswitchable block of peptidomimetics was designed with diarethylene connected to the peptide by a keto group. Absorption of this new compound was shifted to the red for about $50 \mathrm{~nm}$.

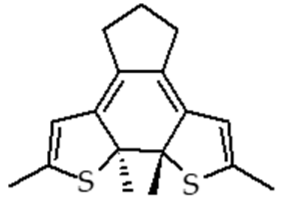

closed-ring form

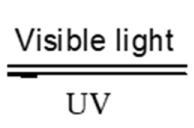

UV

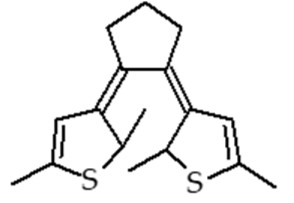

open-ring form

Figure 54. Reversible photoisomerization of the diarylethene core with UV and visible light. Adapted from Babii et al. [206].

Cytotoxicity on HeLa cells and COLO-205 cells showed that the closed ring had always less toxicity (5.5 to 8-fold lower) than the open one (Figure 55). Excitation with $664 \mathrm{~nm}$ light led to about $50 \%$ transformation from closed-ring form to open-ring form.
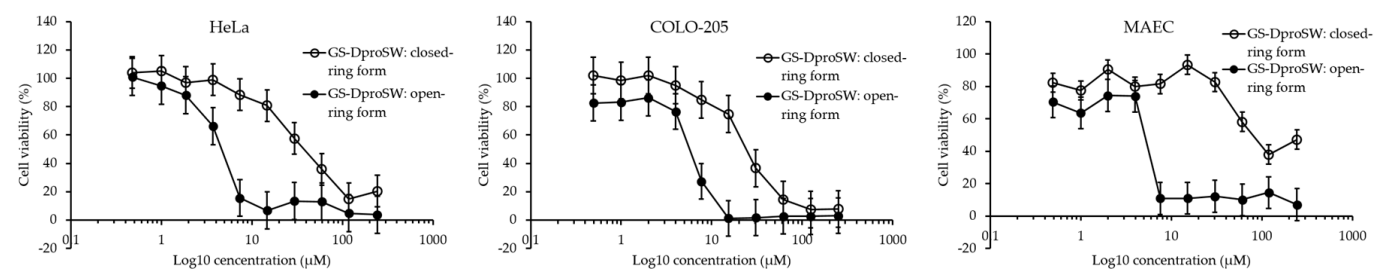

Figure 55. In vitro cytotoxic activities of the two GS- ${ }^{\mathrm{DPRo}}{ }^{\mathrm{S} w}$ photoforms as measured in the MTT test. Adapted from Babii et al. [206].

In vivo, the authors used LLC model in C57B1/6 mice and PDT with visible light $\left(100 \mathrm{~mW} \cdot \mathrm{cm}^{-2}\right.$, $20 \mathrm{~min}$ ), inducing above $60 \%$ more viability of mice after 20 days of therapy.

Fadhel et al. (2016) $[207,208]$ developed in the same work PEG-functionalized and hydrophilic silica NPs-enriched photacid generator (PAG) (Figure 56). These NPs were used to kill HCT-116 cells via an $\mathrm{O}_{2}$ independent mechanism, involving one or two NIR photon excitation. Under illumination, PAG incorporated in the silica NP functionalized with amines, induced the decrease of the $\mathrm{pH}$ inside the cells, leading to their destruction.

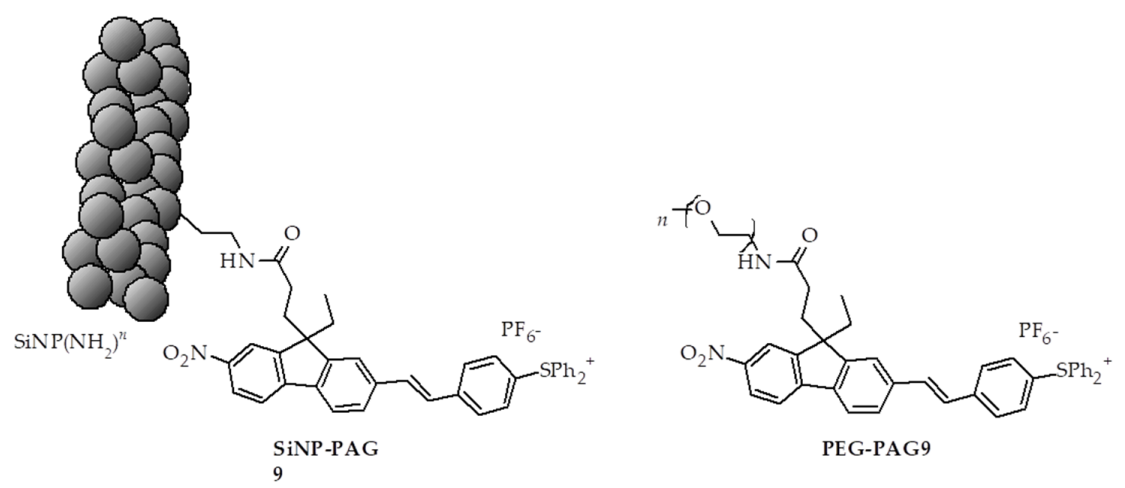

Figure 56. Structure of SiNP-PAG9 and PEG-PAG9. Adapted from Fadhel et al. [207]. 
Table 22. Summary of publications about the use of $\mathrm{O}_{2}$ independent cytotoxic compounds for PDT hypoxia-independent.

\begin{tabular}{|c|c|c|c|c|c|c|c|}
\hline Ref & Application & $\begin{array}{c}\text { Hypoxia-Independent } \\
\text { Strategy }\end{array}$ & PS & Energy of Excitation & Type of ROS & In Vitro & In Vivo \\
\hline [206] & PDT & $\begin{array}{l}\text { Photocontrollable } \\
\text { cytotoxic peptidomimetic } \\
\text { (photoisomerization) }\end{array}$ & $\begin{array}{l}\text { Diaryletene-derived } \\
\text { peptodomimetics }\end{array}$ & $\begin{array}{l}\text { Visible light, } 100 \mathrm{~mW} \cdot \mathrm{cm}^{-2} \\
20 \mathrm{~min}\end{array}$ & No & $\begin{array}{c}\text { HeLa and } \\
\text { COLO-205 cell } \\
\text { lines }\end{array}$ & $\begin{array}{c}\text { LLC } \\
\text { tumour-bearing } \\
\text { mice }\end{array}$ \\
\hline$[207,208]$ & PDT & $\begin{array}{l}\text { Photoacid generators to } \\
\text { induce an imbalance of } \\
\text { the } \mathrm{pH} \text { of tumour cells }\end{array}$ & PAG & $\begin{array}{c}\text { In vitro: } 377 \mathrm{~nm}, \\
5.4 \mathrm{~mW} \cdot \mathrm{cm}^{-2} \\
\text { In vivo: two-photon }(710 \mathrm{~nm}), \\
2.0 \mathrm{~mW} \cdot \mathrm{cm}^{-2}\end{array}$ & No & HCT-116 cell line & No \\
\hline
\end{tabular}

PAG: photacid generator. 
Intrinsic toxicity in cells was evaluated after exposure with light at $377 \mathrm{~nm}\left(5.4 \mathrm{~mW} \cdot \mathrm{cm}^{-2}, 10 \mathrm{~min}\right)$. A viability of $64 \%$ for PEG-PAG9 and $42 \%$ for SiNP-PAG9 was found (Table 22 ).

\subsection{NO Donors}

Several strategies relying on the use of NO donors have been developed to overcome the problem of hypoxia for PDT treatment. Since NO is known to inhibit cell respiration by competition with $\mathrm{O}_{2}$ by binding on mitochondrion, $\mathrm{O}_{2}$ consumption in cancer cells is inhibited and the spared $\mathrm{O}_{2}$ can be used for PDT. Some teams proposed an alternative to the $\mathrm{O}_{2}$-supply strategy i.e. an $\mathrm{O}_{2}$-economizer for the PDT treatment of hypoxic tumour.

Recently, Yu et al. [209], synthesized poly(D,L-lactide-co-glycolide) nanovesicles (PV) in which either sodium nitroprusside (SNP), tetraphenylporphyrin as PS or both were loaded. SNP was a precursor of nitric oxide $\mathrm{NO}$ in the presence of thiol compounds such as glutathione or cysteine. The thiols concentration in tumour cells being much higher than in normal cells, NO production was then higher. At the same time, the higher $\mathrm{O}_{2}$ contain was also evidenced by the use of HIF- $1 \alpha$ and immunofluorescence assay. Thus, $\mathrm{NO}$ could be considered as $\mathrm{O}_{2}$-economizer in hypoxic tumours. This effect was verified in vitro by $\mathrm{pO}_{2}$ measures and $\mathrm{NO}$ release in normal or hypoxic conditions and in the dark or under irradiation $\left(660 \mathrm{~nm}, 20 \mathrm{~mW} \cdot \mathrm{cm}^{-2}\right)$. As expected, hypoxic conditions led to lower cell viability than in normoxic ones after $3 \mathrm{~min}$ irradiation. However, prolonged irradiation time from $3 \mathrm{~min}$ to $10 \mathrm{~min}$ induced the death of about $90 \%$ cells. The nature of oxidizing agent(s) was not clearly explicit. In vivo experiments were conducted on $4 \mathrm{~T} 1$ tumour bearing female BALB/c mice and the first results exhibited a very low tumour growth in the group of PV-TS illuminated by NIR $(660 \mathrm{~nm}$, $150 \mathrm{~mW} \cdot \mathrm{cm}^{-2}, 5 \mathrm{~min}$ ) and a progressive shrinkage of tumour until eradication.

Heinrich et al. (2013) [210] studied the synergy between ROS and NO. A Ru complex $\left(\mathrm{Ru}(\right.$ phthalocyanine $\left.)(\text { pyrazine })_{2}-\left(\mathrm{Ru}(\mathrm{bpy})_{2}(\mathrm{NO})\right)_{2}\right)\left(\mathrm{PF}_{6}\right)_{6}$ (Figure 57$)$ was synthetized and produced both $\mathrm{NO}$ and ${ }^{1} \mathrm{O}_{2}$ under $660 \mathrm{~nm}$ irradiation. NO production depended on excitation wavelength and $\mathrm{pH}$, and reached a maximum value for $377 \mathrm{~nm}$ and $\mathrm{pH} 3.0$. In vitro, viability of B16F10 cells was found to be minimal at about $22 \%, 4 \mathrm{~h}$ after irradiation by $660 \mathrm{~nm}$ laser $\left(5 \mathrm{~J} \cdot \mathrm{cm}^{-2}\right)$. A proposed mechanism was the inhibition of mitochondrial respiration due to $\mathrm{NO}$ allowing an increased sparing of $\mathrm{O}_{2}$.

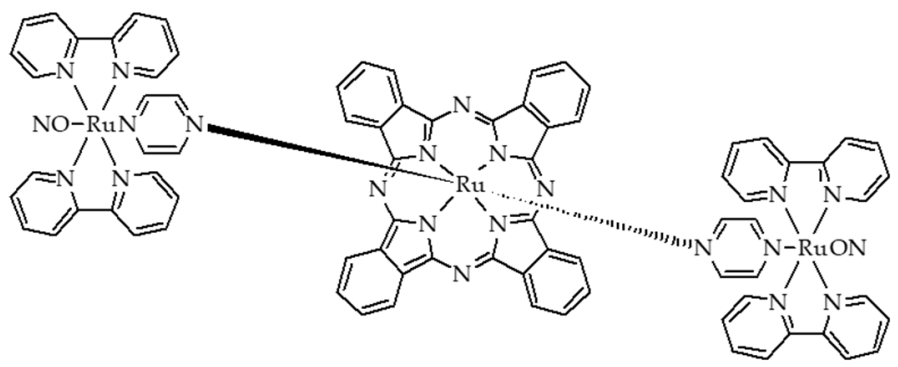

Figure 57. Molecular structure of $[\mathrm{Ru}(\mathrm{phthalocyanine})(\mathrm{pz}) 2\{\mathrm{Ru}(\mathrm{bpy}) 2 \mathrm{NO}\} 2] 6+$. Adapted from Heinrich et al. [210].

Wan et al. (2018) [211] also designed a NP taking benefit from the synergy between PDT and NO production. Starting from a porous coordination network (porphyrinic metal-organic framework), containing L-arginine (a NO donor), they coated it with a cancer cell membrane (4T1 cells) and obtained the so-called (L-Arg@PCN@Mem) NPs. Under NIR (640 nm and $720 \mathrm{~nm}$ ) irradiation, L-Arg reacted with ROS) to produce great amount of NO. In vitro, $4 \mathrm{~T} 1$ cells were incubated under normoxic and hypoxic conditions. The cell death reached up to $71 \%$ in normoxia and $18 \%$ in hypoxia after PDT treatment $\left(660 \mathrm{~nm}, 30 \mathrm{~mW} \cdot \mathrm{cm}^{-2}, 8 \mathrm{~min}\right)$, due in part to the long lifetime of $\mathrm{NO}$ and its large diffusion coefficient. In vivo experiments on $4 \mathrm{~T} 1$ tumour bearing mice showed a nearly complete ablation of tumour 14 days after the treatment $\left(660 \mathrm{~nm}, 200 \mathrm{~mW} \cdot \mathrm{cm}^{-2}, 10 \mathrm{~min}\right)$.

Deng (2018) et al. [212] synthetized a NO nanogenerator, a glutathione (GSH)-sensitive NO carrier by conjugating S-nitrosothiol to alpha-cyclodextrin, integrated in a supramolecular nanocarrier 
alpha-CD-Ce6-NO (Figure 58). This compound presented many advantages: (1) acted as GSH scavenger, (2) SMC (smooth muscle cells) relaxation to increase blood flow and 3) NO generation which could react with ROS to produce radical nitrogen species (RNS).

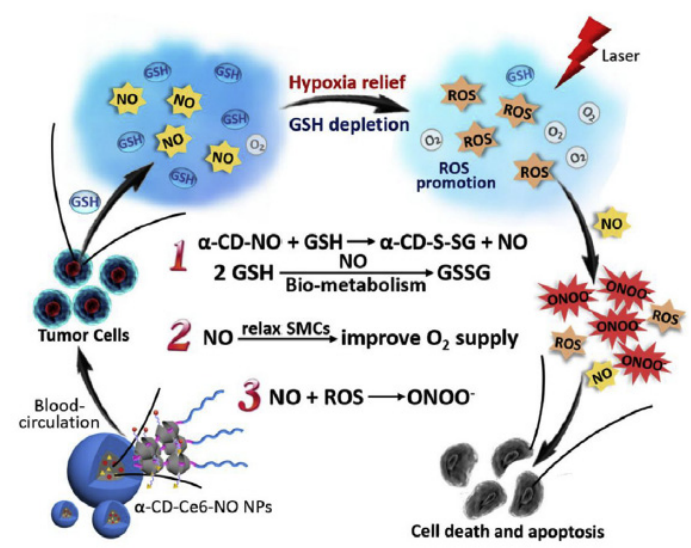

Figure 58. Multiple synergistic effects between NO and PDT generated from the supramolecular NPs $\alpha$-CD-Ce6-NO NPs to improve therapeutic efficacy. Reprinted from [212] with permission from Elsevier Ltd, Copyright 2018.

After NPs internalization in MCF-7 cells great amount of ROS was produced when cells were exposed to $660 \mathrm{~nm}$ laser irradiation without GSH, slightly less when GSH was added, but nevertheless four times larger than NP without NO. Cell viability (Figure 59) decreased up to $12.6 \%$ when synergy between PDT $\left(660 \mathrm{~nm}, 0.2 \mathrm{~W} \cdot \mathrm{cm}^{-2}, 2 \mathrm{~min}\right)$ and NO production was taken into account.

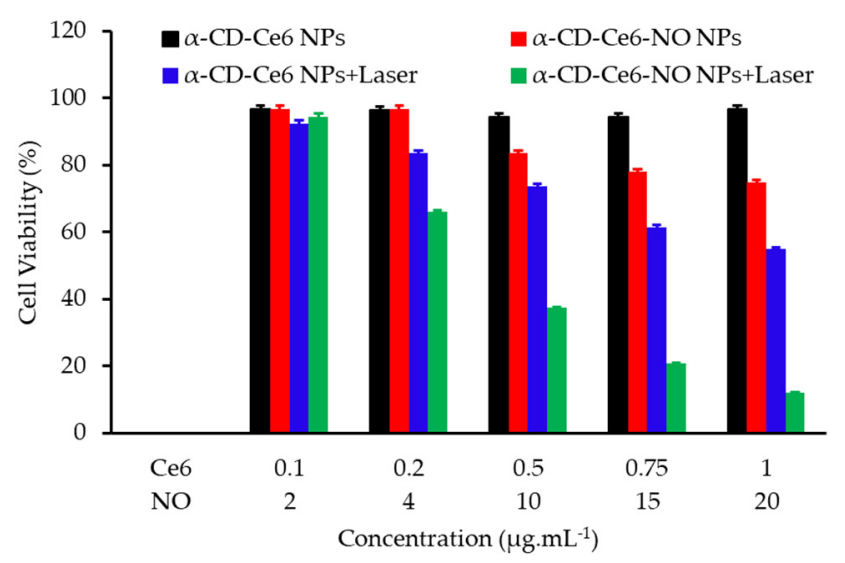

Figure 59. Cytotoxicity of MCF-7 cells incubated with $\alpha$-CDCe6 NPs, $\alpha$-CD-Ce6-NO NPs, $\alpha$-CD-Ce6 NPs with laser, and $\alpha$-CD-Ce6-NO NPs with laser $(660 \mathrm{~nm}, 0.200 \mathrm{~W}, 2 \mathrm{~min})$. Adapted from Deng et al. [212].

In vivo, tumour growth (nude mice bearing MCF-7 xenograft) was clearly inhibited with this treatment, going up to a complete ablation 21 days after treatment $\left(660 \mathrm{~nm}, 0.5 \mathrm{~W} \cdot \mathrm{cm}^{-2}, 5 \mathrm{~min}\right)$ (Table 23). 
Table 23. Summary of publications about the use of NO donor for PDT hypoxia-independent.

\begin{tabular}{|c|c|c|c|c|c|c|c|c|}
\hline Ref & Application & $\begin{array}{l}\text { Hypoxia-Independent } \\
\text { Strategy }\end{array}$ & PS & Energy of Excitation & Type of ROS & $\begin{array}{l}\text { Others } \\
\text { Radicals }\end{array}$ & In Vitro & In Vivo \\
\hline [209] & PDT & $\begin{array}{l}\text { SNP: } \mathrm{NO} \text { donor to } \\
\text { reduce } \mathrm{O}_{2} \text { consumption }\end{array}$ & Tetraphenylporphyrin & $660 \mathrm{~nm}, 20 \mathrm{~mW} \cdot \mathrm{cm}^{-2}, 3$ or $10 \mathrm{~min}$ & ${ }^{1} \mathrm{O}_{2}$ & $\begin{array}{c}\mathrm{NO} \\
+ \text { others ROS }\end{array}$ & $4 \mathrm{~T} 1$ cells & $\begin{array}{c}4 \mathrm{~T} 1 \\
\text { tumour-bearing } \\
\text { mice }\end{array}$ \\
\hline [210] & PDT & $\begin{array}{l}\text { Compound able to } \\
\text { produce both NO and } \\
{ }^{1} \mathrm{O}_{2} \text { under irradiation }\end{array}$ & Ru complex & $660 \mathrm{~nm}, 5 \mathrm{~J} \cdot \mathrm{cm}^{-2}$ & ${ }^{1} \mathrm{O}_{2}$ & $\mathrm{NO}$ & B16F10 cell line & No \\
\hline [211] & PDT & $\begin{array}{l}\text { NO-generation induced } \\
\text { by ROS production } \\
\text { (NO donor: L-arginine) }\end{array}$ & $\begin{array}{l}\text { Porphyrinic } \\
\text { metal-organic } \\
\text { framework }\end{array}$ & $\begin{array}{c}\text { In vitro: } 660 \mathrm{~nm}, 30 \mathrm{~mW} \cdot \mathrm{cm}^{-2}, \\
8 \mathrm{~min} \\
\text { In vivo: } 660 \mathrm{~nm}, 200 \mathrm{~mW} \cdot \mathrm{cm}^{-2} \\
10 \mathrm{~min}\end{array}$ & ${ }^{1} \mathrm{O}_{2}$ & NO & $4 \mathrm{~T} 1$ cell line & $\begin{array}{c}4 \mathrm{~T} 1 \\
\text { tumour-bearing } \\
\text { mice }\end{array}$ \\
\hline [212] & PDT & $\begin{array}{l}\text { Glutathione-sensitive } \\
\text { supramolecular NO } \\
\text { nanogenerator }\end{array}$ & Ce6 & $\begin{array}{l}\text { In vitro: } 660 \mathrm{~nm} \text { laser, } 0.2 \mathrm{~W}, 2 \mathrm{~min} \\
\text { In vivo: } 660 \mathrm{~nm} \text { laser, } 0.5 \mathrm{~W}, 5 \mathrm{~min}\end{array}$ & & $\begin{array}{l}\mathrm{NO}+ \\
\text { Peroxynitrite } \\
\text { anions }\end{array}$ & MCF-7 cell line & $\begin{array}{c}\text { MCF-7 } \\
\text { tumour-bearing } \\
\text { mice }\end{array}$ \\
\hline
\end{tabular}




\section{4. $\mathrm{O}_{2}$ Donor}

We report two teams who have described the use of compounds with endoperoxide able to directly generate ${ }^{1} \mathrm{O}_{2}$ under photothermal conditions. Yuan et al. [213] used substituted diphenyl anthracene (DPA) as ${ }^{1} \mathrm{O}_{2}$ donor. The endoperoxide of DPA is known to be stable and biocompatible, with a great ${ }^{1} \mathrm{O}_{2}$ formation yield. Substituents in various positions affect the cycloreversion. A nanomicelle of $60 \mathrm{~nm}$ diameter was synthesized with an amphiphilic block copolymer in which were introduced both ortho-substituted DPA and tetraphenyl porphyrin. IR780 iodide was then encapsulated in the core of the NPs to form PMT NPs. These PMT NPs could produce heat and ROS under illumination at $808 \mathrm{~nm}$, heat conduced to the release of ${ }^{1} \mathrm{O}_{2}$ from endoperoxide of DPA. In vitro, PDT was performed onto to HepG2 cells (human liver carcinoma) and led to more than $95 \%$ of dead cells, compared to about $20 \%$ when no substituted DPA was used. In vivo experiments on HepG2 tumour bearing mice, with a light density around $1.0 \mathrm{~W} \cdot \mathrm{cm}^{-2}$ were performed. Large tumour with a volume of $500 \mathrm{~mm}^{3}$ was treated both with PT NPs (block copolymer different) and PMT NPs. In the first case, growth was inhibited during treatment but accelerated after. In the second case, a decrease of the tumour volume was observed after three days of treatment $\left(808 \mathrm{~nm}, 1 \mathrm{~W} \cdot \mathrm{cm}^{-2}, 2-4 \mathrm{~min}\right)$, leading to such a weak value of the volume that cannot be measured.

Han et al. [214] designed pH-responsive micelles (C/O@N-Micelle) with an average size of $43 \mathrm{~nm}$ and obtained by self-assembly of the triblock copolymer poly(ethyleneglycol)- $\beta$-poly ( $\varepsilon$-caprolactone)- $\beta$-poly(2-(piperidin-1-yl)ethyl methacrylate) (PEG-b-PCLb-PPEMA) co-encapsulating cypate (a photothermal agent) and a ${ }^{1} \mathrm{O}_{2}$ donor (diphenylanthracene endoperoxide, DPAE). Under NIR irradiation $\left(808 \mathrm{~nm}, 1.5 \mathrm{~W} \cdot \mathrm{cm}^{-2}, 5 \mathrm{~min}\right)$, an increase of temperature of $7^{\circ} \mathrm{C}$ was highlighted confirming the photothermal effect of cypate and an efficient ${ }^{1} \mathrm{O}_{2}$ generation due to this effect. In vitro in $4 \mathrm{~T} 1$ cells, a better cellular uptake of $\mathrm{C} / \mathrm{O} @ \mathrm{~N}-$ Micelle was observed when the $\mathrm{pH}$ was decreased from 7.4 to 6.8 and a high cytotoxic effect was observed under a combined PTT/PDT treatment $\left(808 \mathrm{~nm}, 1.5 \mathrm{~W} \cdot \mathrm{cm}^{-2}\right.$, $5 \mathrm{~min}$ ) with C/O@N-Micelle. In vivo in $4 \mathrm{~T} 1$ tumour-bearing mice, they confirmed in vitro results with high tumour accumulation, significant hyperthermia and ROS production and an efficient tumour growth inhibition after PTT/PDT treatment with C/O@N-Micelle (Table 24). 
Table 24. Summary of publications about ${ }^{1} \mathrm{O}_{2}$ donor for a PDT Hypoxia-independent.

\begin{tabular}{|c|c|c|c|c|c|c|c|}
\hline Ref & Application & $\begin{array}{l}\text { Hypoxia-Independent } \\
\text { Strategy }\end{array}$ & PS & Energy of Excitation & Type of ROS & In Vitro & In Vivo \\
\hline [213] & PTT/PDT & $\begin{array}{l}\text { Use of }{ }^{1} \mathrm{O}_{2} \text { donor: } \\
\text { endoperoxide of DPA }\end{array}$ & tetraphenylporphyrin & $\begin{array}{l}\text { In vitro: } 808 \mathrm{~nm}, 0.5 \mathrm{~W} \cdot \mathrm{cm}^{-2}, 1 \mathrm{~min} \\
\text { In vivo: } 808 \mathrm{~nm}, 1.0 \mathrm{~W} \cdot \mathrm{cm}^{-2}, 0-5 \mathrm{~min}\end{array}$ & $\begin{array}{l}{ }^{1} \mathrm{O}_{2} \text { and others } \\
\text { ROS }\end{array}$ & HepG2 cell line & $\begin{array}{l}\text { HepG2 tumour-bearing } \\
\text { mice }\end{array}$ \\
\hline [214] & PTT/PDT & $\begin{array}{l}\text { Use of }{ }^{1} \mathrm{O}_{2} \text { donor: } \\
\text { DPAE }\end{array}$ & DPAE & $808 \mathrm{~nm}, 1.5 \mathrm{~W} \cdot \mathrm{cm}^{-2}, 5 \mathrm{~min}$ & ROS & $4 \mathrm{~T} 1$ cell line & $\begin{array}{l}4 \mathrm{~T} 1 \text { tumour-bearing } \\
\text { mice }\end{array}$ \\
\hline
\end{tabular}

DPA: diphenylanthracene; DPAE: diphenylanthracene endoperoxide. 


\subsection{Active Compounds in both Normoxic and Hypoxic Conditions}

Lv et al. [215] elaborated bifunctional agents, based on Pt (II) porphyrins, for tumour hypoxia imaging and PDT treatment efficient under hypoxia. A Pt (II) porphyrins core and four cationic fluorine oligomers arms with different lengths composed the three agents synthesized (Pt-1, Pt-2 and Pt-3) (Figure 60).

These compounds presented emission in the red with an increase of phosphorescence emission with decreasing level of $\mathrm{O}_{2}$ and high $\phi_{\Delta}$ of $0.80,0.86$ and 0.92 respectively. Pt-3 showed the lowest aggregation and the highest $\mathrm{O}_{2}$ sensitivity due to its $3 \mathrm{D}$ architecture and was tested in vitro and in vivo. In vitro studies were performed in HeLa cells incubated with Pt-3 and irradiated by light at $520 \mathrm{~nm}$ $\left(10 \mathrm{~mW} \cdot \mathrm{cm}^{-2}, 10 \mathrm{~min}\right)$. The molecule showed high efficiency in normoxic media to kill cancer cells and under hypoxic atmosphere, its efficiency was significantly better than hematoporphyrin used for comparison, with an apparition of apoptosis of cells $1 \mathrm{~h}$ after PDT for Pt-3 against $2 \mathrm{~h}$ for HP. A HeLa xenograft tumour-bearing mice model was used for in vivo studies. Under $520 \mathrm{~nm}$ irradiation $\left(160 \mathrm{~mW} \cdot \mathrm{cm}^{-2}, 10 \mathrm{~min}\right)$, a high decrease of tumour volume was observed for Pt-3 and HP with a more significant decrease for Pt-3 (Table 25).

Pinto et al. [216] investigated a benzophenazine compound (OR141) as a PS for PDT applications under normoxic and hypoxic conditions (Figure 61). They chose this compound after a phenotypic screening.

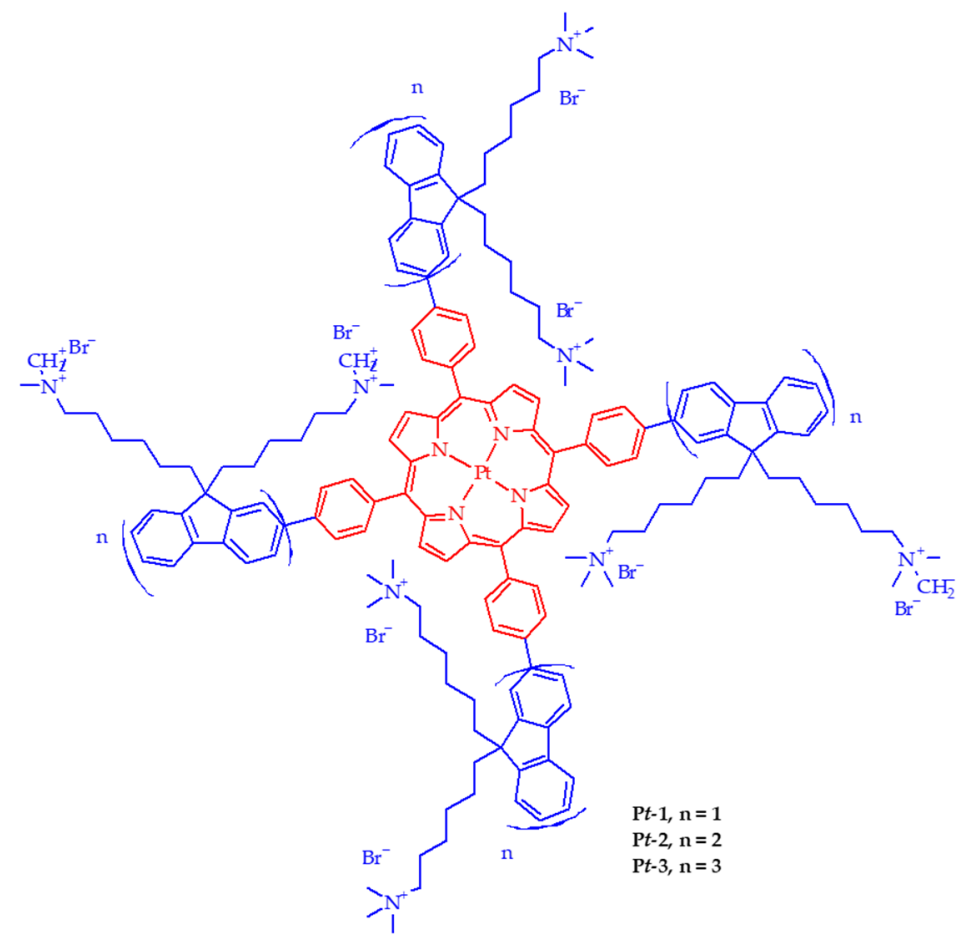

Figure 60. Chemical structures of Pt-1, Pt-2, and Pt-3. Adapted from Lv et al. [215].<smiles>COc1ccc(CNC(=O)CCCCCOc2ccccc2)c(OC)c1</smiles>

Figure 61. Molecular structure of OR141. Adapted from Pinto et al. [216]. 
Generation of ${ }^{1} \mathrm{O}_{2}$ was identified as the main photoinduced mechanism by light excitation of OR141. The authors showed that the production of ${ }^{1} \mathrm{O}_{2}$ was independent of the level of $\mathrm{O}_{2}(1$ or $21 \%$ ) since almost no change was observed between the two conditions contrary to others PS such as verteporfin and MB. They studied in endothelial cells the pathways inhibited under hypoxia by OR141 under light irradiation and found that OR141 inhibited the HIF-2 $\alpha$ expression and the mTOR (mammalian target of rapamycin) pathway. Finally, they investigated OR141 efficiency in vivo in a human colon carcinoma xenograft model. The PS accumulated during $4 \mathrm{~h}$ after injection and the mice were irradiated with white light (optic fiber, $15 \mathrm{~min}$ ) after this time. This protocol was repeated each four days and a significant decrease of tumour growth was observed.

Sun et al. [217] developed a novel PS based on a donor-acceptor-donor (DAD) model for targeting mitochondria and be an effective PDT agent. This molecule (Mito-DAD) was composed of an electron-donor (benzodithiophene), a median electron acceptor (benzotriazole), an oligoethylene glycol for a better water solubility, and a mitochondrial targeting unit (four triphenylphosphonium units) (Figure 62).

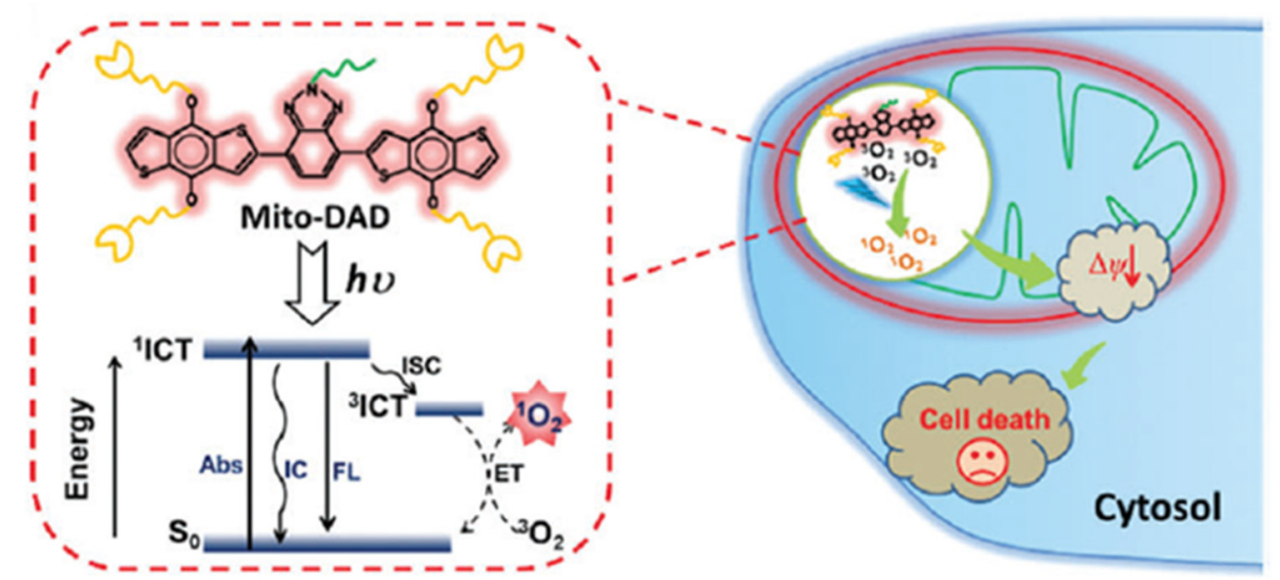

Figure 62. Illustration of enhanced cytotoxicity through photogeneration of ${ }^{1} \mathrm{O}_{2}$ by a mitochondria-targeting DAD molecule. Republished from [217] with permission of the Royal Society of Chemistry, Copyright 2018.

This compound presented a high $\phi_{\Delta}$ of 0.64 in methanol. Under low $\mathrm{O}_{2}$ concentrations ( $5 \%$ ), the $\phi_{\Delta}$ remained high with a value of 0.52 . No ROS generation was observed in the dark but under LED light irradiation an elevation of intracellular ROS was showed. Moreover, the cell death was induced very quickly after $2 \mathrm{~min}$ of visible light irradiation $\left(470 \mathrm{~nm}, 16 \mathrm{~mW} \cdot \mathrm{cm}^{-2}\right)$. After light irradiation (LED lamp, $3 \mathrm{~min}$ ), the HeLa cells viability have been shown to be Mito-DAD concentration-dependent with a decrease of viability of $96 \%$ to $4.6 \%$ with concentration from 0 to $5 \mu \mathrm{M}$ whereas under the dark, the cell viability remained superior at $90 \%$.

Under $5 \% \mathrm{O}_{2}$ concentration, an efficient PDT effect was also observed, after treatment of cells with Mito-DAD and irradiated (LED lamp $470 \mathrm{~nm}, 16 \mathrm{~mW} \cdot \mathrm{cm}^{-2}$ ) during $5 \mathrm{~min}$, with a percentage of cells viability of only $6.6 \%$ (Table 25 ).

Wieczorek et al. [218] designed novels porphyrazines incorporated in liposomes for PDT application in both normoxia and hypoxia media. They synthesized three compounds derived from porphyrazines, one of them the tribenzoporphyrazine (Figure 63) presented a $\phi_{\Delta}$ of 0.069 and 0.180 in DMF and DMSO, respectively. 


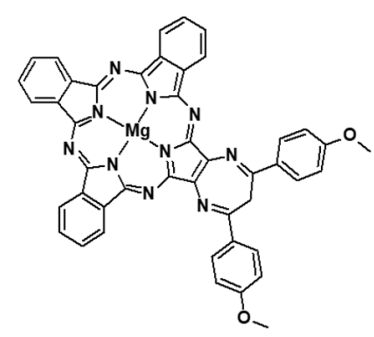

Figure 63. Structure of tribenzoporphyrazine. Adapted from Wieczorek et al. [218].

Two types of liposomes formulations were chosen to incorporate the porphyrazines, the first one, composed of 1- $\alpha$-phosphatidyl-D,L-glycerol (PG) and 1-palmitoyl-2-oleoyl-snglycero-3-phosphocholine (POPC), negatively charged and the second one, composed of 1,2-dioleoyl-3-trimethylammonium-propane (chloride salt, DOTAP) and POPC, positively charged. Porphyrazines alone and their liposomes formulations were tested in vitro in human prostate carcinoma cells (LNCaP). Under normoxic conditions, the tribenzoporphyrazine, as for the DOTAP-POPC and PG-POPC formulations, showed a significant cytotoxicity under light irradiation $\left(690 \mathrm{~nm}, 2 \mathrm{~J} \cdot \mathrm{cm}^{-2}\right)$. IC 50 was significantly lower for the both liposome formulations in comparison with tribenzoporphyrazine alone. The same results were observed in hypoxic conditions $\left(1 \%\right.$ of $\left.\mathrm{O}_{2}\right)$.

\section{Hypoxia-Dependent PDT}

The cell survival and propagation of the tumour are greatly facilitated by a hypoxic TME which is a common factor in tumours. Hypoxia induces a number of complex intracellular signaling pathways, a major one being the HIF pathway. The overexpression of HIF- $1 \alpha$ and HIF- $2 \alpha$ subunits lead to key cellular responses, which cause, among other things, the increase of blood vessel formation, aggressiveness and metastasis.

The use of hypoxia-responsive drug delivery system for PDT seems to be a rising approach for an improvement of its efficiency, which could be alterated by hypoxia. Therefore, several strategies are designed to overcome hypoxia in the treatment of solid cancers such as the development of anti-hypoxia agents, hypoxia-active nanoparticles, and hypoxia-targeting agents for anticancer PDT. The aim of these strategies is to produce $\mathrm{O}_{2}$ and activate the nanoparticles or agents in the TME, but also to target biomarkers of tumour hypoxia to improve the PSs' effectiveness that are administered. 
Table 25. Summary of publications about the use of active compounds in both normoxic and hypoxic conditions for PDT hypoxia-independent.

\begin{tabular}{|c|c|c|c|c|c|c|}
\hline Ref & Application & PS & Energy of Excitation & Type of ROS & In Vitro & In Vivo \\
\hline [215] & PDT & $\begin{array}{l}\mathrm{Pt}(\mathrm{II}) \text { porphyrins } \\
\text { linked to cationic } \\
\text { oligofluorenes arms }\end{array}$ & $\begin{array}{c}\text { In vitro: } 520 \mathrm{~nm}, 10.0 \mathrm{~mW} \cdot \mathrm{cm}^{-2} \\
10 \mathrm{~min} \\
\text { In vivo: } 520 \mathrm{~nm}, 160 \mathrm{~mW} \cdot \mathrm{cm}^{-2}, \\
10 \mathrm{~min}\end{array}$ & ${ }^{1} \mathrm{O}_{2}$ & HeLa cell line & $\begin{array}{l}\text { HeLa tumour-bearing } \\
\text { mice }\end{array}$ \\
\hline [216] & PDT & OR141 & White light, $15 \mathrm{~min}$ & ${ }^{1} \mathrm{O}_{2}$ & Endothelial cells & $\begin{array}{c}\text { Human colon } \\
\text { carcinoma xenograft } \\
\text { model }\end{array}$ \\
\hline [217] & PDT & Mito-DAD & $\begin{array}{l}470 \mathrm{~nm}, 16 \mathrm{~mW} \cdot \mathrm{cm}^{-2}, 3 \mathrm{~min} \text { in } \\
\text { normoxia and } 5 \mathrm{~min} \text { in hypoxia }\end{array}$ & ${ }^{1} \mathrm{O}_{2}$ & HeLa cell line & No \\
\hline [218] & PDT & $\begin{array}{c}\text { Porphyrazines } \\
\text { derivatives }\end{array}$ & $690 \mathrm{~nm}, 2 \mathrm{~J} \cdot \mathrm{cm}^{-2}$ & ${ }^{1} \mathrm{O}_{2}$ & LNCaP cell line & No \\
\hline
\end{tabular}

DAD: donor-acceptor-donor. 


\subsection{Hypoxia-Reducible Compounds}

\subsubsection{Azobenzene (AZO)}

The AZO group $(-\mathrm{N}=\mathrm{N}-$ ) can be reduced and cleaved by azoreductase (a typical biomarker of hypoxia) under the hypoxic environment of tumour cells, acts as the hypoxia responsive linker component.

Zhang et al. [219] reported a NPs (CPs-CPT-Ce6 NPs) composed of a conjugated polymer containing AZO bridges (CPs), which was hypoxia-responsive, adsorbing Ce6 and camptothecin as chemodrug and coating to PVP. Under irradiation $\left(670 \mathrm{~nm}, 50 \mathrm{~mW} \cdot \mathrm{cm}^{-2}, 10 \mathrm{~min}\right)$, an efficient ROS production by CPs-CPT-Ce6 NPs was observed which induced an enhancement of tumour hypoxia and thus induced the dissociation of NPs by the reductive cleavage of AZO bridges and finally release CPT for an efficient chemo-PDT treatment. Both in vitro in HeLa and NIH3T3 cells and in vivo chemo-PDT $\left(670 \mathrm{~nm}, 50 \mathrm{~mW} \cdot \mathrm{cm}^{-2}, 10 \mathrm{~min}\right)$ studies in HeLa tumour-bearing mice proved the better efficiency of this synergistic treatment in comparison with PDT and chemotherapy alone.

Huang et al. [220] also developed a drug delivery system (DDS) based on the use of hypoxia-induced cleaved AZO bridges composed of gold NPs (AuNPs) functionalized with $\beta$-cyclodextrins conjugating on the surface DRHC (double-stranded DNA/RNA hybridization complex) containing HIF-1 $\alpha$-against antisense oligonucleotide (ASO). A PS (5,10,15,20-tetrakis-(1-methyl-4-pyridyl)-21H,23H-porphine, TMPyP4,) was finally loaded on DDS to obtain DDS@TMPyP4. In HepG2 cells and in hypoxic conditions, an effective cleavage of AZO bridges was observed conducting to the release of ASO and a decrease of HIF- $1 \alpha$ expression. In vitro in HepG2 and L02 cells incubated with DDS@TMPyP4, an efficient synergistic effect of hypoxia-triggered ASO release and PDT was observed $\left(660 \mathrm{~nm}, 1 \mathrm{~W} \cdot \mathrm{cm}^{-2}, 30 \mathrm{~min}\right)$.

Piao et al. [221] developed azoSeR based on a seleno-rosamine-based dye (SeR) linked to an AZO. The $\phi_{\Delta}$ was very weak for azoSeR (0.03) in comparison with SeR $(0.56)$ due to the presence of the azo moiety which interfere with the intersystem crossing. In vitro studies were performed in rat liver microsomes to evaluate the ability of NADPH to reduce the AZO in normoxic and hypoxic conditions. Under normoxia, no change on the absorption spectra of azoSeR was observed after addition of NADPH while under hypoxia a new absorbance peak was observed. Its ability to induce cell death under light irradiation ( $535 \mathrm{~nm}, 28 \mathrm{~mW} \cdot \mathrm{cm}^{-2}, 3 \mathrm{~min}$ ) was evaluated in human lung cancer-derived A549 cells incubated with the PS under normoxia or hypoxia conditions. The cell death was mainly induced for cells treated under hypoxia. Moreover, azoSeR was able to selectively kill hypoxic cells without ablating normoxic cells. The evaluation of sensitivity of azoSeR to different $\mathrm{O}_{2}$ concentrations, under light irradiation, showed a significant toxicity even for $\mathrm{O}_{2}$ concentration of $5 \%$ and the authors also observed an increase of cell death in mild hypoxia conditions $\left(\sim 8 \%\right.$ of $\left.\mathrm{O}_{2}\right)$.

$\mathrm{Li}$ et al. [222] developed polymeric micelles which presented the ability to be responsive to both hypoxia and ${ }^{1} \mathrm{O}_{2}$ to improve the tumour uptake and the cargo release of the PS in the tumour site. The micelles (mPEG-Azo-PAsp-IM Micelles) were composed by AZO covalently bind to both hydrophilic (mPEG) and hydrophobic (PAsp-IM) polymers, the last one containing the ${ }^{1} \mathrm{O}_{2}$-responsive moiety (imidazole, IM). The micelles were formed by self-assembly of mPEG-Azo-PAsp-IM and could encapsulated $\mathrm{Ce} 6$ with a content of $4.1 \pm 0.5 \%$. The ${ }^{1} \mathrm{O}_{2}$ production could induce a rapid drug release whereas the hypoxia conditions could induce a dissection of AZOto enhance the PS uptake in tumour. The micelles without AZO (SR micelles) were synthesized as a comparative to mPEG-Azo-PAsp-IM micelles (DR micelles) for investigation of $\mathrm{Ce} 6$ release. The authors showed similar ${ }^{1} \mathrm{O}_{2}$ production for both SR and DR micelles under a $660 \mathrm{~nm}$ irradiation $\left(100 \mathrm{~mW} \cdot \mathrm{cm}^{-2}, 10 \mathrm{~min}\right)$ and observed a good Ce6 release due to the dissociation of micelles by oxidation of imidazole moiety by ${ }^{1} \mathrm{O}_{2}$. In Lewis lung carcinoma (LLC) cells, the intracellular level of Ce6 was significantly higher after laser irradiation of DR micelles in hypoxic conditions in comparison with SR micelles. In vitro PDT studies in Lewis lung carcinoma (LLC) cells were performed to investigate the efficiency of DR micelles in comparison with Ce6 alone and SR micelles. High similar phototoxicity (irradiation at $660 \mathrm{~nm}, 100 \mathrm{~mW} \cdot \mathrm{cm}^{-2}$, 
$10 \mathrm{~min}$ ) was observed in hypoxic conditions for Ce6 alone and DR micelles, which 2 folds more than that for SR micelles. Under normoxic conditions, Ce6 alone showed the highest photocytotoxicity and for DR micelles, it was lower than that in hypoxia. The in vivo PDT tests in LLC tumour-bearing mice highlighted a better efficiency of DR micelles in comparison with SR micelles confirming the in vitro studies.

Li et al. [223] designed a light-enhanced hypoxia responsive NP denoted (PAP-FC NPs) for synergic treatment of solid tumours. The PAP molecules were obtained by covalent combination of poly(ethylene oxide)-block-poly(propylene oxide)-block-poly(ethylene oxide) triblock copolymer Pluronic (P123), polyethyleneimine (PEI600), hypoxia-responsive AZO, and polyethylene glycol (PEG2000), while FC molecules were obtained by covalent conjugation of Ce6 to triblock copolymer Pluronic F127. At critical micellar concentration, PAP and FC polymers self-assembled into PAP-FC NPs, which ensure the encapsulation of DOX and thus afford PAP-FC/DOX for combined chemo-PDT treatment (Figure 64).

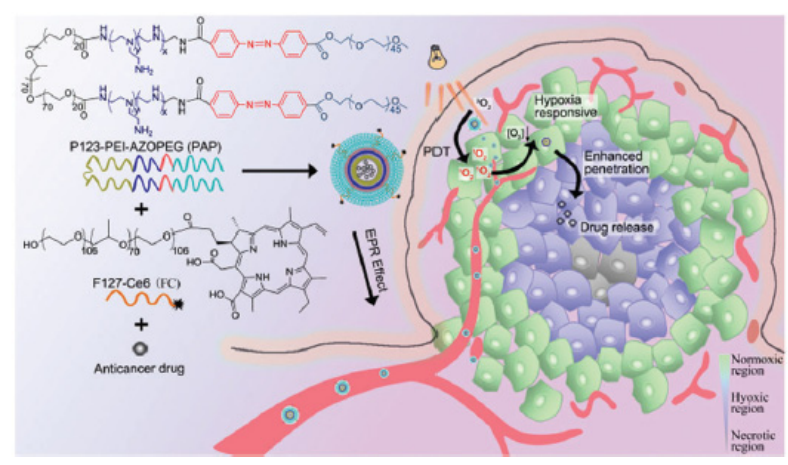

Figure 64. The structure and mechanism of PAP-FC for combined chemo-PDT. Republished from [223] with permission of the Royal Society of Chemistry, Copyright 2018.

According to both the in vitro and in vivo studies against MCF-7 cells, PAP-FC/DOX found to be able to generate high level of ${ }^{1} \mathrm{O}_{2}$ upon laser irradiation $\left(660 \mathrm{~nm}, 8 \mathrm{~mW} \cdot \mathrm{cm}^{-2}, 6 \mathrm{~min}\right)$. In addition, followed by consumption of the tissue $\mathrm{O}_{2}$, the $\mathrm{AZO}$ bond broke quickly in the hypoxia condition, leading to an efficient release of DOX, and therefore triggering apoptosis of the internal tumour cells, which resulted in enhanced antitumour efficacy.

Wang et al. [224] designed a kind of "one stone two birds" living drug delivery system by combining the PDT and hypoxia responsive chemotherapy, denoted as Ce6-PEG-Azo-PCL for cervical cancer treatment. This living drug delivery system was fabricated with three essentials constituents, i.e., AZO, biodegradable hydrophobic poly( $\varepsilon$-caprolactone) (PCL), and hydrophilic poly(ethylene glycol) (PEG)-conjugated Ce6. Subsequently, the functional NP Ce6-PEG-Azo-PCL was further loaded with DOX to afford Ce6-PEG-Azo-PCL@DOX (DOX@NP). Irradiation of DOX@NP with 671 nm laser $(10 \mathrm{~mW}, 5 \mathrm{~min})$ resulted in high ROS generation. The continuous consumption of $\mathrm{O}_{2}$ facilitated intracellular hypoxia microenvironment, and triggered the disassembly of hypoxia responsive AZO at tumour site to release loaded DOX resulting in enhanced anticancer effect.

\subsubsection{Other}

Chen et al. [225] designed pH-sensitive nanoliposomes constituted by a PS activatable under hypoxia conditions (DiBDP), substituted by a nitro group, and a Cy7-marked anti-HIF-1 $\alpha$ antibody (Ab-DiBDP) for theranostic applications. DiBDP was not able to release ${ }^{1} \mathrm{O}_{2}$ due to the nitro group but could be reduced by an enzyme, the nitroreductase (NTR), and thus, was "switched on" and could release ${ }^{1} \mathrm{O}_{2}$ (Figure 65). The nanoliposomes showed an average size of $86 \pm 17 \mathrm{~nm}$ and were able to release quickly $86 \%$ of DiBDP at pH 5.0 within $24 \mathrm{~h}$.

They first evaluated the NTR-activatable generation of ${ }^{1} \mathrm{O}_{2}$ induced by the irradiation of DiBDP by using DPBF and showed a high increase of $\phi_{\Delta}$ of the PS, from 0.05 to 0.46 when it was incubated 
with NTR. They performed the same evaluation for Ab-DIBDP NPs, by using the SOSG and showed a significant increase of SOSG fluorescence with NTR. The combination of Ab-DiDBP NPs and laser in vitro in HeLa cells in hypoxic conditions showed a high cytotoxicity (more than $56 \%$ of cell death). In vivo studies in HeLa tumour-bearing mice were also performed to evaluate the efficiency of Ab-DiBDP NP-mediated PDT. The tumour growth was severely reduced for mice treated with $\mathrm{Ab}$-DiBDP NPs and laser in comparison with other treatments (Ab-NPs + laser and DiBDP + laser) (Table 26).

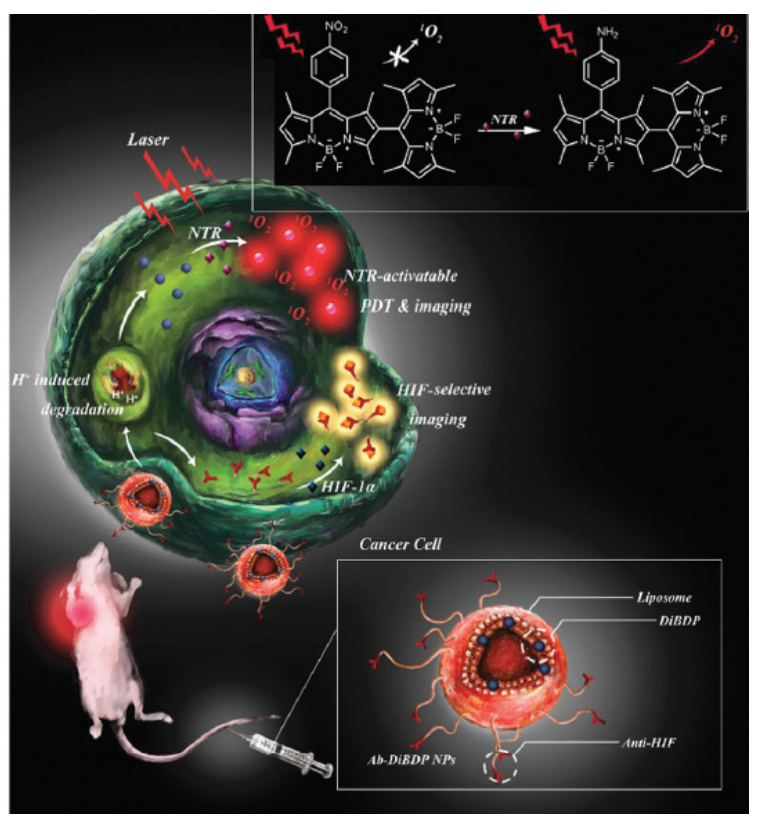

Figure 65. Schematic illustration of Ab-DiBDP NPs for dual hypoxia marker imaging and activatable PDT against tumours. Republished from [225] with permission of the Royal Society of Chemistry, Copyright 2018.

\subsection{Environment-Accumulated Hypoxia Compounds}

Evans et al. [226] described the use of a MB like molecule (EtNBS) capable of destroying hypoxic region in the core of 3D models of OVCAR-5 human OvCa cells of metastatic ovarian cancer. EtNBS was capable to incorporate into the core of the nodule. After PDT $\left(652 \mathrm{~nm}, 15 \mathrm{~J} \cdot \mathrm{cm}^{-2}, 25\right.$ to $\left.300 \mathrm{~mW} \cdot \mathrm{cm}^{-2}\right)$ even at low light fluence $\left(5 \mathrm{~J} \cdot \mathrm{cm}^{-2}\right)$ EtNBS could destroy the nodule core cells. At higher fluence, the entire nodule could be destructed. In hypoxic conditions, PDT $\left(670 \mathrm{~nm}, 100 \mathrm{~mW} \cdot \mathrm{cm}^{-2}, 5\right.$ to $\left.20 \mathrm{~J} \cdot \mathrm{cm}^{-2}\right)$ with EtNBS was still very efficient and the authors could observe significant cell killing at $20 \mathrm{~J} \cdot \mathrm{cm}^{-2}$. In vivo experiments will be performed.

Guan et al. [227] synthesized a novel theranostic nanosheet, composed of a metal complex $\left(\mathrm{Ru}(\mathrm{C}-\mathrm{bpy})_{2}\right)$ loaded to single layered layered double hydroxide $(\mathrm{LDH})$, denoted as $\left.\mathrm{Ru}(\mathrm{C}-\mathrm{bpy})_{2} / \mathrm{mLDH}\right)$ for theranostic applications. The nanosheets $\mathrm{Ru}(\mathrm{C}-\mathrm{bpy})_{2} / \mathrm{mLDH}$ showed an average diameter of $35 \pm 5 \mathrm{~nm}$ and a stronger fluorescence under an excitation at $488 \mathrm{~nm}$ for hypoxia media in comparison with normoxic media. Under light excitation $\left(520 \mathrm{~nm}, 100 \mathrm{~mW} \cdot \mathrm{cm}^{-2}\right.$ for $\left.8 \mathrm{~min}\right)$, a significant decrease of cell viability was observed for $\mathrm{Ru}(\mathrm{C}-\mathrm{bpy})_{2} / \mathrm{mLDH}$ which appeared to be more phototoxic than $\mathrm{Ru}(\mathrm{C} \text {-bpy })_{2}$ alone. They observed that $\phi_{\Delta}$ was depended of the excitation wavelength and the combination of single layered LDH with the ruthenium complex significantly enhanced the generation of ${ }^{1} \mathrm{O}_{2}$ with a $\phi_{\Delta}$ of 0.28 for $\mathrm{Ru}(\mathrm{C}-\mathrm{bpy})_{2} / \mathrm{mLDH}$ against 0.19 for $\mathrm{Ru}(\mathrm{C}-\mathrm{bpy})_{2}$ alone. An in vivo model of nude mice bearing subcutaneous HeLa tumour was used to evaluate the PDT efficiency of the nanosheets. The animals treated with $\mathrm{Ru}(\mathrm{C}-\mathrm{bpy})_{2} / \mathrm{mLDH}$ and irradiation at $520 \mathrm{~nm}\left(100 \mathrm{~mW} \cdot \mathrm{cm}^{-2}\right)$ for $8 \mathrm{~min}$, showed a significant suppression of tumour volume in comparison with the control and $\mathrm{Ru}(\mathrm{C}-\mathrm{bpy})_{2}$ groups. 
Table 26. Summary of publications about the use of Hypoxia-reducible compounds for PDT hypoxia-dependent.

\begin{tabular}{|c|c|c|c|c|c|c|c|}
\hline Ref & Application & $\begin{array}{l}\text { Hypoxia-Dependent } \\
\text { Strategy }\end{array}$ & PS & Energy of Excitation & Type of ROS & In Vitro & In Vivo \\
\hline [219] & Chemo-PDT & $\begin{array}{l}\text { Hypoxia-cleaved } \\
\text { Azobenzene }\end{array}$ & Ce6 & $\begin{array}{l}\text { In vitro: } 670 \mathrm{~nm}, 50 \mathrm{~mW} \cdot \mathrm{cm}^{-2}, 6 \mathrm{~min} \\
\text { In vivo: } 670 \mathrm{~nm}, 50 \mathrm{~mW} \cdot \mathrm{cm}^{-2}, 10 \mathrm{~min}\end{array}$ & ${ }^{1} \mathrm{O}_{2}$ & $\begin{array}{l}\text { HeLa and NIH3T3 } \\
\text { cell lines }\end{array}$ & $\begin{array}{c}\text { HeLa } \\
\text { tumour-bearing } \\
\text { mice }\end{array}$ \\
\hline [220] & Chemo-PDT & $\begin{array}{l}\text { Hypoxia-cleaved } \\
\text { Azobenzene }\end{array}$ & TMPyP4 & $660 \mathrm{~nm}, 1 \mathrm{~W} \cdot \mathrm{cm}^{-2}, 30 \mathrm{~min}$ & ROS & $\begin{array}{l}\text { HepG2 and } \\
\text { L02 cell lines }\end{array}$ & No \\
\hline [222] & PDT & $\begin{array}{l}\text { Hypoxia-cleaved } \\
\text { Azobenzene }\end{array}$ & Ce6 & $\begin{array}{l}\text { In vitro: } 660 \mathrm{~nm}, 100 \mathrm{~mW} \cdot \mathrm{cm}^{-2}, 10 \\
\text { and } 5 \mathrm{~min} \\
\text { In vivo: } 660 \mathrm{~nm}, 200 \mathrm{~mW} \cdot \mathrm{cm}^{-2}, \\
30 \mathrm{~min}\end{array}$ & ${ }^{1} \mathrm{O}_{2}$ & LLC cell line & $\begin{array}{l}\text { LLC } \\
\text { tumour-bearing } \\
\text { mice }\end{array}$ \\
\hline [221] & PDT & $\begin{array}{l}\text { Hypoxia-cleaved } \\
\text { Azobenzene }\end{array}$ & azoSeR & $535 \mathrm{~nm}, 28 \mathrm{~mW} \cdot \mathrm{cm}^{-2}, 3 \mathrm{~min}$ & ${ }^{1} \mathrm{O}_{2}$ & A549 cell line & No \\
\hline [223] & Chemo-PDT & $\begin{array}{l}\text { Hypoxia-cleaved } \\
\text { Azobenzene }\end{array}$ & Ce6 & $\begin{array}{l}\text { In vitro: } 660 \mathrm{~nm}, 8 \mathrm{~mW} \cdot \mathrm{cm}^{-2}, 6 \mathrm{~min} \\
\text { In vivo: } 660 \mathrm{~nm}, 8 \mathrm{~mW} \cdot \mathrm{cm}^{-2}, 30 \mathrm{~min}\end{array}$ & ${ }^{1} \mathrm{O} 2$ & MCF-7 cell line & $\begin{array}{c}\text { MCF-7 } \\
\text { tumour-bearing } \\
\text { mice }\end{array}$ \\
\hline [224] & Chemo-PDT & $\begin{array}{l}\text { Hypoxia-cleaved } \\
\text { Azobenzene }\end{array}$ & Ce6 & $\begin{array}{c}\text { In vitro: } 671 \mathrm{~nm}, 10 \mathrm{~mW} \cdot \mathrm{cm}^{-2}, 5 \mathrm{~min} \\
\text { In vivo: } 671 \mathrm{~nm}, 150 \mathrm{~mW} \cdot \mathrm{cm}^{-2} \\
10 \mathrm{~min}\end{array}$ & ${ }^{1} \mathrm{O} 2$ & HeLa cell line & $\begin{array}{c}\text { HeLa } \\
\text { tumour-bearing } \\
\text { mice }\end{array}$ \\
\hline [225] & PDT & $\begin{array}{l}\text { Hypoxia-reducible } \\
\text { compound by NTR }\end{array}$ & $\begin{array}{l}\text { DiBDP substituted } \\
\text { with a nitro group }\end{array}$ & $520 \mathrm{~nm}, 100 \mathrm{~mW} \cdot \mathrm{cm}^{-2}, 5 \mathrm{~min}$ & ${ }^{1} \mathrm{O}_{2}$ & HeLa cell line & $\begin{array}{c}\text { HeLa } \\
\text { tumour-bearing } \\
\text { mice }\end{array}$ \\
\hline
\end{tabular}

Ce6: Chlorin e6; TMPyP4: 5,10,15,20-tetrakis-(1-methyl-4-pyridyl)-21H,23H-porphine; azoSeR: azobenzene seleno-rosamine-based dye; NTR: Nitroreductases; DiBDP: dimeric BODIPY. 


\subsection{Other}

Guan M. et al. [228] developed a biocompatible, water soluble and photostable PS, the trismethylpyridylporphyrin-C70 (PC70) constituted by $C_{70}$ linked to 5-(4-formylphenyl)-10,15,20-tris(4-pyridyl)-porphine (D-TMPyP), which could be used in hypoxic media. $\mathrm{PC}_{70}$ could be assembled in a structure similar to liposome with a diameter of $30 \mathrm{~nm}$. In vitro studies in A549 cells were performed to evaluate PDT efficiency of this compound in normoxic and hypoxic conditions. Under normoxic conditions, it was shown that $\mathrm{PC}_{70}$ phototoxicity was both concentration and illumination time-dependent. For cells incubated with $1 \mu \mathrm{M}$ of $\mathrm{PC}_{70}$ and illuminated with white light $\left(17 \mathrm{~mW} \cdot \mathrm{cm}^{-2}\right)$ during $10 \mathrm{~min}$, the percentage of cell death reached $98 \%$ (Figure 66).

a)

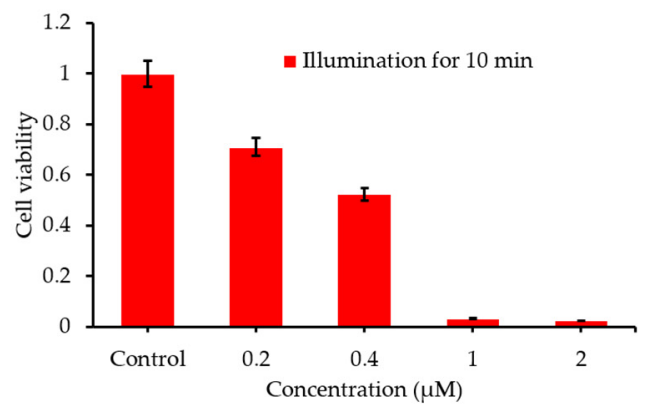

b)

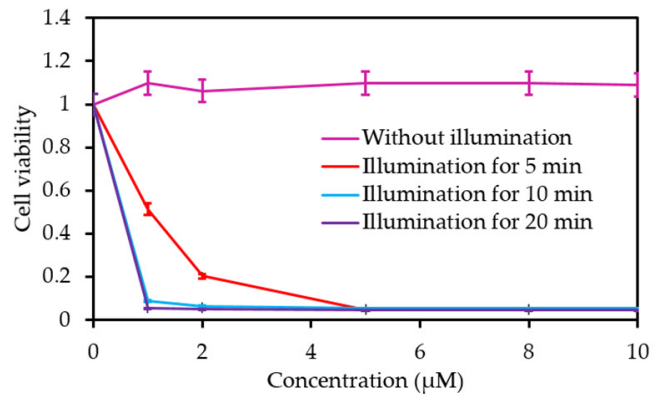

Figure 66. (a) Cell viability of A549 cells incubated with PC70 at gradient concentrations for $3 \mathrm{~h}$ and exposed to light irradiation for $10 \mathrm{~min}$ at a power density of $17 \mathrm{~mW} \cdot \mathrm{cm}^{-2}$ and (b) dose- and time-dependent PDT effects of PC70 on the A549 cell viability. Adapted from Guan et al. [228].

Under hypoxic conditions, in the same conditions of irradiation as previously, the photodamage of A459 cells was significantly higher with $\mathrm{PC}_{70}(80 \%)$ in comparison with D-TMPyP (22\%) demonstrating the high potential of $\mathrm{PC}_{70}$ under white light illumination, to kill hypoxic cells (Table 27).

\section{Fractional PDT}

The strategy is to intermittently irradiate the tumour in order to regulate the consumption of ${ }^{3} \mathrm{O}_{2}$ and the formation of ${ }^{1} \mathrm{O}_{2}$. This discontinuous irradiation technique proved positive in most cases studied. This phenomenon seems due to the fact that the pulsed irradiation allows an optimal replenishment of cellular $\mathrm{O}_{2}$ (Table 28). 
Table 27. Summary of publications about the use of compounds hypoxia environment-accumulated for PDT hypoxia-dependent.

\begin{tabular}{|c|c|c|c|c|c|c|}
\hline Ref & Application & PS & Energy of Excitation & Type of ROS & In Vitro & In Vivo \\
\hline [226] & PDT & EtNBS & $\begin{array}{c}\text { EtNBS-PDT: } 652 \mathrm{~nm}, 15 \mathrm{~J} \cdot \mathrm{cm}^{-2}, 25 \text { to } \\
300 \mathrm{~mW} \cdot \mathrm{cm}^{-2} \\
\text { Hypoxia EtNBS-PDT: } 670 \mathrm{~nm}, \\
100 \mathrm{~mW} \cdot \mathrm{cm}^{-2}, 5 \text { to } 20 \mathrm{~J} \cdot \mathrm{cm}^{-2}\end{array}$ & nd & $\begin{array}{c}\text { 3D adherent } \\
\text { OVCAR-5 human } \\
\text { OvCa model }\end{array}$ & No \\
\hline [227] & PDT & $\mathrm{Ru}(\mathrm{C}-\mathrm{bpy})_{2} / \mathrm{mLDH}$ & $520 \mathrm{~nm}, 100 \mathrm{~mW} \cdot \mathrm{cm}^{-2}, 8 \mathrm{~min}$ & ${ }^{1} \mathrm{O}_{2}$ & HeLa cell line & $\begin{array}{l}\text { HeLa tumour-bearing } \\
\text { mice }\end{array}$ \\
\hline
\end{tabular}


In 1996, Van Geel et al. [229] investigated the influence of different ways of illumination (single or fractionated) or different fluence rates for a discontinuous illumination, on the PDT efficiency of two PS (Photofrin and meta-tetrahydroxyphenylchlorin, mTHPC) in female $\mathrm{C} 3 \mathrm{H} / \mathrm{Km}$ mice inoculated with RIF1 cells. They first studied the difference between interstitial and superficial illumination and showed that to have the same fluence rate of interstitial illumination they have to increase the time of superficial illumination, by a factor of 2.7. However, they did not observe a significant difference of tumour response with PDT treatment Photofrin for both illuminations whereas they highlighted an increased response with mTHPC under superficial illumination. The fractionated illumination studies were performed only with MTHPC and no marked difference on tumour regrowth was observed between continuous or fractionated illumination. They also tested a single dose application of mTHPC in comparison with two doses (each $24 \mathrm{~h}$ before the illumination) and observed no difference in the tumour response. However, for a single dose of mTHPC and by varying the time interval between each illumination, even if no change was observed on the delay for tumour regrowth, an increase of cure mice was observed for a time interval of $1 \mathrm{~h}$. Moreover, the number of cure mice was better with the injection of two doses of mTHPC. They finally determined that the fluence rate, for a discontinuous illumination had no influence on the tumour response.

In two studies, Klimenko et al. [230,231] studied the influence of the type of irradiation (pulse of continuous) on the $\mathrm{O}_{2}$ consumption and ${ }^{1} \mathrm{O}_{2}$ generation. A first theoretical model showed a high decrease of $\mathrm{O}_{2}$ generation and the cumulative ${ }^{1} \mathrm{O}_{2}$ production at high fluence rates under continuous wave $(\mathrm{CW})$ mode whereas, for pulse irradiation mode, a high level of ${ }^{3} \mathrm{O}_{2}$ was maintained as the cumulative ${ }^{1} \mathrm{O}_{2}$ concentration, which increased in comparison with $\mathrm{CW}$ mode.

Both modes of irradiation were tested in vitro in k562 cell line by using radachlorin and the authors observed that there was less cell surviving while $\mathrm{CW}$ mode in comparison with pulse mode at fluence of 1.25 and $2.5 \mathrm{~J} \cdot \mathrm{cm}^{-2}$. Moreover, they observed different mechanisms of cell death with the two modes with an apoptotic mechanism for pulse mode and a necrotic mechanism for CW.

Kawauchi et al. [232] in 2004 studied the difference in mouse renal carcinoma cells (Renca) viability and total $\mathrm{O}_{2}$ consumption and $\mathrm{O}_{2}$ consumption rate after pulsed laser irradiation (670 $\mathrm{nm}$ nanosecond pulsed Nd:YAG laser, peak fluence rate $1 \mathrm{~mW} \cdot \mathrm{cm}^{-2}, 30 \mathrm{~Hz}$ ) or continuous laser irradiation $\left(\mathrm{CW}, 670 \mathrm{~nm}, 40 \mathrm{~J} \cdot \mathrm{cm}^{-2}\right)$ by using (13,17-bis[1-carboxypropionyl]carbamoylethyl-3-ethenyl-8-ethoxyiminoethylidene-7-hydroxy-2,7,12,18-tetramethylporphyrin sodium (PAD-S31)/ Concerning the cytotoxicity at two different irradiances $\left(180 \mathrm{~mW} \cdot \mathrm{cm}^{-2}\right.$ and $\left.270 \mathrm{~mW} \cdot \mathrm{cm}^{-2}\right)$, continuous excitation induced more cell viability than pulsed irradiation. The cytotoxic effect was independent of the fluence rate for both excitation modes. The $\mathrm{O}_{2}$ consumption rate decreased of half after pulsed light compared to $\mathrm{CW}$. The total $\mathrm{O}_{2}$ consumption was also less important with pulsed light compared to CW. Fluence rates for both excitation modes influenced the $\mathrm{O}_{2}$ consumption (less $\mathrm{O}_{2}$ consumption for $270 \mathrm{~mW} \cdot \mathrm{cm}^{-2}$ than for $180 \mathrm{~mW} \cdot \mathrm{cm}^{-2}$ ) but did not have any influence on the total $\mathrm{O}_{2}$ consumed.

In 2016, Turan et al. [233] developed a PS for fractional PDT able to produce ${ }^{1} \mathrm{O}_{2}$ under light irradiation and in the dark. This PS was based on a pyridone (PYR) which could be converted in 2-pyridone endoperoxide (EPO) after light irradiation $(650 \mathrm{~nm})$ by reaction with ${ }^{1} \mathrm{O}_{2}$ generated. In the dark EPO was able to release ${ }^{1} \mathrm{O}_{2}$ by thermal conversion and thus returned to the PYR form (Figure 67).

Under alternation of dark and light $(650 \mathrm{~nm}, 15 \mathrm{~min})$ cycles on this PS, a continuous production of ${ }^{1} \mathrm{O}_{2}$ was observed. The PDT efficiency of PYR and EPO was evaluated in vitro in HeLa cells and for a better solubility the compound was incorporated into micelles. After administration of the compounds and $655 \mathrm{~nm}$ LED array irradiation $\left(324 \mu \mathrm{mol} \cdot \mathrm{m}^{-2} \cdot \mathrm{s}^{-1}\right.$ photon flux $)$ during $10 \mathrm{~min}$ repeated every one hour, a significant decrease of cell viability was observed for both compounds (Table 28). 


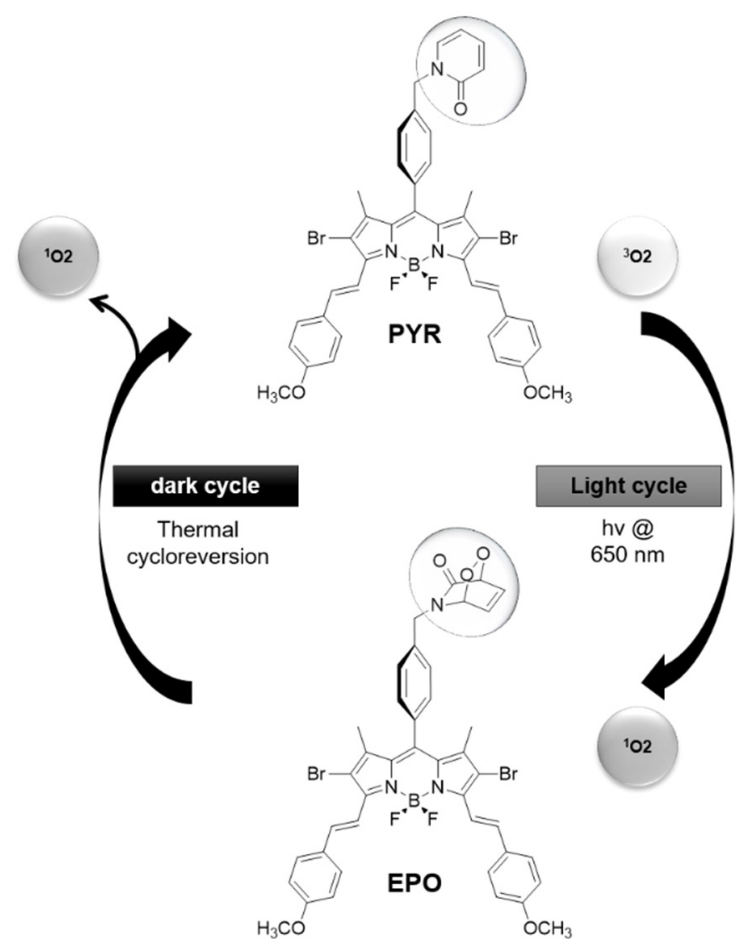

Figure 67. ${ }^{1} \mathrm{O}_{2}$ generation achieved first by irradiation of bifunctional compound PYR at $\lambda=650 \mathrm{~nm}$, and subsequently by thermal cycloreversion in the dark. The cycles can be repeated indefinitely. Adapted from Turan et al. [233].

Moreover, EPO seemed to present a better phototoxic effect with a CC50 (50\% cytotoxic concentration) of $8.6 \mathrm{~nm}$ against $49.0 \mathrm{~nm}$ for PYR.

Table 28. Summary of publications about fractional PDT.

\begin{tabular}{|c|c|c|c|c|c|c|}
\hline Ref & Application & PS & Excitation Wavelength & $\begin{array}{l}\text { Type de } \\
\text { ROS }\end{array}$ & In Vitro & In Vivo \\
\hline [229] & $\begin{array}{c}\text { Continuous } \\
\text { vs. fractional } \\
\text { PDT }\end{array}$ & $\begin{array}{l}\text { Photofrin } \\
\text { and mTHPC }\end{array}$ & $\begin{array}{c}\text { Interstitial: } 628 \pm 3 \mathrm{~nm} \text { for } \\
\text { Photofrin and } 652 \pm 3 \mathrm{~nm} \text { for } \\
\text { mTHPC } \\
\text { Superficial: } 100 \mathrm{~mW} \cdot \mathrm{cm}^{-2}\end{array}$ & nd & No & $\begin{array}{l}\text { RIF1 } \\
\text { tumour-bearing } \\
\text { mice }\end{array}$ \\
\hline $\begin{array}{l}{[230} \\
231]\end{array}$ & $\begin{array}{c}\text { Continuous } \\
\text { vs. fractional } \\
\text { PDT }\end{array}$ & Radachlorin & $\begin{array}{l}20 \mathrm{~mW} \cdot \mathrm{cm}^{-2} \\
\text { Pulse mode: } 200 \mathrm{~ms} \text { - pulse } \\
\text { duration, } 700 \mathrm{~ms} \text { - period }\end{array}$ & ${ }^{1} \mathrm{O}_{2}$ & k562 cell line & No \\
\hline [232] & $\begin{array}{l}\text { Continuous } \\
\text { vs. fractional } \\
\text { PDT }\end{array}$ & PAD-S31 & $\begin{array}{c}\text { Pulsed: } 670 \mathrm{~nm} \text { nanosecond } \\
\text { pulsed Nd:YAG laser, peak } \\
\text { fluence rate } 1 \mathrm{~mW} \cdot \mathrm{cm}^{-2}, 30 \mathrm{~Hz} \\
\mathrm{CW}: 670 \mathrm{~nm}, 40 \mathrm{~J} \cdot \mathrm{cm}^{-2}, \\
180 \mathrm{~mW} \cdot \mathrm{cm}^{-2} \text { or } 270 \mathrm{~mW} \cdot \mathrm{cm}^{-2}\end{array}$ & nd & $\begin{array}{l}\text { Renca cell } \\
\text { line }\end{array}$ & No \\
\hline [233] & $\begin{array}{l}\text { Fractional } \\
\text { PDT }\end{array}$ & Pyridone & $\begin{array}{c}655 \mathrm{~nm}, 324 \mu \mathrm{mol} \cdot \mathrm{m}^{-2} \cdot \mathrm{s}^{-1} \\
\text { photon flux for } 10 \mathrm{~min} \text { every } 1 \mathrm{~h}\end{array}$ & ${ }^{1} \mathrm{O}_{2}$ & $\begin{array}{l}\text { HeLa cell } \\
\text { line }\end{array}$ & No \\
\hline
\end{tabular}

nd: not determined; mTHPC: meta-tetrahydroxyphenylchlorin.

\section{Conclusions}

The first clinical trials in PDT were performed in 1978 by Dougherty in Roswell Park (Buffalo, NY, USA) and the first approval of PDT using Photofrin for the treatment of bladder cancer was 25 years ago in 1993. Since then, many efforts have been done to improve the chemistry of the PS, the light illumination and also the oxygenation of the tissue. In this review, we collected all the data till March 2019 concerning the improvement of oxygenation for PDT applications. We showed that different strategies can be used to decrease hypoxia, leading to highly efficient treatment, and even metastasis 
inhibition of aggressive hypoxic malignant cancers. In all the studies, two main approaches have been described concerning hypoxia. In one side, the authors tried to relieved tumor hypoxia by carrying $\mathrm{O}_{2}$ in tumour or decreasing tumour $\mathrm{O}_{2}$ comsumption and in another side, they used hypoxia to activate their designed platforms and thus improved PDT efficiency. To summarize, five different ways can be followed: (1) playing with the light and realizing fractionated illumination to allow the re-oxygenation of the tissues between two illuminations; (2) designing molecules or NPs that are able to produce ROS even in hypoxic media; (3) adding $\mathrm{O}_{2}$ into the hypoxic media by transporting $\mathrm{O}_{2}$ with hemoglobin or perflu orocarbon systems, improving the blood flow by increasing the temperature or with combination of anti-angiogenic compounds, producing $\mathrm{O}_{2}$ by the decomposition oh $\mathrm{H}_{2} \mathrm{O}_{2}$ in the hypoxic medium; (4) using combined strategies, in particular hypoxic-activated chemotherapy, PTT that does not require $\mathrm{O}_{2}$ or antiangiogenic therapy and (5) development of hypoxia-activated compunds. These strategies present a significant interest to enhanced cancer-PDT effect by fighting hypoxia. Many in vitro and in vivo experiments in all kind of cancer proved that the decrease of hypoxia really improved PDT efficiency. At this time, no clinical trial is registered using one of this strategy, it should be the next step.

Overcoming hypoxia to improve PDT is a relatively new subject whose interest has been steadily increased since the 1990s. In 1991, Freitas and Baronzio [5] reported a few strategies to fight hypoxia by improving the oxygenation of tumours which rely essentially on the increase of tumour $\mathrm{O}_{2}$ concentration. In our review, we reported an enhancement of the attention for hypoxia these last years with an increase of publications about hypoxia and PDT year after year. In our point of view, fighting hypoxia could become essential for an efficient PDT treatment of cancer and could lead to significant improvements for the treatment of patients.

Author Contributions: Writing-review and editing: L.L., B.M., A.B.-M., A.M., N.T., P.A., F.B., R.V., S.A. and C.F. Funding: This research received no external funding.

Conflicts of Interest: The authors declare no conflict of interest.

\section{References}

1. Semenza, G.L. Defining the role of hypoxia-inducible factor 1 in cancer biology and therapeutics. Oncogene 2009, 29, 625. [CrossRef] [PubMed]

2. Hammond, E.M.; Asselin, M.C.; Forster, D.; O'Connor, J.P.B.; Senra, J.M.; Williams, K.J. The meaning, measurement and modification of hypoxia in the laboratory and the clinic. Clin. Oncol. 2014, 26, 277-288. [CrossRef] [PubMed]

3. Dang, J.J; He, H.; Chen, D.L.; Yin, L.C. Manipulating tumor hypoxia toward enhanced photodynamic therapy (PDT). Biomater. Sci. 2017, 5, 1500-1511. [CrossRef] [PubMed]

4. Li, X.; Kwon, N.; Guo, T.; Liu, Z.; Yoon, J. Innovative strategies for hypoxic-tumor photodynamic therapy. Angew. Chem. Int. Ed. 2018, 57, 11522-11531. [CrossRef]

5. Freitas, I.; Baronzio, G.F. Tumor hypoxia, reoxygenation and oxygenation strategies: Possible role in photodynamic therapy. J. Photochem. Photobiol. B Biol. 1991, 11, 3-30. [CrossRef]

6. Frochot, C.; Mordon, S. Update of the situation of clinical photodynamic therapy in Europe in the 2003-2018 period. J. Porphyr. Phthalocyanines 2019, 23, 347-357. [CrossRef]

7. Price, M.; Heilbrun, L.; Kessel, D. Effects of the oxygenation level on formation of different reactive oxygen species during photodynamic therapy. Photochem. Photobiol. 2013, 89, 683-686. [CrossRef]

8. Freitas, I. Facing hypoxia: A must for photodynamic therapy. J. Photochem. Photobiol. B Biol. 1988, 2, 281-282. [CrossRef]

9. $\quad$ Busch, T.M.; Hahn, S.M.; Wileyto, E.P.; Koch, C.J.; Fraker, D.L.; Zhang, P.; Putt, M.; Gleason, K.; Shin, D.B.; Emanuele, M.J.; et al. Hypoxia and photofrin uptake in the intraperitoneal carcinomatosis and sarcomatosis of photodynamic therapy patients. Clin. Cancer Res. 2004, 10, 4630-4638. [CrossRef]

10. Busch, T.M.; Hahn, S.M.; Evans, S.M.; Koch, C.J. Depletion of tumor oxygenation during photodynamic therapy: Detection by the hypoxia marker EF3 2-(2-nitroimidazol-1 H -yl)-N-(3,3,3-trifluoropropyl) acetamide. Cancer Res. 2000, 60, 2636-2642. 
11. Hirsch, B.D.; Walz, N.C.; Meeker, B.E.; Arnfield, M.R.; Tulip, J.; McPhee, M.S.; Chapman, J.D. Photodynamic therapy-induced hypoxia in rat-tumors and normal-tissues. Photochem. Photobiol. 1987, 46, 847-852. [CrossRef] [PubMed]

12. Busch, T.M. Hypoxia and perfusion labeling during photodynamic therapy. In Photodynamic Therapy: Methods and Protocols; Gomer, C.J., Ed.; Humana Press: Totowa, NJ, USA, 2010; Volume 635, pp. 107-120.

13. Al-Waili, N.S.; Butler, G.J. Phototherapy and malignancy: Possible enhancement by iron administration and hyperbaric oxygen. Med. Hypotheses 2006, 67, 1148-1158. [CrossRef] [PubMed]

14. Al-Waili, N.S.; Butler, G.J.; Beale, J.; Hamilton, R.W.; Lee, B.Y.; Lucas, P. Hyperbaric oxygen and malignancies: A potential role in radiotherapy, chemotherapy, tumor surgery and phototherapy. Med. Sci. Monit. 2005, 11, RA279-RA289. [PubMed]

15. Li, Q.; Huang, C.; Liu, L.; Hu, R.; Qu, J. Enhancing Type I Photochemistry in Photodynamic Therapy Under Near Infrared Light by Using Antennae-Fullerene Complexes. Cytom. Part A 2018, 93, 997-1003. [CrossRef] [PubMed]

16. Usacheva, M.; Swaminathan, S.K.; Kirtane, A.R.; Panyam, J. Enhanced photodynamic therapy and effective elimination of cancer stem cells using surfactant-polymer nanoparticles. Mol. Pharm. 2014, 11, 3186-3195. [CrossRef]

17. Ariffin, A.B.; Forde, P.F.; Jahangeer, S.; Soden, D.M.; Hinchion, J. Releasing pressure in tumors: What do we know so far and where do we go from here? A review. Cancer Res. 2014, 74, 2655-2662. [CrossRef]

18. Fuchs, J.; Thiele, J. The role of oxygen in cutaneous photodynamic therapy. Free Radic. Biol. Med. 1998, 24, 835-847. [CrossRef]

19. Moen, I.; Stuhr, L.E. Hyperbaric oxygen therapy and cancer-A review. Target. Oncol. 2012, 7, $233-242$. [CrossRef]

20. Hjelde, A.; Gederaas, O.A.; Krokan, H.E.; Brubakk, A.O. Lack of effect of hyperoxia on photodynamic therapy and lipid peroxidation in three different cancer cell lines. Med. Sci. Monit. 2005, 11, Br351-Br356.

21. Mei, L.H.; Yang, G.; Fang, F. Hyperbaric oxygen combined with 5-aminolevulinic acid photodynamic therapy inhibitedhuman squamous cell proliferation. Biol. Pharm. Bull. 2019, 42, 394-400. [CrossRef]

22. Chen, Q.; Beckers, J.; Hetzel, F.W. Modification of tumor response by manipulation of tumor oxygenation. In Optical Methods for Tumor Treatment and Detection: Mechanisms and Techniques in Photodynamic Therapy, Proceedings of SPIE-The International Society for Optical Engineering, San Jose, CA, USA, 23 January 1999; Dougherty, T.J., Katzir, A., Eds.; International Society for Optics and Photonics: San Diego, CA, USA, 1999; Volume 3592, pp. 60-64.

23. Chen, Q.; Huang, Z.; Chen, H.; Shapiro, H.; Beckers, J.; Hetzel, F.W. Improvement of tumor response to photodynamic therapy by manipulation of tumor oxygenation in an In vivo model system. In Proceedings of the Photonics Asia, Shanghai, China, 12 september 2002; Volume 4916, pp. 43-52.

24. Hetzel, F.W.; Shakil, A.; Beckers, J.; Chen, Q. Hyperoxygenation enhances photodynamic therapy tumor cure. In Proceedings of the International Symposium on Biomedical Optics (BiOS 2001), San Jose, CA, USA, 9 April 2001; Dougherty, T.J., Ed.; Volume 4248, pp. 56-59.

25. Huang, Z.; Chen, Q.; Shakil, A.; Chen, H.; Beckers, J.; Shapiro, H.; Hetzel, F.W. Hyperoxygenation enhances the tumor cell killing of photofrin-mediated photodynamic therapy. Photochem. Photobiol. 2003, 78, 496-502. [CrossRef]

26. Li, J.Q.; Huang, J.Z.; Ao, Y.X.; Li, S.Y.; Miao, Y.; Yu, Z.Z.; Zhu, L.T.; Lan, X.L.; Zhu, Y.H.; Zhang, Y.; et al. Synergizing upconversion nanophotosensitizers with hyperbaric oxygen to remodel the extracellular matrix for enhanced photodynamic cancer therapy. ACS Appl. Mater. Interfaces 2018, 10, 22985-22996. [CrossRef] [PubMed]

27. Maier, A.; Anegg, U.; Tomaselli, F.; Rehak, P.; Sankin, O.; Fell, B.; Renner, H.; Pinter, H.; Smolle-Juttner, F.M.; Friehs, G.B. Does hyperbaric oxygen enhance the effect of photodynamic therapy in patients with advanced esophageal carcinoma? A clinical pilot study. Endoscopy 2000, 32, 42-48. [CrossRef] [PubMed]

28. Maier, A.; Anegg, U.; Fell, B.; Rehak, P.; Ratzenhofer, B.; Tomaselli, F.; Sankin, O.; Pinter, H.; Smolle-Juttner, F.M.; Friehs, G.B. Hyperbaric oxygen and photodynamic therapy in the treatment of advanced carcinoma of the cardia and the esophagus. Lasers Surg. Med. 2000, 26, 308-315. [CrossRef]

29. Maier, A.; Tomaselli, F.; Anegg, U.; Rehak, P.; Fell, B.; Luznik, S.; Pinter, H.; Smolle-Juttner, F.M. Combined photodynamic therapy and hyperbaric oxygenation in carcinoma of the esophagus and the esophago-gastric junction. Eur. J. Cardiothorac. Surg. 2000, 18, 649-654. [CrossRef] 
30. Maier, A.; Tomaselli, F.; Matzi, V.; Rehak, P.; Pinter, H.; Smolle-Juttner, F.M. Photosensitization with hematoporphyrin derivative compared to 5-aminolaevulinic acid for photodynamic therapy of esophageal carcinoma. Ann. Thorac. Surg. 2001, 72, 1136-1140. [CrossRef]

31. Maier, A.; Tomaselli, F.; Matzi, V.; Rehak, P.; Pinter, H.; Smolle-Juttner, F.M. Does new photosensitizer improve photodynamic therapy in advanced esophageal carcinoma? Lasers Surg. Med. 2001, 29, 323-327. [CrossRef]

32. Tomaselli, F.; Maier, A.; Pinter, H.; Stranzl, H.; Smolle-Juttner, F.M. Photodynamic therapy enhanced by hyperbaric oxygen in acute endoluminal palliation of malignant bronchial stenosis (clinical pilot study in 40 patients). Eur. J. Cardiothorac. Surg. 2001, 19, 549-554. [CrossRef]

33. Tomaselli, F.; Maier, A.; Sankin, O.; Anegg, U.; Stranzl, U.; Pinter, H.; Kapp, K.; Smolle-Juttner, F.M. Acute effects of combined photodynamic therapy and hyperbaric oxygenation in lung cancer-A clinical pilot study. Lasers Surg. Med. 2001, 28, 399-403. [CrossRef]

34. Schouwink, H.; Ruevekamp, M.; Oppelaar, H.; van Veen, R.; Baas, P.; Stewart, F.A. Photodynamic therapy for malignant mesothelioma: Preclinical studies for optimization of treatment protocols. Photochem. Photobiol. 2001, 73, 410-417. [CrossRef]

35. Asimov, M.M. The biomedical effect of laser-induced photodissociation of oxyhemoglobin In vivo. Opt. Spectrosc. 2013, 115, 774-778. [CrossRef]

36. Luo, Z.Y.; Zheng, M.B.; Zhao, P.F.; Chen, Z.; Siu, F.M.; Gong, P.; Gao, G.H.; Sheng, Z.H.; Zheng, C.F.; Ma, Y.F.; et al. Self-monitoring artificial red cells with sufficient oxygen supply for enhanced photodynamic therapy. Sci. Rep. 2016, 6, 23393. [CrossRef] [PubMed]

37. Chen, Z.K.; Liu, L.L.; Liang, R.J.; Luo, Z.Y.; He, H.M.; Wu, Z.H.; Tian, H.; Zheng, M.B.; Ma, Y.F.; Cai, L.T. Bioinspired hybrid protein oxygen nanocarrier amplified photodynamic therapy for eliciting anti-tumor immunity and abscopal effect. ACS Nano 2018, 12, 8633-8645. [CrossRef]

38. Tang, W.; Zhen, Z.P.; Wang, M.Z.; Wang, H.; Chuang, Y.J.; Zhang, W.Z.; Wang, G.D.; Todd, T.; Cowger, T.; Chen, H.M.; et al. Red blood cell-facilitated photodynamic therapy for cancer treatment. Adv. Funct. Mater. 2016, 26, 1757-1768. [CrossRef]

39. Wang, P.Y.; Li, X.M.; Yao, C.; Wang, W.X.; Zhao, M.Y.; El -Toni, A.M.; Zhang, F. Orthogonal near-infrared upconversion co-regulated site-specific $\mathrm{O}_{2}$ delivery and photodynamic therapy for hypoxia tumor by using red blood cell microcarriers. Biomaterials 2017, 125, 90-100. [CrossRef] [PubMed]

40. Cao, H.Q.; Wang, L.; Yang, Y.; Li, J.; Qi, Y.F.; Li, Y.; Li, Y.; Wang, H.; Li, J.B. An assembled nanocomplex for improving both therapeutic efficiency and treatment depth in photodynamic therapy. Angew. Chem. Int. Ed. 2018, 57, 7759-7763. [CrossRef] [PubMed]

41. Guo, X.M.; Qua, J.X.; Zhu, C.Q.; Li, W.; Luo, L.H.; Yang, J.; Yin, X.Y.; Li, Q.P.; Du, Y.Z.; Chen, D.W.; et al. Synchronous delivery of oxygen and photosensitizer for alleviation of hypoxia tumor microenvironment and dramatically enhanced photodynamic therapy. Drug Deliv. 2018, 25, 585-599. [CrossRef] [PubMed]

42. Liu, L.; Li, T.W.; Ruan, Z.; Yan, L.F. Polypeptide-based artificial erythrocytes conjugated with near infrared photosensitizers for imaging-guided photodynamic therapy. J. Mater. Sci. 2018, 53, 9368-9381. [CrossRef]

43. Xu, X.; Cui, Y.C.; Bu, H.X.; Chen, J.M.; Li, Y.; Tang, G.P.; Wang, L.Q. A photosensitizer loaded hemoglobin-polymer conjugate as a nanocarrier for enhanced photodynamic therapy. J. Mater. Chem. B 2018, 6, 1825-1833. [CrossRef]

44. Liu, W.L.; Liu, T.; Zou, M.Z.; Yu, W.Y.; Li, C.X.; He, Z.Y.; Zhang, M.K.; Liu, M.D.; Li, Z.H.; Feng, J.; et al. Aggressive man-made red blood cells for hypoxia-resistant photodynamic therapy. Adv. Mater. 2018, 30, 1802006. [CrossRef]

45. Gao, S.T.; Zheng, P.L.; Li, Z.H.; Feng, X.C.; Yan, W.X.; Chen, S.Z.; Guo, W.S.; Liu, D.D.; Yang, X.J.; Wang, S.X.; et al. Biomimetic $\mathrm{O}_{2}$-Evolving metal-organic framework nanoplatform for highly efficient photodynamic therapy against hypoxic tumor. Biomaterials 2018, 178, 83-94. [CrossRef] [PubMed]

46. Rapoport, N.; Nam, K.H.; Gupta, R.; Gao, Z.; Mohan, P.; Payne, A.; Todd, N.; Liu, X.; Kim, T.; Shea, J.; et al. Ultrasound-mediated tumor imaging and nanotherapy using drug loaded, block copolymer stabilized perfluorocarbon nanoemulsions. J. Control. Release 2011, 153, 4-15. [CrossRef] [PubMed]

47. Young, L.H.; Jaffe, C.C.; Revkin, J.H.; McNulty, P.H.; Cleman, M. Metabolic and functional effects of perfluorocarbon distal perfusion during coronary angioplasty. Am. J. Cardiol. 1990, 65, 986-990. [CrossRef]

48. Cheng, Y.H.; Cheng, H.; Jiang, C.X.; Qiu, X.F.; Wang, K.K.; Huan, W.; Yuan, A.; Wu, J.H.; Hu, Y.Q. Perfluorocarbon nanoparticles enhance reactive oxygen levels and tumour growth inhibition in photodynamic therapy. Nat. Commun. 2015, 6, 8785. [CrossRef] [PubMed] 
49. Day, R.A.; Estabrook, D.A.; Logan, J.K.; Sletten, E.M. Fluorous photosensitizers enhance photodynamic therapy with perfluorocarbon nanoemulsions. Chem. Commun. 2017, 53, 13043-13046. [CrossRef] [PubMed]

50. Liu, C.H.; Dong, H.F.; Wu, N.Q.; Cao, Y.; Zhang, X.J. Plasmonic resonance energy transfer enhanced photodynamic therapy with $\mathrm{Au} @ \mathrm{SiO}_{2} @ \mathrm{Cu}_{2} \mathrm{O}$ /perfluorohexane nanocomposites. ACS Appl. Mater. Interfaces 2018, 10, 6991-7002. [CrossRef] [PubMed]

51. Que, Y.R.; Liu, Y.J.; Tan, W.; Feng, C.; Shi, P.; Li, Y.J.; Huang, X. Enhancing photodynamic therapy efficacy by using fluorinated nanoplatform. ACS Macro Lett. 2016, 5, 168-173. [CrossRef]

52. Sheng, D.L.; Liu, T.Z.; Deng, L.M.; Zhang, L.; Li, X.L.; Xu, J.; Hao, L.; Li, P.; Ran, H.T.; Chen, H.R.; et al. Perfluorooctyl bromide \& indocyanine green co-loaded nanoliposomes for enhanced multimodal imaging-guided phototherapy. Biomaterials 2018, 165, 1-13.

53. Song, X.J.; Feng, L.Z.; Liang, C.; Yang, K.; Liu, Z. Ultrasound triggered tumor oxygenation with oxygen-shuttle nanoperfluorocarbon to overcome hypoxia-associated resistance in cancer therapies. Nano Lett. 2016, 16, 6145-6153. [CrossRef]

54. Tang, W.; Yang, Z.; Wang, S.; Wang, Z.T.; Song, J.B.; Yu, G.C.; Fan, W.P.; Dai, Y.L.; Wang, J.J.; Shan, L.L.; et al. Organic semiconducting photoacoustic nanodroplets for laser-activatable ultrasound imaging and combinational cancer therapy. ACS Nano 2018, 12, 2610-2622. [CrossRef]

55. Tang, X.L.; Cheng, Y.H.; Huang, S.T.; Zhi, F.; Yuan, A.H.; Hu, Y.Q.; Wu, J.H. Overcome the limitation of hypoxia against photodynamic therapy to treat cancer cells by using perfluorocarbon nanodroplet for photosensitizer delivery. Biochem. Biophys. Res. Commun. 2017, 487, 483-487. [CrossRef]

56. Tao, D.L.; Feng, L.Z.; Chao, Y.; Liang, C.; Song, X.J.; Wang, H.R.; Yang, K.; Liu, Z. Covalent organic polymers based on fluorinated porphyrin as oxygen nanoshuttles for tumor hypoxia relief and enhanced photodynamic therapy. Adv. Funct. Mater. 2018, 28, 1804901. [CrossRef]

57. Wang, J.P.; Liu, L.; You, Q.; Song, Y.L.; Sun, Q.; Wang, Y.D.; Cheng, Y.; Tan, F.P.; Li, N. All-in-one theranostic nanoplatform based on hollow mosx for photothermally-maneuvered oxygen self-enriched photodynamic therapy. Theranostics 2018, 8, 955-971. [CrossRef] [PubMed]

58. Wang, Q.; Li, J.M.; Yu, H.; Deng, K.; Zhou, W.; Wang, C.X.; Zhang, Y.; Li, K.H.; Zhuo, R.X.; Huang, S.W. Fluorinated polymeric micelles to overcome hypoxia and enhance photodynamic cancer therapy. Biomater. Sci. 2018, 6, 3096-3107. [CrossRef] [PubMed]

59. Yu, M.; Xu, X.L.; Cai, Y.J.; Zou, L.Y.; Shuai, X.T. Perfluorohexane-cored nanodroplets for stimulations-responsive ultrasonography and $\mathrm{O}_{2}$-potentiated photodynamic therapy. Biomaterials 2018, 175, 61-71. [CrossRef]

60. Yuan, P.; Ruan, Z.; Jiang, W.; Liu, L.; Dou, J.X.; Li, T.W.; Yan, L.F. Oxygen self-sufficient fluorinated polypeptide nanoparticles for NIR imaging-guided enhanced photodynamic therapy. J. Mater. Chem. B 2018, 6, 2323-2331. [CrossRef]

61. Zhang, L.; Wang, D.; Yang, K.; Sheng, D.L.; Tan, B.; Wang, Z.G.; Ran, H.T.; Yi, H.J.; Zhong, Y.X.; Lin, H.; et al. Mitochondria-targeted artificial "nano-RBCs" for amplified synergistic cancer phototherapy by a single NIR irradiation. Adv. Sci. 2018, 5, 1800049. [CrossRef]

62. Zhao, C.Y.; Tong, Y.J.; Li, X.L.; Shao, L.H.; Chen, L.; Lu, J.Q.; Deng, X.W.; Wang, X.; Wu, Y. Photosensitive nanoparticles combining vascular-independent intratumor distribution and on-demand oxygen-depot delivery for enhanced cancer photodynamic therapy. Small 2018, 14, 1703045. [CrossRef]

63. Hu, D.R.; Zhong, L.; Wang, M.Y.; Li, H.H.; Qu, Y.; Liu, Q.Y.; Han, R.X.; Yuan, L.P.; Shi, K.; Peng, J.R.; et al. Perfluorocarbon-loaded and redox-activatable photosensitizing agent with oxygen supply for enhancement of fluorescence/photoacoustic imaging guided tumor photodynamic therapy. Adv. Funct. Mater. 2019, 29, 1806199. [CrossRef]

64. Hu, H.M.; Yan, X.F.; Wang, H.; Tanaka, J.; Wang, M.Z.; You, W.; Li, Z.B. Perfluorocarbon-based $\mathrm{O}_{2}$ nanocarrier for efficient photodynamic therapy. J. Mater. Chem. B 2019, 7, 1116-1123. [CrossRef]

65. Ma, S.N.; Zhou, J.; Zhang, Y.X.; Yang, B.; He, Y.Y.; Tian, C.; Xu, X.H.; Gu, Z.W. An oxygen self-sufficient fluorinated nanoplatform for relieved tumor hypoxia and enhanced photodynamic therapy of cancers. ACS Appl. Mater. Interfaces 2019, 11, 7731-7742. [CrossRef] [PubMed]

66. Khan, M.S.; Hwang, J.; Lee, K.; Choi, Y.; Kim, K.; Koo, H.J.; Hong, J.W.; Choi, J. Oxygen-carrying micro/nanobubbles: Composition, synthesis techniques and potential prospects in photo-triggered theranostics. Molecules 2018, 23, 2210. [CrossRef] [PubMed] 
67. Huang, W.C.; Shen, M.Y.; Chen, H.H.; Lin, S.C.; Chiang, W.H.; Wu, P.H.; Chang, C.W.; Chiang, C.S.; Chiu, H.C. Monocytic delivery of therapeutic oxygen bubbles for dual-modality treatment of tumor hypoxia. J. Control. Release 2015, 220, 738-750. [CrossRef] [PubMed]

68. Song, R.Y.; Hu, D.H.; Chung, H.Y.; Sheng, Z.H.; Yao, S.H. Lipid-polymer bilaminar oxygen nanobubbles for enhanced photodynamic therapy of cancer. ACS Appl. Mater. Interfaces 2018, 10, 36805-36813. [CrossRef] [PubMed]

69. Niu, N.; Zhang, Z.; Gao, X.; Chen, Z.J.; Li, S.J.; Li, J. Photodynamic therapy in hypoxia: Near-infrared-sensitive, self-supported, oxygen generation nano-platform enabled by upconverting nanoparticles. Chem. Eng. J. 2018, 352, 818-827. [CrossRef]

70. Castells, M.; Thibault, B.; Delord, J.P.; Couderc, B. Implication of tumor microenvironment in chemoresistance: Tumor-associated stromal cells protect tumor cells from cell death. Int. J. Mol. Sci. 2012, 13, 9545-9571. [CrossRef]

71. Szatrowski, T.P.; Nathan, C.F. Production of large amounts of hydrogen peroxide by human tumor cells. Cancer Res. 1991, 51, 794-798.

72. Chen, Q.; Chen, J.; Liang, C.; Feng, L.; Dong, Z.; Song, X.; Song, G.; Liu, Z. Drug-induced co-assembly of albumin/catalase as smart nano-theranostics for deep intra-tumoral penetration, hypoxia relieve, and synergistic combination therapy. J. Control. Release 2017, 263, 79-89. [CrossRef]

73. Liu, C.-P.; Wu, T.-H.; Liu, C.-Y.; Chen, K.-C.; Chen, Y.-X.; Chen, G.-S.; Lin, S.-Y. Self-Supplying O2 through the Catalase-Like Activity of Gold Nanoclusters for Photodynamic Therapy against Hypoxic Cancer Cells. Small 2017, 13, 1700278. [CrossRef]

74. Policastro, L.; Molinari, B.; Larcher, F.; Blanco, P.; Podhajcer, O.L.; Costa, C.S.; Rojas, P.; Duran, H. Imbalance of antioxidant enzymes in tumor cells and inhibition of proliferation and malignant features by scavenging hydrogen peroxide. Mol. Carcinog. 2004, 39, 103-113. [CrossRef]

75. Onumah, O.E.; Jules, G.E.; Zhao, Y.; Zhou, L.; Yang, H.; Guo, Z. Overexpression of catalase delays G0/G1- to S-phase transition during cell cycle progression in mouse aortic endothelial cells. Free Radic. Biol. Med. 2009, 46, 1658-1667. [CrossRef] [PubMed]

76. Xu, X.L.; Shao, J.; Chen, Q.Y.; Li, C.H.; Kong, M.Y.; Fang, F.; Ji, L.; Boison, D.; Huang, T.; Gao, J.; et al. A Mn(II) complex of boradiazaindacene (BODIPY) loaded graphene oxide as both LED light and $\mathrm{H}_{2} \mathrm{O}_{2}$ enhanced anticancer agent. J. Inorg. Biochem. 2016, 159, 1-6. [CrossRef] [PubMed]

77. Zhu, W.W.; Dong, Z.L.; Fu, T.T.; Liu, J.J.; Chen, Q.; Li, Y.G.; Zhu, R.; Xu, L.G.; Liu, Z. Modulation of hypoxia in solid tumor microenvironment with $\mathrm{MnO}_{2}$ nanoparticles to enhance photodynamic therapy. Adv. Funct. Mater. 2016, 26, 5490-5498. [CrossRef]

78. Chu, C.C.; Lin, H.R.; Liu, H.; Wang, X.Y.; Wang, J.Q.; Zhang, P.F.; Gao, H.Y.; Huang, C.; Zeng, Y.; Tan, Y.Z.; et al. Tumor microenvironment-triggered supramolecular system as an in situ nanotheranostic generator for cancer phototherapy. Adv. Mater. 2017, 29, 1605928. [CrossRef]

79. Gao, S.; Wang, G.H.; Qin, Z.N.; Wang, X.Y.; Zhao, G.Q.; Ma, Q.J.; Zhu, L. Oxygen-generating hybrid nanoparticles to enhance fluorescent/photoacoustic/ultrasound imaging guided tumor photodynamic therapy. Biomaterials 2017, 112, 324-335. [CrossRef]

80. Hao, Y.W.; Zhang, B.X.; Zheng, C.X.; Niu, M.Y.; Guo, H.C.; Zhang, H.L.; Chang, J.B.; Zhang, Z.Z.; Wang, L.; Zhang, Y. Multifunctional nanoplatform for enhanced photodynamic cancer therapy and magnetic resonance imaging. Colloids Surf. B. Biointerfaces 2017, 151, 384-393. [CrossRef]

81. Kim, J.; Cho, H.R.; Jeon, H.; Kim, D.; Song, C.; Lee, N.; Choi, S.H.; Hyeon, T. Continuous $\mathrm{O}_{2}$-evolving $\mathrm{MnFe}_{2} \mathrm{O}_{4}$ nanoparticle-anchored mesoporous silica nanoparticles for efficient photodynamic therapy in hypoxic cancer. J. Am. Chem. Soc. 2017, 139, 10992-10995. [CrossRef]

82. Liu, H.; Liu, Y.; Chu, C.C.; Tong, H.P.; Xue, W.; Wang, J.Q.; Liu, G.; Zhang, W.G. Intelligent albumin-stabilized manganese dioxide nanocomposites for tumor microenvironment responsive phototherapy. J. Biomed. Nanotechnol. 2017, 13, 1321-1332. [CrossRef]

83. Ma, Z.F.; Jia, X.D.; Bai, J.; Ruan, Y.D.; Wang, C.; Li, J.M.; Zhang, M.C.; Jiang, X. $\mathrm{MnO}_{2}$ Gatekeeper: An intelligent and $\mathrm{O}_{2}$-evolving shell for preventing premature release of high cargo payload core, overcoming tumor hypoxia, and acidic $\mathrm{H}_{2} \mathrm{O}_{2}$-sensitive MRI. Adv. Funct. Mater. 2017, 27, 1604258. [CrossRef]

84. Ai, X.Z.; Hu, M.; Wang, Z.M.; Lyu, L.N.; Zhang, W.M.; Li, J.; Yang, H.H.; Lin, J.; Xing, B.G. Enhanced cellular ablation by attenuating hypoxia status and reprogramming tumor-associated macrophages via NIR light-responsive upconversion nanocrystals. Bioconj. Chem. 2018, 29, 928-938. [CrossRef] 
85. Gu, T.X.; Cheng, L.; Gong, F.; Xu, J.; Li, X.; Han, G.R.; Liu, Z. Upconversion composite nanoparticles for tumor hypoxia modulation and enhanced near-infrared-triggered photodynamic therapy. ACS Appl. Mater. Interfaces 2018, 10, 15494-15503. [CrossRef] [PubMed]

86. Chen, S.Q.; Jia, Q.Y.; Zheng, X.L.; Wen, Y.M.; Liu, W.M.; Zhang, H.Y.; Ge, J.C.; Wang, P.F. PEGylated carbon $\operatorname{dot} / \mathrm{MnO}_{2}$ nanohybrid: A new $\mathrm{pH} / \mathrm{H}_{2} \mathrm{O}_{2}$-driven, turn-on cancer nanotheranostics. Sci. China Mater. 2018, 61, 1325-1338. [CrossRef]

87. He, Z.M.; Xiao, Y.; Zhang, J.R.; Zhang, P.H.; Zhu, J.J. In situ formation of large pore silica-MnO $\mathrm{M}_{2}$ nanocomposites with $\mathrm{H}^{+} / \mathrm{H}_{2} \mathrm{O}_{2}$ sensitivity for $\mathrm{O}_{2}$-elevated photodynamic therapy and potential MR imaging. Chem. Commun. 2018, 54, 2962-2965. [CrossRef] [PubMed]

88. Kapri, S.; Bhattacharyya, S. Molybdenum sulfide-reduced graphene oxide p-n heterojunction nanosheets with anchored oxygen generating manganese dioxide nanoparticles for enhanced photodynamic therapy. Chem. Sci. 2018, 9, 8982-8989. [CrossRef] [PubMed]

89. Liang, R.J.; Liu, L.L.; He, H.M.; Chen, Z.K.; Han, Z.Q.; Luo, Z.Y.; Wu, Z.H.; Zheng, M.B.; Ma, Y.F.; Cai, L.T. Oxygen-boosted immunogenic photodynamic therapy with gold nanocages@manganese dioxide to inhibit tumor growth and metastases. Biomaterials 2018, 177, 149-160. [CrossRef] [PubMed]

90. Zhou, L.H.; Wu, Y.Y.; Meng, X.Q.; Li, S.P.; Zhang, J.L.; Gong, P.; Zhang, P.F.; Jiang, T.; Deng, G.J.; Li, W.J.; et al. Dye-anchored $\mathrm{MnO}$ nanoparticles targeting tumor and inducing enhanced phototherapy effect via mitochondria-mediated pathway. Small 2018, 14, 1801008. [CrossRef]

91. Lin, T.S.; Zhao, X.Z.; Zhao, S.; Yu, H.; Cao, W.M.; Chen, W.; Wei, H.; Guo, H.Q. O ${ }_{2}$-generating $\mathrm{MnO}_{2}$ nanoparticles for enhanced photodynamic therapy of bladder cancer by ameliorating hypoxia. Theranostics 2018, 8, 990-1004. [CrossRef]

92. Wang, R.G.; Zhao, M.Y.; Deng, D.; Ye, X.; Zhang, F.; Chen, H.; Kong, J.L. An intelligent and biocompatible photosensitizer conjugated silicon quantum dots- $\mathrm{MnO}_{2}$ nanosystem for fluorescence imaging-guided efficient photodynamic therapy. J. Mater. Chem. B 2018, 6, 4592-4601. [CrossRef]

93. Zhu, H.J.; Li, J.C.; Qi, X.Y.; Chen, P.; Pu, K.Y. Oxygenic hybrid semiconducting nanoparticles for enhanced photodynamic therapy. Nano Lett. 2018, 18, 586-594. [CrossRef]

94. Zhu, W.; Zhang, L.; Yang, Z.; Liu, P.; Wang, J.; Cao, J.; Shen, A.; Xu, Z. An efficient tumor-inducible nanotheranostics for magnetic resonance imaging and enhanced photodynamic therapy. Chem. Eng. J. 2019, 358, 969-979. [CrossRef]

95. Liu, J.; Du, P.; Liu, T.; Cordova Wong, B.J.; Wang, W.; Ju, H.; Lei, J. A black phosphorus/manganese dioxide nanoplatform: Oxygen self-supply monitoring, photodynamic therapy enhancement and feedback. Biomaterials 2019, 192, 179-188. [CrossRef] [PubMed]

96. Cao, Y.; Meng, X.D.; Wang, D.D.; Zhang, K.; Dai, W.H.; Dong, H.F.; Zhang, X.J. Intelligent $\mathrm{MnO}_{2} / \mathrm{Cu}_{2}-\mathrm{xS}$ for multimode imaging diagnostic and advanced single-laser irradiated photothermal/photodynamic therapy. ACS Appl. Mater. Interfaces 2018, 10, 17732-17741. [CrossRef] [PubMed]

97. Yin, Z.H.; Chen, D.P.; Zou, J.H.; Shao, J.J.; Tang, H.; Xu, H.; Si, W.L.; Dong, X.C. Tumor microenvironment responsive oxygen-self-generating nanoplatform for dual-imaging guided photodynamic and photothermal therapy. ChemistrySelect 2018, 3, 4366-4373. [CrossRef]

98. Liu, X.; Tian, K.; Zhang, J.; Zhao, M.; Liu, S.; Zhao, Q.; Huang, W. Smart NIR-light-mediated nanotherapeutic agents for enhancing tumor accumulation and overcoming hypoxia in synergistic cancer therapy. ACS Appl. Bio Mater. 2019, 2, 1225-1232. [CrossRef]

99. Chen, Q.; Feng, L.Z.; Liu, J.J.; Zhu, W.W.; Dong, Z.L.; Wu, Y.F.; Liu, Z. Intelligent albumin-MnO 2 nanoparticles as $\mathrm{pH}-/ \mathrm{H}_{2} \mathrm{O}_{2}$-responsive dissociable nanocarriers to modulate tumor hypoxia for effective combination therapy. Adv. Mater. 2016, 28, 7129-7136. [CrossRef] [PubMed]

100. Zhang, W.T.; Li, S.H.; Liu, X.N.; Yang, C.Y.; Hu, N.; Dou, L.N.; Zhao, B.X.; Zhang, Q.Y.; Suo, Y.R.; Wang, J.L. Oxygen-generating $\mathrm{MnO}_{2}$ nanodots-anchored versatile nanoplatform for combined chemo-photodynamic therapy in hypoxic cancer. Adv. Funct. Mater. 2018, 28, 1706375. [CrossRef]

101. Fan, W.P.; Bu, W.B.; Shen, B.; He, Q.J.; Cui, Z.W.; Liu, Y.Y.; Zheng, X.P.; Zhao, K.L.; Shi, J.L. Intelligent $\mathrm{MnO}_{2}$ nanosheets anchored with upconversion nanoprobes for concurrent $\mathrm{pH}-/ \mathrm{H}_{2} \mathrm{O}_{2}$-responsive UCL imaging and oxygen-elevated synergetic therapy. Adv. Mater. 2015, 27, 4155-4161. [CrossRef]

102. He, D.G.; Hai, L.; He, X.; Yang, X.; Li, H.W. Glutathione-activatable and $\mathrm{O}_{2} / \mathrm{Mn}^{2+}$-evolving nanocomposite for highly efficient and selective photodynamic and gene-silencing dual therapy. Adv. Funct. Mater. 2017, 27, 1704089. [CrossRef] 
103. Jia, Q.Y.; Ge, J.C.; Liu, W.M.; Zheng, X.L.; Chen, S.Q.; Wen, Y.M.; Zhang, H.Y.; Wang, P.F. A magnetofluorescent carbon dot assembly as an acidic $\mathrm{H}_{2} \mathrm{O}_{2}$-driven oxygenerator to regulate tumor hypoxia for simultaneous bimodal imaging and enhanced photodynamic therapy. Adv. Mater. 2018, 30, 1706090. [CrossRef]

104. Chen, H.C.; Tian, J.W.; He, W.J.; Guo, Z.J. $\mathrm{H}_{2} \mathrm{O}_{2}$-Activatable and $\mathrm{O}_{2}$-evolving nanoparticles for highly efficient and selective photodynamic therapy against hypoxic tumor cells. J. Am. Chem. Soc. 2015, 137, 1539-1547. [CrossRef]

105. Zhang, Y.; Shen, T.T.; Kirillov, A.M.; Liu, W.S.; Tang, Y. NIR light $/ \mathrm{H}_{2} \mathrm{O}_{2}$-triggered nanocomposites for a highly efficient and selective synergistic photodynamic and photothermal therapy against hypoxic tumor cells. Chem. Commun. 2016, 52, 7939-7942. [CrossRef] [PubMed]

106. Hu, D.H.; Chen, Z.W.; Sheng, Z.H.; Gao, D.Y.; Yan, F.; Ma, T.; Zheng, H.R.; Hong, M. A catalase-loaded hierarchical zeolite as an implantable nanocapsule for ultrasound-guided oxygen self-sufficient photodynamic therapy against pancreatic cancer. Nanoscale 2018, 10, 17283-17292. [CrossRef] [PubMed]

107. Cheng, H.; Zhu, J.Y.; Li, S.Y.; Zeng, J.Y.; Lei, Q.; Chen, K.W.; Zhang, C.; Zhang, X.Z. An O $\mathrm{O}_{2}$ self-sufficient biomimetic nanoplatform for highly specific and efficient photodynamic therapy. Adv. Funct. Mater. 2016, 26, 7847-7860. [CrossRef]

108. Yang, G.B.; Xu, L.G.; Xu, J.; Zhang, R.; Song, G.S.; Chao, Y.; Feng, L.Z.; Han, F.X.; Dong, Z.L.; Li, B.; et al. Smart nanoreactors for $\mathrm{pH}$-responsive tumor homing, mitochondria-targeting, and enhanced photodynamic-immunotherapy of cancer. Nano Lett. 2018, 18, 2475-2484. [CrossRef] [PubMed]

109. Shen, L.Y.; Huang, Y.; Chen, D.; Qiu, F.; Ma, C.; Jin, X.; Zhu, X.Y.; Zhou, G.Y.; Zhang, Z.Y. pH-Responsive aerobic nanoparticles for effective photodynamic therapy. Theranostics 2017, 7, 4537-4550. [CrossRef] [PubMed]

110. Zhao, H.J.; Li, L.; Zheng, C.X.; Hao, Y.W.; Niu, M.Y.; Hu, Y.J.; Chang, J.B.; Zhang, Z.Z.; Wang, L. An intelligent dual stimuli-responsive photosensitizer delivery system with $\mathrm{O}_{2}$-supplying for efficient photodynamic therapy. Colloids Surf. B. Biointerfaces 2018, 167, 299-309. [CrossRef]

111. Wu, P.; Cai, Z.; Chen, J.; Zhang, H.; Cai, C. Electrochemical measurement of the flux of hydrogen peroxide releasing from RAW 264.7 macrophage cells based on enzyme-attapulgite clay nanohybrids. Biosens. Bioelectron. 2011, 26, 4012-4017. [CrossRef]

112. Lu, K.Y.; Lin, P.Y.; Chuang, E.Y.; Shih, C.M.; Cheng, T.M.; Lin, T.Y.; Sung, H.W.; Mi, F.L. $\mathrm{H}_{2} \mathrm{O}_{2}$-Depleting and $\mathrm{O}_{2}$-generating selenium nanoparticles for fluorescence imaging and photodynamic treatment of proinflammatory-activated macrophages. ACS Appl. Mater. Interfaces 2017, 9, 5158-5172. [CrossRef]

113. Ouyang, J.; Wang, L.Q.; Chen, W.S.; Zeng, K.; Han, Y.J.; Xu, Y.; Xu, Q.F.; Deng, L.; Liu, Y.N. Biomimetic nanothylakoids for efficient imaging-guided photodynamic therapy for cancer. Chem. Commun. 2018, 54, 3468-3471. [CrossRef]

114. Sheptovitsky, Y.G.; Brudvig, G.W. Isolation and characterization of spinach photosystem II membrane-associated catalase and polyphenol oxidase. Biochemistry (Mosc) 1996, 35, 16255-16263. [CrossRef]

115. Wang, H.R.; Chao, Y.; Liu, J.J.; Zhu, W.W.; Wang, G.L.; Xu, L.G.; Liu, Z.G. Photosensitizer-crosslinked in-situ polymerization on catalase for tumor hypoxia modulation \& enhanced photodynamic therapy. Biomaterials 2018, 181, 310-317. [PubMed]

116. Yang, Y.; Zhu, W.J.; Feng, L.Z.; Chao, Y.; Yi, X.; Dong, Z.L.; Yang, K.; Tan, W.H.; Liu, Z.; Chen, M.W. G-Quadruplex-based nanoscale coordination polymers to modulate tumor hypoxia and achieve nuclear-targeted drug delivery for enhanced photodynamic therapy. Nano Lett. 2018, 18, 6867-6875. [CrossRef]

117. Ruan, Y.D.; Jia, X.D.; Wang, C.; Zhen, W.Y.; Jiang, X. Mn-Fe layered double hydroxide nanosheets: A new photothermal nanocarrier for $\mathrm{O}_{2}$-evolving phototherapy. Chem. Commun. 2018, 54, 11729-11732. [CrossRef] [PubMed]

118. Wang, D.D.; Shi, R.H.; Zhou, J.J.; Shi, S.X.; Wu, H.H.; Xu, P.P.; Wang, H.; Xia, G.L.; Barnhart, T.E.; Cai, W.B.; et al. Photo-enhanced singlet oxygen generation of prussian blue-based nanocatalyst for augmented photodynamic therapy. iScience 2018, 9, 14-26. [CrossRef] [PubMed]

119. Yang, Z.L.; Tian, W.; Wang, Q.; Zhao, Y.; Zhang, Y.L.; Tian, Y.; Tang, Y.X.; Wang, S.J.; Liu, Y.; Ni, Q.Q.; et al. Oxygen-evolving mesoporous organosilica coated prussian blue nanoplatform for highly efficient photodynamic therapy of tumors. Adv. Sci. 2018, 5, 1700847. [CrossRef] 
120. Ma, Z.F.; Zhang, M.C.; Jia, X.D.; Bai, J.; Ruan, Y.D.; Wang, C.; Sun, X.P.; Jiang, X. FeIII-doped two-dimensional C3N4 nanofusiform: A new $\mathrm{O}_{2}$-evolving and mitochondria-targeting photodynamic agent for mri and enhanced antitumor therapy. Small 2016, 12, 5477-5487. [CrossRef]

121. Zhen, W.Y.; Bai, J.; Jia, X.D.; Wu, L.; Jiang, X.E. $\mathrm{H}_{2} \mathrm{O}_{2}$-Responsive MB-BSA-Fe(III) nanoparticles as oxygen generators for MRI-guided photodynamic therapy. J. Anal.Test. 2018, 2, 69-76. [CrossRef]

122. Hu, F.; Mao, D.; Kenry; Wang, Y.X.; Wu, W.B.; Zhao, D.; Kong, D.L.; Liu, B. Metal-organic framework as a simple and general inert nanocarrier for photosensitizers to implement activatable photodynamic therapy. Adv. Funct. Mater. 2018, 28, 1707519. [CrossRef]

123. Lan, G.X.; Ni, K.Y.; Xu, Z.W.; Veroneau, S.S.; Song, Y.; Lin, W.B. Nanoscale metal-organic framework overcomes hypoxia for photodynamic therapy primed cancer immunotherapy. J. Am. Chem. Soc. 2018, 140, 5670-5673. [CrossRef]

124. Liu, J.T.; Du, P.; Mao, H.; Zhang, L.; Ju, H.X.; Lei, J.P. Dual-triggered oxygen self-supply black phosphorus nanosystem for enhanced photodynamic therapy. Biomaterials 2018, 172, 83-91. [CrossRef]

125. Zhang, Y.; Wang, F.M.; Liu, C.Q.; Wang, Z.Z.; Kang, L.H.; Huang, Y.Y.; Dong, K.; Ren, J.S.; Qu, X.G. Nanozyme decorated metal-organic frameworks for enhanced photodynamic therapy. ACS Nano 2018, 12, 651-661. [CrossRef] [PubMed]

126. Wei, J.P.; Li, J.C.; Sun, D.; Li, Q.; Ma, J.Y.; Chen, X.L.; Zhu, X.; Zheng, N.F. A novel theranostic nanoplatform based on Pd@Pt-PEG-Ce6 for enhanced photodynamic therapy by modulating tumor hypoxia microenvironment. Adv. Funct. Mater. 2018, 28, 1706310. [CrossRef]

127. Wang, X.S.; Zeng, J.Y.; Zhang, M.K.; Zeng, X.; Zhang, X.Z. A versatile Pt-based core-shell nanoplatform as a nanofactory for enhanced tumor therapy. Adv. Funct. Mater. 2018, 28, 1801783. [CrossRef]

128. Cai, X.L.; Luo, Y.A.; Song, Y.; Liu, D.; Yan, H.Y.; Li, H.; Du, D.; Zhu, C.Z.; Lin, Y.H. Integrating in situ formation of nanozymes with three-dimensional dendritic mesoporous silica nanospheres for hypoxia-overcoming photodynamic therapy. Nanoscale 2018, 10, 22937-22945. [CrossRef] [PubMed]

129. Ouyang, J.; Deng, Y.Y.; Chen, W.S.; Xu, Q.F.; Wang, L.Q.; Liu, Z.J.; Tang, F.Y.; Deng, L.; Liu, Y.N. Marriage of artificial catalase and black phosphorus nanosheets for photodynamic antitumor therapy. J. Mater. Chem. B 2018, 6, 2057-2064. [CrossRef]

130. Li, J.J.; Wei, K.; Zuo, S.; Xu, Y.X.; Zha, Z.S.; Ke, W.D.; Chen, H.B.; Ge, Z.S. Light-triggered clustered vesicles with self-supplied oxygen and tissue penetrability for photodynamic therapy against hypoxic tumor. Adv. Funct. Mater. 2017, 27, 1702108. [CrossRef]

131. Wang, B.; Lin, W.M.; Mao, Z.W.; Gao, C.Y. Near-infrared light triggered photothermal therapy and enhanced photodynamic therapy with a tumor-targeting hydrogen peroxide shuttle. J. Mater. Chem. B 2018, 6, 3145-3155. [CrossRef]

132. Manifold, R.N.; Anderson, C.D. Increased cutaneous oxygen availability by topical application of hydrogen peroxide cream enhances the photodynamic reaction to topical 5-aminolevulinic acid-methyl ester. Arch. Dermatol. Res. 2011, 303, 285-292. [CrossRef]

133. Zhen, W.Y.; Liu, Y.; Jia, X.D.; Wu, L.; Wang, C.; Jiang, X. Reductive surfactant-assisted one-step fabrication of a $\mathrm{BiOI} / \mathrm{BiOIO}_{3}$ heterojunction biophotocatalyst for enhanced photodynamic theranostics overcoming tumor hypoxia. Nanoscale Horiz. 2019, 4, 720-726. [CrossRef]

134. Wu, X.; Yan, P.J.; Ren, Z.H.; Wang, Y.F.; Cai, X.J.; Li, X.; Deng, R.R.; Han, G.R. Ferric hydroxide-modified upconversion nanoparticles for $808 \mathrm{~nm}$ NIR-triggered synergetic tumor therapy with hypoxia modulation. ACS Appl. Mater. Interfaces 2019, 11, 385-393. [CrossRef]

135. Jafari, T.; Moharreri, E.; Amin, A.S.; Miao, R.; Song, W.; Suib, S.L. Photocatalytic water splitting-The untamed dream: A review of recent advances. Molecules 2016, 21, 900. [CrossRef]

136. Hu, L.D.; Wang, P.Y.; Zhao, M.Y.; Liu, L.; Zhou, L.; Li, B.H.; Albaqami, F.H.; El-Toni, A.M.; Li, X.M.; Xie, Y.; et al. Near-infrared rechargeable "optical battery" implant for irradiation-free photodynamic therapy. Biomaterials 2018, 163, 154-162. [CrossRef] [PubMed]

137. Liu, L.H.; Zhang, Y.H.; Qiu, W.X.; Zhang, L.; Gao, F.; Li, B.; Xu, L.; Fan, J.X.; Li, Z.H.; Zhang, X.Z. Dual-stage light amplified photodynamic therapy against hypoxic tumor based on an $\mathrm{O}_{2}$ self-sufficient nanoplatform. Small 2017, 13, 1701621. [CrossRef] [PubMed]

138. Sheng, Y.; Nesbitt, H.; Callan, B.; Taylor, M.A.; Love, M.; McHale, A.P.; Callan, J.F. Oxygen generating nanoparticles for improved photodynamic therapy of hypoxic tumours. J. Control. Release 2017, 264, 333-340. [CrossRef] [PubMed] 
139. Zheng, D.W.; Li, B.; Li, C.X.; Fan, J.X.; Lei, Q.; Li, C.; Xu, Z.S.; Zhang, X.Z. Carbon-dot-decorated carbon nitride nanoparticles for enhanced photodynamic therapy against hypoxic tumor via water splitting. ACS Nano 2016, 10, 8715-8722. [CrossRef]

140. Li, R.Q.; Zhang, C.; Xie, B.R.; Yu, W.Y.; Qiu, W.X.; Cheng, H.; Zhang, X.Z. A two-photon excited O ${ }_{2}$-evolving nanocomposite for efficient photodynamic therapy against hypoxic tumor. Biomaterials 2019, 194, 84-93. [CrossRef]

141. Yang, D.; Yang, G.X.; Gai, S.L.; He, F.; Li, C.X.; Yang, P.P. Multifunctional theranostics for dual-modal photodynamic synergistic therapy via stepwise water splitting. ACS Appl. Mater. Interfaces 2017, 9, 6829-6838. [CrossRef]

142. Zheng, D.W.; Li, B.; Xu, L.; Zhang, Q.L.; Fan, J.X.; Li, C.X.; Zhang, X.Z. Normalizing tumor microenvironment based on photosynthetic abiotic/biotic nanoparticles. ACS Nano 2018, 12, 6218-6227. [CrossRef]

143. Zhou, Y.; Zhang, Y.; Lin, M.; Long, J.; Zhang, Z.; Lin, H.; Wu, J.C.S.; Wang, X. Monolayered $\mathrm{Bi}_{2} \mathrm{WO}_{6}$ nanosheets mimicking heterojunction interface with open surfaces for photocatalysis. Nat. Commun. 2015, 6, 8340. [CrossRef]

144. Zhang, C.; Ren, J.; Hua, J.S.; Xia, L.Y.; He, J.; Huo, D.; Hu, Y. Multifunctional $\mathrm{Bi}_{2} \mathrm{WO}_{6}$ nanoparticles for CT-guided photothermal and oxygen-free photodynamic therapy. ACS Appl. Mater. Interfaces 2018, 10, 1132-1146. [CrossRef]

145. Fan, J.X.; Liu, M.D.; Li, C.X.; Hong, S.; Zheng, D.W.; Liu, X.H.; Chen, S.; Cheng, H.; Zhang, X.Z. A metal-semiconductor nanocomposite as an efficient oxygen-independent photosensitizer for photodynamic tumor therapy. Nanoscale Horiz. 2017, 2, 349-355. [CrossRef]

146. Gong, H.; Chao, Y.; Xiang, J.; Han, X.; Song, G.S.; Feng, L.Z.; Liu, J.J.; Yang, G.B.; Chen, Q.; Liu, Z. Hyaluronidase to enhance nanoparticle-based photodynamic tumor therapy. Nano Lett. 2016, 16, 2512-2521. [CrossRef] [PubMed]

147. Liu, J.J.; Tian, L.L.; Zhang, R.; Dong, Z.L.; Wang, H.R.; Liu, Z. Collagenase-encapsulated pH-responsive nanoscale coordination polymers for tumor microenvironment modulation and enhanced photodynamic nanomedicine. ACS Appl. Mater. Interfaces 2018, 10, 43493-43502. [CrossRef]

148. Song, X.J.; Feng, L.Z.; Liang, C.; Gao, M.; Song, G.S.; Liu, Z. Liposomes co-loaded with metformin and chlorin e6 modulate tumor hypoxia during enhanced photodynamic therapy. Nano Res. 2017, 10, 1200-1212. [CrossRef]

149. Zuo, H.Q.; Tao, J.X.; Shi, H.; He, J.; Zhou, Z.Y.; Zhang, C. Platelet-mimicking nanoparticles co-loaded with $\mathrm{W}_{18} \mathrm{O}_{49}$ and metformin alleviate tumor hypoxia for enhanced photodynamic therapy and photothermal therapy. Acta Biomater. 2018, 80, 296-307. [CrossRef] [PubMed]

150. Yang, Z.; Chen, Q.; Chen, J.; Dong, Z.; Zhang, R.; Liu, J.; Liu, Z. Tumor-pH-responsive dissociable albumin-tamoxifen nanocomplexes enabling efficient tumor penetration and hypoxia relief for enhanced cancer photodynamic therapy. Small 2018, 14, 1803262. [CrossRef]

151. Xia, D.L.; Xu, P.P.; Luo, X.Y.; Zhu, J.F.; Gu, H.Y.; Huo, D.; Hu, Y. Overcoming hypoxia by multistage nanoparticle delivery system to inhibit mitochondrial respiration for photodynamic therapy. Adv. Funct. Mater. 2019, 29, 1807294. [CrossRef]

152. Gui, L.; Zhou, J.H.; Zhou, L.; Wei, S.H. A smart copper-phthalocyanine framework nanoparticle for enhancing photodynamic therapy in hypoxic conditions by weakening cells through ATP depletion. J. Mater. Chem. B 2018, 6, 2078-2088. [CrossRef]

153. Lv, W.; Zhang, Z.; Zhang, K.Y.; Yang, H.R.; Liu, S.J.; Xu, A.Q.; Guo, S.; Zhao, Q.; Huang, W. A mitochondria-targeted photosensitizer showing improved photodynamic therapy effects under hypoxia. Angew. Chem. Int. Ed. 2016, 55, 9947-9951. [CrossRef]

154. Bayat Mokhtari, R.; Homayouni, T.S.; Baluch, N.; Morgatskaya, E.; Kumar, S.; Das, B.; Yeger, H. Combination therapy in combating cancer. Oncotarget 2017, 8, 38022-38043. [CrossRef]

155. Brodin, N.P.; Guha, C.; Tome, W.A. Photodynamic therapy and its role in combined modality anticancer treatment. Technol. Cancer Res. Treat. 2015, 14, 355-368. [CrossRef] [PubMed]

156. Liu, Y.Y.; Liu, Y.; Bu, W.B.; Cheng, C.; Zuo, C.J.; Xiao, Q.F.; Sun, Y.; Ni, D.L.; Zhang, C.; Liu, J.A.; et al. Hypoxia induced by upconversion-based photodynamic therapy: Towards highly effective synergistic bioreductive therapy in tumors. Angew. Chem. Int. Ed. 2015, 54, 8105-8109. [CrossRef] [PubMed] 
157. Guo, D.B.; Xu, S.T.; Wang, N.; Jiang, H.Y.; Huang, Y.; Jin, X.; Xue, B.; Zhang, C.; Zhu, X.Y. Prodrug-embedded angiogenic vessel-targeting nanoparticle: A positive feedback amplifier in hypoxia-induced chemo-photo therapy. Biomaterials 2017, 144, 188-198. [CrossRef] [PubMed]

158. Li, S.Y.; Cheng, H.; Qiu, W.X.; Zhang, L.; Wan, S.S.; Zeng, J.Y.; Zhang, X.Z. Cancer cell membrane-coated biomimetic platform for tumor targeted photodynamic therapy and hypoxia-amplified bioreductive therapy. Biomaterials 2017, 142, 149-161. [CrossRef] [PubMed]

159. Wang, Y.Z.; Xie, Y.; Li, J.; Peng, Z.H.; Sheinin, Y.; Zhou, J.P.; Oupicky, D. Tumor-penetrating nanoparticles for enhanced anticancer activity of combined photodynamic and hypoxia-activated therapy. ACS Nano 2017, 11, 2227-2238. [CrossRef] [PubMed]

160. Chen, J.; Liu, L.; Motevalli, S.M.; Wu, X.L.; Yang, X.H.; Li, X.L.; Han, L.; Magrini, A.; Guo, W.S.; Chang, J.; et al. Light-triggered retention and cascaded therapy of albumin-based theranostic nanomedicines to alleviate tumor adaptive treatment tolerance. Adv. Funct. Mater. 2018, 28, 1707291. [CrossRef]

161. Liu, M.; Wang, L.; Zheng, X.H.; Liu, S.; Xie, Z.G. Hypoxia-triggered nanoscale metal-organic frameworks for enhanced anticancer activity. ACS Appl. Mater. Interfaces 2018, 10, 24638-24647. [CrossRef]

162. Yang, Y.; Yang, X.; Li, H.; Li, C.; Ding, H.; Zhang, M.; Guo, Y.; Sun, M. Near-infrared light triggered liposomes combining photodynamic and chemotherapy for synergistic breast tumor therapy. Colloids Surf. B. Biointerfaces 2019, 173, 564-570. [CrossRef]

163. Zhang, K.; Zhang, Y.D.; Meng, X.D.; Lu, H.T.; Chang, H.; Dong, H.F.; Zhang, X.J. Light-triggered theranostic liposomes for tumor diagnosis and combined photodynamic and hypoxia-activated prodrug therapy. Biomaterials 2018, 185, 301-309. [CrossRef]

164. Wang, Q.; Tian, L.; Xu, J.; Xia, B.; Li, J.; Lu, F.; Lu, X.; Wang, W.; Huang, W.; Fan, Q. Multifunctional supramolecular vesicles for combined photothermal/photodynamic/hypoxia-activated chemotherapy. Chem. Commun. 2018, 54, 10328-10331. [CrossRef]

165. Qian, C.G.; Yu, J.C.; Chen, Y.L.; Hu, Q.Y.; Xiao, X.Z.; Sun, W.J.; Wang, C.; Feng, P.J.; Shen, Q.D.; Gu, Z. Light-activated hypoxia-responsive nanocarriers for enhanced anticancer therapy. Adv. Mater. 2016, 28, 3313-3320. [CrossRef] [PubMed]

166. Hu, D.R.; Chen, L.J.; Qu, Y.; Peng, J.R.; Chu, B.Y.; Shi, K.; Hao, Y.; Zhong, L.; Wang, M.Y.; Qian, Z.Y. Oxygen-generating hybrid polymeric nanoparticles with encapsulated doxorubicin and chlorin e6 for trimodal imaging-guided combined chemo-photodynamic therapy. Theranostics 2018, 8, 1558-1574. [CrossRef] [PubMed]

167. Luo, Z.Y.; Tian, H.; Liu, L.L.; Chen, Z.K.; Liang, R.J.; Chen, Z.; Wu, Z.H.; Ma, A.Q.; Zheng, M.B.; Cai, L.T. Tumor-targeted hybrid protein oxygen carrier to simultaneously enhance hypoxia-dampened chemotherapy and photodynamic therapy at a single dose. Theranostics 2018, 8, 3584-3596. [CrossRef]

168. Xu, J.; Han, W.; Yang, P.; Jia, T.; Dong, S.; Bi, H.; Gulzar, A.; Yang, D.; Gai, S.; He, F.; et al. Tumor microenvironment-responsive mesoporous $\mathrm{MnO}_{2}$-coated upconversion nanoplatform for self-enhanced tumor theranostics. Adv. Funct. Mater. 2018, 28, 1803804. [CrossRef]

169. Xie, Z.; Cai, X.; Sun, C.; Liang, S.; Shao, S.; Huang, S.; Cheng, Z.; Pang, M.; Xing, B.; Kheraif, A.A.A.; et al. $\mathrm{O}_{2}$-Loaded $\mathrm{pH}$-responsive multifunctional nanodrug carrier for overcoming hypoxia and highly efficient chemo-photodynamic cancer therapy. Chem. Mater. 2019, 31, 483-490. [CrossRef]

170. He, H.; Zhu, R.Y.; Sun, W.; Cai, K.M.; Chen, Y.B.; Yin, L.C. Selective cancer treatment via photodynamic sensitization of hypoxia-responsive drug delivery. Nanoscale 2018, 10, 2856-2865. [CrossRef]

171. Yang, Y.; Wang, C.; Tian, C.; Guo, H.L.; Shen, Y.H.; Zhu, M.Z. Fe $\mathrm{O}_{4} @ \mathrm{MnO}_{2} @ P P y$ nanocomposites overcome hypoxia: Magnetic-targeting-assisted controlled chemotherapy and enhanced photodynamic/photothermal therapy. J. Mater. Chem. B 2018, 6, 6848-6857. [CrossRef]

172. Deng, J.; Liu, F.; Wang, L.N.; An, Y.; Gao, M.; Wang, Z.; Zhao, Y.J. Hypoxia- and singlet oxygen-responsive chemo-photodynamic micelles featured with glutathione depletion and aldehyde production. Biomater. Sci. 2019, 7, 429-441. [CrossRef]

173. Feng, L.; Cheng, L.; Dong, Z.; Tao, D.; Barnhart, T.E.; Cai, W.; Chen, M.; Liu, Z. Theranostic liposomes with hypoxia-activated prodrug to effectively destruct hypoxic tumors post-photodynamic therapy. ACS Nano 2017, 11, 927-937. [CrossRef]

174. Luan, X.; Guan, Y.Y.; Liu, H.J.; Lu, Q.; Zhao, M.; Sun, D.X.; Lovell, J.F.; Sun, P.; Chen, H.Z.; Fang, C. A tumor vascular-targeted interlocking trimodal nanosystem that induces and exploits hypoxia. Adv. Sci. 2018, 5, 1800034. [CrossRef] 
175. He, Z.; Dai, Y.; Li, X.; Guo, D.; Liu, Y.; Huang, X.; Jiang, J.; Wang, S.; Zhu, G.; Zhang, F.; et al. Hybrid nanomedicine fabricated from photosensitizer-terminated metal-organic framework nanoparticles for photodynamic therapy and hypoxia-activated cascade chemotherapy. Small 2019, 15, 1804131. [CrossRef] [PubMed]

176. Guo, D.B.; Xu, S.T.; Huang, Y.; Jiang, H.Y.; Yasen, W.; Wang, N.; Su, Y.; Qian, J.W.; Li, J.; Zhang, C.; et al. Platinum (IV) complex-based two-in-one polyprodrug for a combinatorial chemo-photodynamic therapy. Biomaterials 2018, 177, 67-77. [CrossRef] [PubMed]

177. Xu, S.; Zhu, X.; Zhang, C.; Huang, W.; Zhou, Y.; Yan, D. Oxygen and Pt (II) self-generating conjugate for synergistic photo-chemo therapy of hypoxic tumor. Nat. Commun. 2018, 9, 2053. [CrossRef] [PubMed]

178. Wang, H.R.; Zhu, W.W.; Feng, L.Z.; Chen, Q.; Chao, Y.; Dong, Z.L.; Liu, Z. Nanoscale covalent organic polymers as a biodegradable nanomedicine for chemotherapy-enhanced photodynamic therapy of cancer. Nano Res. 2018, 11, 3244-3257. [CrossRef]

179. Chen, W.H.; Lecaros, R.L.G.; Tseng, Y.C.; Huang, L.; Hsu, Y.C. Nanoparticle delivery of HIF1 alpha siRNA combined with photodynamic therapy as a potential treatment strategy for head-and-neck cancer. Cancer Lett. 2015, 359, 65-74. [CrossRef] [PubMed]

180. Sun, S.J.; Xu, Y.X.; Fu, P.; Chen, M.; Sun, S.H.; Zhao, R.R.; Wang, J.R.; Liang, X.L.; Wang, S.M. Ultrasound-targeted photodynamic and gene dual therapy for effectively inhibiting triple negative breast cancer by cationic porphyrin lipid microbubbles loaded with HIF1 alpha-siRNA. Nanoscale 2018, 10, 19945-19956. [CrossRef]

181. Broekgaarden, M.; Weijer, R.; Krekorian, M.; van den Ijssel, B.; Kos, M.; Alles, L.K.; van Wijk, A.C.; Bikadi, Z.; Hazai, E.; van Gulik, T.M.; et al. Inhibition of hypoxia-inducible factor 1 with acriflavine sensitizes hypoxic tumor cells to photodynamic therapy with zinc phthalocyanine-encapsulating cationic liposomes. Nano Res. 2016, 9, 1639-1662. [CrossRef]

182. Weijer, R.; Broekgaarden, M.; Krekorian, M.; Alles, L.K.; van Wijk, A.C.; Mackaaij, C.; Verheij, J.; van der Wal, A.C.; van Gulik, T.M.; Storm, G.; et al. Inhibition of hypoxia inducible factor 1 and topoisomerase with acriflavine sensitizes perihilar cholangiocarcinomas to photodynamic therapy. Oncotarget 2016, 7, 3331-3346. [CrossRef]

183. Ferrario, A.; von Tiehl, K.F.; Rucker, N.; Schwarz, M.A.; Gill, P.S.; Gomer, C.J. Antiangiogenic treatment enhances photodynamic therapy responsiveness in a mouse mammary carcinoma. Cancer Res. 2000, $60,4066-4069$.

184. Zhou, Q.Y.; Olivo, M.; Lye, K.Y.K.; Moore, S.; Sharma, A.; Chowbay, B. Enhancing the therapeutic responsiveness of photodynamic therapy with the antiangiogenic agents SU5416 and SU6668 in murine nasopharyngeal carcinoma models. Cancer Chemother. Pharmacol. 2005, 56, 569-577. [CrossRef]

185. Weiss, A.; van Beijnum, J.R.; Bonvin, D.; Jichlinski, P.; Dyson, P.J.; Griffioen, A.W.; Nowak-Sliwinska, P. Low-dose angiostatic tyrosine kinase inhibitors improve photodynamic therapy for cancer: Lack of vascular normalization. J. Cell. Mol. Med. 2014, 18, 480-491. [CrossRef] [PubMed]

186. Lecaros, R.L.G.; Huang, L.; Lee, T.C.; Hsu, Y.C. Nanoparticle delivered VEGF-A siRNA enhances photodynamic therapy for head and neck cancer treatment. Mol. Ther. 2016, 24, 106-116. [CrossRef] [PubMed]

187. Liang, P.P.; Huang, X.Y.; Wang, Y.; Chen, D.P.; Ou, C.J.; Zhang, Q.; Shao, J.J.; Huang, W.; Dong, X.C. Tumor-microenvironment-responsive nanoconjugate for synergistic antivascular activity and phototherapy. ACS Nano 2018, 12, 11446-11457. [CrossRef] [PubMed]

188. Ferrario, A.; Fisher, A.M.; Rucker, N.; Gomer, C.J. Celecoxib and NS-398 enhance photodynamic therapy by increasing in vitro apoptosis and decreasing In vivo inflammatory and angiogenic factors. Cancer Res. 2005, 65, 9473-9478. [CrossRef] [PubMed]

189. Tuncel, S.; Trivella, A.; Atilla, D.; Bennis, K.; Savoie, H.; Albrieux, F.; Delort, L.; Billard, H.; Dubois, V.; Ahsen, V.; et al. Assessing the dual activity of a chalcone-phthalocyanine conjugate: Design, synthesis, and antivascular and photodynamic properties. Mol. Pharm. 2013, 10, 3706-3716. [CrossRef] [PubMed]

190. Li, Y.J.; Sui, H.; Jiang, C.L.; Li, S.M.; Han, Y.; Huang, P.; Du, X.X.; Du, J.W.; Bai, Y.X. Dihydroartemisinin increases the sensitivity of photodynamic therapy via NF-kappa B/HIF-1 alpha/VEGF pathway in esophageal cancer cell in vitro and In vivo. Cell. Physiol. Biochem. 2018, 48, 2035-2045. [CrossRef] 
191. Li, Y.J.; Zhou, J.H.; Du, X.X.; Jia, D.X.; Wu, C.L.; Huang, P.; Han, Y.; Sui, H.; Wei, X.L.; Liu, L.; et al. Dihydroartemisinin accentuates the anti-tumor effects of photodynamic therapy via inactivation of NF-kappa B in Eca109 and Ec9706 esophageal cancer cells. Cell. Physiol. Biochem. 2014, 33, 1527-1536. [CrossRef]

192. Jung, H.S.; Han, J.; Shi, H.; Koo, S.; Singh, H.; Kim, H.J.; Sessler, J.L.; Lee, J.Y.; Kim, J.H.; Kim, J.S. Overcoming the limits of hypoxia in photodynamic therapy: A carbonic anhydrase IX-targeted approach. J. Am. Chem. Soc. 2017, 139, 7595-7602. [CrossRef]

193. Jin, C.S.; Lovell, J.F.; Chen, J.; Zheng, G. Ablation of hypoxic tumors with dose-equivalent photothermal, but not photodynamic, therapy using a nanostructured porphyrin assembly. ACS Nano 2013, 7, 2541-2550. [CrossRef]

194. Zhu, W.; Liu, Y.; Yang, Z.; Zhang, L.; Xiao, L.J.; Liu, P.; Wang, J.; Yi, C.F.; Xu, Z.S.; Ren, J.H. Albumin/sulfonamide stabilized iron porphyrin metal organic framework nanocomposites: Targeting tumor hypoxia by carbonic anhydrase IX inhibition and T-1-T-2 dual mode MRI guided photodynamic/photothermal therapy. J. Mater. Chem. B 2018, 6, 265-276. [CrossRef]

195. Hu, D.H.; Sheng, Z.H.; Gao, G.H.; Siu, F.M.; Liu, C.B.; Wan, Q.; Gong, P.; Zheng, H.R.; Ma, Y.F.; Cai, L.T. Activatable albumin-photosensitizer nanoassemblies for triple-modal imaging and thermal-modulated photodynamic therapy of cancer. Biomaterials 2016, 93, 10-19. [CrossRef] [PubMed]

196. Feng, L.Z.; Tao, D.L.; Dong, Z.L.; Chen, Q.; Chao, Y.; Liu, Z.; Chen, M.W. Near-infrared light activation of quenched liposomal Ce6 for synergistic cancer phototherapy with effective skin protection. Biomaterials 2017, 127, 13-24. [CrossRef] [PubMed]

197. Im, S.; Lee, J.; Park, D.; Park, A.; Kim, Y.M.; Kim, W.J. Hypoxia-triggered transforming immunomodulator for cancer immunotherapy via photodynamically enhanced antigen presentation of dendritic cell. ACS Nano 2018, 13, 476-488. [CrossRef]

198. Zhou, Z.; Song, J.; Nie, L.; Chen, X. Reactive oxygen species generating systems meeting challenges of photodynamic cancer therapy. Chem. Soc. Rev. 2016, 45, 6597-6626. [CrossRef] [PubMed]

199. Ding, H.Y.; Yu, H.J.; Dong, Y.; Tian, R.H.; Huang, G.; Boothman, D.A.; Sumer, B.D.; Gao, J.M. Photoactivation switch from type II to type I reactions by electron-rich micelles for improved photodynamic therapy of cancer cells under hypoxia. J. Control. Release 2011, 156, 276-280. [CrossRef]

200. Li, M.L.; Xia, J.; Tian, R.S.; Wang, J.Y.; Fan, J.L.; Du, J.J.; Long, S.; Song, X.Z.; Foley, J.W.; Peng, X.J. Near-infrared light-initiated molecular superoxide radical generator: Rejuvenating photodynamic therapy against hypoxic tumors. J. Am. Chem. Soc. 2018, 140, 14851-14859. [CrossRef]

201. Liu, Y.; Zhen, W.Y.; Jin, L.H.; Zhang, S.T.; Sun, G.Y.; Zhang, T.Q.; Xu, X.; Song, S.Y.; Wang, Y.H.; Liu, J.H.; et al. All-in-one theranostic nanoagent with enhanced reactive oxygen species generation and modulating tumor microenvironment ability for effective tumor eradication. ACS Nano 2018, 12, 4886-4893. [CrossRef]

202. Lv, Z.; Wei, H.J.; Li, Q.; Su, X.L.; Liu, S.J.; Zhang, K.Y.; Lv, W.; Zhao, Q.; Li, X.H.; Huang, W. Achieving efficient photodynamic therapy under both normoxia and hypoxia using cyclometalated $\mathrm{Ru}(\mathrm{II})$ photosensitizer through type I photochemical process. Chem. Sci. 2018, 9, 502-512. [CrossRef]

203. Wang, X.X.; Xu, J.T.; Yang, D.; Sun, C.Q.; Sun, Q.Q.; He, F.; Gai, S.L.; Zhong, C.N.; Li, C.X.; Yang, P.P. $\mathrm{Fe}_{3} \mathrm{O}_{4} @$ MIL-100(Fe)-UCNPs heterojunction photosensitizer: Rational design and application in near infrared light mediated hypoxic tumor therapy. Chem. Eng. J. 2018, 354, 1141-1152. [CrossRef]

204. Tian, N.; Sun, W.Z.; Guo, X.S.; Lu, J.; Li, C.; Hou, Y.J.; Wang, X.S.; Zhou, Q.X. Mitochondria targeted and NADH triggered photodynamic activity of chloromethyl modified Ru(ii) complexes under hypoxic conditions. Chem. Commun. 2019, 55, 2676-2679. [CrossRef]

205. Lazic, S.; Kaspler, P.; Shi, G.; Monro, S.; Sainuddin, T.; Forward, S.; Kasimova, K.; Hennigar, R.; Mandel, A.; McFarland, S.; et al. Novel osmium-based coordination complexes as photosensitizers for panchromatic photodynamic therapy. Photochem. Photobiol. 2017, 93, 1248-1258. [CrossRef] [PubMed]

206. Babii, O.; Afonin, S.; Garmanchuk, L.V.; Nikulina, V.V.; Nikolaienko, T.V.; Storozhuk, O.V.; Shelest, D.V.; Dasyukevich, O.I.; Ostapchenko, L.I.; Iurchenko, V.; et al. Direct photocontrol of peptidomimetics: An aternative to oxygen-dependent photodynamic cancer therapy. Angew. Chem. Int. Ed. 2016, 55, 5493-5496. [CrossRef] [PubMed]

207. Fadhel, A.A.; Yue, X.L.; Zadeh, E.H.G.; Bondar, M.V.; Belfield, K.D. Pegylated and nanoparticle-conjugated sulfonium salt photo triggers necrotic cell death. Int. J. Nanomed. 2016, 11, 6161-6168. [CrossRef] [PubMed]

208. Yue, X.L.; Yanez, C.O.; Yao, S.; Belfield, K.D. Selective cell death by photochemically induced pH imbalance in cancer cells. J. Am. Chem. Soc. 2013, 135, 2112-2115. [CrossRef] [PubMed] 
209. Yu, W.Y.; Liu, T.; Zhang, M.K.; Wang, Z.X.; Ye, J.J.; Li, C.X.; Liu, W.L.; Li, R.Q.; Feng, J.; Zhang, X.Z. O 2 economizer for inhibiting cell respiration to combat the hypoxia obstacle in tumor treatments. ACS Nano 2019, 13, 1784-1794. [CrossRef]

210. Heinrich, T.A.; Tedesco, A.C.; Fukuto, J.M.; da Silva, R.S. Production of reactive oxygen and nitrogen species by light irradiation of a nitrosyl phthalocyanine ruthenium complex as a strategy for cancer treatment. Dalton Trans. 2014, 43, 4021-4025. [CrossRef]

211. Wan, S.S.; Zeng, J.Y.; Cheng, H.; Zhang, X.Z. ROS-induced NO generation for gas therapy and sensitizing photodynamic therapy of tumor. Biomaterials 2018, 185, 51-62. [CrossRef]

212. Deng, Y.Y.; Jia, F.; Chen, S.Y.; Shen, Z.D.; Jin, Q.; Fu, G.S.; Ji, J. Nitric oxide as an all-rounder for enhanced photodynamic therapy: Hypoxia relief, glutathione depletion and reactive nitrogen species generation. Biomaterials 2018, 187, 55-65. [CrossRef]

213. Yuan, Z.; Yu, S.; Cao, F.Y.; Mao, Z.W.; Gao, C.Y.; Ling, J. Near-infrared light triggered photothermal and photodynamic therapy with an oxygen-shuttle endoperoxide of anthracene against tumor hypoxia. Polym. Chem. 2018, 9, 2124-2133. [CrossRef]

214. Han, Y.; Chen, Z.P.; Zhao, H.; Zha, Z.S.; Ke, W.D.; Wang, Y.H.; Ge, Z.S. Oxygen-independent combined photothermal/photodynamic therapy delivered by tumor acidity-responsive polymeric micelles. J. Control. Release 2018, 284, 15-25. [CrossRef]

215. Lv, Z.; Zou, L.; Wei, H.J.; Liu, S.J.; Huang, W.; Zhao, Q. Phosphorescent starburst Pt(II) porphyrins as bifunctional therapeutic agents for tumor hypoxia imaging and photodynamic therapy. ACS Appl. Mater. Interfaces 2018, 10, 19523-19533. [CrossRef] [PubMed]

216. Pinto, A.; Mace, Y.; Drouet, F.; Bony, E.; Boidot, R.; Draoui, N.; Lobysheva, I.; Corbet, C.; Polet, F.; Martherus, R.; et al. A new ER-specific photosensitizer unravels ${ }^{1} \mathrm{O}_{2}$-driven protein oxidation and inhibition of deubiquitinases as a generic mechanism for cancer PDT. Oncogene 2016, 35, 3976-3985. [CrossRef] [PubMed]

217. Sun, J.; Li, X.; Du, K.; Feng, F.D. A water soluble donor-acceptor-donor conjugated oligomer as a photosensitizer for mitochondria-targeted photodynamic therapy. Chem. Commun. 2018, 54, 9194-9197. [CrossRef] [PubMed]

218. Wieczorek, E.; Mlynarczyk, D.T.; Kucinska, M.; Dlugaszewska, J.; Piskorz, J.; Popenda, L.; Szczolko, W.; Jurga, S.; Murias, M.; Mielcarek, J.; et al. Photophysical properties and photocytotoxicity of free and liposome-entrapped diazepinoporphyrazines on LNCaP cells under normoxic and hypoxic conditions. Eur. J. Med. Chem. 2018, 150, 64-73. [CrossRef] [PubMed]

219. Zhang, X.L.; Wu, M.; Li, J.; Lan, S.Y.; Zeng, Y.Y.; Liu, X.L.; Liu, J.F. Light-enhanced hypoxia-response of conjugated polymer nanocarrier for successive synergistic photodynamic and chemo-therapy. ACS Appl. Mater. Interfaces 2018, 10, 21909-21919. [CrossRef] [PubMed]

220. Huang, C.X.; Zheng, J.; Ma, D.D.; Liu, N.; Zhu, C.; Li, J.S.; Yang, R.H. Hypoxia-triggered gene therapy: A new drug delivery system to utilize photodynamic-induced hypoxia for synergistic cancer therapy. J. Mater. Chem. B 2018, 6, 6424-6430. [CrossRef]

221. Piao, W.; Hanaoka, K.; Fujisawa, T.; Takeuchi, S.; Komatsu, T.; Ueno, T.; Terai, T.; Tahara, T.; Nagano, T.; Urano, Y. Development of an azo-based photosensitizer activated under mild hypoxia for photodynamic therapy. J. Am. Chem. Soc. 2017, 139, 13713-13719. [CrossRef]

222. Li, J.J.; Meng, X.; Deng, J.; Lu, D.; Zhang, X.; Chen, Y.R.; Zhu, J.D.; Fan, A.P.; Ding, D.; Kong, D.L.; et al. Multifunctional micelles dually responsive to hypoxia and singlet oxygen: Enhanced photodynamic therapy via interactively triggered photosensitizer delivery. ACS Appl. Mater. Interfaces 2018, 10, 17117-17128. [CrossRef]

223. Li, Z.B.; Wu, M.; Bai, H.Z.; Liu, X.G.; Tang, G.P. Light-enhanced hypoxia-responsive nanoparticles for deep tumor penetration and combined chemo-photodynamic therapy. Chem. Commun. 2018, 54, 13127-13130. [CrossRef]

224. Wang, W.L.; Lin, L.; Ma, X.J.; Wang, B.; Liu, S.R.; Yan, X.X.; Li, S.R.; Tian, H.Y.; Yu, X.F. Light-induced hypoxia-triggered living nanocarriers for synergistic cancer therapy. ACS Appl. Mater. Interfaces 2018, 10, 19398-19407. [CrossRef]

225. Chen, H.C.; Bi, Q.R.; Yao, Y.R.; Tan, N.H. Dimeric BODIPY-loaded liposomes for dual hypoxia marker imaging and activatable photodynamic therapy against tumors. J. Mater. Chem. B 2018, 6, 4351-4359. [CrossRef] 
226. Evans, C.L.; Abu-Yousif, A.O.; Park, Y.J.; Klein, O.J.; Celli, J.P.; Rizvi, I.; Zheng, X.; Hasan, T. Killing hypoxic cell populations in a 3D tumor model with EtNBS-PDT. PLoS ONE 2011, 6, e23434. [CrossRef] [PubMed]

227. Guan, S.Y.; Yang, D.; Weng, Y.Z.; Lu, H.; Meng, X.M.; Qu, X.Z.; Zhou, S.Y. Excitation-dependent theranostic nanosheet for cancer treatment. Adv. Healthc. Mater. 2018, 7, 1701123. [CrossRef] [PubMed]

228. Guan, M.R.; Qin, T.X.; Ge, J.C.; Zhen, M.M.; Xu, W.; Chen, D.Q.; Li, S.M.; Wang, C.R.; Su, H.M.; Shu, C.Y. Amphiphilic trismethylpyridylporphyrin-fullerene (C-70) dyad: An efficient photosensitizer under hypoxia conditions. J. Mater. Chem. B 2015, 3, 776-783. [CrossRef]

229. Vangeel, I.P.J.; Oppelaar, H.; Marijnissen, J.P.A.; Stewart, F.A. Influence of fractionation and fluence rate in photodynamic therapy with photofrin or mTHPC. Radiat. Res. 1996, 145, 602-609. [CrossRef]

230. Klimenko, V.V.; Bogdanov, A.A.; Knyazev, N.A.; Dubina, M.V. Pulse mode irradiation at Radachlorin PDT shifted cell death to apoptosis in vitro. In Proceedings of the European Conferences on Biomedical Optics, Munich, Germany, 15 July 2015; Lilge, L.D., Sroka, R., Eds.; Volume 9542, p. 95421.

231. Klimenko, V.V.; Knyazev, N.A.; Moiseenko, F.V.; Rusanov, A.A.; Bogdanov, A.A.; Dubina, M.V. Pulse mode of laser photodynamic treatment induced cell apoptosis. Photodiagn. Photodyn. Ther. 2016, 13, 101-107. [CrossRef]

232. Kawauchi, S.; Morimoto, Y.; Sato, S.; Arai, T.; Seguchi, K.; Asanuma, H.; Kikuchi, M. Differences between cytotoxicity in photodynamic therapy using a pulsed laser and a continuous wave laser: Study of oxygen consumption and photobleaching. Lasers Med. Sci. 2004, 18, 179-183. [CrossRef]

233. Turan, I.S.; Yildiz, D.; Turksoy, A.; Gunaydin, G.; Akkaya, E.U. A bifunctional photosensitizer for enhanced fractional photodynamic therapy: Singlet oxygen generation in the presence and absence of light. Angew. Chem. Int. Ed. 2016, 55, 2875-2878. [CrossRef]

(C) 2019 by the authors. Licensee MDPI, Basel, Switzerland. This article is an open access article distributed under the terms and conditions of the Creative Commons Attribution (CC BY) license (http://creativecommons.org/licenses/by/4.0/). 